\author{
UNIVERSIDADE DE SÃO PAULO \\ ESCOLA DE ENGENHARIA DE SÃO CARLOS \\ DEPARTAMENTO DE ENGENHARIA ELÉTRICA E DE COMPUTAÇÃO
}

FERNANDO BAMBOZZI BOTTURA

Arranjo otimizado de monitores para sistemas de distribuição frente às variações de tensão de curta duração e potenciais condições de ressonância harmônica

São Carlos 



\section{Arranjo otimizado de monitores para sistemas de distribuição frente às variações de tensão de curta duração e potenciais condições de ressonância harmônica}

Tese apresentada ao Programa de Engenharia Elétrica da Escola de Engenharia de São Carlos da Universidade de São Paulo para a obtenção do título de Doutor em Ciências.

Área de concentração:

Sistemas Elétricos de Potência.

Orientador:

Professor Associado Mário Oleskovicz

São Carlos

2019

Trata-se da versão corrigida da tese. A versão original se encontra disponível na EESC/USP que aloja o Programa de Pós-Graduação de Engenharia Elétrica. 
AUTORIZO A REPRODUÇÃO TOTAL OU PARCIAL DESTE TRABALHO, POR QUALQUER MEIO ÇONVENCIONAL OU ELETRÔNICO, PARA FINS' DE ESTUDO E PESQUISA, DESDE QUE CITADA A FONTE.

Ficha catalográfica elaborada pela Biblioteca Prof. Dr. Sérgio Rodrigues Fontes da EESC/USP com os dados inseridos pelo(a) autor(a).

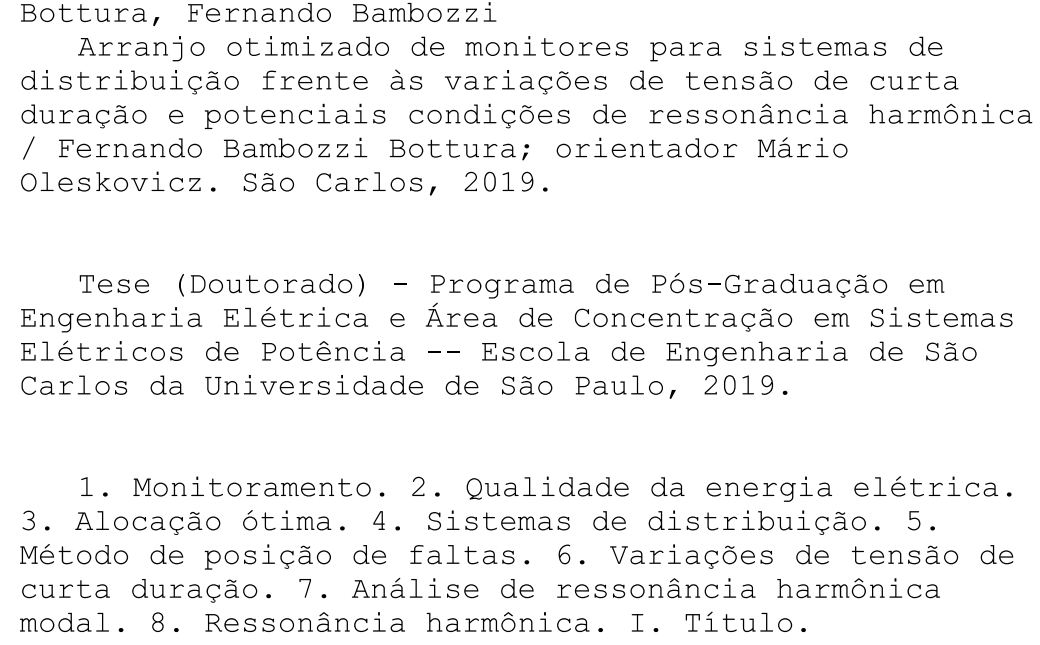

1. Monitoramento. 2. Qualidade da energia elétrica. 3. Alocação ótima. 4. Sistemas de distribuição. 5. Método de posição de faltas. 6. Variações de tensão de curta duração. 7. Análise de ressonância harmônica modal. 8. Ressonância harmônica. I. Título.

Eduardo Graziosi Silva - CRB - 8/8907 


\section{FOLHA DE JULGAMENTO}

Candidato: Engenheiro FERNANDO BAMBOZI BOTTURA.

Título da tese: "Arranjo otimizado de monitores para sistemas de distribuição frente às variações de tensão de curta duração e potenciais condições de ressonância harmônica".

Data da defesa: 15/04/2019

\section{Comissão Julgadora:}

Prof. Associado Mario Oleskovicz

(Orientador)

(Escola de Engenharia de São Carlos/EESC)

Prof. Dr. Benvindo Rodrigues Pereira Junior

(Escola de Engenharia de São Carlos/EESC)

Prof. Dr. Eduardo Gontijo Carrano

(Universidade Federal de Minas Gerais/UFMG)

Dr. Wesley Fernando Usida

(Agência Nacional de Energia Elétrica/ANEEL)

Profa. Dra. Maria Emília de Lima Tostes

(Universidade Federal do Pará/UFPA)
Resultado:

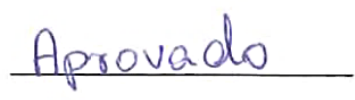

Aprovado

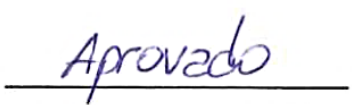

Apwovad

Coordenador do Programa de Pós-Graduação em Engenharia Elétrica:

Prof. Associado Ivan Nunes da Silva

Presidente da Comissão de Pós-Graduação:

Prof. Titular Murilo Araujo Romero 



\section{Agradecimentos}

Agradeço ao Prof. Associado Mário Oleskovicz do Laboratório de Sistemas de Energia Elétrica (LSEE) do Departamento de Engenharia Elétrica e de Computação, da Escola de Engenharia de São Carlos (EESC) da Universidade de São Paulo (USP), pela orientação, confiança, ensinamentos, conselhos e parceria, sempre muito produtiva, em todas as etapas de desenvolvimento desta tese de doutorado e em diversas atividades acadêmicocientíficas realizadas ao longo desses anos.

Agradeço também ao Prof. Dr. José Carlos de Melo Vieira Júnior, ao Prof. Tit. Denis V. Coury (LSEE) e ao Prof. Dr. Eduardo N. Asada (Laboratório de Análise de Sistemas de Energia Elétrica - LASEE, EESC, USP), com os quais tive a oportunidade de trabalhar em diversos momentos de minha trajetória na pós-graduação, especialmente nos projetos de Pesquisa \& Desenvolvimento.

Agradeço ao Prof. Dr. Eduardo Gontijo Carrano, do Departamento de Engenharia Elétrica da Universidade Federal de Minas Gerais (UFMG), e ao Prof. Dr. Guilherme Guimarães Lage, do Departamento de Engenharia Elétrica da Universidade Federal de São Carlos (UFSCar), pelas importantes contribuições e sugestões feitas na etapa do exame de qualificação desta tese de doutorado.

Também agradeço ao Programa de Pós-graduação em Engenharia Elétrica da EESC - USP e aos funcionários do Departamento de Engenharia Elétrica e de Computação.

Estendo meus agradecimentos ao Prof. Dr. Renato Machado Monaro, do Departamento de Engenharia de Energia e Automação Elétrica, da Escola Politécnica da USP, pelos incentivos e sugestões em momentos importantes de meu doutorado.

Também agradeço ao Prof. Dr. Marc Petit e ao Prof. Dr. Trung Dung Le, do laboratório Génie Électrique e Électronique de Paris (GeePs) - CentraleSupélec, da Université Paris-Saclay, pelo acolhimento em seu grupo de pesquisa e pelas contribuições realizadas durante meu período sanduíche na França, financiado pela Comissão Européia (552042-EM1-2014-1-FR-ERA MUNDUS - EMA2). Agradeço ainda ao Prof. Dr. Gilney Damm (IBISC - Université Paris-Saclay), pelo acolhimento e conselhos durante meu estágio no exterior.

Expresso também meus agradecimentos aos muitos amigos com os quais convivi no LSEE durante todo esse período na pós-graduação. Seria impossível listar todos nesta seção de agradecimentos sem correr o risco de algum injusto esquecimento, mas gostaria de 
registrar que todos foram muito importantes e direta ou indiretamente contribuíram com esta pesquisa de doutorado.

Agradeço especialmente aos amigos do LSEE envolvidos no projeto de P\&D (PD0042/2014 ANEEL): Thais, Rui, Fabrício, Douglas e Gustavo. Agradeço também ao Wellington (LASEE), pela amizade e parceria acadêmica.

Também gostaria de agradecer aos amigos que fiz durante meu estágio na CentraleSupélec, em especial à Guacira, Filipe e Rafaela, Hydayet, João Alberto, João Neto, Ricardo, Higor e Paulo, pela intensa convivência profissional e pelos momentos memoráveis na "Cidade Luz", que certamente tornaram a experiência no exterior muito mais rica.

Agradeço também aos meus queridos pais, Herbert e Maria Teresa, pelo imenso apoio, suporte e incentivo durante todos esses anos, fundamentais para a conclusão desta tese de doutorado. Agradeço também imensamente à minha querida irmã Eleonora, pela amizade, parceria e apoio nos momentos mais difíceis desta jornada.

Por fim, agradeço ao meu querido avô Antonio Bambozzi (in memoriam), por sempre ser uma fonte de inspiração, energia, bom humor e vitalidade. Sem dúvidas você está presente em cada página desta tese. Muito obrigado! 


\section{Resumo}

BOTTURA, F. B. Arranjo otimizado de monitores para sistemas de distribuição frente às variações de tensão de curta duração e potenciais condições de ressonância harmônica. 2019180 p. Tese (Doutorado) - Escola de Engenharia de São Carlos, Universidade de São Paulo, São Carlos, 2019.

Esta pesquisa propõe uma metodologia de alocação otimizada de monitores da Qualidade da Energia Elétrica (QEE) em sistemas de distribuição, de modo que estes sejam sensíveis tanto às variações de tensão de curta duração, bem como às potenciais condições de ressonância harmônica. A metodologia de alocação dispõe da aplicação do Método de Posição de Faltas (MPF) e da Análise de Ressonância Harmônica Modal (ARHM) para a construção de uma matriz binária de cobertura. Esta matriz é então utilizada pelo processo de otimização para a determinação dos melhores locais de instalação dos monitores, garantindo assim o completo monitoramento dos distúrbios da QEE considerados. A partir do MPF, é estudado o comportamento das tensões nodais remanescentes do Sistema de Distribuição (SD) em análise frente a situações de curtos-circuitos que provocam afundamentos e /ou elevações de tensão. Pela ARHM, as impedâncias modais associadas ao modo crítico são calculadas para a identificação das respectivas frequências de ressonância harmônica do SD. Além disso, a partir dos autovetores críticos, associados ao modo crítico, também se obtém o grau de observabilidade das condições de ressonância para cada nó do SD. A otimização minimiza a quantidade necessária de monitores para a completa observação dos distúrbios de QEE considerados, e é formulada como um modelo de programação linear inteira com variáveis binárias. Para a resolução deste problema de otimização utilizou-se o algoritmo Branch and Bound. A metodologia foi testada para um SD de 15 nós, baseado em uma rede do CIGRÉ, e para um SD de 24 nós, baseado no SD de 34 nós do IEEE. Os resultados apontam a necessidade de instalação de 2 a 4 monitores para o SD de 15 nós, e de 2 a 9 monitores para o SD de 24 nós, para a completa observabilidade dos distúrbios de QEE considerados. A metodologia de alocação otimizada de monitores de QEE apresenta-se como uma ferramenta auxiliar para o planejamento de um sistema de monitoramento que promova meios para a melhoria dos índices de QEE.

Palavras-chave: Monitoramento. Qualidade da energia elétrica. Alocação ótima. Sistemas de distribuição. Método de posição de faltas. Variações de tensão de curta duração. Análise de ressonância harmônica modal. Ressonância harmônica. 



\section{Abstract}

BOTTURA, F.B. Optimized allocation of power quality meters in distribution systems for short duration voltage variations and potential harmonic resonance conditions. 2019 180 p. Thesis $(\mathrm{PhD})$ - São Carlos School of Engineering, University of São Paulo, São Carlos, 2019.

This research proposes an optimized allocation methodology of Power Quality (PQ) meters in Distribution System (DS), considering short duration voltage variations and potential harmonic resonance conditions. The allocation methodology uses the Fault Position Method (FPM) and the Harmonic Resonance Modal Analysis (HRMA) in order to obtain a binary covering matrix, which is lately used by the optimization process. The optimization process determines the best installation nodes of the minimum number of PQ monitors that complete observe the considered PQ disturbances. From the FPM, the behavior of the remaining nodal voltages is studied for different short-circuit situations, which cause voltage sags and/ or swells. The HRMA is used to calculate the modal impedances related to the critical modes and identify the respective harmonic frequencies of the DS. Moreover, from the critical eigenvectors, associated with the critical mode, it is also obtained the observability level of the respective harmonic resonance frequencies. The allocation problem is modeled as an integer linear programming that minimizes the number of necessary PQ meters, ensuring the complete observation of the considered PQ disturbances. The optimization is performed using a Branch and Bound algorithm. The allocation methodology was tested for a 15 nodes DS based on a CIGRÉ network, and for 24 node DS derived from the IEEE 34 node test system. Results indicate that 2 to 4 PQ monitors are required for the 15 nodes DS, and 2 to 9 PQ monitors for the 34 DS in order to completely observe the considered PQ disturbances. The allocation methodology presentes itself as an auxiliary tool for the PQ monitoring planning, which may leads to the improvement of the PQ indices.

Keywords: Monitoring. Power quality. Optimal allocation. Distribution systems. Fault position method. Short duration voltage variations. Harmonic resonance modal analysis. Harmonic resonance. 



\section{Lista de figuras}

Figura 1 - Circuito RLC paralelo excitado por uma fonte de corrente alternada.

Figura 2 - Esboço do comportamento de $|\boldsymbol{Z}|$ em função de $\boldsymbol{\omega}$.

Figura 3 - Diagrama unifilar simplificado de um SD hipotético, no qual se observa uma potencial condição de ressonância paralela entre elementos do sistema e cargas conectadas ao PAC.

Figura 4 - Fluxograma geral da metodologia de alocação otimizada de monitores de QEE... 38

Figura 5 - Exemplo de áreas de vulnerabilidade associadas ao nó genérico $i$ para um SD hipotético.

Figura 6 - Rede de sequência positiva para o cálculo do curto-circuito trifásico aplicado no nó j.

Figura 7 - Conexão das redes de sequência positiva e negativa para o cálculo do curto-circuito bifásico aplicado no nó $\boldsymbol{j}$......

Figura 8 - Conexão das redes de sequência positiva, negativa e zero para o cálculo do curtocircuito bifásico aterrado aplicado no nó $\boldsymbol{j}$.

Figura 9 - Conexão das redes de sequência positiva, negativa e zero para o cálculo do curtocircuito monofásico aterrado aplicado no nó $\boldsymbol{j}$.

Figura 10 - Fluxograma que descreve a metodologia de obtenção da MCVT.

Figura 11 - Fluxograma que descreve a metodologia de obtenção da MCRH.

Figura 12 - SD hipotético de 4 nós.

Figura 13 - Sistema de distribuição teste de 15 nós.

Figura 14 - Modelo de carga utilizado (modelo tipo 2) com a resistência $\boldsymbol{R}$, reatância capacitiva $\boldsymbol{X}$, e ordem harmônica $\boldsymbol{n}$ evidenciadas.

Figura 15 - Modelo $\pi-$ nominal (a), e modelo $\pi$ equivalente (b).

Figura 16 - MCF obtida para $\boldsymbol{\tau}=\mathbf{1}, \mathbf{0}, \boldsymbol{\delta} \boldsymbol{i n f}=\mathbf{0 , 5}$ p.u. e $\boldsymbol{\delta} \boldsymbol{s u p}=\mathbf{1}, \mathbf{1}$ p.u..

Figura $17-$ MCF obtida para $\tau=\mathbf{1}, \mathbf{0}, \boldsymbol{\delta i n f}=\mathbf{0 , 5}$ p.u. e $\boldsymbol{\delta} \boldsymbol{s u p}=\mathbf{1}, \mathbf{2}$ p.u.

Figura 18 - MCF obtida para $\boldsymbol{\tau}=\mathbf{1}, \mathbf{0}, \boldsymbol{\delta} \boldsymbol{i n} \boldsymbol{f}=\mathbf{0}, \mathbf{5}$ p.u.e $\boldsymbol{\delta} \boldsymbol{s u p}=\mathbf{1}, \mathbf{1}$ p.u. com a solução de alocação destacada.

Figura 19 - MCF reduzida a partir da MCF para $\boldsymbol{\tau}=\mathbf{1}, \mathbf{0}, \boldsymbol{\delta} \boldsymbol{i n f}=\mathbf{0}, \mathbf{5}$ p.u. e $\boldsymbol{\delta} \boldsymbol{s u p}=$ 1, 1p.u. , somente com as linhas 3; 8; 12 e 15 (solução de alocação). 
Figura 20 - MCF obtida para $\boldsymbol{\tau}=\mathbf{1}, \mathbf{0}, \boldsymbol{\delta} \boldsymbol{i n f}=\mathbf{0 , 5}$ p.u. e $\boldsymbol{\delta} \boldsymbol{s} \boldsymbol{u} \boldsymbol{p}=\mathbf{1}, \mathbf{2}$ p.u. com a solução de alocação destacada.

Figura 21 - MCF reduzida a partir da MCF para $\boldsymbol{\tau}=\mathbf{1}, \mathbf{0}, \boldsymbol{\delta} \boldsymbol{i n f}=\mathbf{0 , 5}$ p.u. e $\boldsymbol{\delta} \boldsymbol{s u p}=\mathbf{1 , 2}$ p.u., somente com as linhas $3,8,12$ e 15 (solução de alocação).

Figura 22 - MCF obtida para $\boldsymbol{\tau}=\mathbf{0}, \mathbf{8}, \boldsymbol{\delta} \boldsymbol{i n f}=\mathbf{0 , 5}$.u. e $\boldsymbol{\delta} \boldsymbol{s} \boldsymbol{u p}=\mathbf{1}, \mathbf{1}$ p.u.................... 120

Figura $23-$ MCF obtida para $\tau=0,8, \boldsymbol{\delta} \boldsymbol{i n} \boldsymbol{f}=\mathbf{0}, 5$ p.u. e $\boldsymbol{\delta} \boldsymbol{s u p}=1,2$ p.u.

Figura 24 - MCF obtida para $\boldsymbol{\tau}=\mathbf{0}, \mathbf{8}, \boldsymbol{\delta} \boldsymbol{i n} \boldsymbol{f}=\mathbf{0}, \mathbf{5}$ p.u. e $\boldsymbol{\delta} \boldsymbol{s u p}=\mathbf{1}, \mathbf{1}$ p.u. com a solução de alocação destacada.

Figura 25 - MCF obtida para $\boldsymbol{\tau}=\mathbf{0}, \mathbf{8}, \boldsymbol{\delta} \boldsymbol{i n} \boldsymbol{f}=\mathbf{0}, \mathbf{5}$ p.u. e $\boldsymbol{\delta} \boldsymbol{s u p}=\mathbf{1}, \mathbf{2}$ p.u. com a solução de alocação destacada.

Figura 26 - MCF reduzida a partir da MCF para $\boldsymbol{\tau}=\mathbf{0}, \mathbf{8}, \boldsymbol{\delta} \boldsymbol{i n f}=\mathbf{0}, \mathbf{5}$ p.u. e $\boldsymbol{\delta} \boldsymbol{s u p}=\mathbf{1}, \mathbf{1}$ p.u., somente com as linhas 12 e 15 (solução de alocação).

Figura 27 - MCF reduzida a partir da MCF para $\boldsymbol{\tau}=\mathbf{0 , 8}, \boldsymbol{\delta i n f}=\mathbf{0 , 5}$ p.u. e $\boldsymbol{\delta} \boldsymbol{s u p}=\mathbf{1}, \mathbf{2}$ p.u., somente com as linhas 12 e 15 (solução de alocação).

Figura 28 - MCF obtida para $\boldsymbol{\delta} \boldsymbol{i n} \boldsymbol{f}=\mathbf{0 , 5}$ p.u. e $\boldsymbol{\delta} \boldsymbol{s u p}=\mathbf{1}, \mathbf{1}$ p.u. com a solução de alocação destacada.

Figura 29 - MCF reduzida a partir da MCF para $\boldsymbol{\delta} \boldsymbol{i n} \boldsymbol{f}=\mathbf{0}, \mathbf{5}$ p.u.e $\boldsymbol{\delta s u p}=\mathbf{1}, \mathbf{1}$ p.u., somente com as linhas 12 e 15 (solução de alocação).

Figura 30 - MCF obtida para $\boldsymbol{\tau}=\mathbf{1}, \mathbf{0}, \boldsymbol{\delta} \boldsymbol{i n} \boldsymbol{f}=\mathbf{0 , 5}$ p.u.e $\boldsymbol{\delta} \boldsymbol{s u p}=\mathbf{1}, \mathbf{2}$ p.u.com a solução de alocação destacada.

Figura 31 - MCF reduzida a partir da MCF para $\boldsymbol{\delta} \boldsymbol{i n} \boldsymbol{f}=\mathbf{0}, \mathbf{5}$ p.u. e $\boldsymbol{\delta} \boldsymbol{s u p}=\mathbf{1}, \mathbf{2}$ p.u., somente com as linhas 12 e 15 (solução de alocação).

Figura 32 - Varredura em frequência para 1,0 p.u. de corrente injetada no nó 3 do SD de 15 nós sob operação nas condições do cenário de número 16.

Figura 33 - Varredura em frequência para 1,0 p.u. de corrente injetada no nó 8 do SD de 15 nós sob operação nas condições do cenário de número 16.

Figura 34 - Varredura em frequência para 1,0 p.u. de corrente injetada no nó 12 do SD de 15 nós sob operação nas condições do cenário de número 16.

Figura 35 - Varredura em frequência para 1,0 p.u. de corrente injetada no nó 15 do SD de 15 nós sob operação nas condições do cenário de número 16 .

Figura 36 - Perfil da Impedância modal obtida pela execução da ARHM.

Figura 37 - Sistema de distribuição de 24 nós.

Figura 38 -Diagrama unifilar do SD de 24 nós com as três principais regiões referentes aos nós de instalação dos medidores de QEE, segundo a maioria das soluções de alocação 
Figura 39 - MCF obtida para $\boldsymbol{\tau}=\mathbf{1}, \mathbf{0}, \boldsymbol{\delta} \boldsymbol{i n f}=\mathbf{0}, \mathbf{5}$ p.u. e $\boldsymbol{\delta} \boldsymbol{s u p}=\mathbf{1}, \mathbf{1}$ p.u.

Figura 40 - MCF reduzida a partir da MCF para $\tau=\mathbf{1}, \mathbf{0} ; \boldsymbol{\delta} \boldsymbol{i n f}=\mathbf{0}, \mathbf{5}$ p.u. e $\boldsymbol{\delta} \boldsymbol{s u p}=\mathbf{1}, \mathbf{1}$ p.u., somente com linhas relativas às solução de alocação.

Figura $41-$ MCF obtida para $\tau=0,7, \delta i n f=0,5$ p.u.e $\delta \boldsymbol{s u p}=1,1$ p.u.

Figura 42 - MCF reduzida a partir da MCF para $\boldsymbol{\tau}=\mathbf{0}, 7 ; \boldsymbol{\delta i n f}=\mathbf{0}, 5$ e $\boldsymbol{\delta} \boldsymbol{s u p}=\mathbf{1}, \mathbf{1}$, somente com linhas relativas às solução de alocação.

Figura $43-$ MCF obtida para $\boldsymbol{\delta i n f}=\mathbf{0 , 5}$ p.u. e $\boldsymbol{\delta} \boldsymbol{s u p}=\mathbf{1}, \mathbf{1}$.u.

Figura $44-$ MCF reduzida a partir da MCF para $\boldsymbol{\delta i n f}=\mathbf{0}, \mathbf{5}$ p.u. e $\boldsymbol{\delta} \boldsymbol{s u p}=\mathbf{1}, \mathbf{1}$ p.u., somente com as linhas referentes à solução de alocação

Figura 45 - MCF obtida para $\boldsymbol{\delta i n f}=\mathbf{0 , 5}$ p.u. e $\boldsymbol{\delta} \boldsymbol{s} \boldsymbol{u p}=\mathbf{1}, \mathbf{2}$ p.u.

Figura 46 - MCF reduzida a partir da MCF para $\boldsymbol{\delta} \boldsymbol{i n} \boldsymbol{f}=\mathbf{0}, \mathbf{5}$ p.u. e $\boldsymbol{\delta} \boldsymbol{s u p}=\mathbf{1}, \mathbf{2}$ p.u., somente com as linhas referentes à solução de alocação 



\section{Lista de tabelas}

Tabela 1 - Nós de instalação, capacitância e potência reativa trifásica nominal dos bancos de capacitores.

Tabela 2 - Cenários de bancos de capacitores do conjunto $\boldsymbol{C}$ para o sistema de 15 nós

Tabela 3 - Soluções de alocação e nós equivalentes para $\boldsymbol{\tau}$ variando de 1,0 a 0,$5 ; \boldsymbol{\delta s u p}$ de 1,1 p.u. a 1,2 p.u. e $\boldsymbol{\delta} \boldsymbol{i n} \boldsymbol{f}$ de 0,9 p.u. a 0,5 p.u.

Tabela 4 - Soluções de alocação e nós equivalentes para $\boldsymbol{\tau}$ variando de 0,4 p.u. a 0,1 p.u.;

$\boldsymbol{\delta} \boldsymbol{s u p}$ de 1,1 p.u. a 1,2 p.u. e $\boldsymbol{\delta} \boldsymbol{i n} \boldsymbol{f}$ de 0,9 a 0,5 .

Tabela 5 - Frequências de ressonância harmônicas encontradas pela ARHM e suas respectivas magnitudes de impedância modal.

Tabela 6 - Soluções de alocação e nós equivalentes para a MCF igual à MCVT variando-se os limiares de tensão $\boldsymbol{\delta i n f}$ e $\boldsymbol{\delta} \boldsymbol{s u p}$.

Tabela 7 - Soluções de alocação e nós equivalentes para a MCF igual à MCRH variando-se $\boldsymbol{\tau}$.

Tabela 8 - Soluções de alocação e nós equivalentes para $\boldsymbol{\tau}=\mathbf{1 , 0}$ para os quatro casos estudados e o número de frequências de ressonância harmônicas calculadas pela $\operatorname{ARHM}(\boldsymbol{F})$.

Tabela 9 - Trechos de linhas (nós de origem e nós de destino), comprimento e configuração do trecho.

Tabela 10 - Nós de instalação, capacitância e potência reativa trifásica nominal dos bancos de capacitores.

Tabela 11 - Capacitância e potência reativa trifásica nominal para os bancos de capacitores fixos.

Tabela 12 - Cenários de bancos de capacitores do conjunto $\boldsymbol{C}$ para o sistema de 24 nós.

Tabela 13 - Soluções de alocação e nós equivalentes para $\tau$ variando de 1,0 a 0,$5 ; \boldsymbol{\delta s u p}$ de 1,1 a 1,2 p.u. e $\boldsymbol{\delta} \boldsymbol{i n f}$ de 0,9 a 0,5 p.u..

Tabela 14 - Soluções de alocação e nós equivalentes para $\tau$ variando de 0,4 a 0,$1 ; \boldsymbol{\delta s u p}$ de 1,1 a 1,2 p.u. e $\boldsymbol{\delta i n f}$ de 0,9 a 0,5 p.u..

Tabela 15 - Soluções de alocação e nós equivalentes para MCF igual à MCVT variando-se os limiares de tensão $\boldsymbol{\delta i n f}$ e $\boldsymbol{\delta} \boldsymbol{s u p}$ para o SD de 24 nós.

Tabela 16 - Soluções de alocação e nós equivalentes para a MCF igual à MCRH variando-se

$\boldsymbol{\tau}$. 
Tabela 17 - Nós de instalação, potência ativa trifásica $\boldsymbol{P}$, potência reativa trifásica $(\boldsymbol{Q})$; e FP das cargas presentes no SD de 15 nós.

Tabela 18 - Segmentos de linhas, parâmetros de sequência $(\boldsymbol{R 0}, R \mathbf{1}, \boldsymbol{X 0}, \boldsymbol{X 1}, \boldsymbol{B 0}, \boldsymbol{B 1})$, comprimento e tipo de linhas do SD de 15 nós.

Tabela 19 - Nós de instalação, potência ativa $(\boldsymbol{P})$ e reativa $(\boldsymbol{Q})$ trifásica nominal; e FP das cargas presentes no SD de 15 nós.

Tabela 20 - Parâmetros de sequência dos tipos de linhas presentes no SD de 24 nós, calculados a partir das matrizes de impedância e susceptância de fase do SD de 34 nós original.

Tabela 21 - Frequências de ressonância harmônicas encontradas pela ARHM e suas respectivas magnitudes de impedância modal - caso $(i)$.

Tabela 22 - Frequências de ressonância harmônicas encontradas pela ARHM e suas respectivas magnitudes de impedância modal - caso (ii).

Tabela 23 - Frequências de ressonância harmônicas encontradas pela ARHM e suas respectivas magnitudes de impedância modal - caso (iii).

Tabela 24 - Frequências de ressonância harmônicas encontradas pela ARHM e suas respectivas magnitudes de impedância modal - caso (iv)

Tabela 25 - Frequências de ressonância harmônicas encontradas pela ARHM e suas respectivas magnitudes de impedância modal - SD de 24 nós 


\section{Lista de siglas}

QEE - Qualidade da Energia Elétrica;

SEP - Sistema Elétrico de Potência;

PRODIST - Procedimentos de Distribuição de Energia Elétrica no Sistema Elétrico Nacional;

DHT - Distorção Harmônica Total;

VTCD - Variação de Tensão de Curta Duração;

VTLD - Variação de Tensão de Longa Duração;

EPRI - Electric Power Research Institue;

HVDC - High Voltage Direct Current;

SD - Sistema de Distribuição;

PAC - Ponto de Acoplamento Comum;

ARHM - Análise de Ressonância Harmônica Modal;

TP - Transformador de Potencial;

CEER - Council of European Energy Regulators;

ECRB - Energy Community Regulatory Board;

B\&B - Branch And Bound;

MPF - Método da Posição de Faltas;

MCVT - Matriz de Cobertura das Variações de Tensão;

MCRH - Matriz de Cobertura de Ressonância Harmônica;

MCF - Matriz de Cobertura Final;

MPI - Método da Potência Inversa;

AEMT - Algoritmo Evolutivo Multiobjetivo com Tabelas;

IEEE - Institute of Electrical and Electronics Engineers;

MTDF - Matriz de Tensão Durante a Falta;

MOR - Matriz de Observabilidade das Ressonâncias;

FP - Fator de Potência;

MP - Método das Potências;

PLI - Programação Linear Inteira;

CIGRÉ - Conseil International des Grands Réseaux Électriques. 



\section{Sumário}

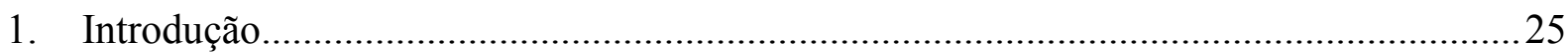

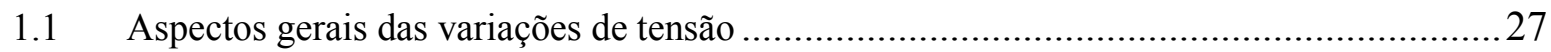

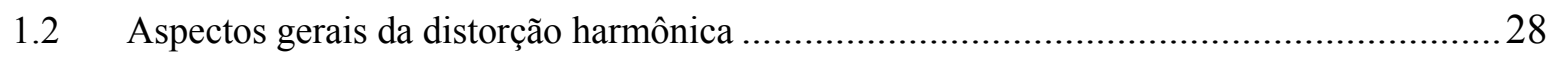

1.3 Aspectos gerais da ressonância paralela ..............................................................29

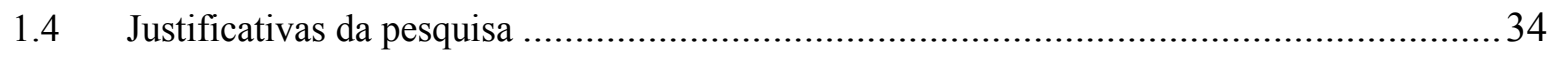

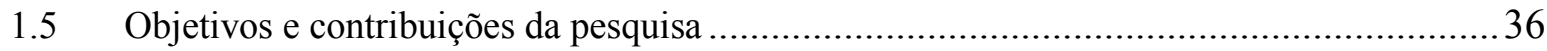

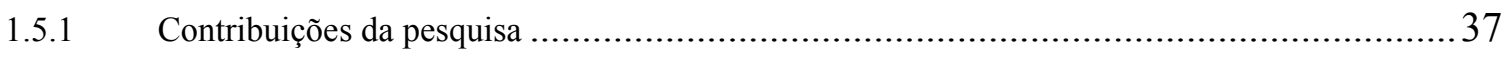

1.6 Uma visão geral da metodologia de monitoramento proposta..................................... 38

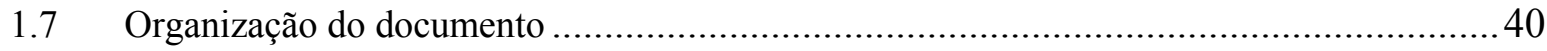

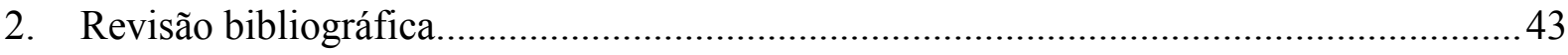

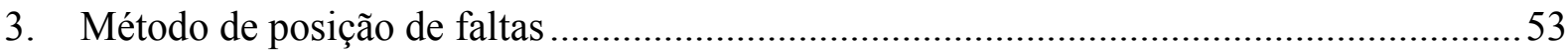

3.1 Formulação das MTDFs segundo os tipos de curtos-circuitos ........................................55

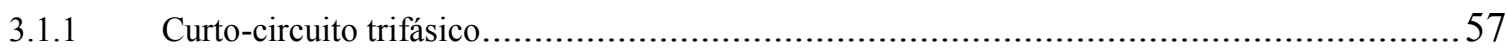

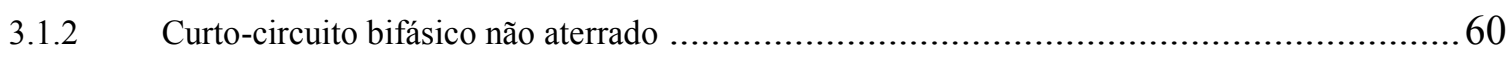

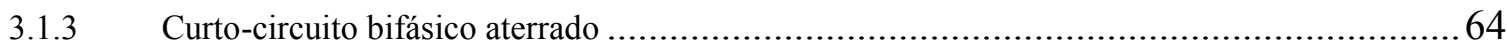

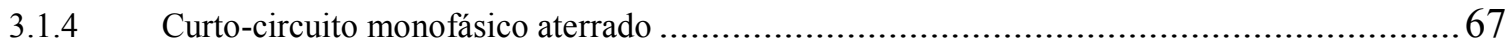

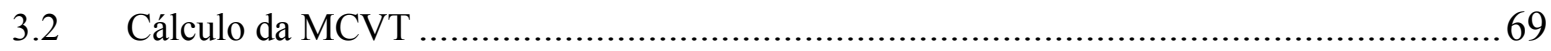

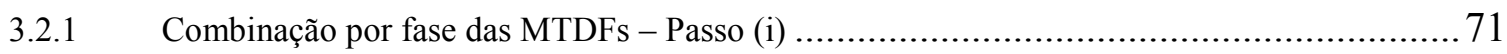

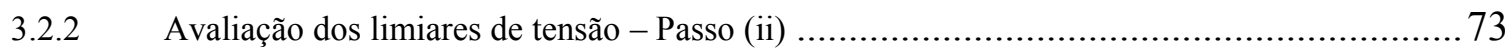

3.2.3 Combinação das matrizes binárias - Passo (iii) ........................................................... 74

3.2.4 Obtenção da MCVT: concatenação das matrizes de cobertura combinadas - Passo (iv) ......... 75

3.2.5 Considerações sobre os limiares de tensão e tipos de curtos-circuitos na formação da MCVT.76

4. Análise de ressonância harmônica modal ............................................................................ 79 
4.1 Matriz de cobertura das potenciais condições de ressonância harmônica

4.2 Metodologia para a obtenção da MCRH …............................................................. 86

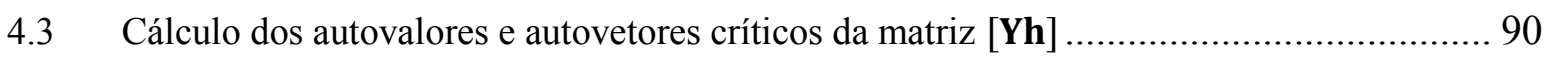

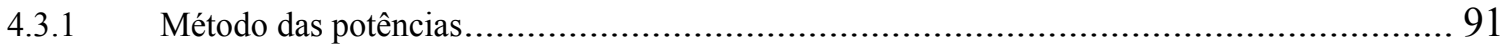

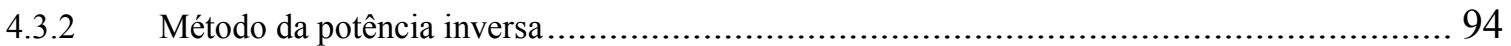

4.3.3 Considerações importantes sobre a matriz de admitâncias $[\mathrm{Yh}]$........................................ 95

5. Formulação do problema de otimização....................................................................... 99

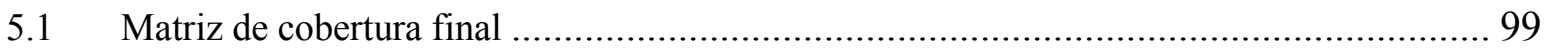

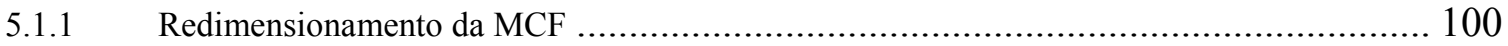

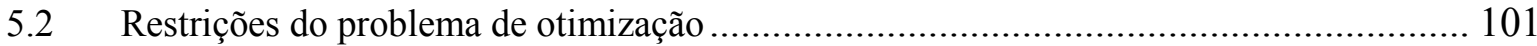

5.3 Função objetivo e forma geral do problema de otimização ........................................... 104

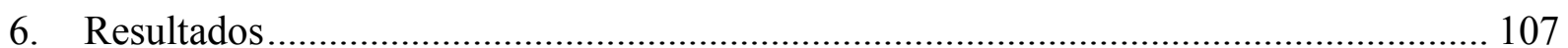

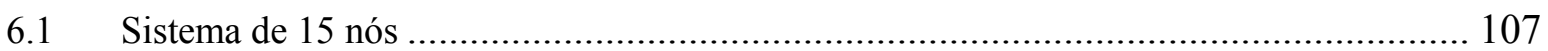

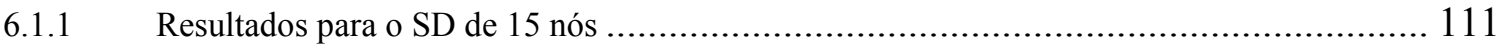

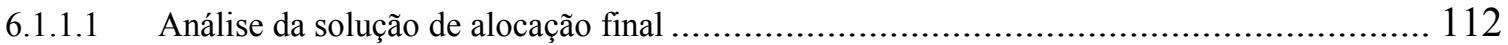

6.1.1.2 Análise da solução de alocação do ponto de vista das VTCDs (MCF igual à MCVT) .......... 124

6.1.1.3 Análise da solução de alocação do ponto de vista das potenciais condições de ressonância (MCRH) 128

6.1.1.4 Análise de varredura em frequência .................................................................... 131

6.1.1.5 Sensibilidade da solução de alocação conservadora frente às variações de potência reativa dos

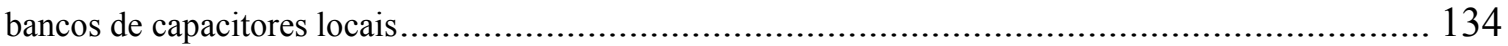

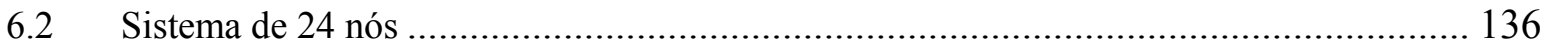

6.2.1 Resultados da alocação para o SD de 24 nós................................................... 142

6.2.1.1 Análise da solução de alocação final ............................................................ 142

6.2.1.2 Análise da solução de alocação do ponto de vista das VTCDs (MCF igual à MCVT) ........ 149 
6.2.1.3 Análise da solução de alocação do ponto de vista das potenciais condições de ressonância (MCRH).

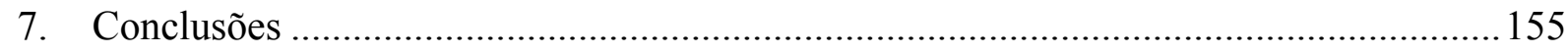

7.1 Propostas de continuidade da pesquisa .......................................................... 159

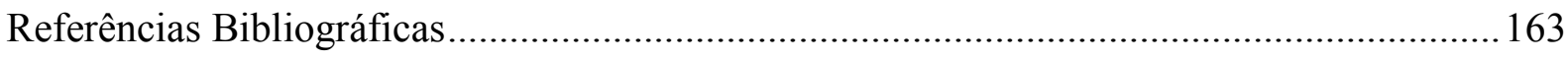

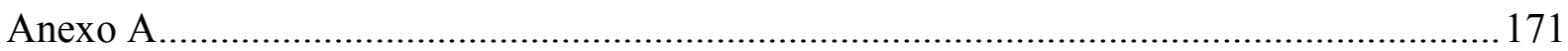

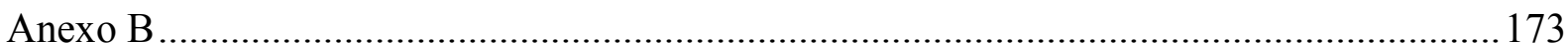

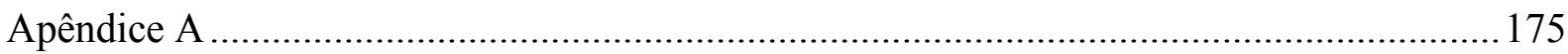

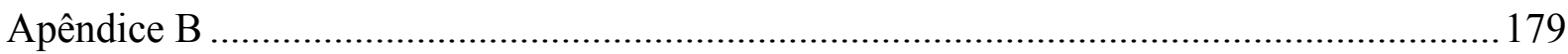





\section{Introdução}

A Qualidade da Energia Elétrica (QEE) é caracterizada pela disponibilidade da energia na forma de uma onda senoidal pura, sem alterações em amplitude e frequência (DUGAN et al., 2012). Entretanto, um Sistema Elétrico de Potência (SEP) está sujeito a diversos fenômenos que podem comprometer a QEE. Frequentemente, estes distúrbios ocasionam a operação inadequada de equipamentos, redução da vida útil dos mesmos, além da perda de processos industriais.

Estas situações indesejáveis observadas em um SEP estão justamente em oposição à definição da QEE proposta por Sankaran (2002), em que a QEE é entendida como um conjunto de delimitações das grandezas elétricas que devem permitir certo equipamento operar conforme projetado sem perda de rendimento ou redução de sua vida útil.

Além das variações de tensão, causadas principalmente por faltas elétricas (curtoscircuitos) incidentes em SEPs (BOLLEN; GU, 2006), verifica-se também a preocupação com a margem de tolerância estabelecida para a Distorção Harmônica Total (DHT) da tensão, causada pela presença de cargas não lineares (ou um conjunto destas) de potência expressiva, que eventualmente podem excitar modos de ressonância em locais específicos do SEP (XU et al., 2005).

Diante do exposto, é fundamental que ocorra uma adequada avaliação das causas destes desvios nos parâmetros nominais da tensão (variações de tensão e DHT), bem como da extensão dos danos provocados por tais situações para que seja possível propor diretrizes para a elaboração de estratégias mitigadoras dos fenômenos de QEE mencionados.

Como decorrência de uma má QEE, certos equipamentos, tais como computadores, controladores lógico programáveis, robôs industriais, máquinas elétricas, dentre outros, poderão operar incorretamente, já que possuem baixa tolerância aos possíveis distúrbios advindos da rede de energia elétrica de distribuição. Além disso, grande parte destes equipamentos é parte integrante das etapas que agregam valores aos processos industriais. Logo, quando acometidos por distúrbios associados à falta da QEE, poderão acarretar em prejuízos financeiros consideráveis ao longo da cadeia produtiva.

Neste contexto, consumidores dos setores industrial, comercial e residencial, estão cada vez mais conscientes de que possuem a necessidade, e também o direito, de serem supridos com uma energia elétrica de qualidade, já que se observa o surgimento e a consolidação de normatizações (em âmbitos nacional e internacional) que visam assegurar a 
qualidade da energia contratada. Além disso, a pressão tecnológica advinda da aplicação do conceito das smart grids (redes inteligentes) aos sistemas elétricos reforça a tendência necessária do maior monitoramento da QEE nos sistemas de distribuição.

Embora o conceito das smart grids ainda possua uma definição ampla, as smart grids possuem dentre as principais diretivas o monitoramento, controle, comunicação e a transferência massiva de dados entre diversos elementos do SEP (BOLLEN et al., 2017). Esta intensa integração entre os elementos do SEP visa aprimorar e modernizar as condições de operação das redes, desde a geração até a distribuição da energia elétrica.

Como será observado na sequência deste documento, embora o direcionamento dado à pesquisa não recaia sobre o estudo das smart grids em si, ainda assim, é importante ressaltar que a proposta de uma metodologia de alocação otimizada de monitores de QEE, que vai ao encontro das principais características e demandas atuais das smart grids, é de fundamental importância.

Destaca-se, por exemplo, o papel das smart grids em viabilizarem a integração de fontes renováveis, cuja produção é mundialmente crescente. O papel do monitoramento no emprego de tais fontes renováveis é essencial, já que requer a utilização de técnicas avançadas de medição e controle, além do uso de ferramentas de gerenciamento da demanda. Ademais, espera-se que uma smart grid possua uma elevada QEE, tanto no que se refere às variações de tensão como às distorções harmônicas (REGULA et al., 2016). Os fatos mencionados reforçam a importância da metodologia de monitoramento proposta nesta pesquisa de doutorado, e a insere no contexto das smart grids.

De fato, a implantação de um sistema de monitoramento eficaz das situações de Variação de Tensão de Curta Duração (VTCD) e de Variação de Tensão de Longa Duração (VTLD), bem como das distorções harmônicas, pode ser de extrema utilidade para assegurar ou orientar ações para a melhoria dos níveis de QEE nos sistemas de distribuição. Sendo assim, adianta-se que a metodologia de alocação otimizada de monitores de QEE proposta, possui como enfoque principal o desenvolvimento de um método para subsidiar a avaliação e planejamento de sistemas de monitoramento, especialmente no que diz respeito às VTCDs, e também das potenciais condições de ressonância harmônica, que podem desencadear elevada distorção harmônica na tensão.

Diante do exposto, primeiramente cabe discorrer brevemente sobre as definições e entendimentos dados aos fenômenos supracitados do ponto de vista da QEE. Esta discussão está organizada nos itens $1.1,1.2$ e 1.3 . 


\subsection{Aspectos gerais das variações de tensão}

A variação de tensão é caracterizada pela permanência do nível de tensão de fornecimento fora da faixa nominal durante um determinado intervalo de tempo. As variações de tensão estão subdivididas em: VTLDs e VTCDs.

Segundo Dugan et al. (2012), o tempo tomado como base para caracterizar as VTLDs é a persistência do evento por um tempo superior a 1 minuto. Neste caso, quando a tensão se eleva para valores entre 1,1 p.u. e 1,2 p.u. em relação à tensão nominal de fornecimento, tem-se uma sobretensão. Já quando um fenômeno remete a uma tensão remanescente que permaneça abaixo de 0,9 p.u. da nominal, este é classificado como sendo subtensão. As VTLDs são fenômenos decorrentes, em geral, de variações na carga do sistema, chaveamentos sobre o mesmo, além de poderem estar relacionadas às situações de faltas elétricas sustentadas.

Mais especificamente, como exposto por Dugan et al. (2012), a sobretensão é principalmente resultante do processo de desligamento de grandes cargas ou da energização de bancos de capacitores. Por outro lado, a subtensão pode também ter sua origem, por exemplo, no excesso de carregamento dos circuitos alimentadores e na entrada de cargas no sistema. Estas condições de operação do sistema desencadeiam efeitos negativos, como a interrupção da operação de equipamentos eletrônicos e a elevação do tempo de partida de máquinas de indução, potencializando assim os efeitos indesejáveis que ocorrem durante este processo, além de outras consequências danosas. Em um caso mais grave de VTLD, tem-se a presença da interrupção sustentada, em que a tensão de fornecimento permanece nula por um tempo maior do que 1 minuto (DUGAN et al., 2012), ou 3 minutos pelo PRODIST.

De menor duração que as VTLDs, porém não menos preocupantes, os fenômenos de VTCDs estão relacionados às durações inferiores a 1 minuto e são subdivididas em variações instantâneas (0,5 a 30 ciclos), momentâneas (30 ciclos a 3 segundos) e temporárias (3 segundos a 1 minuto) (DUGAN et al., 2012). Com relação à magnitude da tensão, uma VTCD pode ser classificada como: interrupção, afundamento e elevação de tensão.

$\mathrm{Na}$ prática, quando há a incidência de curtos-circuitos sobre o SEP, estes podem causar a completa interrupção do fornecimento da tensão (interrupção de curta duração tensão remanescente entre 0 e 0,1 p.u.), ou um aumento no valor nominal da tensão (elevação de tensão - tensão remanescente entre 1,1 e 1,8 p.u.), ou ainda provocar afundamentos de tensão (tensão remanescente entre 0,1 e 0,9 p.u.) (DUGAN et al., 2012). É importante 
ressaltar que para os três fenômenos caracterizados, a frequência predominante no sinal é a frequência nominal (fundamental) do sistema, que no Brasil é de $60 \mathrm{~Hz}$.

Segundo estudos de QEE realizados pelo Electric Power Research Institue (EPRI) em sistemas elétricos de distribuição dos Estados Unidos da América, os afundamentos de tensão representam a maioria das ocorrências dos fenômenos de QEE, totalizando 54\% dos eventos registrados. Este fato confere às VTCDs a classe de fenômenos de QEE mais observada em SDs (ELECTRIC POWER RESEARCH INSTITUTE, 2003).

\subsection{Aspectos gerais da distorção harmônica}

A distorção harmônica, conforme exposto por Dugan et al. (2012), também se apresenta como um dos principais problemas de QEE, especialmente pelo fato de que os SEPs são projetados para operarem na frequência fundamental do sistema (60 Hz, por exemplo), sendo aconselhável o emprego de uma abordagem com ferramentas adequadas e específicas para tratar tal fenômeno.

Essencialmente, as distorções harmônicas são causadas pela presença de cargas não lineares no SEP, isto é, dispositivos cujas correntes não obedecem a uma relação linearmente proporcional à tensão aplicada em seus terminais (DUGAN et al., 2012). Como exemplo é possível citar o amplo uso de fontes chaveadas, fornos elétricos a arco, acionamento estático de máquinas de indução, estações conversoras em sistemas de transmissão de alta tensão em corrente contínua (High Voltage Direct Current - HVDC) (SAKSVIK, 2012), dentre outros.

A presença de componentes harmônicas no SEP pode provocar considerável redução da vida útil dos equipamentos, já que estes podem operar fora das condições para os quais foram projetados, provocando, por exemplo, sobreaquecimento nos enrolamentos de motores elétricos e transformadores. Dentre outros efeitos indesejáveis, conforme exposto por Sankaran (2002), as distorções harmônicas podem induzir o aumento de perdas pelo efeito pelicular em cabos e a má operação de dispositivos de proteção do SEP.

Além dos danos causados aos equipamentos elétricos e situações indesejadas de operação do SEP, a presença de componentes harmônicas também está sujeita a aplicação de certas normativas, como é o caso do módulo 8 do PRODIST (AGÊNCIA NACIONAL DE ENERGIA ELÉTRICA, 2018) Esta norma especifica valores globais de referência para os índices de distorções harmônicas totais e individuais da tensão, a depender da classe de tensão do SEP. 
Segundo o módulo 8 do PRODIST, por exemplo, considerando-se a tensão nominal de operação do Sistema de Distribuição (SD) entre 1 kV e 69 kV, o máximo valor desejável a ser observado no SD para o índice de DHT da Tensão (DTT\%) não deverá ultrapassar $8 \%$ em relação à componente fundamental. Este índice é calculado de acordo com a equação (1).

$$
\operatorname{DTT}_{\%}=\frac{\sqrt{\sum_{h=2}^{h_{\text {máx }}} V_{h}^{2}}}{V_{1}} \times 100
$$

Sendo $V_{l}$ a tensão da componente fundamental do sistema, $V_{h}$ a tensão harmônica de ordem $h$, e $h_{\text {máx }}$ a ordem harmônica máxima.

Cabe ressaltar que o valor mínimo para $h_{\text {máx }}$ é especificado no módulo 8 do PRODIST como sendo 40 (componente harmônica de $40^{\mathrm{a}}$ ordem). Este valor mínimo é definido de acordo com o tipo de equipamento da "Classe S", nomenclatura esta definida de acordo com a norma IEC 61000-4-30 (INTERNATIONAL ELECTROTECHNICAL COMISSION, 2003).

A norma Std. IEEE 519-2014 (INSTITUTE OF ELECTRICAL AND ELECTRONICS ENGINEERS, 2014), por sua vez, estabelece um limite de 5\% da DHT da tensão em relação a componente fundamental para SEPs entre $1 \mathrm{kV}$ e $69 \mathrm{kV}$. O cálculo da DHT da tensão é efetuado assim como na equação (1), entretanto, deve ser realizado até a $50^{\mathrm{a}}$ ordem, sendo permitida a inclusão de ordens harmônicas superiores quando necessário.

Recentemente, verifica-se ainda a proposição em se ampliar a faixa de análise das ordens harmônicas. Este fato é decorrente da introdução de novas cargas não lineares nos SEPs que causam distorções harmônicas na faixa de 2 a $150 \mathrm{kHz}$, ou seja, superiores à $40^{\mathrm{a}}$ ordem. Estas cargas são decorrentes da aplicação de novas tecnologias, encontradas, por exemplo, nos carregadores de veículos elétricos, sistemas de armazenamento de energia e na geração de energia por fontes renováveis (BOLLEN et al., 2014; ELPHICK et al., 2017).

\subsection{Aspectos gerais da ressonância paralela}

Além da distorção das formas de onda de tensão e corrente, a presença de componentes harmônicas no SEP, provenientes de cargas não lineares, tem como uma de suas principais consequências o fenômeno da ressonância série e/ou paralela. Este fenômeno é caracterizado pela troca de energia entre elementos indutivos e capacitivos dispostos ao longo 
do SEP, podendo resultar na amplificação das tensões nodais do sistema (ARRILLAGA; WATSON, 2003; XU et al., 2005).

Dentre alguns dos principais problemas causados pelas condições de ressonância é possível destacar: a possibilidade de amplificação das componentes harmônicas; redução na eficiência da geração, transmissão e distribuição da energia; degradação da isolação de componentes elétricos com consequente redução de vida útil; e também o funcionamento inadequado do sistema e cargas conectadas (ARRILLAGA; WATSON, 2003).

Uma vez que a maioria das fontes harmônicas comporta-se como fonte de corrente, a ressonância paralela é o tipo de ressonância de maior interesse para a análise de componentes harmônicos no SEP (ARRILLAGA; WATSON, 2003; XU et al., 2005).

O circuito elétrico da Figura 1 mostra um circuito de segunda ordem, conhecido como circuito RLC paralelo, excitado por uma fonte de corrente alternada (JOHNSON; HILBURN; JOHNSON, 2000). Neste circuito, os elementos armazenadores de energia (indutor $L$ e capacitor $C$ ) e o elemento resistivo $R$ estão conectados em paralelo entre os terminais da fonte.

Figura 1 - Circuito RLC paralelo excitado por uma fonte de corrente alternada.

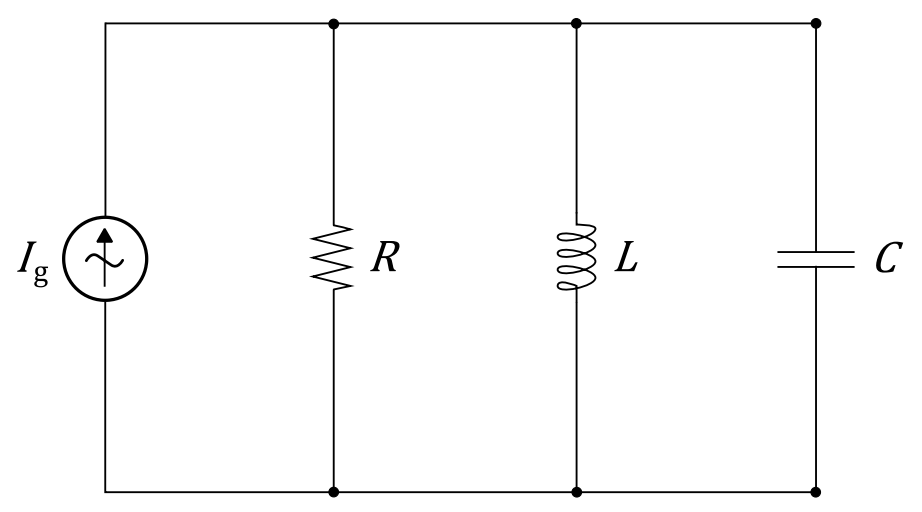

Na condição de ressonância, a impedância equivalente $Z$ do circuito da Figura 1, formada pelo paralelo entre as impedâncias dos elementos $R, L$ e $C$, possui valor mínimo. A análise da expressão de $Z$ permite deduzir a frequência de ressonância para o circuito RLC paralelo, conforme será mostrado na sequência.

A impedância equivalente $Z$ do circuito da Figura 1 pode ser obtida mais facilmente a partir da expressão da admitância, conforme mostra a equação (2). 


$$
\begin{aligned}
Y=\frac{1}{Z} & =\frac{1}{Z_{R}}+\frac{1}{Z_{L}}+\frac{1}{Z_{C}} \\
& =\frac{1}{R}+\frac{1}{j \omega L}+j \omega C \\
& =\frac{1}{R}+j\left(\omega C-\frac{1}{\omega L}\right)
\end{aligned}
$$

Sendo $Z_{R}, Z_{L}$ e $Z_{C}$ as impedâncias de $R, L$ e $C$, respectivamente; $\omega$ a frequência angular; e, por simplicidade da notação, $R, L$ e $C$ são, respectivamente, os próprios valores de resistência, indutância e capacitância dos elementos do circuito RLC paralelo.

Tomando-se o inverso do módulo de $Y$ (equação 2), obtém-se a expressão do módulo de $Z$, como mostra a equação (3).

$$
|Z|=\left|\frac{1}{Y}\right|=\frac{1}{\sqrt{\left(\frac{1}{R}\right)^{2}+\left(\omega C-\frac{1}{\omega L}\right)^{2}}}
$$

Inspecionando-se a equação (3), constata-se que o valor máximo de $|Z|$ é alcançado quando $(\omega C-1 / \omega L)^{2}=0$. Logo, nestas condições, a reatância capacitiva e a reatância indutiva serão iguais, caracterizando-se assim a condição de ressonância. Além disso, conforme mostra a equação (4), é possível calcular em qual frequência $\left(\omega=\omega_{r}\right)$ a condição de ressonância ocorre. Esta frequência é denominada de frequência de ressonância $\left(\omega_{r}\right)$.

$$
\begin{gathered}
\left(\omega_{r} C=\frac{1}{\omega_{r} L}\right)^{2} \\
\omega_{r}=\frac{1}{\sqrt{L C}}
\end{gathered}
$$

Como pode ser observada na equação (4), a frequência de ressonância dependerá dos valores de indutância e capacitância presentes no circuito. O gráfico da Figura 2 mostra o comportamento de $|Z|$ em função da frequência angular $\omega$ (JOHNSON; HILBURN; JOHNSON, 2000).

Como pode ser observado na Figura 2, o máximo do valor da impedância do circuito se dá para $\omega=\omega_{r}$, e na medida em que $\omega \rightarrow \infty,|Z| \rightarrow 0$.

Em um SD, a ressonância paralela pode ocorrer devido à interação da própria indutância com a capacitância do sistema e também com a capacitância de uma carga conectada. Esta situação está representada esquematicamente no diagrama unifilar 
simplificado da Figura 3. Nesta figura, a carga harmônica do consumidor "2", que está representada pela fonte de corrente harmônica $\left(I_{h}\right)$ conectada ao Ponto de Acoplamento Comum (PAC), poderá encontrar uma elevada impedância decorrente da ressonância paralela. Esta condição de ressonância é causada pela interação entre a capacitância $\left(C_{\text {sist }}\right)$ e indutância $\left(L_{\text {sist }}\right)$ do sistema e/ ou entre a capacitância da carga $\left(C_{\text {carga }}\right)$ do consumidor “3”, também conectada ao PAC (ARRILLAGA; WATSON, 2003).

Figura 2 - Esboço do comportamento de $|\boldsymbol{Z}|$ em função de $\boldsymbol{\omega}$.

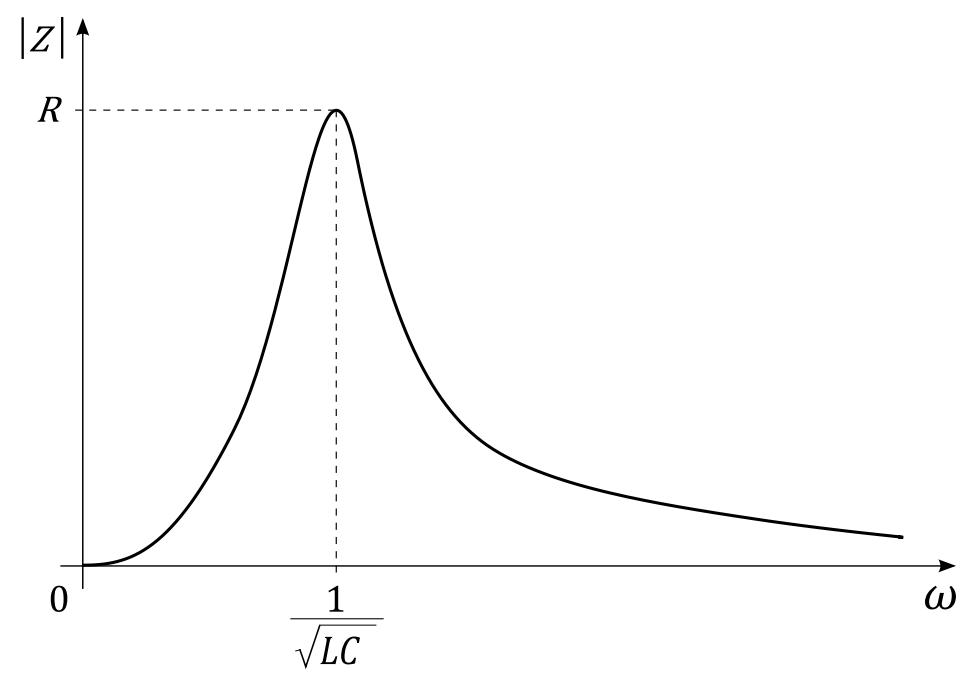

Fonte: Adaptado de Johnson, Hilburn e Johnson (2000).

Figura 3 - Diagrama unifilar simplificado de um SD hipotético, no qual se observa uma potencial condição de ressonância paralela entre elementos do sistema e cargas conectadas ao PAC.

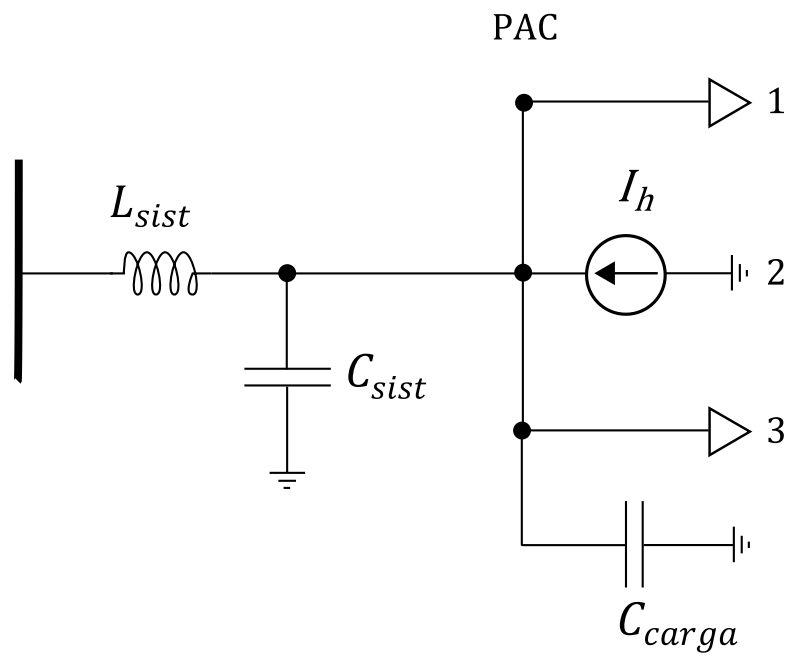

Fonte: Adaptado de Arrillaga e Watson (2003).

Na prática, para os SDs, a avaliação do módulo das impedâncias em função da frequência, ou ainda, o cálculo das frequências de ressonância a partir das equações (3) e (4) 
torna-se inviável. Para tanto, usualmente, procede-se com o cálculo da impedância harmônica (módulo de $Z$ em função da frequência) a partir do método de Varredura em Frequência (ou Frequency Scan) (BONNER et al., 1996; ARRILLAGA; WATSON, 2003).

A varredura em frequência consiste em derivar a resposta da rede elétrica a partir de um determinado ponto do SEP (nó elétrico no caso de um SD). Logo, para cada frequência de avaliação da faixa de frequências de interesse, injeta-se no nó de interesse $(j)$ uma corrente senoidal de $1 \angle 0^{\circ}$ p.u. com frequência igual à frequência de avaliação. Desta maneira, sendo $[Y]_{N \times N}$ a matriz de admitâncias de um SD com $N$ nós, calculada para uma determinada frequência harmônica, tem-se que as tensões harmônicas nodais correspondentes, isto é $[V]_{N \times 1}$, serão calculadas pela resolução do sistema linear dado pela equação (5) (ARRILLAGA; WATSON, 2003).

$$
[I]=[Y][V]
$$

$\mathrm{Na}$ equação, $[I]_{N \times 1}$ é o vetor de injeção de correntes, cujo valor da $j$-ésima componente, correspondente ao nó de injeção da corrente, vale $1 \angle 0^{\circ}$ p.u.; e as demais componentes de [I] possuem valor nulo.

Uma vez calculadas as tensões harmônicas conforme a equação (5), a impedância harmônica observada entre um nó genérico $i$, fixado a injeção de corrente no nó $j$, é dada conforme a equação (6). Cabe ressaltar que $Z_{i j}$ é calculada para cada uma das frequências harmônicas de interesse.

$$
Z_{i j}=\left.\frac{V_{i}}{I_{j}}\right|_{I_{j}=1 \angle 0^{\circ} p . u .}, i=1,2, \cdots, N
$$

Pela equação (6), se $j=i$ tem-se a impedância harmônica própria, e para $j \neq i$ temse a impedância harmônica de transferência entre o nó $i$ e o nó de injeção da corrente $j$. Dessa maneira, fixado um ponto de interesse do sistema (nó $j$ ), e resolvendo-se o sistema da equação (5) para toda a faixa de frequências de análise, é possível obter o perfil das impedâncias harmônicas próprias e de transferência em função da frequência (ARRILLAGA; WATSON, 2003).

Neste contexto, como será detalhadamente explicado no capítulo 4, a Análise de Ressonância Harmônica Modal (ARHM) (XU et al., 2005), apresenta-se também como um método adequado para a identificação das frequências de ressonância. 
Por fim, cabe relembrar que as condições de ressonância paralela estão associadas às amplificações das componentes harmônicas nos SEPs, especialmente no que se refere à amplificação das tensões harmônicas. Este fato pode implicar na elevação da DHT da tensão medida, configurando assim um problema da QEE como comentado no item 1.2.

\subsection{Justificativas da pesquisa}

A ocorrência dos distúrbios de QEE sobre os sistemas das concessionárias, tais como as variações de tensão e as distorções harmônicas, assim como a necessidade de modernização e transformação da infraestrutura atual destes sistemas para incorporar as características das smart grids, configura um campo de pesquisa relevante e promissor que necessita ser mais explorado.

O monitoramento dos distúrbios associados ao SD é uma condição essencial na tarefa de se manter níveis aceitáveis da QEE. Como consequência, é importante estudar de que maneira este monitoramento será realizado, isto é, será fundamental definir quais serão os propósitos e as metodologias mais adequadas para o que é desejado.

As dificuldades enfrentadas na definição de um plano de monitoramento podem ter início logo no instante de se eleger os melhores locais de instalação dos equipamentos de monitoramento. Em geral, não se tem conhecimento prévio sobre quais os pontos do SD que poderão fornecer registros relevantes, ou ainda, uma perspectiva representativa da real situação de operação do sistema sob o ponto de vista do monitoramento da QEE.

Em muitos dos casos, o monitoramento da QEE pode ser um procedimento de complexidade considerável e de investimento técnico-financeiro relativamente elevado, podendo se tornar cada vez mais complexo na medida em que a dimensão do SEP aumenta. Além disso, a ocorrência de certos distúrbios de QEE, tais como as VTCDs e VTLDs, possui caráter estocástico, sendo necessário considerar também outros parâmetros menos controláveis (BOLLEN; GU, 2006).

Na prática verifica-se a tendência de instalar o medidor de QEE na subestação de média tensão, nos alimentadores de saída para o SD, principalmente devido à maior facilidade de manutenção destes equipamentos por parte das concessionárias de energia. Todavia, algumas pesquisas já apontam que nem sempre a instalação de um monitor na subestação proporcionará o melhor monitoramento do SD, acarretando, por exemplo, em afundamentos de tensão não monitorados devido à incidência de curtos-circuitos (KEMPNER, 2016; 
KEMPNER; OLESKOVICZ; GOMES, 2017). Estas constatações, reforçam a importância em se obter um programa de monitoramento otimizado e que considere as características inerentes a cada SD.

Para se identificar as causas e os impactos dos distúrbios que afetam a QEE, o monitoramento do SD deve ser contínuo, fato que pode auxiliar a tomada de ações corretivas e preventivas para a manutenção da QEE (ELDERY et al., 2006). Sendo assim, a situação ideal de monitoramento continuado pode ser traduzida na instalação de medidores em todos os barramentos do sistema considerado, denotando um monitoramento completo e abrangente.

Contudo, considerando fatores como o significativo custo de implantação e manutenção dos medidores e dos entraves técnicos inerentes ao monitoramento dos distúrbios de QEE, observa-se uma forte tendência em se alocar medidores de QEE em pontos (barramentos e/ ou ramais) considerados efetivamente essenciais ao monitoramento global do SEP, promovendo assim um melhor gerenciamento da QEE fornecida sem a necessidade do monitoramento de todos os barramentos do sistema (CEBRIAN; ALMEIDA; KAGAN, 2010; ELPHICK et al., 2017).

Além do preço unitário de cada monitor, o cálculo do custo total do plano de monitoramento também deve considerar o custo de implementação e manutenção dos medidores. De fato, o custo final deve incluir as despesas capitais ("capital expenses") e também as despesas operacionais ("operational expenses"), conforme aponta o relatório elaborado pelo Conselho de Reguladores Europeus de Energia (Council of European Energy Regulators - CEER) e a Comunidade do Conselho Regulatório de Energia (Energy Community Regulatory Board - ECRB) (COUNCIL OF EUROPEAN ENERGY REGULATORS / ENERGY COMMUNITY REGULATORY BOARD, 2012), cujo principal propósito é o de avaliar os programas de monitoramento da QEE (qualidade da tensão) em países da Comunidade Europeia. Logo, afirma-se que redução do número de medidores permitirá não somente a redução imediata do custo capital, mas também contribuirá para a diminuição do custo operacional, podendo proporcionar uma economia considerável de recursos financeiros.

Cabe destacar também que a redução do número de monitores também refletirá na economia de custos associados aos canais de comunicação utilizados na recuperação e processamento de todas as informações registradas nos medidores. Nesse sentido, verifica-se que é crescente a preocupação em se obter uma relação de melhor custo-benefício entre qualidade de monitoramento e quantidade de medidores utilizados (BRANCO et al., 2015; BRANCO et al., 2018). 
Diante do exposto, afirma-se que o tema de pesquisa proposto tem como objetivo principal propor uma metodologia para a implementação de um sistema de monitoramento da QEE abrangente, eficaz e otimizado, contemplando as questões supracitadas, além de outros pontos relevantes, como será mais bem detalhado no item 1.5.

\subsection{Objetivos e contribuições da pesquisa}

O objetivo principal da pesquisa é desenvolver e apresentar um método para a alocação otimizada de medidores de QEE. Este método deve apontar pontos estratégicos sobre os SDs de energia elétrica que permitam fornecer subsídios para a implementação de um plano de monitoramento eficaz e continuado, contemplando VTCDs, acarretadas pela incidência de curtos-circuitos, bem como potenciais condições de ressonância harmônica decorrentes da interação de reatâncias capacitivas e indutivas presentes no SD, as quais podem desencadear elevada distorção harmônica da tensão nodal.

Para o desenvolvimento do método de monitoramento, objetiva-se realizar o processamento de informações que sejam relevantes e inerentes à sensibilidade do SD monitorado, tanto no que diz respeito às VTCDs (afundamentos e/ ou elevações de tensão), como também aos efeitos das potenciais condições de ressonância harmônica. Cabe ainda salientar que as condições de ressonância harmônicas analisadas nos SDs em estudo serão decorrentes da interação entre bancos de capacitores, projetados para a correção do fator de potência local de determinadas cargas, e demais elementos do SD.

O processamento das referidas informações é realizado a partir da obtenção de dois parâmetros de observabilidade do sistema, sendo cada um designado a um dos distúrbios de QEE mencionados (VTCDs e condições de ressonância harmônica).

A obtenção do parâmetro de observabilidade referente às VTCDs será fundamentada na aplicação do Método da Posição de Faltas (MPF) (CONRAD; LITTLE; GRIGG, 1991; CARPINELLI et al., 2009; KEMPNER, 2016), do qual é possível extrair conclusões sobre o comportamento da tensão remanescente do SD perante certas condições de curtos-circuitos.

Para obter o parâmetro de observabilidade que será responsável por traduzir as características do SD frente às potenciais condições de ressonância harmônica, propõe-se uma metodologia baseada na teoria de ARHM (XU et al., 2005). Sendo assim, aplicando-se a ARHM será possível identificar quais os nós do SD (ou um conjunto destes) que possuam maior observabilidade às condições de ressonância. 
Por fim, com ambos os parâmetros de observabilidade obtidos e adequadamente condicionados, será empregado um algoritmo Branch and Bound (B\&B) (LAND; DOIG, 1960; WOLSEY, 1998; RAO, 2009) de modo a solucionar o problema de otimização linear inteiro concebido para a metodologia proposta. Como consequência da otimização, disponibiliza-se a melhor solução de alocação final dos monitores de QEE, os quais deverão ser sensibilizados e registrar possíveis ocorrências de VTCDs e/ ou condições de ressonância harmônica.

No item 1.6 deste capitulo, apresenta-se a concepção geral da metodologia de monitoramento desenvolvida, tornando mais compreensível e detalhado os pontos destacados acima como objetivos da pesquisa.

\subsubsection{Contribuições da pesquisa}

Esta pesquisa de doutorado traz como principal contribuição a proposta de uma metodologia de alocação otimizada de monitores de QEE em SDs, considerando simultaneamente a maximização da observabilidade das VTCDs (afundamentos e/ ou elevações de tensão) e das potenciais condições de ressonância harmônica.

Através da determinação do melhor arranjo de monitores de QEE pela metodologia de alocação, propõe-se subsídios para projetar um programa de monitoramento da QEE mais amplo, eficaz e otimizado para os SDs. Sendo assim, as concessionárias de energia, por exemplo, poderão tomar ações preditivas e ou de um melhor acompanhamento das situações recorrentes sobre o SD de interesse, podendo incorrer na melhora dos índices da QEE fornecida.

Destaca-se ainda que, conforme mencionado no item 1.3, os distúrbios de QEE contemplados na metodologia de monitoramento proposta, bem como a maneira em que o monitoramento é realizado, são de grande relevância, tendo em vista o cenário atual em que se inserem as concessionárias distribuidoras de energia.

De fato, como será discutido no capítulo 2, diversos trabalhos encontrados na literatura técnica correlata visam tratar do monitoramento das distorções harmônicas, especialmente via técnicas de estimação de estado. Entretanto, a proposta desta tese de doutorado em monitorar as potenciais condições de ressonância dos SDs, empregando a teoria de ARHM, diferencia-se dos pontos abordados em tais trabalhos nos seguintes aspectos: $(i)$ proposição de uma metodologia de alocação otimizada de medidores de QEE com o objetivo 
de monitorar, além das VTCDs, as potenciais amplificações da tensão em SDs, causadas por condições de ressonância harmônica resultantes da interação entre bancos de capacitores e demais componentes do SD; (ii) aplicação da ARHM combinada com otimização linear inteira para determinar os melhores nós do SD para a observação das condições de ressonância harmônica e das VTCDs; (iii) considerar a análise das potenciais condições de ressonância harmônicas para uma ampla faixa de frequências (até a $128^{a}$ harmônica); e (iv) investigar a sensibilidade da solução de alocação final, fornecida pela metodologia de alocação proposta, para distintos estados de conexão de bancos de capacitores locais, utilizados para a correção do fator de potência de determinadas cargas no SD.

\subsection{Uma visão geral da metodologia de monitoramento proposta}

O fluxograma da Figura 4, fornece uma visão global da metodologia de alocação otimizada proposta. Como pode ser verificado, existem duas etapas principais ("Etapa 1" e “Etapa 2”).

Figura 4 - Fluxograma geral da metodologia de alocação otimizada de monitores de QEE.

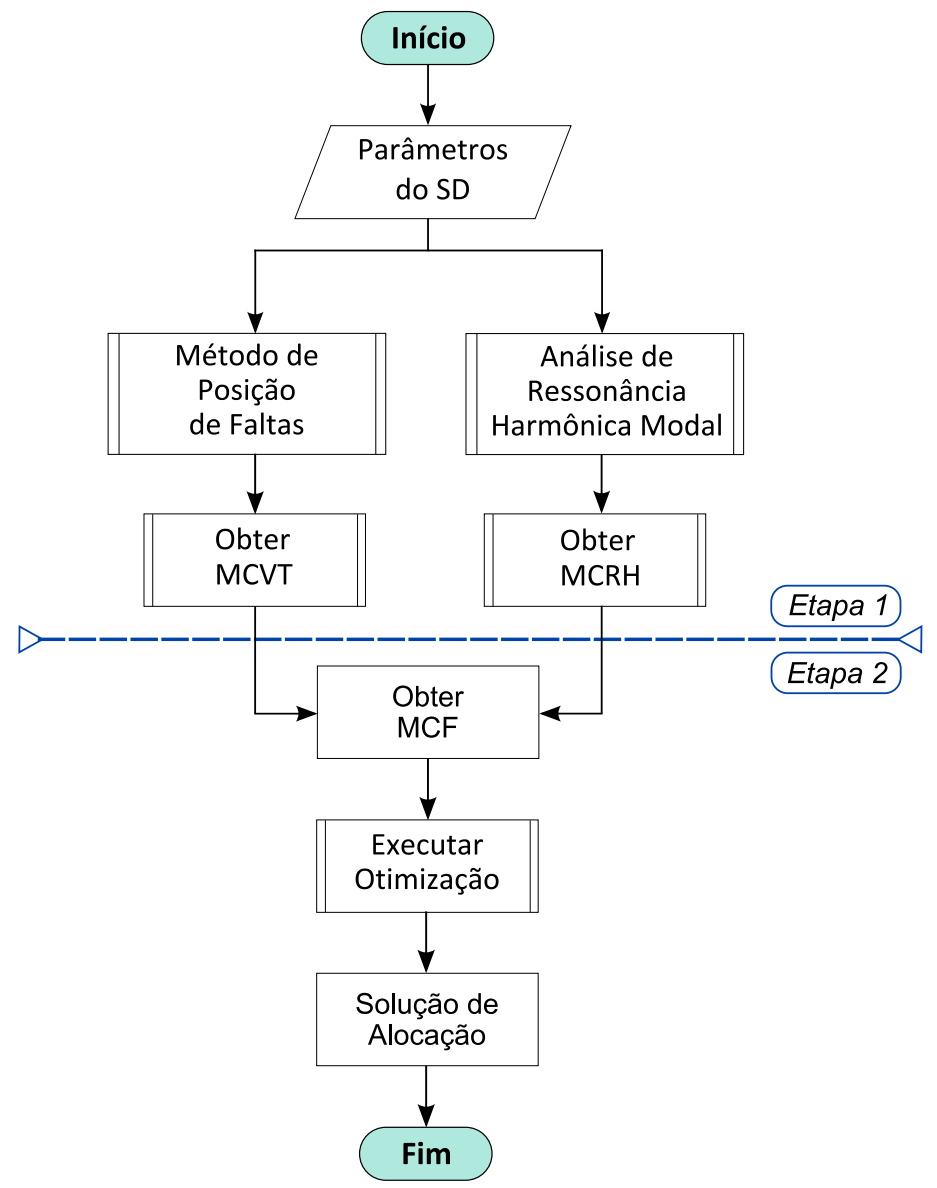


A "Etapa 1" inicia-se com a entrada de dados referentes SD, isto é, parâmetros de linhas, dados de carga, bancos de capacitores e topologia da rede.

Em seguida, como pode ser observado na Figura 4, duas ramificações dão origem a processos realizados paralelamente, isto é, um dos ramos consistindo na execução do MPF com a posterior obtenção da Matriz de Cobertura das Variações de Tensão (MCVT); e o outro ramo que consiste na execução da ARHM com a consequente obtenção da Matriz de Cobertura de Ressonância Harmônica (MCRH).

A execução do MPF, juntamente com a obtenção da MCVT, constitui a parcela da metodologia responsável pelo processamento da observabilidade das VTCDs no SD. Por sua vez, a execução da ARHM, juntamente com a obtenção da MCRH, será responsável pelo processamento da observabilidade das potenciais condições de ressonância harmônica no SD. Dessa maneira, ao término da "Etapa 1", todas as informações de observabilidade referentes aos fenômenos de QEE de interesse para esta pesquisa estarão processadas e organizadas de maneira independente, prontas para a ativação da "Etapa 2".

É importante salientar que as duas parcelas da "Etapa 1", isto é, a execução do MPF com a obtenção da MCVT e a execução da ARHM com a obtenção da MCRH, serão detalhadamente explicadas nos capítulos 3 e 4, respectivamente. Além disso, a explicação destas duas parcelas da metodologia conta com o auxílio de outros dois fluxogramas com maior nível de detalhamento (Figura 10 e Figura 11), devidamente apresentados e explicados nos capítulos 3 e 4, respectivamente. É importante ressaltar que a opção pela posterior apresentação dos fluxogramas com maior nível de detalhamento deve-se à necessidade de melhor organização e apresentação da metodologia como um todo.

Cabe adiantar que as matrizes MCVT e MCRH são matrizes binárias, capazes de denotarem o status da observabilidade em cada nó do SD referente às VTCDs (MCVT) e às condições de ressonância harmônica (MCRH). Como estas matrizes são obtidas por processos conduzidos paralelamente, isto é, independentes entre si, logo no início da "Etapa 2" as mesmas serão concatenadas por justaposição horizontal, formando-se assim uma matriz aumentada denominada Matriz de Cobertura Final (MCF).

O objetivo principal da obtenção da MCF é o de possibilitar uma única execução do algoritmo de otimização, visando obter um arranjo de monitores que seja simultaneamente sensível às VTCDs e às potenciais condições de ressonância harmônica. Sendo assim, encerrando-se a "Etapa 2", após a execução do processo de otimização, será disponibilizado quais são os melhores nós de instalação no SD que garantem e maximizam a observabilidade dos fenômenos de QEE de interesse. 
Conforme será explicado no capítulo 5, tem-se a caracterização de um problema de otimização linear inteira, sendo a solução de alocação final dada em termos de um vetor de alocação binário. Este vetor possui elementos cujos valores são binários, denotando apenas duas possibilidades para cada nó do SD: instalação (valor unitário) ou não instalação (valor nulo). Conforme já comentado, para a resolução do problema de otimização mencionado, optou-se pelo algoritmo B\&B. Este algoritmo é amplamente difundido e constitui um método de enumeração que explora soluções candidatas em um espaço de busca particionado. Entretanto, a maioria das soluções não factíveis são descartadas sem a necessidade de serem diretamente testadas (LAND; DOIG, 1960; RAO, 2009).

Além das referidas características vantajosas do algoritmo B\&B, a opção pelo seu emprego deve-se também aos excelentes resultados alcançados em pesquisas realizadas anteriormente e relacionadas à alocação otimizada de monitores de QEE em SEPs, como, por exemplo, em (KEMPNER, 2016; KEMPNER et al., 2016; KEMPNER; OLESKOVICZ; GOMES, 2017).

Em suma, a partir dos parâmetros e informações do SD em análise, tem-se como objetivo a obtenção de um arranjo otimizado de monitores estrategicamente posicionados e preparados para a observação das VTCDs e potencias condições de ressonância harmônica. Para tanto, serão utilizadas como ferramentas as teorias do MPF e da ARHM, fundamentais para o processamento e organização das informações de observabilidade dos fenômenos de QEE de interesse. Posteriormente, estas informações de observabilidade são utilizadas na solução do problema de otimização linear inteira, formulado para a metodologia de monitoramento proposta.

\subsection{Organização do documento}

Conforme já evidenciado, o capítulo 1 dedica-se à apresentação e contextualização do tema de pesquisa proposto, enfatizando-se a justificativa, objetivos e contribuições da pesquisa. Além disso, foram apresentados alguns dos principais conceitos relacionados ao tema central da pesquisa no contexto da QEE. Ainda neste capítulo, a concepção geral da metodologia de monitoramento foi introduzida, servindo como guia para o detalhamento da mesma ao longo do texto.

O capítulo 2 traz o referencial teórico pertinente ao tema da pesquisa, procurando mobilizar os pontos centrais abordados pelos trabalhos desenvolvidos atualmente no campo 
de pesquisa correlato, que trata sobre alocação otimizada de monitores de QEE perante as VTCDs ou a presença de componentes harmônicas nos SEPs.

No capítulo 3, são introduzidos o MPF e a obtenção das expressões analíticas matriciais para as tensões nodais remanescentes, referentes à ocorrência de cada um dos tipos de curtos-circuitos assimétricos considerados nesta pesquisa. Ainda no capítulo 3, tem-se o detalhamento de todo o procedimento realizado para a obtenção da MCVT, que, conforme já adiantado, contém as informações sobre a observabilidade das VTCDs no SD. Por fim, o capítulo 3 apresenta uma breve discussão sobre a influência dos limiares de tensão utilizados e os tipos de curtos-circuitos estudados na formação da MCVT.

O capítulo 4 introduz a teoria da ARHM, contextualizando-a frente ao problema de monitoramento da QEE abordado na pesquisa. Após a apresentação da teoria da ARHM, temse o detalhamento do processo de obtenção da MCRH, que contém as informações sobre a observabilidade das potenciais condições de ressonância no SD. Outro importante assunto abordado neste capítulo é a apresentação do Método da Potência Inversa (MPI), utilizado para o cálculo dos autovalores e autovetores críticos da matriz de admitância do SD. Este cálculo é necessário para determinar a impedância modal e os graus de observabilidade às ressonâncias harmônicas. Encerrando-se o capítulo 4, apresenta-se uma breve discussão acerca de algumas questões técnicas, levantadas durante o desenvolvimento da pesquisa, referentes ao cálculo dos autovalores e autovetores críticos da matriz de admitâncias.

No capítulo 5, a obtenção da $\mathrm{MCF}$, que contém ambas as informações de observabilidade das VTCDs e das potenciais condições de ressonância, é explicada. Neste capítulo, apresenta-se também a formulação do problema de otimização linear inteiro para a metodologia de alocação de medidores proposta. Por fim, é realizada uma breve introdução ao algoritmo de otimização $\mathrm{B} \& \mathrm{~B}$, utilizado para a resolução do referido problema de otimização.

No capítulo 6 estão apresentados os SDs utilizados para os testes da metodologia de alocação dos medidores de QEE, bem como todas as condições de contorno assumidas. Em seguida, são expostos, analisados e discutidos os resultados obtidos com a aplicação da metodologia como um todo.

Finalmente, o capítulo 7 reúne todas as principais conclusões depreendidas durante o desenvolvimento da pesquisa e também dos resultados observados. Ademais, neste capítulo constam também os pontos a serem abordados para a continuidade e aprimoramento da pesquisa até então desenvolvida. 


\section{Revisão bibliográfica}

A alocação de monitores de Qualidade da Energia Elétrica (QEE) apresenta-se como uma área de pesquisa de destaque nos últimos anos. Pesquisadores apontam para a importância do estabelecimento de um plano de monitoramento eficiente e que agregue o menor custo possível às concessionárias de energia. Entretanto, o conceito de eficiência pode se referir a mais de um parâmetro nas várias pesquisas desenvolvidas. Neste sentido, a maioria das metodologias de alocação de monitores de QEE por técnicas de otimização possuem enfoques característicos, como, por exemplo, a alocação de medidores de QEE que garantem a cobertura das ocorrências dos afundamentos de tensão (ESPINOSA-JUARÉZ; HERNANDÉZ; OLGUIN, 2009; SALIM; NOR, 2010), afundamentos e elevações de tensão (CEBRIAN; ALMEIDA; KAGAN, 2010) e a maximização do monitoramento das distorções harmônicas (RAD; MOKHTARI; KARIMI, 2012).

Espinosa-Juaréz, Hernandéz e Olguin (2009) apresentam um método de alocação otimizada de monitores de QEE utilizando uma matriz específica, que denota um índice de alcance do monitoramento dos afundamentos de tensão. Por meio de uma abordagem de otimização mono objetivo, utilizando o algoritmo Branch and Bound (B\&B), os autores demonstram a aplicação da técnica de alocação desenvolvida para os sistemas de transmissão de 24 e 128 barras do IEEE (Institute of Electrical and Electronics Engineers). Segundo os resultados apresentados, os arranjos de monitores encontrados são capazes de monitorar todo o sistema elétrico a partir dos melhores locais de observação e com o menor número de monitores possível.

A pesquisa de Salim e Nor (2010) também salienta a importância do monitoramento dos afundamentos de tensão, especialmente devido à crescente preocupação com este tipo de fenômeno de QEE. O método apresentado pelos pesquisadores visa obter um número mínimo de monitores de QEE instalados de maneira a maximizar a redundância das medidas como um todo. Este fato, segundo os autores, pode acarretar em uma maior confiabilidade no plano de monitoramento de QEE proposto. Os resultados ilustram a metodologia aplicada sobre os sistemas de transmissão de 30 e 300 barras do IEEE, considerando-se distintos tipos de curtos-circuitos que podem recair sobre um sistema elétrico trifásico.

Conforme mencionado anteriormente, Cebrian, Almeida e Kagan (2010) apresentam uma metodologia de alocação ótima de monitores voltada para a observabilidade dos 
afundamentos de tensão e também das elevações de tensão. A metodologia exposta pelos autores inclui uma abordagem estocástica referente à taxa de incidência típica de curtoscircuitos em sistemas de distribuição. Nesta abordagem estocástica estão considerados todos os tipos de curtos-circuitos (simétricos e assimétricos), além de valores típicos da resistência de falta associadas aos mesmos. O número mínimo de monitores de QEE, que venha a maximizar índices específicos de observabilidade introduzidos pelos autores, é determinado por meio de um algoritmo genético com aprimoramentos em seus operadores. Através da aplicação da referida metodologia de alocação em um sistema de distribuição real, são determinados os melhores locais para a instalação dos monitores de QEE, sensíveis tanto aos afundamentos de tensão como às elevações de tensão.

O monitoramento dos afundamentos de tensão a partir da alocação otimizada de monitores de QEE também pode ser verificado e consultado em Branco et al. (2015), Kempner et al. (2016), e Branco et al. (2018).

Branco et al. (2015) propõem uma metodologia para resolver o problema de alocação de monitores de QEE em sistemas de transmissão. A alocação é formulada como um problema de otimização multiobjetivo, cujos objetivos são a minimização do custo de monitoramento e a maximização da redundância das medições dos afundamentos de tensão. Os autores utilizaram um Algoritmo Evolutivo Multiobjetivo com Tabelas (AEMT) para o problema de alocação mencionado em sistemas teste do IEEE. Os resultados mostram que soluções factíveis bem diversificadas e distribuídas ao longo da fronteira de Pareto foram encontradas, proporcionando uma análise de custo-benefício entre custo e redundância das medidas que pode ser útil para a implementação de um plano de monitormamento da QEE.

$\mathrm{Na}$ pesquisa de Kempner et al. (2016), uma metodologia de alocação otimizada visando a total observabilidade aos afundamentos de tensão em um SD é proposta. A alocação dos monitores foi formulada como um problema de otimização a ser resolvido por um algoritmo B\&B. Além disso, os autores investigam a sensibilidade da solução de alocação obtida frente a distintos cenários de carregamento do SD. O SD teste utilizado foi o de 34 nós do IEEE. Os resultados demonstram que as soluções de alocação obtidas são robustas em relação aos distintos carregamentos do SD considerado, isto é, o arranjo final de alocação não sofre significativas alterações em função do carregamento.

Em Branco et al. (2018), os autores também propõe uma metodologia de alocação de medidores para a cobertura dos afundamentos de tensão. O problema de alocação é formulado como um problema de otimização multiobjetivo de muitos objetivos (ao todo 6 objetivos). A metodologia foi testada para SDs do IEEE, utilizando o AEMT para a resolução do problema 
multiobjetivo estabelecido. Conforme destacado pelos autores, uma vez que são considerados 6 objetivos, as análises de custo-benefício proporcionam maior flexibilidade para o planejamento do plano de monitoramento da QEE.

Outras pesquisas pertinentes ao tema de monitoramento da QEE dizem respeito às técnicas de estimação de estado no contexto da QEE e smart grids (redes elétricas inteligentes), em que, a partir de um número limitado de medidores em barramentos específicos do Sistema Elétrico de Potência (SEP), é possível estimar as quantidades monitoradas para o restante do sistema, conforme exposto por Farzanehrafat e Watson (2013).

Neste contexto, encontram-se metodologias que estimam os afundamentos de tensão (LUCIO; ESPINOSA-JUARÉZ; HERNANDÉZ, 2011; HERNANDÉZ et al. 2013) ou então as componentes harmônicas do sistema a partir de barramentos estratégicos, com o intuito de fornecer um monitoramento abrangente dos índices associados à QEE (KETABI; SHEIBANI; NOSRATABADI, 2012; ARRUDA; KAGAN; RIBEIRO, 2010).

As técnicas de estimação de estado mencionadas, que estão relacionadas às distorções harmônicas, possuem em comum o objetivo de minimizar o erro das medidas estimadas, uma vez que uma quantidade limitada de monitores de QEE é pressuposta. Para atingir o erro mínimo das medidas com o menor número de monitores de QEE disponível, os pesquisadores empregam distintos algoritmos de otimização.

Na pesquisa de Rad, Mokhtari e Karimi (2012), por exemplo, é utilizado o algoritmo Weighted Least Square, que minimiza a soma dos erros quadráticos entre os valores de distorção harmônica registrados pelo monitor e os respectivos valores estimados. Segundo os autores, a escolha por este tipo de algoritmo deve-se a sua rapidez de processamento. A metodologia de alocação otimizada proposta é testada sobre o sistema de transmissão de 14 barras do IEEE, proporcionando estimações confiáveis para as distorções harmônicas, dado o baixo índice de erro encontrado, mesmo quando a quantidade de monitores é inferior à quantidade de variáveis de estado desconhecidas.

$\mathrm{Na}$ metodologia proposta por Ketabi, Sheibani e Nosratabadi (2012), a soma dos erros quadráticos entre os valores de distorção harmônica registrados pelo monitor e os respectivos valores estimados, também é minimizada. Entretanto, para esta tarefa, os autores utilizam o algoritmo Seeker Optimization Algorithm. A metodologia de alocação e estimação de estado para distorções harmônicas também é testada sobre o sistema de transmissão de 14 barras do IEEE. Contudo, é válido salientar que os autores demonstram a eficácia dos resultados de maneira mais aprofundada e contundente em relação ao apresentado por Rad, 
Mokhtari e Karimi (2012), analisando mais cenários de operação do sistema elétrico escolhido para testes.

Arruda, Kagan e Ribeiro (2010) utilizam uma abordagem envolvendo um algoritmo com estratégia evolutiva, desenvolvido com regras específicas para atender as restrições do problema de estimação das distorções harmônicas. Conforme apresentado pelos autores, no geral, a metodologia fornece estimativas com erros inferiores a $1 \%$. O sistema de 14 barras do IEEE, assim como nos trabalhos anteriormente mencionados, foi utilizado nos testes.

Lucio, Espinosa-Juaréz e Hernandéz (2010) apresentam uma metodologia baseada em algoritmos genéticos para tratar o problema de estimação do número de afundamentos de tensão. Além disso, os autores tecem uma comparação entre o desempenho da abordagem com algoritmos genéticos, e outra, similar, na qual é empregada a programação linear inteira. A metodologia, com ambas as abordagens mencionadas, foi testada para os sistemas de transmissão de 24 e 57 barras do IEEE. Pelos resultados, os autores demonstram que a abordagem via algoritmos genéticos apresentou-se mais rápida na busca pela solução factível, e com resultados de boa qualidade quando comparada ao método de programação linear inteira.

Alternativamente à aplicação de algoritmos genéticos e programação linear inteira, Hernandéz et al. (2013) propõem a utilização do método Singular Value Decomposition para a solução do sistema de equações resultante da formulação matemática do problema de estimação dos afundamentos de tensão. $\mathrm{O}$ método apresentado pelos autores foi testado para o sistema de transmissão de 118 barras do IEEE para diversas condições de operação, revelando-se como uma alternativa viável para a estimação da quantidade dos afundamentos de tensão, a partir de um número restrito de monitores de QEE.

De fato, conforme discutido acima, as técnicas de estimação de estado de QEE estão relacionadas às metodologias de alocação de monitores de QEE, e podem auxiliar na avaliação da observabilidade do sistema, seja perante as VTCDs, ou às distorções harmônicas. Vale salientar que a avaliação da observabilidade do SD é imprescindível à modelagem do problema de alocação otimizada de medidores de QEE.

No âmbito das pesquisas que abordam os distúrbios de QEE associados às distorções harmônicas, constata-se uma ampla área de pesquisa que trata das condições de ressonância harmônica.

No trabalho de Zheng, Bollen e Zhong (2010), o impacto das condições de ressonância harmônica é avaliado para um parque de geração eólica. Para tanto, os autores apresentam modelos do parque eólico que foram desenvolvidos especialmente para o estudo 
do comportamento das condições de ressonância. Estes modelos são utilizados para a obtenção do perfil da impedância harmônica do sistema, tanto analiticamente, como em ambiente de simulação computacional, para que as frequências de ressonância fossem determinadas. Desse modo, a amplificação das distorções harmônicas da tensão foram analisadas para um parque eólico constituído de cem turbinas de $2 \mathrm{MW}$ cada, conectados à rede de média tensão por meio dos respectivos transformadores de potência de cada turbina e cabos subterrâneos. Na análise também foram considerados distintos cenários de conexão dos bancos de capacitores presentes no sistema, cuja potência reativa total é de 72 MVAr. Com principal resultado da pesquisa, os autores apontam que a presença dos bancos de capacitores são prepoderantes para a observação das condições de ressonância harmônica.

Em Huan e Tayjasanant (2013), a obtenção de modelos de parques eólicos também é investigada para o estudo das condições de ressonância harmônica. Os autores afirmam que este é um importante tema de pesquisa, já que os parques eólicos lideram a crescente implementação de fontes alternativas de energia. A pesquisa apresenta distintas abordagens para a modelagem dos parques eólicos, procurando determinar a qualidade dos modelos estudados para a avaliação das condições de ressonância. O sistema utilizado nos teste é referente a um parque eólico da Tailândia, constituído de 45 turbinas eólicas, totalizando 90 MW.

Em Bradt et al.(2011), também é reportada a preocupação em melhor encaminhar os problemas que venham a ser causados pelas emissões de correntes harmônicas das usinas eólicas. Neste trabalho, os autores reúnem e discutem os principais problemas relacionados ao conteúdo harmônico em parques eólicos, perpassando desde as diretrizes para a correta modelagem dos componentes que compõem o modelo do sistema, até a necessidade do atendimento de normativas, como a norma Std. IEEE 519-1992, cuja versão atualizada é a Std. IEEE 519-2014 (INSTITUTE OF ELECTRICAL AND ELECTRONICS ENGINEERS, 2014) que regulamenta a emissão de harmônicos das plantas eólicas em conexão aos SDs dos Estados Unidos da América. Dentre os vários tópicos abordados no trabalho, destaca-se a necessidade de avaliação do perfil harmônico do sistema de modo a controlar as condições de ressonância. Dentre as causas deste fenômeno, os autores citam a interação de elementos capacitivos e indutivos de elementos do sistema, como, por exemplo, a impedância representativa do sistema de transmissão, transformadores de potência do SD, turbinas eólicas, dispositivos de compensação de reativos, instalação de filtros passivos e forte recorrência de uso de cabos subterrâneos. 
Assim como nos trabalhos já mencionados, Dang et al.(2015) relatam a necessidade de uma correta avaliação das potenciais condições de ressonância em um parque eólico. Os autores utilizam simulações computacionais e medidas em campo de plantas eólicas situadas no Canadá para salientar o risco de amplificações significativas das tensões harmônicas em determinados bancos de capacitores, e das correntes harmônicas no transformador da subestação.

Ainda reportando os problemas que surgem da crescente implementação de parques eólicos, Hoseinzadeh et al. (2018) chamam a atenção para a ocorrência de ressonância harmônica em usinas offshore vem sendo observada em função da substituição da antiga geração de geradores síncronos por conversores de potência, além da substituição de linhas aéreas por cabos submarinos e ou subterrâneos dos sistemas de transmissão das referidas usinas eólicas offshore. Os autores ressaltam que a capacitância dos cabos submarinos/ subterrâneos são cerca de 40 vezes superior às linhas aéreas, fato que pode resultar na coincidência ou aproximação da frequência de ressonância dos referidos cabos com as frequências harmônicas de chaveamento dos conversores de potência. Como consequência, é possível que ocorra a amplificação harmônica sobre o conjunto de transmissão e distribuição associado ao parque eólico offshore. A discussão da pesquisa apresentada é conduzida de maneira a endereçar os problemas da QEE advindos da amplificação harmônica de um parque eólico offshore real. Os autores apresentam a varredura em frequência do sistema elétrico modelado, seguido de estudos com expressões analíticas dos circuitos ressonantes presentes, através das potenciais frequências de ressonância que são identificadas.

O fenômeno de ressonância também é objeto de estudo para plantas de geração fotovoltaicas, como é o caso da pesquisa de Fortes et al. (2016). Neste trabalho, os autores investigam a possibilidade de detecção de potenciais condições de ressonância paralela em um sistema de geração fotovoltaico. Para tanto, uma técnica baseada na resposta em frequência do circuito equivalente do sistema de geração fotovoltaica, quando conectado ao ponto de acoplamento comum, é utilizada. O sistema teste possui características típicas de uma rede com regulação da tensão por meio de bancos de capacitores. Depois de verificada a potencial condição de ressonância, os limites de emissão de harmônicos para a rede em questão são testados em ambiente de simulação computacional. Para a condição de ressonância determinada, os resultados discutidos pelos autores mostram a significativa amplificação das tensões harmônicas sobre os bancos de capacitores do sistema teste, além da indesejável amplificação das tensões ao longo do alimentador do SD. 
O levantamento do perfil harmônico do sistema através da Análise de Ressonância Harmônica Modal (ARHM) é outra área de pesquisa que vêm ganhando destaque e espaço entre os pesquisadores. A técnica de ARHM foi inicialmente introduzida por Xu et al. (2005). Neste trabalho, os autores propõem uma técnica alternativa à convencional de varredura em frequência para a análise de potenciais condições de ressonância. Maiores detalhes desta técnica serão apresentados no capítulo 4.

Em Cui e Xu (2007), por exemplo, a ARHM é apresentada como uma ferramenta útil para a avaliação de potenciais problemas relacionados a frequências de ressonância em sistemas elétricos. Em especial, os sistemas elétricos estudados possuem fontes harmônicas distribuídas e não necessariamente localizadas em um ou poucos pontos específicos, como tradicionalmente considerados. Os autores ressaltam que com a proliferação cada vez mais crescente de cargas poluidoras nos sistemas elétricos, as fontes harmônicas tendem a apresentar dispersão aleatória na rede, inviabilizando o levantamento da impedância harmônica do sistema via a técnica de varredura em frequência, já que este método é mais adequado quando as fontes harmônicas possuem localização definida. Como uma das causas mais comuns de problemas relacionados com as harmônicas, os autores citam o fenômeno de ressonância causado pela recorrente aplicação de bancos de capacitores para a correção do fator de potência e para regulação de tensão.

Tendo em vista este cenário, o trabalho de Cui e Xu (2007) propõe uma análise de sensibilidade da impedância harmônica, via ARHM, para determinar quais componentes do sistema elétrico possuem maior responsabilidade no fenômeno da ressonância. A metodologia de análise de sensibilidade proposta foi testada sobre dois sistemas de distribuição operando sob duas condições distintas. No estudo, os autores ilustram as vantagens em se utilizar a ARHM para a análise de sensibilidade, isto é, determinando-se a responsabilidade de cada componente do SD em condições de ressonância.

Mais tarde, no trabalho de Cui e Wang (2012), observa-se a complementação à pesquisa apresentada por Cui e Xu (2007), no qual a análise de sensibilidade da frequência modal é realizada de maneira a aprimorar o diagnóstico dos componentes que mais possuem participação nas condições de ressonância. Para os testes, os autores utilizaram o sistema de transmissão de 14 barras do IEEE, obtendo resultados que demonstram a melhor qualidade na determinação dos componentes mais participantes de uma condição de ressonância harmônica.

De fato, o principal resultado dos trabalhos de Cui e Xu (2007) e de Cui e Wang (2012), foi determinar índices de sensibilidade no domínio modal para identificar com mais 
clareza quais os componentes dos sistemas elétricos estão mais envolvidos nas condições de ressonância harmônica verificadas. Como consequência, os referidos autores ressaltam a utilidade destes índices em planos de mitigação dos problemas relacionados à ressonância harmônica.

Em Amornvipas e Hofmann (2010), a ARHM também é utilizada para a determinação das frequências de ressonância como alternativa à convencional varredura em frequência. Os autores apresentam uma maneira de modelar o chaveamento de componentes do SEP diretamente na matriz de admitância de barras. Posteriormente esta matriz é transformada para o domínio modal e a ARHM pode ser aplicada. Duas condições de operação de um sistema de transmissão alemão de 268 barras foram testadas, sendo estas referentes à condição de carga leve e carga pesada. Nos resultados os autores exploram as vantagens em se utilizar a ARHM, uma vez que o desacoplamento dos modos pode ser útil para se determinar com mais praticidade as frequências de ressonância paralela.

Em Hasan et al. (2013), a ARHM é novamente utilizada para a determinação de condições de ressonância e dos componentes que mais as influenciam. Desta vez, os autores aplicaram o estudo para uma usina que gera energia a partir do movimento das ondas do mar (no termo em inglês esta usina é conhecida como: wave power plant). Segundo os autores, o sistema foi modelado para representar o mais fielmente possível as condições de operação de uma usina deste tipo. O sistema teste possui 10 geradores de $1 \mathrm{MW}$ cada, aos quais estão conectados seus respectivos conversores e transformadores de potência. Assim como no caso das usinas eólicas, o emprego de cabos submarinos é uma característica inerente a este tipo de sistema de energia. Nos estudos realizados, os autores procuram projetar o uso de filtros que melhorem o perfil harmônico como um todo. Além disso, um estudo paramétrico sobre a influência do comprimento dos cabos submarinos nas frequências de ressonância também foi realizado, demonstrando assim o efeito significativo das elevadas capacitâncias associadas a este tipo de cabo.

Diante do exposto, é possível verificar o crescente interesse no estudo das potenciais condições de ressonância harmônica que podem levar às amplificações das tensões harmônicas e, consequentemente, à violação dos limites de emissão harmônica. Conforme mostram os trabalhos citados, esta preocupação é em grande parte, decorrente da proliferação e integração de fontes de energias renováveis aos sistemas elétricos no contexto atual e futuro.

Cabe salientar que até o momento de elaboração desta revisão bibliográfica não foram encontrados trabalhos relacionados à alocação de monitores de QEE que levem em consideração as potenciais condições de ressonância. Todavia, diante do amplo interesse da 
comunidade científica em estudos relacionados às ressonâncias harmônicas em sistemas elétricos modernos, além das recentes aplicações da técnica de ARHM reportadas, acredita-se que a pesquisa de doutorado desenvolvida traz contribuições úteis no âmbito do monitoramento de tais condições que podem deteriorar a QEE, conforme será apresentado mais adiante no capítulo de resultados (capítulo 6) e no capítulo das conclusões (capítulo 7) deste trabalho. 


\section{Método de posição de faltas}

Segundo a norma IEEE Std. 493-2007 (INSTITUTE OF ELECTRICAL AND ELECTRONICS ENGINEERS, 2007), o Método de Posição de Faltas (MPF) foi inicialmente apresentado por Conrad, Little e Grigg (1991) e constitui uma ferramenta de análise empregada pela maioria das concessionárias de energia elétrica. Por esta análise, as distribuidoras de energia podem verificar o desempenho do Sistema de Distribuição (SD) na presença de afundamentos e elevações de tensão, sendo possível, por exemplo, estimar a quantidade destes distúrbios que são causados por situações de curtos-circuitos.

Essencialmente, o MPF considera situações de curtos-circuitos em todos os nós (um por vez) do SD, seguido do cálculo e armazenamento das tensões remanescentes em todos os nós do sistema. Assim, para um sistema de $N$ nós, as tensões remanescentes formarão então uma matriz quadrada $N \times N$ denominada Matriz de Tensão Durante a Falta (MTDF).

Conforme especificado, a aplicação das faltas se dá em todos os nós do sistema (um por vez), de modo que a cada aplicação da falta associada ao $j$-ésimo nó, o cálculo das tensões remanescentes dos demais seja efetuado. Ou seja, as $N$ colunas da MTDF conterão as $N$ tensões remanescentes ( $N$ linhas) devido às sucessivas aplicações de faltas desde o nó $j=1$ até o nó $j=N$.

As colunas da MTDF definem o que se entende por área afetada (CARPINELLI et $a l ., 2009)$, indicando quais nós estão ou não sofrendo afundamentos de tensão devido a um curto-circuito no nó genérico $j$. Ou seja, para uma falta no nó $j$, a coluna $j$ da MTDF contém as $N$ tensões remanescentes que determinam quais nós do $\mathrm{SD}$ estão ou não sofrendo afundamentos de tensão.

Por sua vez, as linhas da MTDF definem a área de vulnerabilidade (ou área exposta) (CARPINELLI et al., 2009). Diferentemente da área afetada, a área de vulnerabilidade indica qual é a tensão remanescente em um dado nó $i$, devido à aplicação de curtos-circuitos em todos os demais nós do sistema: $j=1,2, \cdots, N$. Assim, a linha $i$ da MTDF contém as $N$ tensões remanescentes registradas no nó genérico $i$, determinando em quais das $N$ situações de curtos-circuitos este nó sofre afundamento de tensão. De fato, a análise da linha $i$ da MTDF é equivalente ao monitoramento da tensão em $i$ para as condições de curtos-circuitos consideradas, o que significa dizer que a área de vulnerabilidade está diretamente associada a um ponto de monitoração (nó $i$ ) (KEMPNER, 2016). 
A delimitação tanto da área afetada como da área de vulnerabilidade se dá em função de um limiar de tensão pré-definido, ou seja, as mencionadas áreas são estratificadas de acordo com os níveis das tensões remanescentes estipulados (magnitudes dos afundamentos de tensão). Dessa maneira, a comparação entre os limiares estipulados e as tensões remanescentes, verificadas após a ocorrência dos curtos-circuitos, determinará a fronteira da área de vulnerabilidade e da área afetada.

A Figura 5 ilustra, por exemplo, a estratificação da área de vulnerabilidade para três limiares definidos em um SD hipotético. Nesta figura, a área de vulnerabilidade delimitada é associada ao ponto de monitoramento no nó genérico $i$, destacado em vermelho.

Figura 5 - Exemplo de áreas de vulnerabilidade associadas ao nó genérico $i$ para um SD hipotético.

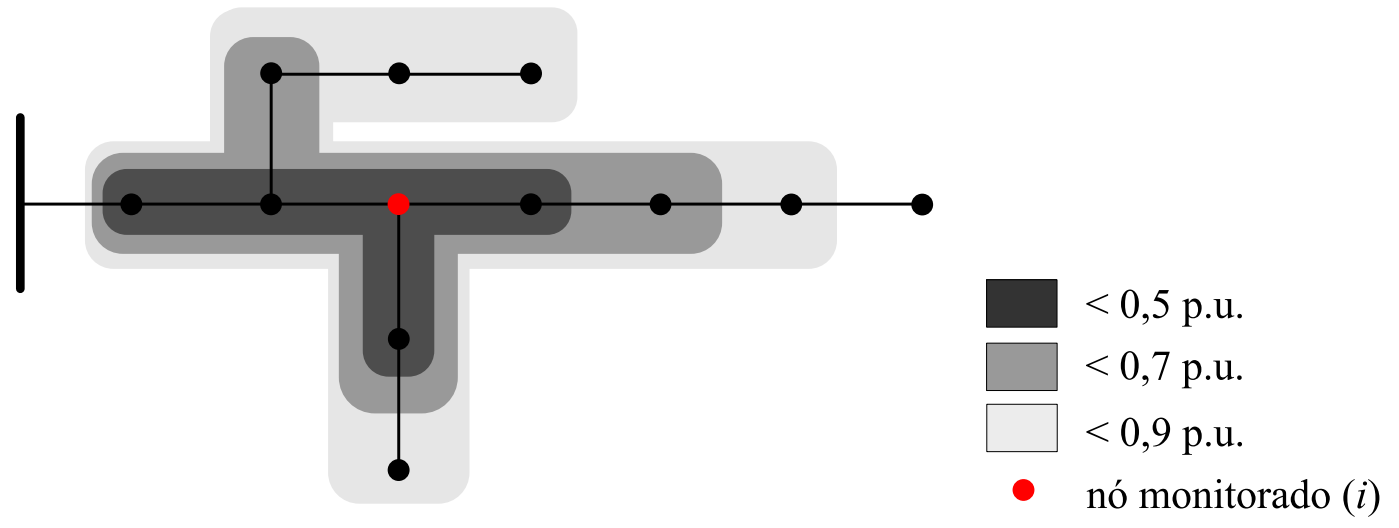

Conforme pode ser observado neste exemplo, o registro dos afundamentos de tensão mais severos no ponto de monitoramento (nó $i$ ), isto é, com menor tensão remanescente registrada, ocorre para a incidência de curtos-circuitos em nós eletricamente mais próximos de $i$ (KEMPNER, 2016). Cabe salientar que a exposição de uma carga sensível a afundamentos de tensão pode levar a desligamentos, ou até mesmo danos irreversíveis nesta carga, o que reforça a necessidade da execução de um plano de monitoramento que esteja preparado para o registro destes fenômenos associados à falta de Qualidade da Energia Elétrica (QEE).

É importante relembrar que o monitoramento das elevações de tensão também será objeto de estudo para a metodologia de alocação de monitores de QEE proposta. Sendo assim, conforme será mais detalhadamente discutido no item 3.1, será considerada a aplicação de quatro tipos de curtos-circuitos, obtendo-se assim uma representação diversificada do comportamento das VTCDs (afundamentos e/ ou elevações de tensão) nos SDs em análise devido à ocorrência de curtos-circuitos balanceados e desbalanceados. A aplicação de cada tipo de curto-circuito considerado é realizada segundo o MPF. 
No item 3.1, serão apresentadas as formulações das MTDFs para os referidos curtoscircuitos em termos dos componentes simétricos do sistema (OLGUIN, 2005; KEMPNER, 2016).

Após a apresentação das formulações das MTDFs, será explicado no item 3.2 o processo de obtenção da Matriz de Cobertura das Variações de Tensão de Curta Duração (MCVT) a partir das MTDFs. Conforme será mais bem compreendido ao final do item 3.2.5, a MCVT é obtida após uma série de procedimentos de combinação e concatenação que permitem reunir as informações fundamentais para a determinação dos melhores nós, do ponto de vista da eficiência do monitoramento das VTCDs, nos quais serão instalados os medidores de QEE.

O processamento da MCVT, no entanto, se dá no contexto da etapa de otimização da metodologia de alocação, que fornecerá a solução de alocação final dos medidores de QEE. Ademais, cabe relembrar que a solução de alocação final também contemplará a sensibilização dos monitores às potenciais condições de ressonância do SD, conforme já mencionado no capítulo precedente.

\subsection{Formulação das MTDFs segundo os tipos de curtos-circuitos}

Como anteriormente mencionado, para a metodologia de alocação otimizada de monitores de QEE são considerados quatro tipos de curtos-circuitos, sendo eles: curto-circuito trifásico; bifásico entre as fases $B$ e $C$ aterrado; bifásico entre as fases $B$ e $C$ não aterrado; e monofásico envolvendo a fase $A$ e a terra. Todos os curtos-circuitos citados serão considerados como do tipo sólido, isto é, com resistência de falta nula. Cabe salientar que a adoção destes tipos de curtos-circuitos (simétricos e assimétricos) permite a observação tanto de afundamentos de tensão, bem como de elevações de tensão, servindo assim ao propósito do estudo do comportamento do SD perante aos distúrbios mencionados. Destaca-se também que os outros tipos de curtos-circuitos que envolvem a combinação das demais fases, como o curto-circuito monofásico envolvendo a fase $B$, por exemplo, fornecerá um perfi de tensão remanescente muito similar, ao curto-circuito monofásico envolvendo a fase $A$. Este comportamento é esperado já que os SDs nesta pesquisa são considerados sistemas simétricos e equilibrados. A mesma observação vale para as demais combinações de fases sãs e em falta.

Uma vez que o SD seja equilibrado, o estudo de um curto-circuito desbalanceado “[...] consiste em determinar os componentes simétricos das correntes desequilibradas que 
estão circulando" (STEVENSON, 1986, p. 312). Logo, conforme demonstra (OLGUIN, 2005), as MTDFs de cada fase do sistema, que contém as tensões remanescentes decorrentes dos curtos-circuitos desbalanceados, podem ser dadas em função dos componentes simétricos do SD.

Aplicando-se o princípio da superposição no domínio dos componentes simétricos, as MTDFs das sequências zero, positiva e negativa, são calculadas como na equação (7) (OLGUIN, 2005).

$$
\begin{aligned}
& {[M T D F]_{0}=\left[\dot{V}_{0}^{p f}\right]+\left[\Delta \dot{V}_{0}\right]} \\
& {[M T D F]_{1}=\left[\dot{V}_{1}^{p f}\right]+\left[\Delta \dot{V}_{1}\right]} \\
& {[M T D F]_{2}=\left[\dot{V}_{2}^{p f}\right]+\left[\Delta \dot{V}_{2}\right]}
\end{aligned}
$$

Sendo $\left[\dot{V}_{0}^{p f}\right],\left[\dot{V}_{1}^{p f}\right]$ e $\left[\dot{V}_{2}^{p f}\right]$ as matrizes $N \times N$ de tensões de pré-falta das sequências zero, positiva e negativa, respectivamente; e $\left[\Delta \dot{V}_{0}\right],\left[\Delta \dot{V}_{1}\right]$ e $\left[\Delta \dot{V}_{2}\right]$ as matrizes $N \times N$ contendo, respectivamente, as variações das tensões para as sequências zero, positiva e negativa, devido ao curto-circuito aplicado em todos os nós do SD como determina o MPF.

Dado que antes do curto-circuito as tensões nodais contenham somente $o$ componente de sequência positiva, isto é, que o SD é equilibrado até o ponto de aplicação da falta elétrica, então $\left[\dot{V}_{0}^{p f}\right]=\left[\dot{V}_{2}^{p f}\right]=0$ na equação (7) (OLGUIN, 2005). Além disso, aplicando-se a transformação dos componentes simétricos nas MTDFs da equação (7), obtêmse as MTDFs por fase conforme mostra a equação (8) (OLGUIN, 2005).

$$
\begin{gathered}
{[M T D F]_{A}=\left|\left[\dot{V}_{1}^{p f}\right]+\left[\Delta \dot{V}_{0}\right]+\left[\Delta \dot{V}_{1}\right]+\left[\Delta \dot{V}_{2}\right]\right|} \\
{[M T D F]_{B}=\left|a^{2}\left[\dot{V}_{1}^{p f}\right]+\left[\Delta \dot{V}_{0}\right]+a^{2}\left[\Delta \dot{V}_{1}\right]+a\left[\Delta \dot{V}_{2}\right]\right|} \\
{[M T D F]_{C}=\left|a\left[\dot{V}_{1}^{p f}\right]+\left[\Delta \dot{V}_{0}\right]+a\left[\Delta \dot{V}_{1}\right]+a^{2}\left[\Delta \dot{V}_{2}\right]\right|}
\end{gathered}
$$

Em (8), $a$ é o operador de rotação de $120^{\circ}$ nos fasores no plano complexo $\left(e^{j 2 \pi / 3}\right)$. Ademais, salienta-se que a razão em se tomar o módulo nas expressões das MTDFs dá-se em função do interesse exclusivo pelas magnitudes das tensões remanescentes, uma vez que para as análises das VTCDs este é o parâmetro desejado. Pela mesma razão, a adoção do módulo das MTDFs estará presente deste ponto do texto em diante.

A equação (8) é geral, e é aplicável para quaisquer tipos de curtos-circuitos, inclusive equilibrados, como é o caso do curto-circuito trifásico. Todavia, as matrizes de mudança de tensão $\left[\Delta \dot{V}_{0}\right],\left[\Delta \dot{V}_{1}\right]$ e $\left[\Delta \dot{V}_{2}\right]$ serão distintas para cada tipo de curto-circuito. 
A partir das redes de sequência do SD (STEVENSON, 1986), configuradas para os tipos de curtos-circuitos considerados, é possível derivar-se a expressão analítica para as matrizes de variação de tensão. É importante ressaltar que a derivação de tais expressões analíticas considera que as correntes de carga do SD são desconsideradas, e as tensões de préfalta são consideradas nominais até o ponto de aplicação da falta (OLGUIN, 2005). Esta situação é equivalente a estudar o comportamento dos curtos-circuitos assimétricos para o gerador síncrono operando em vazio (STEVENSON, 1986; KINDERMANN, 1997).

Nos itens de 3.1.1 a 3.1.4, será apresentada a obtenção das expressões das matrizes de variação de tensão para os quatro tipos de curtos-circuitos considerados na metodologia de alocação, assim como a expressão analítica final das respectivas MTDFs em sua forma matricial.

Cabe ressaltar que a adoção desta variedade de curtos-circuitos, isto é, curtoscircuitos simétricos e assimétricos, visa à obtenção de uma MCVT que contenha uma representação da susceptibilidade de cada nó do SD tanto para os afundamentos, como também para as elevações de tensão. Dessa forma, após a etapa de otimização (capítulo 5), será possível garantir que a solução da alocação final estará sensível à ocorrência dos afundamentos de tensão, bem como das elevações de tensão.

\subsubsection{Curto-circuito trifásico}

De maneira a descrever o curto-circuito trifásico, toma-se apenas a rede de sequência positiva. Isto se deve ao fato de que o curto-circuito trifásico é simétrico, e de que se considera o SD equilibrado. Logo, as correntes de curto-circuito serão balanceadas (KINDERMANN, 1997; STEVENSON, 1986).

Conforme mencionado anteriormente, todos os curtos-circuitos considerados são sólidos e assim a tensão de pós-falta no ponto de falta será nula para todas as fases $\left(\dot{V}_{A}=\right.$ $\dot{V}_{B}=\dot{V}_{C}=0$ ).

Sendo assim, pela decomposição em componentes simétricos, e tomando-se para a análise somente a fase $A$ do sistema, tem-se que a tensão para as três fases também serão nulas no domínio dos componentes simétricos. Na análise subsequente, considera-se somente a fase $A$, já que o mesmo comportamento é esperado para as demais fases do sistema (SD equilibrado e curto-circuito balanceado). 
O circuito da Figura 6 mostra a rede de sequência para o cálculo do curto-circuito trifásico aplicado no nó $j$. Nesta figura, $\dot{V}_{p f(j)}^{A}$ é a tensão de pré-falta da fase $A$ no local do curto-circuito; $Z_{t h 1}$ é a impedância de Thévenin de sequência positiva vista do local do curtocircuito; e $\dot{V}_{A 1}$ é a tensão de sequência positiva da fase $A$, que é nula durante o curto-circuito (KINDERMANN, 1997). Dessa maneira, a corrente de falta na fase $A$ de sequência positiva, em um nó genérico $j$ de incidência da falta, será dada pela equação (9).

Figura 6 - Rede de sequência positiva para o cálculo do curto-circuito trifásico aplicado no nó $\boldsymbol{j}$

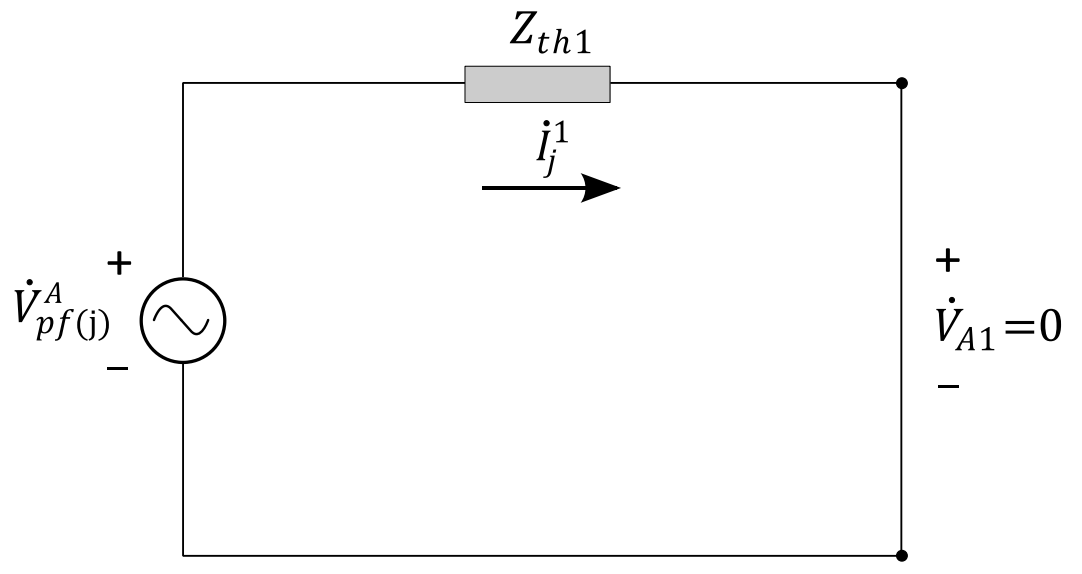

Fonte: Adaptado de Kindermann (1997) e Olguin (2005).

$$
\dot{I}_{j}{ }^{1}=\frac{\dot{V}_{p f(j)}^{A}}{Z_{t h 1}}
$$

Pelo teorema da superposição, afirma-se que a tensão na fase $A$ no nó genérico $i$, devido à ocorrência de um curto-circuito trifásico no nó $j$, é dada pela equação (10) (KEMPNER, 2016; OLGUIN, 2005).

$$
\dot{V}_{i j}^{A}=\dot{V}_{p f(i)}^{A}+\Delta \dot{V}_{i j}
$$

Na equação, $\dot{V}_{p f(i)}^{A}$ é a tensão de pré-falta na fase $A$ para o nó $i$; e $\Delta \dot{V}_{i j}$ denota a variação de tensão no ponto de observação (nó $i$ ).

A tensão em $i$ pode ser calculada em termos da matriz de impedâncias de sequência positiva $\left[Z^{1}\right]$ do sistema. Logo, conhecida a corrente de curto-circuito (equação 9) e a impedância de transferência $\left(Z_{i j}^{1}\right)$, ou seja, a impedância entre o nó monitorado $(i)$ e o nó de aplicação do curto-circuito $(j)$, calcula-se a mudança de tensão $\Delta \dot{V}_{i j}$ devido à ocorrência do curto-circuito trifásico, conforme mostrado na equação (11). 


$$
\Delta \dot{V}_{i j}=-Z_{i j}^{1} \dot{I}_{j}^{1}=-Z_{i j}^{1} \frac{\dot{V}_{p f(j)}^{A}}{Z_{t h}^{1}}
$$

Em (11), o sinal negativo denota a queda de tensão sobre $Z_{i j}^{1}$.

De fato, conforme afirma (OLGUIN, 2005), $Z_{t h}^{1}$ é equivalente à impedância própria $\left(Z_{j j}^{1}\right)$ relativa ao nó $j$, contida na matriz de impedância de sequência positiva do sistema $\left[Z^{1}\right]$. Sendo assim, a equação (11) pode ser reescrita como (12).

$$
\Delta \dot{V}_{i j}=-Z_{i j}^{1} \frac{\dot{V}_{p f(j)}^{A}}{Z_{j j}^{1}}
$$

Substituindo a equação (12) na equação (10), obtém-se a expressão que descreve a tensão $\dot{V}_{i j}^{A}$ no nó genérico $i$, dado um curto-circuito em $j$, conforme mostra a equação (13).

$$
\dot{V}_{i j}^{A}=\dot{V}_{p f(i)}^{A}-\frac{Z_{i j}^{1}}{Z_{j j}^{1}} \dot{V}_{p f(j)}^{A}
$$

Da equação (13), verifica-se que a expressão de $\dot{V}_{i j}^{A}$ é dada exclusivamente em termos das tensões de pré-falta de $i$ e $j$; da impedância própria de sequência positiva relativa ao nó $i$; e da impedância de transferência de sequência positiva entre os nós $i$ e $j$.

Conforme demonstrado por (CARPINELLI et al., 2007), a partir da matriz de impedância de sequência positiva, a MTDF para as três fases do sistema pode ser obtida matricialmente pela equação (14).

$$
\begin{aligned}
& {[M T D F]_{A}^{3 \phi}=\left|\left[\dot{V}_{1}^{p f}\right]-\left[Z^{1}\right] \cdot\left\{\operatorname{diag}\left[Z^{1}\right]\right\}^{-1} \cdot \operatorname{diag}\left[\dot{V}_{1}^{p f}\right]\right|} \\
& {[M T D F]_{B}^{3 \phi}=[M T D F]_{C}^{3 \phi}=[M T D F]_{A}^{3 \phi}}
\end{aligned}
$$

Sendo $\left[\dot{V}_{1}^{p f}\right]$ a matriz $N \times N$ de tensões de pré-falta de sequência positiva do SD com $N$ nós; e $\operatorname{diag}\left[Z^{1}\right]$ uma matriz $N \times N$ cujos elementos fora da diagonal são nulos e a sua diagonal é formada pelas impedâncias próprias $\left(Z_{i i}\right)$ da matriz de impedância do SD. Cabe ainda salientar que sendo o SD equilibrado, as matrizes de tensões de pré-falta de sequências negativa e zero serão nulas, sendo este fato também observado na obtenção das MTDFs referentes aos demais tipos de curtos-circuitos (item 3.1.2 ao item 3.1.4).

Conforme mencionado ao longo deste capítulo, tomou-se somente o componente de sequência positiva, visto que as matrizes de variação de tensão de sequência zero e negativa 
da equação (8), isto é, $\left[\Delta \dot{V}_{0}\right]$ e $\left[\Delta \dot{V}_{2}\right]$, respectivamente, serão nulas. Sendo assim, conclui-se que as MTDFs das fases $B$ e $C$ são idênticas, assim como denota a equação (14).

Por analogia, infere-se que a matriz de variação de tensão de sequência positiva, isto é, $\left[\Delta \dot{V}_{1}\right]$, é a própria forma matricial da equação (12), conforme mostrado na equação (15).

$$
\left[\Delta \dot{V}_{1}\right]=-\left[Z^{1}\right] \cdot\left\{\operatorname{diag}\left[Z^{1}\right]\right\}^{-1} \cdot \operatorname{diag}\left[\dot{V}_{1}^{p f}\right]
$$

Dessa maneira, conforme inicialmente comentado, a equação (14) fornece as MTDFs das três fases do SD, originadas pela incidência de curtos-circuitos trifásicos, em termos dos componentes simétricos da matriz de impedâncias de sequência positiva do sistema.

$\mathrm{Na}$ prática, em geral, as tensões de pré-falta nos SDs são desconhecidas, pois estas são dependentes da disponibilidade de informações precisas sobre o sistema, tais como: cargas conectadas, bancos de capacitores, status dos taps dos transformadores, dentre outras (OLGUIN, 2005). Sendo assim, comumente as tensões nodais de pré-falta são consideradas como sendo $1 \angle 0^{\circ}$ p.u.. A equação (16) mostra a forma final expandida das MTDFs para o curto-circuito trifásico, admitindo-se que $\left[\dot{V}_{1}^{p f}\right]_{N \times N}$ seja uma matriz unitária.

$$
[M T D F]_{A}^{3 \phi}=[M T D F]_{B}^{3 \phi}=[M T D F]_{C}^{3 \phi}=\left[\begin{array}{ccc}
1-\frac{Z_{11}}{Z_{11}} & \cdots & 1-\frac{Z_{1 N}}{Z_{N N}} \\
\vdots & \ddots & \vdots \\
1-\frac{Z_{N, 1}}{Z_{11}} & \cdots & 1-\frac{Z_{N N}}{Z_{N N}}
\end{array}\right]
$$

Uma vez que os curtos-circuitos trifásicos são sólidos, de acordo com o considerado para a metodologia de alocação de monitores, afirma-se que a expressão da equação (16) será exatamente a forma final esperada para as MTDFs das três fases. Nota-se também que os elementos da diagonal das MTDFs descritas pela equação (16), serão nulos quando o curtocircuito é considerado sólido.

\subsubsection{Curto-circuito bifásico não aterrado}

Ao se curto-circuitar duas fases do sistema, as tensões nestas fases serão idênticas. Sendo assim para o caso do curto-circuito com envolvimento das fases $B$ e $C$, por exemplo, tem-se que $\dot{V}_{B}=\dot{V}_{C}$. Dessa maneira, as correntes circulantes nas fases curtos-circuitadas 
possuirão mesmo módulo e sentidos opostos, isto é, $\dot{I}_{B}=-\dot{I}_{C}$ (KEMPNER, 2016; OLGUIN, 2005).

Como as correntes de carga são desconsideradas, a corrente na fase $A$ (fase sã) será nula $\left(\dot{I}_{A}=0\right)$, tanto na condição de pré-falta como de pós-falta.

$\mathrm{Na}$ equação (17) estão sumarizadas as condições de contorno para a análise da falta bifásica não aterrada.

$$
\begin{aligned}
& \dot{V}_{B}=\dot{V}_{C} \\
& \dot{I}_{B}=-\dot{I}_{C} \\
& \dot{I}_{A}=0
\end{aligned}
$$

Aplicando-se a transformação para a decomposição em componentes simétricos sobre os fasores da equação (17), obtém-se a equação (18).

$$
\begin{aligned}
& \dot{V}_{A 1}=\dot{V}_{A 2} \\
& \dot{I}_{A 2}=-\dot{I}_{A 1} \\
& \dot{I}_{A 0}=0
\end{aligned}
$$

O circuito da Figura 7 é o equivalente de Thévenin para o curto-circuito bifásico sem aterramento. De maneira a atender as condições especificadas na equação (18), a conexão das redes de sequência positiva e negativa deve ser em paralelo.

Figura 7 - Conexão das redes de sequência positiva e negativa para o cálculo do curto-circuito bifásico aplicado no nó $\boldsymbol{j}$.

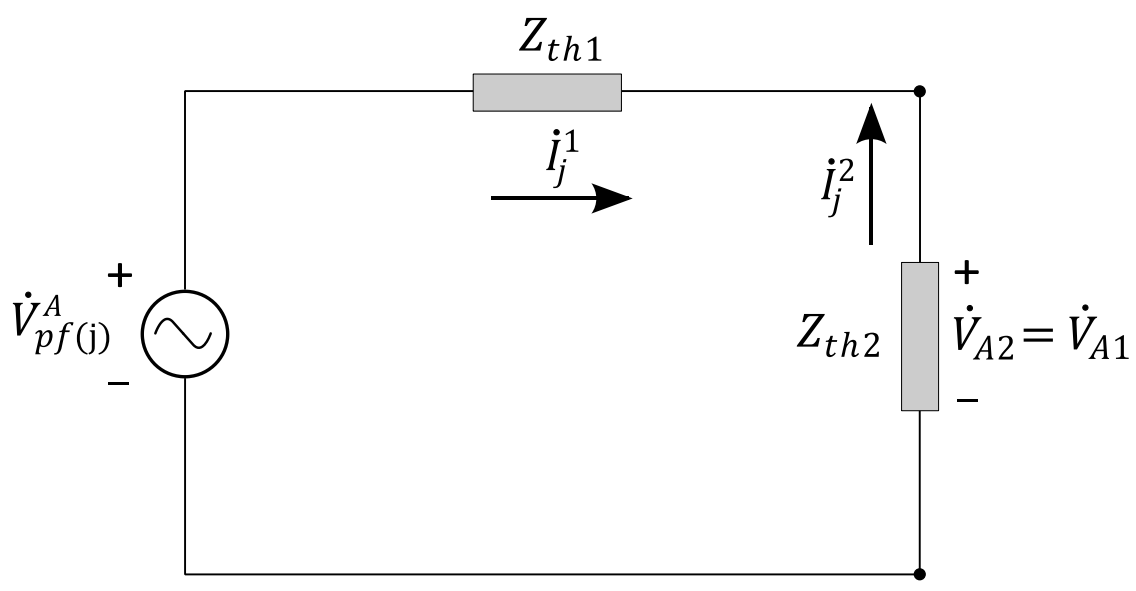

Fonte: Adaptado de Kindermann (1997) e Olguin (2005). 
De fato, como o curto-circuito não é aterrado, não haverá um caminho para o fluxo de corrente à terra do sistema. Logo, $\dot{I}_{A 0}=0$ (equação 18), e, portanto, a rede de sequência zero não está conectada ao circuito da Figura 7 (STEVENSON, 1986; KINDERMANN, 1997; OLGUIN, 2005).

Na Figura $7, \dot{V}_{p f(j)}^{A}$ é a tensão de pré-falta da fase $A$ no local do curto-circuito (nó genérico $j$ ); $Z_{t h 1}$ e $Z_{t h 2}$ são as impedâncias de Thévenin de sequências positiva e negativa, respectivamente; e $\dot{I}_{f}^{A 1}, \dot{I}_{f}^{A 2}$ são as correntes de falta na fase $A$ de sequência positiva e negativa, respectivamente, no nó genérico $j$ de aplicação da falta.

Diante do exposto, a equação (19) traz a expressão das correntes de falta $\dot{I}_{f}^{A 1}$ e $\dot{I}_{f}^{A 2}$.

$$
\begin{aligned}
\dot{I}_{f}^{A 1} & =\frac{\dot{V}_{p f(j)}^{A}}{Z_{t h 1}+Z_{t h 2}} \\
\dot{I}_{f}^{A 2} & =-\frac{\dot{V}_{p f(j)}^{A}}{Z_{t h 1}+Z_{t h 2}}
\end{aligned}
$$

A partir do resultado da equação (19) é possível calcular a variação de tensão $\Delta \dot{V}_{i j}$ observada no nó $i$ dada a aplicação do curto-circuito no nó $j$. Sendo assim, a equação (20) mostra o cálculo das variações de tensão a partir de ambas às redes de sequências representadas no modelo do equivalente de Thévenin da Figura 7.

$$
\begin{aligned}
& \Delta \dot{V}_{i j}^{1}=-Z_{i j}^{1} I_{f}^{A 1} \\
& \Delta \dot{V}_{i j}^{2}=-Z_{i j}^{2} I_{f}^{A 2}
\end{aligned}
$$

Assim, $Z_{i j}^{1}$ e $Z_{i j}^{2}$ representam a impedância de transferência de sequência positiva e negativa, respectivamente, entre o ponto monitorado (nó $i$ ) e o ponto de aplicação da falta (nó $j$ ). Ademais nota-se que, assim como na equação (11), o sinal negativo denota a queda de tensão sobre as respectivas impedâncias de sequência.

Substituindo-se as expressões da equação (19) na equação (20), e recordando-se de que a impedância de Thévenin é igual à impedância própria da matriz do sistema (OLGUIN, 2005), as variações de tensão $\Delta \dot{V}_{i j}$ são reescritas como na equação (21). 


$$
\begin{gathered}
\Delta \dot{V}_{i j}^{1}=-Z_{i j}^{1} \frac{\dot{V}_{p f(j)}^{A}}{Z_{j j}^{1}+Z_{j j}^{2}} \\
\Delta \dot{V}_{i j}^{2}=Z_{i j}^{2} \frac{\dot{V}_{p f(j)}^{A}}{Z_{j j}^{1}+Z_{j j}^{2}}
\end{gathered}
$$

Sendo $Z_{j j}^{1}$ e $Z_{j j}^{2}$, respectivamente, as impedâncias próprias de sequência positiva e negativa, contidas nas relativas matrizes de impedâncias de sequência positiva, $\left[Z^{1}\right]$, e negativa, $\left[Z^{2}\right]$, referentes à aplicação do curto-circuito no nó $j$.

As expressões da equação (21) podem ser reescritas em sua forma matricial conforme mostrado na equação (22) (CARPINELLI et al., 2007; KEMPNER, 2016).

$$
\begin{aligned}
& {\left[\Delta \dot{V}_{1}\right]=-\left[Z^{1}\right] \cdot\left\{\operatorname{diag}\left[Z^{1}+Z^{2}\right]\right\}^{-1} \cdot \operatorname{diag}\left[\dot{V}_{1}^{p f}\right]} \\
& {\left[\Delta \dot{V}_{2}\right]=\left[Z^{2}\right] \cdot\left\{\operatorname{diag}\left[Z^{1}+Z^{2}\right]\right\}^{-1} \cdot \operatorname{diag}\left[\dot{V}_{1}^{p f}\right]}
\end{aligned}
$$

Nesta última equação, $\left[\dot{V}_{1}^{p f}\right]$ é a matriz $N \times N$ de tensões de pré-falta de sequência positiva do SD com $N$ nós; e diag $\left[Z^{1}+\mathrm{Z}^{2}\right]$ é uma matriz $N \times N$ cujos elementos fora da diagonal são nulos e a sua diagonal é formada pela soma das impedâncias próprias $\left(Z_{j j}^{1}+Z_{j j}^{2}\right)$ das matrizes de impedâncias de sequências $\left[Z^{1}\right]$ e $\left[Z^{2}\right]$ do SD.

Por fim, substituindo-se as expressões matriciais da equação (22) na equação (8), obtém-se a forma final das MTDFs, para todas as fases do sistema, devido ao curto-circuito bifásico não aterrado, conforme mostra a equação (23).

$$
\begin{aligned}
& {[M T D F]_{A}^{2 \phi}=\left|\left[\dot{V}_{1}^{p f}\right]+\left\{\left[Z^{2}\right]-\left[Z^{1}\right]\right\} \cdot\left\{\operatorname{diag}\left[Z^{1}+Z^{2}\right]\right\}^{-1} \cdot \operatorname{diag}\left[\dot{V}_{1}^{p f}\right]\right|} \\
& {[M T D F]_{B}^{2 \phi}=\left|a^{2}\left[\dot{V}_{1}^{p f}\right]+\left\{-a^{2}\left[Z^{1}\right]+a\left[Z^{2}\right]\right\} \cdot\left\{\operatorname{diag}\left[Z^{1}+Z^{2}\right]\right\}^{-1} \cdot \operatorname{diag}\left[\dot{V}_{1}^{p f}\right]\right|} \\
& {[M T D F]_{C}^{2 \phi}=\left|a\left[\dot{V}_{1}^{p f}\right]+\left\{-a\left[Z^{1}\right]+a^{2}\left[Z^{2}\right]\right\} \cdot\left\{\operatorname{diag}\left[Z^{1}+Z^{2}\right]\right\}^{-1} \cdot \operatorname{diag}\left[\dot{V}_{1}^{p f}\right]\right|}
\end{aligned}
$$

Usualmente, para os SDs, as impedâncias de sequência positiva são iguais às de sequência negativa, resultando em $\left[Z^{1}\right]=\left[Z^{2}\right]$ (KERSTING, 2002). Logo, constata-se da equação (23) que a fase $A$ não sofrerá nem afundamento nem elevação de tensão para o curtocircuito bifásico sem aterramento, permanecendo com a tensão nominal de pré-falta. As fases $B$ e $C$, por sua vez, sofrerão diminuição da tensão em igual magnitude. Contudo, este comportamento das tensões trifásicas é esperado somente quando se desconsidera o efeito do deslocamento de fase, que pode ser provocado, por exemplo, por um transformador de potência entre o nó de observação e o ponto de aplicação do curto-circuito (OLGUIN, 2005). 
De fato, conforme explicado por Olguin (2005), as equações das MTDFs apresentadas no item 3.1 não incluem os efeitos dos deslocamentos de fases causados pelas conexões dos enrolamentos dos transformadores de potência. A presença do efeito do deslocamento de fase afetará as características das equações que descrevem a tensão remanescente para cada tipo de curto-circuito desbalanceado. Ainda de acordo com Olguin (2005), para curtos-circuitos desbalanceados incidentes no lado de alta do transformador de potência, e observados em seu lado de baixa, é necessário adicionar $+60^{\circ}$, isto é, $-a^{2}$, à impedância de sequência negativa. Já para os curtos-circuitos desbalanceados incidentes no lado de baixa, e observados no lado de alta do transformador de potência, deve-se considerar um defasamento de $-60^{\circ}$, ou seja, $-a$, na impedância de sequência negativa.

Para a metodologia de alocação de monitores, o deslocamento de fase será desconsiderado, já que todos os curtos-circuitos decorrentes do MPF são aplicados sobre o alimentador principal e seus ramos trifásicos todos em média tensão. Portanto, não é verificada a presença de um transformador de potência entre o ponto de aplicação de falta e o ponto de observação.

\subsubsection{Curto-circuito bifásico aterrado}

Considere as fases $B$ e $C$ curto-circuitadas e aterradas representando um curtocircuito bifásico aterrado, conforme mostra a Figura 8. Nestas condições tem-se que as tensões nas fases curtos-circuitadas serão nulas, já que se admite um curto-circuito sólido. Além disso, como as correntes de carga do SD são desconsideradas, e as tensões de pré-falta são consideradas nominais até o ponto de aplicação da falta, tem-se que a corrente na fase $A$ será nula, isto é, $\dot{I}_{A}=0$.

Partindo-se da condição de que $\dot{V}_{B}=\dot{V}_{C}=0$ e aplicando-se a decomposição em componentes simétricos, obtém-se a tensão no domínio dos componentes simétricos, conforme apresentado na equação (24).

$$
\dot{V}_{A 1}=\dot{V}_{A 2}=\dot{V}_{A 0}
$$

Pela equação (24) conclui-se que as redes de sequência que representam o curtocircuito bifásico aterrado devem ser conectadas em paralelo, conforme mostrado na Figura 8 (STEVENSON, 1986; OLGUIN, 2005). Nesta figura, $\dot{V}_{p f(j)}^{A}$ é a tensão de pré-falta da fase $A$ no local do curto-circuito (nó genérico $j$ ); $Z_{t h 1}, Z_{t h 2}$ e $Z_{t h 0}$ são as impedâncias de Thévenin 
de sequências positiva e negativa e zero, respectivamente; e $\dot{I}_{f}^{A 1}, \dot{I}_{f}^{A 2}$ e $\dot{I}_{f}^{A 0}$ são as correntes de falta na fase $A$ de sequência positiva e negativa, respectivamente, no nó genérico $j$ de aplicação do curto-circuito.

Além disso, pela decomposição em componentes simétricos da corrente de falta, tem-se que $\dot{I}_{A}=\dot{I}_{A 1}=\dot{I}_{A 2}=\dot{I}_{A 3}$. Entretanto, conforme afirmado anteriormente, $\dot{I}_{A}=0$, o que leva a concluir que $\dot{I}_{A 1}=\dot{I}_{A 2}=\dot{I}_{A 3}=0$. Este fato corrobora a disposição da conexão das redes de sequência em paralelo, como mostrado na Figura 8.

Figura 8 - Conexão das redes de sequência positiva, negativa e zero para o cálculo do curto-circuito bifásico aterrado aplicado no nó $\boldsymbol{j}$.

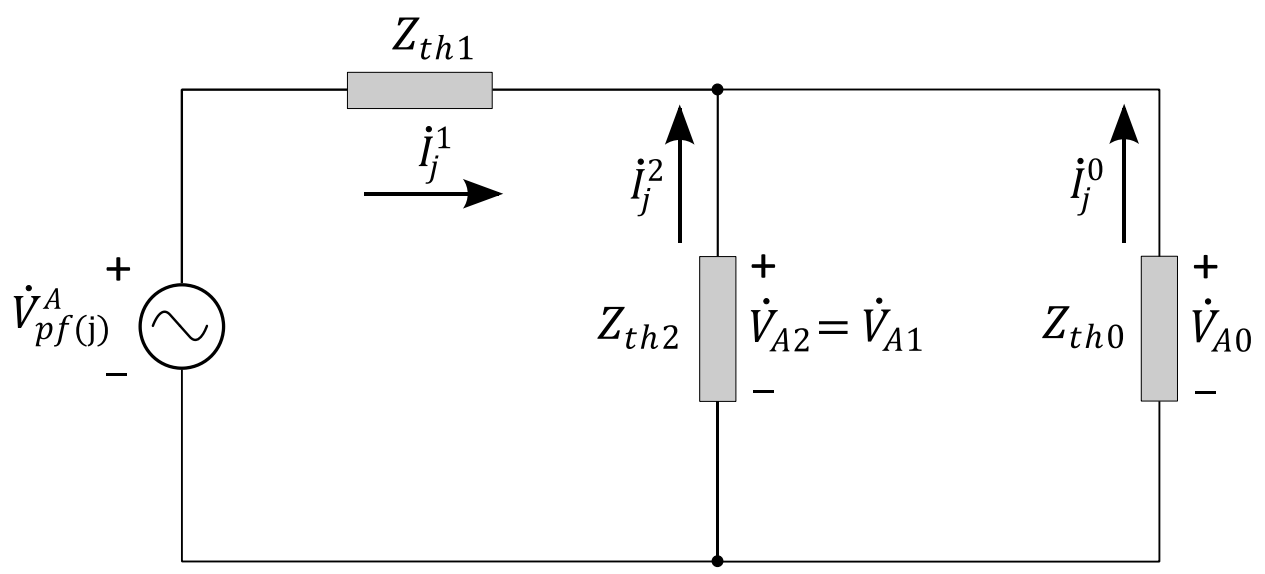

Fonte: Adaptado de Kindermann (1997) e Olguin (2005).

Do circuito da Figura 8 obtêm-se as expressões para as correntes de sequência no momento da ocorrência do curto-circuito (STEVENSON, 1986; KEMPNER, 2016). Estas expressões estão reunidas na equação (25).

$$
\begin{aligned}
& \dot{I}_{f}^{A 1}=\frac{\dot{V}_{p f(j)}^{A}}{Z_{t h 1}+Z_{t h 0} Z_{t h 2} /\left(Z_{t h 0}+Z_{t h 2}\right)}=\frac{Z_{t h 0}+Z_{t h 2}}{Z_{t h 1} Z_{t h 0}+Z_{t h 2} Z_{t h 1}+Z_{t h 0} Z_{t h 2}} \cdot \dot{V}_{p f(j)}^{A} \\
& \dot{I}_{f}^{A 2}=-\dot{I}_{f}^{A 1} \frac{Z_{t h 0}}{Z_{t h 2}+Z_{t h 0}}=-\frac{Z_{t h 0}}{Z_{t h 1} Z_{t h 0}+Z_{t h 2} Z_{t h 1}+Z_{t h 0} Z_{t h 2}} \cdot \dot{V}_{p f(j)}^{A} \\
& \dot{I}_{f}^{A 0}=-\dot{I}_{f}^{A 1} \frac{Z_{t h 2}}{Z_{t h 2}+Z_{t h 0}}=-\frac{Z_{t h 2}}{Z_{t h 1} Z_{t h 0}+Z_{t h 2} Z_{t h 1}+Z_{t h 0} Z_{t h 2}} \cdot \dot{V}_{p f(j)}^{A}
\end{aligned}
$$

Com as correntes de falta da equação (25) obtém-se a variação de tensão $\Delta \dot{V}_{i j}$ observada no nó $i$ devido à aplicação do curto-circuito no nó $j$, conforme mostra a equação (26). Destaca-se que na equação (26) as impedâncias de Thévenin já foram substituídas pelas impedâncias próprias das respectivas matrizes de impedâncias de sequência do sistema, referentes à aplicação do curto-circuito no nó $j$ (OLGUIN, 2005). 


$$
\begin{aligned}
& \Delta \dot{V}_{i j}^{1}=-Z_{i j}^{1} \cdot \frac{\left(Z_{j j}^{0}+Z_{j j}^{2}\right)}{Z_{j j}^{1} Z_{j j}^{0}+Z_{j j}^{2} Z_{j j}^{1}+Z_{j j}^{0} Z_{j j}^{2}} \cdot \dot{V}_{p f(j)}^{A} \\
& \Delta \dot{V}_{i j}^{2}=Z_{i j}^{2} \cdot \frac{Z_{j j}^{0}}{Z_{j j}^{1} Z_{j j}^{0}+Z_{j j}^{2} Z_{j j}^{1}+Z_{j j}^{0} Z_{j j}^{2}} \cdot \dot{V}_{p f(j)}^{A} \\
& \Delta \dot{V}_{i j}^{0}=Z_{i j}^{0} \cdot \frac{Z_{j j}^{2}}{Z_{j j}^{1} Z_{j j}^{0}+Z_{j j}^{2} Z_{j j}^{1}+Z_{j j}^{0} Z_{j j}^{2}} \cdot \dot{V}_{p f(j)}^{A}
\end{aligned}
$$

$Z_{i j}^{1}, Z_{i j}^{2}$ e $Z_{i j}^{2}$ representam as impedâncias de transferência de sequências positiva, negativa e zero, respectivamente, entre o ponto monitorado (nó $i$ ) e o ponto de aplicação da falta (nó $j$ ).

As formas matriciais das expressões da equação (26) são apresentadas na equação (27) (CARPINELLI et al., 2007; KEMPNER, 2016).

$$
\begin{aligned}
& {\left[\Delta \dot{V}_{1}\right]=-\left[Z^{1}\right] \cdot\left\{\operatorname{diag}\left[Z^{0}+Z^{2}\right]\right\} \cdot[D]^{-1} \cdot \operatorname{diag}\left[\dot{V}_{p f}^{1}\right]} \\
& {\left[\Delta \dot{V}_{2}\right]=-\left[Z^{2}\right] \cdot \operatorname{diag}\left[Z^{0}\right] \cdot[D]^{-1} \cdot \operatorname{diag}\left[\dot{V}_{p f}^{1}\right]} \\
& {\left[\Delta \dot{V}_{0}\right]=-\left[Z^{0}\right] \cdot \operatorname{diag}\left[Z^{2}\right] \cdot[D]^{-1} \cdot \operatorname{diag}\left[\dot{V}_{p f}^{1}\right]}
\end{aligned}
$$

Nesta, $[D]=\left\{\operatorname{diag}\left[Z^{1}\right] \cdot \operatorname{diag}\left[Z^{0}\right]\right\}+\left\{\operatorname{diag}\left[Z^{2}\right] \cdot \operatorname{diag}\left[Z^{1}\right]\right\}+\left\{\operatorname{diag}\left[Z^{0}\right] \cdot \operatorname{diag}\left[Z^{2}\right]\right\} ;\left[\dot{V}_{1}^{p f}\right]$ é a matriz $N \times N$ de tensões de pré-falta de sequência positiva do SD com $N$ nós; e $\operatorname{diag}\left[Z^{0}+\right.$ $\mathrm{Z}^{1}$ ] é uma matriz $N \times N$ cujos elementos fora da diagonal são nulos e a sua diagonal é formada pela soma das impedâncias próprias $\left(Z_{j j}^{0}+Z_{j j}^{2}\right)$ das matrizes de impedâncias de sequências $\left[Z^{0}\right]$ e $\left[Z^{2}\right]$ do $\mathrm{SD}$.

A forma final das MTDFs, para as três fases do sistema, devido ao curto-circuito bifásico aterrado é obtida substituindo-se as expressões matriciais da equação (26) na equação (8), conforme mostra a equação (28).

$$
\begin{aligned}
& {[M T D F]_{A}^{2 \phi, t}=\left|\left[\dot{V}_{p f}^{1}\right]+\left\{\left\{\left[Z^{2}\right]-\left[Z^{1}\right]\right\} \cdot \operatorname{diag}\left[Z^{0}\right]+\left\{\left[Z^{0}\right]-\left[Z^{1}\right]\right\} \cdot \operatorname{diag}\left[Z^{2}\right]\right\} \cdot[D]^{-1} \cdot \operatorname{diag}\left[\dot{V}_{p f}^{1}\right]\right|} \\
& {[M T D F]_{B}^{2 \phi, t}=\left|a^{2}\left[\dot{V}_{p f}^{1}\right]+\left\{\left\{a\left[Z^{2}\right]-a^{2}\left[Z^{1}\right]\right\} \cdot \operatorname{diag}\left[Z^{0}\right]+\left\{\left[Z^{0}\right]-a^{2}\left[Z^{1}\right]\right\} \cdot \operatorname{diag}\left[Z^{2}\right]\right\} \cdot[D]^{-1} \cdot \operatorname{diag}\left[\dot{ }_{p f}^{1}\right]\right|} \\
& {[M T D F]_{C}^{2 \phi, t}=\left|a\left[\dot{V}_{p f}^{1}\right]+\left\{\left\{a^{2}\left[Z^{2}\right]-a\left[Z^{1}\right]\right\} \cdot \operatorname{diag}\left[Z^{0}\right]+\left\{\left[Z^{0}\right]-a\left[Z^{1}\right]\right\} \cdot \operatorname{diag}\left[Z^{2}\right]\right\} \cdot[D]^{-1} \cdot \operatorname{diag}\left[\dot{V}_{p f}^{1}\right]\right|}
\end{aligned}
$$

Conforme anteriormente mencionado, em SDs, é usual considerar que $\left[Z^{1}\right]=\left[Z^{2}\right]$. Além disso, as impedâncias de sequência zero são consideradas maiores do que àquelas de sequências positiva e negativa, isto é $\left[Z^{0}\right]>\left[Z^{1}\right]=\left[Z^{2}\right]$ (KERSTING, 2002). Vale ressaltar que sob as condições supracitadas, ao se analisar a expressão da matriz $[M T D F]_{\mathrm{A}}^{2 \phi, t}$, verifica- 
se com facilidade que a fase sã (fase $A$ ) sofrerá um aumento da tensão durante a ocorrência do curto circuito.

\subsubsection{Curto-circuito monofásico aterrado}

Considere a ocorrência de um curto-circuito monofásico, sólido e aterrado, envolvendo a fase $A$. Além disso, assim como nos demais tipos de curtos-circuitos apresentados anteriormente, as correntes de carga do SD são desconsideradas, e as tensões de pré-falta são consideradas nominais até o ponto de aplicação da falta. Logo, tem-se que as correntes nas fases sãs serão nulas: $\dot{I}_{B}=\dot{I}_{C}=0$, e, pelas características do tipo de curtocircuito considerado, a tensão na fase em falta será nula: $\dot{V}_{A}=0$.

Aplicando-se a decomposição em componentes simétricos sobre $\dot{I}_{B}=\dot{I}_{C}=0$, tem-se a relação entre as correntes de sequência, conforme mostra a equação (29).

$$
\dot{I}_{A 0}=\dot{I}_{A 1}=\dot{I}_{A 2}
$$

Da decomposição em componentes simétricas, sabe-se que $\dot{V}_{A}=\dot{V}_{A 1}++\dot{V}_{A 2}+$ $\dot{V}_{A 3}=0$.

Sendo assim, o modelo da rede de sequência para o curto-circuito monofásico aterrado é conforme ilustra a Figura 9 (STEVENSON, 1986; OLGUIN, 2005).

Seguindo a notação dos modelos das redes de sequência anteriores, na Figura 9, $\dot{V}_{p f(j)}^{A}$ é a tensão de pré-falta da fase $A$ no local do curto-circuito (nó genérico $j$ ); $Z_{t h 1}, Z_{t h 2}$ e $Z_{\text {th0 }}$ são as impedâncias de Thévenin de sequências positiva e negativa e zero, respectivamente; e $\dot{I}_{f}^{A 1}, \dot{I}_{f}^{A 2}$ e $\dot{I}_{f}^{A 0}$ são, respectivamente, as correntes de falta na fase $A$ de sequência positiva, negativa e zero no nó genérico $j$ de aplicação do curto-circuito.

Do circuito da Figura 9, obtêm-se as expressões para as correntes de falta no domínio dos componentes simétricos, como mostra a equação (30).

$$
\dot{I}_{f}^{A 1}=\dot{I}_{f}^{A 2}=\dot{I}_{f}^{A 0}=\frac{\dot{V}_{p f(j)}^{A}}{Z_{t h 1}+Z_{t h 2}+Z_{t h 3}}
$$

A partir da equação (30), a variação de tensão $\Delta \dot{V}_{i j}$ observada no nó $i$ devido à aplicação do curto-circuito no nó $j$, é calculada conforme mostra a equação (31). Cabe destacar que na equação (31) as impedâncias de Thévenin já foram substituídas pelas 
impedâncias próprias das respectivas matrizes de impedâncias de sequência do sistema, referentes à aplicação do curto-circuito no nó $j$ (OLGUIN, 2005).

$$
\begin{aligned}
& \Delta \dot{V}_{i j}^{1}=-Z_{i j}^{1} \frac{\dot{V}_{p f(j)}^{A}}{Z_{j j}^{1}+Z_{j j}^{2}+Z_{j j}^{0}} \\
& \Delta \dot{V}_{i j}^{2}=-Z_{i j}^{2} \frac{\dot{V}_{p f(j)}^{A}}{Z_{j j}^{1}+Z_{j j}^{2}+Z_{j j}^{0}} \\
& \Delta \dot{V}_{i j}^{0}=-Z_{i j}^{0} \frac{\dot{V}_{p f(j)}^{A}}{Z_{j j}^{1}+Z_{j j}^{2}+Z_{j j}^{0}}
\end{aligned}
$$

Figura 9 - Conexão das redes de sequência positiva, negativa e zero para o cálculo do curto-circuito monofásico aterrado aplicado no nó $\boldsymbol{j}$.

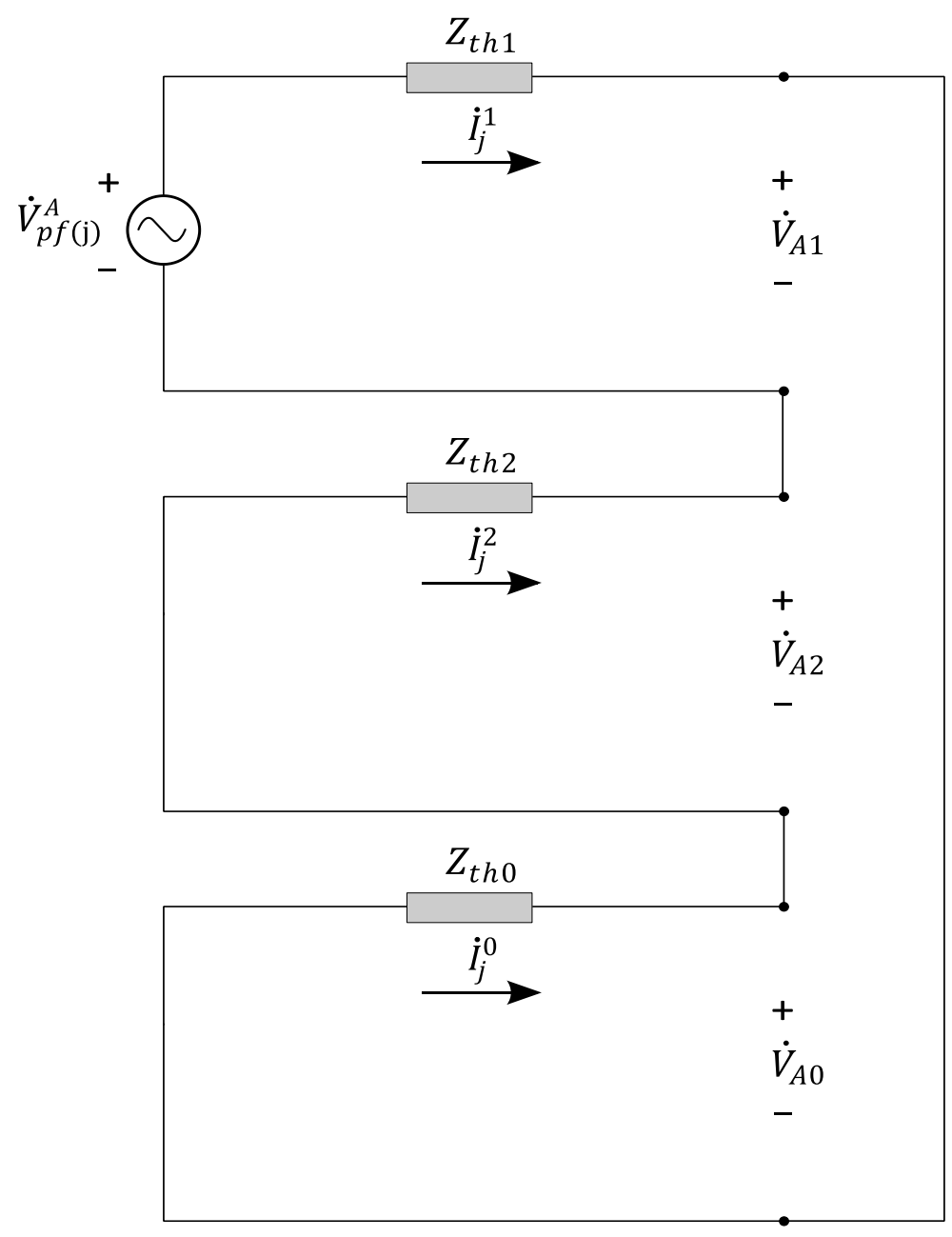

Fonte: Adaptado de Kindermann (1997) e Olguin (2005).

As formas matriciais da equação (31) são apresentadas na equação (32) (CARPINELLI et al., 2007; KEMPNER, 2016). 


$$
\begin{aligned}
& {\left[\Delta V_{1}\right]=-\left[Z^{1}\right] \cdot\left\{\operatorname{diag}\left[Z^{1}+Z^{2}+Z^{0}\right]\right\}^{-1} \cdot \operatorname{diag}\left[\dot{V}_{p f}^{1}\right]} \\
& {\left[\Delta V_{2}\right]=-\left[Z^{2}\right] \cdot\left\{\operatorname{diag}\left[Z^{1}+Z^{2}+Z^{0}\right]\right\}^{-1} \cdot \operatorname{diag}\left[\dot{V}_{p f}^{1}\right]} \\
& {\left[\Delta V_{0}\right]=-\left[Z^{0}\right] \cdot\left\{\operatorname{diag}\left[Z^{1}+Z^{2}+Z^{0}\right]\right\}^{-1} \cdot \operatorname{diag}\left[\dot{V}_{p f}^{1}\right]}
\end{aligned}
$$

Em (32), $\left[\dot{V}_{p f}^{1}\right]$ é a matriz $N \times N$ de tensões de pré-falta de sequência positiva do SD com $N$ nós; e diag $\left[Z^{1}+\mathrm{Z}^{2}+\mathrm{Z}^{0}\right]$ é uma matriz $N \times N$ cujos elementos fora da diagonal são nulos e a sua diagonal é formada pela soma das impedâncias próprias $\left(Z_{j j}^{1}+Z_{j j}^{2}+Z_{j j}^{0}\right)$ das matrizes de impedâncias de sequências $\left[Z^{1}\right],\left[Z^{2}\right]$ e $\left[Z^{0}\right]$ do SD.

Substituindo-se as expressões matriciais da equação (32) na equação (8), determinam-se as MTDFs para o curto-circuito considerado, conforme mostra a equação (33).

$$
\begin{aligned}
& {[M T D F]_{A}^{1 \phi}=\left|\left[\dot{V}_{p f}^{1}\right]-\left\{\left[Z^{1}\right]+\left[Z^{2}\right]+\left[Z^{0}\right]\right\} \cdot\left\{\operatorname{diag}\left[Z^{1}+Z^{2}+Z^{0}\right]\right\}^{-1} \cdot \operatorname{diag}\left[\dot{V}_{p f}^{1}\right]\right|} \\
& {[M T D F]_{B}^{1 \phi}=\left|a^{2}\left[\dot{V}_{p f}^{1}\right]-\left\{a^{2}\left[Z^{1}\right]+a\left[Z^{2}\right]+\left[Z^{0}\right]\right\} \cdot\left\{\operatorname{diag}\left[Z^{1}+Z^{2}+Z^{0}\right]\right\}^{-1} \cdot \operatorname{diag}\left[\dot{V}_{p f}^{1}\right]\right|} \\
& {[M T D F]_{C}^{1 \phi}=\left|a\left[\dot{V}_{p f}^{1}\right]+\left\{a\left[Z^{1}\right]+a^{2}\left[Z^{2}\right]+\left[Z^{0}\right]\right\} \cdot\left\{\operatorname{diag}\left[Z^{1}+Z^{2}+Z^{0}\right]\right\}^{-1} \cdot \operatorname{diag}\left[\dot{V}_{p f}^{1}\right]\right|}
\end{aligned}
$$

\subsection{Cálculo da MCVT}

Conforme procedimento descrito no fluxograma da Figura 10, a MCVT é construída a partir das MTDFs que foram obtidas após a aplicação do MPF para os quatro tipos de curtos-circuitos considerados (itens 3.1.1 a 3.1.4). É importante salientar que este fluxograma descreve com detalhes um dos dois procedimentos que compõem a "Etapa 1" (Figura 4) da metodologia de alocação de monitores, isto é, a obtenção da MCVT. Vale mencionar que o bloco de aquisição dos dados do SD, necessário para o cálculo da matriz de impedâncias associada, não está representado no fluxograma da Figura 10. Todavia, afirma-se que a matriz de admitâncias do SD foi inicialmente obtida a partir dos dados do SD, sendo, posteriormente, utilizada para o cálculo da matriz de impedâncias, viabilizando todo o equacionamento do MPF e a consequente obtenção de todas as MTDFs necessárias.

Como será detalhadamente exposto ao longo do item 3.2.1, a MCVT é uma matriz binária, que será responsável por incorporar ao processo de otimização as características de sensibilidade de cada nó do SD às VTCDs (afundamento e elevação de tensão). Além disso, 
com base no exposto por Olguin e Bollen (2003), afirma-se que a MCVT traduzirá o alcance do monitoramento dos afundamentos e elevações de tensão que cada nó do SD possui. Cabe ressaltar que o significado do alcance do monitoramento será mais bem compreendido ao longo do Capítulo 5.

Figura 10 - Fluxograma que descreve a metodologia de obtenção da MCVT.

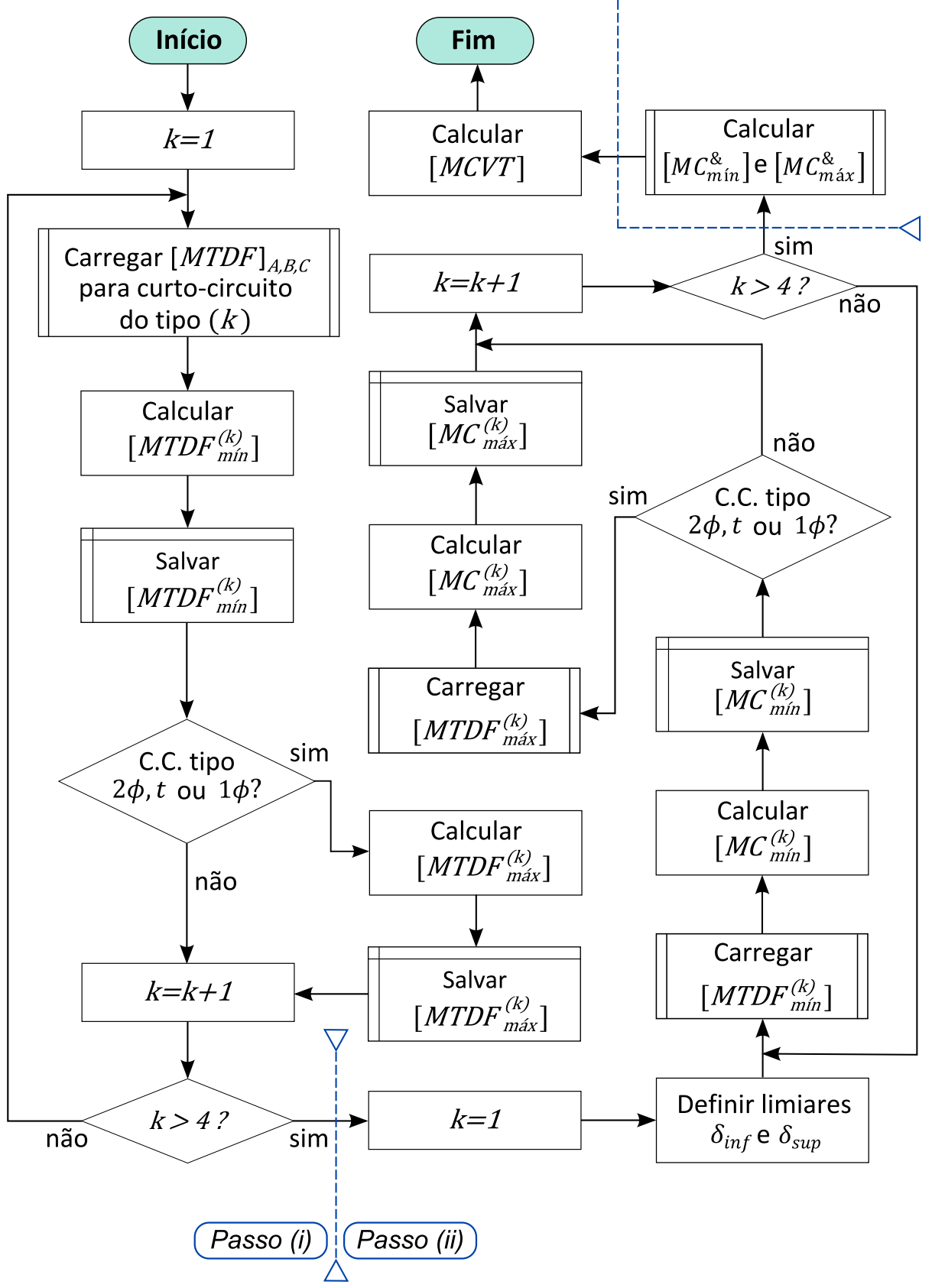

Conforme mostra o fluxograma da Figura 10, a obtenção da MCVT é resultante de quatro passos principais, nos quais as MTDFs originadas do MPF são manipuladas para 
formarem a MCVT. Estes passos serão explicados nos itens de 3.2.1 a 3.2.4. Além disso, como será visto também ao longo dos itens de 3.2.1 a 3.2.3, a MCVT é dependente tanto da escolha de limiares de tensão, que definem a ocorrência ou não afundamento e/ ou elevação de tensão, como também dos tipos de curtos-circuitos analisados. Sendo assim, no item 3.2.5, será apresentada uma breve discussão sobre os limiares de tensão e a influência dos tipos de curtos-circuitos na construção da MCVT.

\subsubsection{Combinação por fase das MTDFs - Passo (i)}

Como anteriormente comentado, para cada tipo de curto-circuito três MTDFs são obtidas, isto é, uma MTDF por fase do sistema. O monitoramento das três fases do SD é fundamental, pois a depender da característica do curto-circuito aplicado, tensões remanescentes distintas podem ser observadas em cada fase. De fato, os curtos-circuitos apresentados nos itens de 3.1.1 a 3.1.4 podem provocar afundamentos de tensão, elevações de tensão, ou ainda simultaneamente afundamento na fase em curto-circuito e elevações nas fases sãs (OLGUIN, 2005; KEMPNER, 2016).

Neste contexto, a MCVT deve ser construída de modo a ser capaz de representar o comportamento do SD perante as possíveis ocorrências de afundamentos e/ ou elevações de tensão residuais em cada nó do SD.

O Passo ( $i$ ) do fluxograma da Figura 10 consiste na combinação entre as MTDFs das três fases, originando assim duas novas matrizes a depender do tipo de curto-circuito considerado. Estas matrizes são denotadas por $\left[M T D F_{\text {mín }}\right]$ e $\left[M T D F_{\text {máx }}\right]$.

As matrizes $\left[M T D F_{m i ́ n}\right]$ contêm as menores tensões remanescentes dentre as três MTDFs de cada fase, referentes ao respectivo tipo de curto-circuito estudado. Logo, para cada um dos tipos de curtos-circuitos incluídos no MPF (itens 3.1.1 a 3.1.4) uma matriz $\left[M T D F_{\text {mín }}\right]$ será calculada, já que todos estes curtos-circuitos podem eventualmente desencadear afundamentos de tensão na fase em curto-circuito e /ou na(s) fase(s) sã(s). Sendo assim, para um SD de $N$ barramentos, a $\left[M T D F_{\text {mín }}\right]$, para cada tipo de curto-circuito, é obtida conforme mostra a equação (34).

$$
\left[M T D F_{m i n}\right]=\left[\begin{array}{ccc}
a_{1,1} & \cdots & a_{1, N} \\
\vdots & \ddots & \vdots \\
a_{N, 1} & \cdots & a_{N, N}
\end{array}\right]
$$


Nesta, cada elemento matricial é o mínimo valor entre os elementos das MTDFs das fases $A$, $B$ e $C$, ou seja, $a_{i, j}=\min \left\{a_{i, j}^{A}, a_{i, j}^{B}, a_{i, j}^{C}\right\}$, para $j$ e $i$ variando de 1 até $N$.

As matrizes $\left[M T D F_{m a ́ x}\right]$ contêm as maiores tensões remanescentes dentre as três MTDFs de cada fase, referentes a um determinado tipo de curto-circuito. Estas são calculadas somente para os curtos-circuitos bifásicos aterrados e monofásicos aterrados (itens 3.1.3 e 3.1.4, respectivamente). Esta restrição justifica-se uma vez que o curto-circuito trifásico (item 3.1.1), por ser balanceado, não é capaz de provocar elevações de tensão em nenhuma das fases, conforme descreve a equação (13). Além disso, o curto-circuito do tipo bifásico não aterrado, sob as condições já mencionadas no item 3.1.2, não apresentará elevação de tensão em nenhuma das fases.

Sendo assim, para um SD de $N$ barramentos, a $\left[M T D F_{\text {máx }}\right]$ para os curtos-circuitos bifásicos aterrados e monofásicos aterrados são obtidas conforme mostra a equação (35).

$$
\left[M T D F_{\text {máx }}\right]=\left[\begin{array}{ccc}
b_{1,1} & \cdots & b_{1, N} \\
\vdots & \ddots & \vdots \\
b_{N, 1} & \cdots & b_{N, N}
\end{array}\right]
$$

Assim, cada elemento matricial é o máximo valor entre os elementos das MTDFs das fases $A$, $B$ e $C$, ou seja, $b_{i, j}=\max \left\{b_{i, j}^{A}, b_{i, j}^{B}, b_{i, j}^{C}\right\}$, para $j$ e $i$ variando de 1 até $N$.

Diante do exposto, o Passo ( $i$ ) do fluxograma da Figura 10 é completado após os quatro tipos de curtos-circuitos $(k=4)$ serem analisados. Para cada tipo $k$ de curto-circuito, as MTDFs resultantes do MPF são recuperadas e as respectivas $\left[M T D F_{\text {mín }}\right]$ e $\left[M T D F_{\text {máx }}\right]$ são calculadas. No fluxograma, estas matrizes são denotadas, respectivamente, por $\left[M T D F_{\min }^{(k)}\right] \mathrm{e}$ $\left[M T D F_{m a ́ x}^{(k)}\right]$.

Como pode ser visto no fluxograma da Figura 10, as $\left[M T D F_{\text {máx }}^{(k)}\right]$ serão calculadas somente para os curtos do tipo bifásico aterrado $(F F T)$ e monofásico aterrado $(F T)$. Sendo assim, ao término do passo $(i)$ serão obtidas quatro $\left[M T D F_{\text {mín }}\right]:\left[M T D F_{\text {mín }}^{(1)}\right], \cdots,\left[M T D F_{\text {mín }}^{(4)}\right]$; e duas $\left[M T D F_{\text {máx }}\right]:\left[M T D F_{\text {máx }}^{(3)}\right]$ e $\left[M T D F_{\text {máx }}^{(4)}\right]$. Vale ressaltar que o índice $k$ está indexado aos tipos de curtos-circuitos conforme a ordem em que foram apresentados nos itens de 3.1.1 a 3.1.4. 


\subsubsection{Avaliação dos limiares de tensão - Passo (ii)}

O Passo (ii) inicia-se com a definição dos limiares de tensão inferior $\left(\delta_{\text {inf }}\right)$ e superior $\left(\delta_{\text {sup }}\right)$, possibilitando caracterizar afundamentos e elevações de tensão, respectivamente. A faixa de valores utilizada para a metodologia de alocação otimizada de monitores está especificada no item 3.2.4.

Tomando como base o exposto por (OLGUIN; BOLLEN, 2003), as matrizes $\left[M T D F_{m i ́ n}^{(k)}\right]$ e $\left[M T D F_{m a ́ x}^{(k)}\right]$ são convertidas em matrizes binárias de mesma dimensão, na qual serão atribuídos valores unitários ou nulos aos seus elementos matriciais de acordo com o limiar de tensão inferior $\left(\delta_{\text {inf }}\right)$ e superior $\left(\delta_{\text {sup }}\right)$ pré-definidos. As matrizes binárias correspondentes à $\left[M T D F_{\text {mín }}^{(k)}\right]$ e $\left[M T D F_{\text {máx }}^{(k)}\right]$ são denominadas de matrizes de cobertura, denotadas por $\left[M C_{m i ́ n}^{(k)}\right]$ e $\left[M C_{m a ́ x}^{k}\right]$.

Para uma matriz $\left[M T D F_{m i n}^{(k)}\right]$, se os valores atribuídos a seus elementos de matriz estão abaixo de $\delta_{\text {inf }}$ considerado na análise, o valor do elemento matricial correspondente na matriz de cobertura $\left[M C_{\min }^{(k)}\right]$ será unitário, caracterizando um afundamento de tensão; caso contrário, será nulo, indicando a não necessidade de registro das tensões remanescentes. Logo, $\left[M C_{m i ́ n}^{(k)}\right]$ é uma matriz de cobertura para os afundamentos de tensão pelo curto-circuito do tipo $k$ utilizado no MPF.

A equação (36) descreve a atribuição dos valores aos elementos $\bar{a}_{i, j}$ da matriz $\left[M C_{m i ́ n}^{(k)}\right]$ a partir dos elementos $a_{i, j}$ de $\left[M T D F_{\text {mín }}^{(k)}\right]$.

$$
\bar{a}_{i, j}=\left\{\begin{array}{cc}
1, & \text { se } a_{i, j}<\delta_{\text {inf }} \\
0, & \text { c.c. }
\end{array}\right.
$$

Analogamente, para uma matriz $\left[M T D F_{\text {máx }}^{(k)}\right]$, se os valores atribuídos a seus elementos matriciais estão acima de $\delta_{\text {sup }}$ considerado na análise, o valor do elemento correspondente na matriz de cobertura $\left[M C_{\text {máx }}^{(k)}\right]$ será unitário, indicando uma elevação de tensão; caso contrário será nulo. Sendo assim, $\left[M C_{\text {máx }}^{(k)}\right]$ é uma matriz de cobertura para as elevações de tensão originadas pelo curto-circuito do tipo $k$ aplicado no MPF. 
A equação (37) descreve a atribuição dos valores aos elementos $\bar{b}_{i, j}$ da matriz $\left[M C_{\text {máx }}^{(k)}\right]$ a partir dos elementos $b_{i, j}$ de $\left[M T D F_{\text {máx }}^{(k)}\right]$.

$$
\bar{b}_{i, j}=\left\{\begin{array}{cc}
1, & \text { se } b_{i, j}>\delta_{\text {sup }} \\
0, & \text { c.c. }
\end{array}\right.
$$

Como pode ser verificado no fluxograma da Figura 10, no total serão obtidas quatro matrizes de cobertura $\left[M C_{\text {mín }}^{(k)}\right]$, para afundamentos de tensão, e duas matrizes de cobertura $\left[M C_{m a ́ x}^{(k)}\right]$, para elevações de tensão; uma vez que estas matrizes de cobertura foram originadas a partir das matrizes $\left[M T D F_{\text {mín }}^{(k)}\right]$ e $\left[M T D F_{\text {máx }}^{(k)}\right]$ descritas no item 3.2.1.

\subsubsection{Combinação das matrizes binárias - Passo (iii)}

Com o intuito de reduzir a quantidade de matrizes a serem processadas na formação da MCVT e, consequentemente, no processo de otimização para a alocação dos monitores de QEE, são realizadas combinações entre as matrizes $\left[M C_{\text {mín }}^{(k)}\right]$ e entre as matrizes $\left[M C_{\text {máx }}^{(k)}\right]$.

Estas combinações consistem em utilizar o operador lógico "E" (AND) para determinar a intersecção entre as matrizes binárias supracitadas (KEMPNER, 2016) ${ }^{1}$. Cabe salientar ainda que em Kempner (2016), a intersecção das matrizes é feita somente para os casos de afundamentos de tensão, sendo que na metodologia de alocação ora proposta, tem-se como objetivo a inclusão dos casos de elevação de tensão.

$\mathrm{Na}$ prática, o efeito da intersecção das matrizes $\left[M C_{m i ́ n}^{(k)}\right]$ é o de assegurar a observabilidade simultânea dos afundamentos de tensão decorrentes de todos os tipos de curtos-circuitos considerados no MPF. Analogamente, a intersecção das matrizes $\left[M C_{\text {máx }}^{(k)}\right]$ garante a observabilidade das situações de elevação de tensão causadas pelos tipos de curtoscircuitos pertinentes, considerados no MPF.

\footnotetext{
${ }^{1}$ Nota: Em Kempner (2016), a matriz de cobertura é denominada “matriz de observabilidade”. A opção pela variação da nomenclatura deve-se à necessidade de dissociação do termo "observabilidade", utilizado na teoria de ARHM e que possui significado conceitual distinto.
} 
A combinação entre as matrizes $\left[M C_{\min }^{(k)}\right]$, denotada por $\left[M C_{\text {mín }}^{\&}\right]$, consiste em aplicar o operador lógico "E" entre todos os elementos das matrizes $\left[M C_{\text {mín }}^{(k)}\right]$. Logo, um elemento da linha $i$ e coluna $j$ de $\left[M C_{m i ́ n}^{\&}\right]$, denotado por $m c_{i j}^{m i ́ n}$, é obtido em função da operação lógica entre os elementos correspondentes da linha $i$ e coluna $j$ das matrizes $\left[M C_{m i n}^{k}\right]$, denotados por $m_{i j}^{k}$, conforme apresentado na equação (38).

$$
m c_{i j}^{\min }=m_{i j}^{(1)} \wedge m_{i j}^{(2)} \wedge m_{i j}^{(3)} \wedge m_{i j}^{(4)}, \forall i, j \in\{1,2, \cdots, N\}
$$

Em (38) o símbolo “ $\wedge$ ” indica a operação lógica " $E "$ (AND) entre os elementos matriciais $m_{i j}^{k}$; e os índices de (1) a (4) referem-se ao $k$-ésimo tipo de curto-circuito considerado no MPF que provoca afundamento de tensão.

De maneira semelhante, a combinação entre as matrizes $\left[M C_{m a ́ x}^{(k)}\right]$, denotada por $\left[M C_{\text {máx }}^{\&}\right]$, consiste em aplicar o operador lógico "E" entre os elementos das matrizes $\left[M C_{m a ́ x}^{(k)}\right]$. Sendo assim, um elemento da linha $i$ e coluna $j$ de $\left[M C_{m a ́ x}^{\&}\right]$, denotado por $m c_{i j}^{m a ́ x}$, é obtido em função da operação lógica entre os elementos correspondentes da linha $i$ e coluna $j$ das matrizes [ $\left.M C_{m a ́ x}^{k}\right]$, denotados por $m_{i j}^{k}$, conforme apresentado na equação (39).

$$
m c_{i j}^{m a ́ x}=m_{i j}^{(3)} \wedge m_{i j}^{(4)} \quad, \forall i, j \in\{1,2, \cdots, N\}
$$

Desta vez, os índices de 3 e 4 referem-se ao $k$-ésimo tipo de curto-circuito considerado no MPF que provoca elevação de tensão (curtos-circuitos do tipo bifásico aterrado e curtocircuito monofásico aterrado).

A obtenção das matrizes combinadas $\left[M C_{\text {mín }}^{\&}\right]$ e $\left[M C_{\text {máx }}^{\&}\right]$ encerram o Passo (iii), e permitem a construção da MCVT executada no Passo (iv), conforme detalhado no item 3.2.4.

\subsubsection{Obtenção da MCVT: concatenação das matrizes de cobertura combinadas - Passo (iv)}

No quarto e último passo, a MCVT é construída concatenando-se as matrizes de cobertura $\left[M C_{\text {mín }}^{\&}\right]$ e $\left[M C_{\text {máx }}^{\&}\right]$. A concatenação destas matrizes visa incorporar ao processo de otimização a observabilidade dos fenômenos de afundamento e elevação de tensão, cujas ocorrências, eventualmente, não se verificam necessariamente de maneira simultânea. Isto é, a 
MCVT conterá as informações necessárias para que possa direcionar o processo de otimização a buscar pelos nós (locais de instalação dos medidores de QEE), que permitam a sensibilização de ao menos um dos medidores de QEE do arranjo final, quando da ocorrência de afundamentos e/ ou elevações de tensão.

Considerando-se um SD de $N$ nós, a concatenação das matrizes de cobertura é feita de tal forma que a MCVT final seja uma matriz aumentada de dimensão $N \times 2 N$. Vale relembrar que $\left[M C_{\text {mín }}^{\&}\right]$ e $\left[M C_{\text {máx }}^{\&}\right]$ são matrizes quadradas $N \times N$, uma vez que são derivadas originalmente das MTDFs de cada curto-circuito considerado, conforme comentado anteriormente.

A equação (40) mostra a forma final da MCVT, devido à concatenação realizada entre as matrizes de cobertura.

$$
[M C V T]_{N \times 2 N}=\left[\begin{array}{cccccc}
m c_{1,1}^{m i n} & \ldots & m c_{1, N}^{\text {mín }} & m c_{1,1}^{\text {máx }} & \ldots & m c_{1, N}^{\text {máx }} \\
\vdots & \ddots & \vdots & \vdots & \ddots & \vdots \\
m c_{N, 1}^{\text {mín }} & \ldots & m c_{N, N}^{\text {mín }} & m c_{N, 1}^{\text {máx }} & \ldots & m c_{N, N}^{\text {máx }}
\end{array}\right]
$$

Cabe salientar que a matriz $[M C V T]$ sofrerá uma nova concatenação com a matriz de cobertura das condições de ressonância harmônica (vide fluxograma da Figura 4), assegurando que a solução de alocação final esteja sensível tanto às VTCDs (afundamentos e /ou elevações de tensão), bem como às potenciais condições de ressonância harmônica. Esta nova concatenação está explicada detalhadamente no capítulo 5.

\subsubsection{Considerações sobre os limiares de tensão e tipos de curtos-circuitos na formação da MCVT}

A escolha dos limiares de tensão não é, a priori, uma tarefa simples e direta, pois é sensivelmente dependente da análise e da ponderação de alguns aspectos que são levados em consideração na etapa de aplicação do MPF sobre o SD em análise.

Como será discutido mais apropriadamente no capítulo 6, os valores dos limiares de tensão terão consequência direta na esparsidade da MCVT, implicando, principalmente, na quantidade mínima de monitores a serem instalados no sistema para torná-lo totalmente observável do ponto de vista das VTCDs.

Se a magnitude de $\delta_{\text {inf }}$ for suficientemente próxima de 0,9 p.u., por exemplo, é

provável que a matriz $\left[M C_{\text {mín }}^{\&}\right]$ e, consequentemente, a MCVT, apresentem uma elevada 
quantidade de valores unitários para uma dada situação de curto-circuito pelo MPF. Este fato ocorre já que afundamentos de tensão poucos severos (tensões remanescentes próximas a 0,9 p.u.) serão considerados para a alocação de monitores de QEE. Este comportamento tende a diminuir a quantidade de monitores necessária para tornar o sistema totalmente observável do ponto de vista dos afundamentos de tensão.

Em contrapartida, se $\delta_{\text {inf }}$ for suficientemente reduzido, é plausível prever que tanto a matriz $\left[M C_{m i ́ n}^{\&}\right]$ como a MCVT tenderão a apresentar maior quantidade de valores nulos, uma vez que somente os afundamentos de tensão mais severos, ocasionados por certa condição de curto-circuito pelo MPF, serão considerados no processo de alocação dos medidores de QEE. Como consequência direta deste fato, a quantidade mínima de monitores para tornar o sistema totalmente observável para os afundamentos de tensão tenderá a ser maior, já que a MCVT apresentará maior esparsidade.

Um comportamento análogo poderá ser verificado para o limiar superior de tensão. Ou seja, magnitudes de $\delta_{\text {sup }}$ mais próximas de 1,1 p.u. implicarão em uma maior quantidade de valores unitários nas matrizes $\left[M C_{m a ́ x}^{\&}\right]$ e $[M C V T]$. Sendo assim, mesmo as elevações de tensão menos severas (tensões remanescentes acima 1,1 p.u., porém próximas a este valor) serão consideradas no processo de alocação, demandando a instalação de uma menor quantidade de medidores de QEE para assegurar a total observação das elevações de tensão pelo arranjo de medidores.

Por outro lado, é provável que as matrizes $\left[M C_{\text {máx }}^{\&}\right]$ e $[M C V T]$ se tornem mais esparsas quando $\delta_{\text {sup }}$ possuir magnitudes mais elevadas, exigindo assim uma maior quantidade de medidores de QEE para assegurar a total observação das elevações de tensão. Isto ocorre já que somente as elevações de tensão mais severas (tensão remanescente acima de 1,1 p.u. e mais distantes deste valor) serão consideradas no processo de alocação dos medidores de QEE.

Diante do exposto, afirma-se que há uma interdependência implícita entre a definição dos limiares de tensão e a quantidade mínima necessária de monitores para tornar o SD totalmente observável do ponto de vista das VTCDs.

Cabe ainda destacar que a ocorrência de VTCDs de maior ou menor severidade está condicionada às características do SD estudado, tais como: parâmetros do sistema, nível de tensão nominal e potência de curto-circuito no nó de referência. Afirma-se também que as características dos curtos-circuitos considerados no MPF também exercerão influência na 
severidade das possíveis VTCDs calculadas nas MTDFs, tais como fases envolvidas e resistência de falta (curto-circuito sólido, ou de alta impedância, por exemplo).

Situações de curtos-circuitos que provoquem VTCDs mais brandas implicarão em uma solução de alocação em que mais monitores de QEE serão exigidos para tornar o sistema totalmente observável às mesmas. Este fato, como mencionado anteriormente, esta relacionado à esparsidade da MCVT, pois variações mais brandas favorecem uma maior quantidade de elementos nulos nesta matriz. Este comportamento é verificado mesmo quando $\delta_{\text {inf }}$ e $\delta_{\text {sup }}$ favorecerem uma menor esparsidade da MCVT, isto é, quando $\delta_{\text {inf }}$ for suficientemente próximo a 0,9 p.u. e quando $\delta_{\text {sup }}$ for suficientemente próximo a 1,1 p.u.

Cabe salientar que o ajuste de $\delta_{\text {inf }}$ e $\delta_{\text {sup }}$, utilizados para a construção da matriz [MCVT], poderá diferir, em certas condições, do ajuste dos limiares dos medidores de QEE instalados em campo. A equação (41) mostra qual a faixa de valores possível para o ajuste em campo dos limiares de tensão.

$$
\begin{aligned}
& \delta_{\text {inf }} \leq \bar{\delta}_{\text {inf }}<0,9 \text { p.u. } \\
& 1,1 \text { p.u. }<\bar{\delta}_{\text {sup }} \leq \delta_{\text {sup }}
\end{aligned}
$$

Sendo $\bar{\delta}_{\text {inf }}$ e $\bar{\delta}_{\text {sup }}$, respectivamente, os ajustes em campo do limiar inferior e superior de tensão; e $\delta_{\text {inf }}$ e $\delta_{\text {sup }}$, respectivamente, os limiares inferior e superior de tensão definidos para a construção da MCVT.

Além disso, cabe ressaltar que um afundamento de tensão é caracterizado por tensão remanescente entre 0,1 p.u. e 0,9 p.u.; e uma elevação de tensão por tensão remanescente entre 1,1 p.u. e 1,8 p.u. (DUGAN et al., 2012). Sendo assim, definem-se os intervalos para $\delta_{\text {inf }}$ e $\delta_{\text {sup }}$, conforme mostra a equação (42).

$$
\begin{aligned}
& 0,1 \text { p.u. }<\delta_{\text {inf }} \leq 0,9 \text { p.u. } \\
& 1,1 \text { p.u. } \leq \delta_{\text {sup }}<1,8 \text { p.u. }
\end{aligned}
$$

De fato, as expressões descritas na equação (42) são válidas, pois quaisquer ajustes em campo dos limiares de tensão, nas condições descritas, farão com que os medidores de QEE sejam sensibilizados e detectem as VTCDs. Contudo a violação destas condições terá como efeito a não garantia da qualidade do monitoramento, ou seja, é possível que a completa observabilidade das VTCDs fique comprometida. Neste caso, será eventualmente necessário obter um novo arranjo de monitores que atenda aos novos ajustes desejados. 


\section{Análise de ressonância harmônica modal}

De acordo com XU et al. (2005), uma condição de ressonância paralela está associada à existência de um autovalor nulo da matriz de admitância $[Y]$ do sistema. Neste sentido, a decomposição em autovalores da matriz $[Y]$, é capaz de fornecer informações substanciais sobre as situações de ressonância paralela em sistemas elétricos. Conforme anteriormente discutido no referencial técnico-científico (capítulo 2), a Análise de Ressonância Harmônica Modal (ARHM) é uma técnica que demonstra ser comprovadamente adequada para ser aplicada ao problema de decomposição em autovalores mencionado. Vale ressaltar que originalmente, esta técnica foi empregada para estudos em sistemas de transmissão, sendo que para esta pesquisa foi aplicada para sistemas de distribuição de média tensão.

Uma vez que os elementos de $[Y]$ são dependentes da frequência, a decomposição em autovalores deve ser conduzida para uma determinada frequência de avaliação, condicionando, portanto, o estudo de ressonância paralela a um determinado intervalo de frequências. Como esta pesquisa possui a prerrogativa de um estudo voltado à Qualidade da Energia Elétrica (QEE), as frequências de avaliação são assumidas como sendo as frequências harmônicas $(h)$, sendo que $h$ denotará a $h$-ésima frequência harmônica.

Conforme exposto por Belmann (1970), a decomposição de [Y] em uma matriz de autovalores pode ser obtida por um procedimento de redução à sua forma diagonal. Em linhas gerais este procedimento consiste em obter uma matriz diagonal $[\Lambda]$, contendo os autovalores de $[Y]$, os quais se presumem distintos, e uma matriz $[A]$ cujas colunas são formadas pelo conjunto linearmente independente de autovetores para $[Y]$, de tal forma que $[Y]=$ $[A][\Lambda][A]^{-1}$.

Logo, para cada frequência $h$, a decomposição de [Y] é então dada pela equação (43) (XU et al., 2005).

$$
\left[Y_{h}\right]=\left[A_{h}\right]\left[\Lambda_{h}\right]\left[B_{h}\right]
$$

Sendo que o subscrito $h$ denota a $h$-ésima frequência harmônica; $\left[\Lambda_{h}\right]$ a matriz diagonal dos distintos autovalores de $\left[Y_{h}\right] ;\left[A_{h}\right]$ a matriz cujas colunas são formadas pelo conjunto linearmente independente de autovetores para $\left[Y_{h}\right]$; e $\left[B_{h}\right]=\left[A_{h}\right]^{-1}$. Além disso, se $\left[B_{h}\right]$ é 
um conjunto ortogonal, então é possível afirmar que $\left[A_{h}\right]^{-1}=\left[A_{h}\right]^{T}$, isto é, as linhas do vetor $\left[B_{h}\right]$ são formadas pelos autovetores linearmente independentes de $\left[Y_{h}\right]$ (BELLMAN, 1970; DATTA, 2010).

A equação (44) descreve a relação entre as tensões $\left[V_{h}\right]$ e correntes nodais $\left[I_{h}\right]$, para cada frequência harmônica $h$, através da matriz de admitância.

$$
\left[V_{h}\right]=\left[Y_{h}\right]^{-1}\left[I_{h}\right]
$$

Logo, substituindo a equação (43) na equação (44), e sabendo que $\left[B_{h}\right]=\left[A_{h}\right]^{-1}$, é possível expressar as tensões e correntes nodais em termos da matriz $\left[Y_{h}\right]$ decomposta em autovalores, conforme descrito pela equação (45).

$$
\left[V_{h}\right]=\left(\left[A_{h}\right]\left[\Lambda_{h}\right]\left[B_{h}\right]\right)^{-1}\left[I_{h}\right]=\left[B_{h}\right]^{-1}\left[\Lambda_{h}\right]^{-1}\left[B_{h}\right]\left[I_{h}\right]
$$

Além disso, da equação (45) é possível definir a relação existente entre as grandezas modais (tensões modais $\left[U_{h}\right]$ e correntes modais $\left[J_{h}\right]$ ), com as suas respectivas grandezas nodais (tensões nodais $\left[V_{h}\right]$ e correntes nodais $\left[I_{h}\right]$ ), conforme descrito na equação (46).

$$
\begin{aligned}
& {\left[B_{h}\right]\left[V_{h}\right]=\left[\Lambda_{h}\right]^{-1}\left[B_{h}\right]\left[I_{h}\right]} \\
& {\left[U_{h}\right]=\left[\Lambda_{h}\right]^{-1}\left[J_{h}\right]}
\end{aligned}
$$

$\operatorname{Em}(46),\left[U_{h}\right]=\left[B_{h}\right]\left[V_{h}\right]$ e $\left[J_{h}\right]=\left[B_{h}\right]\left[I_{h}\right]$.

Ao considerar um sistema elétrico hipotético com $N$ nós, $\left[U_{h}\right]$ e $\left[J_{h}\right]$ serão vetores de dimensão $N \times 1$, e $\left[\Lambda_{h}\right]^{-1}$ uma matriz diagonal $N \times N$, que contém o inverso dos $N$ autovalores distintos ( $N$ modos) da matriz de admitância $\left[Y_{h}\right]$ do sistema elétrico. A equação (47) traz a representação matricial da equação (46).

$$
\left[\begin{array}{c}
u_{h}^{1} \\
u_{h}^{2} \\
\vdots \\
u_{h}^{N}
\end{array}\right]=\left[\begin{array}{cccc}
\left(\lambda_{h}^{1}\right)^{-1} & 0 & \ldots & 0 \\
0 & \left(\lambda_{h}^{2}\right)^{-1} & \ldots & 0 \\
\vdots & \vdots & \ddots & \vdots \\
0 & 0 & \ldots & \left(\lambda_{h}^{N}\right)^{-1}
\end{array}\right]\left[\begin{array}{c}
j_{h}^{1} \\
j_{h}^{2} \\
\vdots \\
j_{h}^{N}
\end{array}\right]
$$

Nesta, $\lambda_{h}^{N}$ é o $N$-ésimo autovalor de $\left[Y_{h}\right]$, correspondente ao modo $N$, avaliado na frequência $h$.

Os elementos da diagonal de $\left[\Lambda_{h}\right]^{-1}$ possuem unidade de impedância e são denominados de impedância modal (XU et al., 2005). Logo, a impedância modal do modo $N$ avaliada na frequência $h$ é calculada dada pela equação (48). 


$$
\zeta_{h}^{N}=1 / \lambda_{h}^{N}
$$

De acordo com Xu et al. (2005), uma condição de ressonância paralela (doravante denominada, por simplicidade, ressonância) é verificada para valores significativamente elevados da impedância modal. De acordo com a equação (48), esta situação corresponde a magnitudes pequenas (zero ou próximas de zero) dos autovalores da matriz $\left[Y_{h}\right]$, já que a impedância modal equivale ao inverso do autovalor correspondente na matriz diagonal $\left[\Lambda_{h}\right]$.

Além disso, denomina-se de modo crítico $\kappa$ o menor autovalor de $\left[Y_{h}\right]$, para o qual a respectiva impedância modal $\left(\zeta_{h}^{\kappa}\right)$ será responsável por amplificar significativamente a respectiva tensão modal $\left(u_{h}^{\kappa}\right)$, mesmo para pequenas quantidades de injeção de corrente modal no modo crítico $\left(j_{h}^{\kappa}\right)$ (XU et al., 2005).

Da equação (46), sabe-se que $\left[U_{h}\right]=\left[B_{h}\right]\left[V_{h}\right]$. Valendo-se também do fato de que $\left[A_{h}\right]=\left[B_{h}\right]^{-1}$, é possível afirmar que $\left[V_{h}\right]=\left[A_{h}\right]\left[U_{h}\right]$. Assumindo-se ainda que a magnitude da tensão modal no modo crítico é muito maior do que as demais magnitudes de tensões modais, a aproximação denotada pela equação (49) é considerada (XU et al., 2005).

$$
\left[V_{h}\right]=\left[A_{h}\right]\left[U_{h}\right] \approx\left[a_{1, \kappa}, a_{2, \kappa}, \cdots, a_{N, \kappa}\right]^{T} u_{h}^{\kappa}
$$

Em (49), $\left[a_{1, \kappa}, a_{2, \kappa}, \cdots, a_{N, \kappa}\right]^{T}$ é a coluna da matriz $\left[A_{h}\right]_{N \times N}$ associada ao modo crítico (autovetor crítico em $\left[A_{h}\right]$ ), e $u_{h}^{\kappa}$ é o elemento de $\left[U_{h}\right]_{N \times 1}$ acoplado ao modo crítico.

Sendo assim, na condição de ressonância associada a um determinado modo crítico $\kappa$, todas as tensões nodais $\left[V_{h}\right]$ serão expressas em termos do autovetor crítico de $\left[A_{h}\right]$ e a correspondente tensão modal no modo $\kappa$. Consequentemente, a amplificação da tensão em cada nó do sistema devido a uma condição de ressonância é avaliada. Logo, é possível determinar a partir de qual nó do sistema o fenômeno da ressonância é mais facilmente observado. Neste sentido, infere-se que os elementos do autovetor crítico em $\left[A_{h}\right]$ contém uma medida da observabilidade do modo crítico. Ou seja, os nós do sistema com maior amplificação da tensão apresentarão uma maior observabilidade do modo crítico. Analogamente, os nós do sistema com menor amplificação da tensão serão considerados nós com menor observabilidade do modo crítico.

A amplificação de tensão é caracterizada como um aumento indesejado na magnitude das tensões harmônicas além dos níveis de distorção que já estão presentes na condição normal de operação do SD. Pela metodologia proposta, entende-se que a amplificação da tensão harmônica, caracterizada pelo aumento dos níveis de DHT, pode ser medida e 
registrada por um medidor de QEE, já que, em geral, este equipamento pode fornecer e registrar a DHT da tensão e/ou o espectro de frequências do sinal medido (sinal de tensão).

Sendo assim, diante da ocorrência de uma condição de ressonância harmônica, os medidores de QEE instalados nos nós com maior observabilidade, estarão preparados para medir as consequentes amplificações de tensão.

Com relação às medições realizadas pelos monitores instalados em campo, recomenda-se que as tensões de fases sejam monitoradas. É prática comum entre as concessionárias de energia a adoção de três transformadores de potencial (TPs) conectados em estrela aterrado, sendo possível assim acessar todas as tensões de fase no secundário dos TPs. Por outro lado, destaca-se que algumas concessionárias adotam em seus procedimentos de medições um arranjo com apenas dois TPs conectados em delta aberto, o que permite apenas o acesso às tensões de linha. É importante salientar que na configuração com dois TPs, toda informação atrelada à componente de sequência zero será perdida, consequentemente resultando em uma leitura inadequada da DHT da tensão.

Uma análise similar à observabilidade dos nós pode ser realizada verificando-se a relação existente entre $\left[J_{h}\right]$ e $\left[I_{h}\right]$. Por esta análise, tem-se a medida de excitabilidade, que indica em quais nós do sistema um dado modo crítico é induzido (ou excitado) mais facilmente em detrimento dos demais nós. Nesse sentido, partindo-se da equação (46), em que $\left[J_{h}\right]=\left[B_{h}\right]\left[I_{h}\right]$, a corrente modal de um dado modo crítico $\kappa$ pode ser expressa em termos da corrente nodal conforme a equação (50).

$$
j_{h}^{\kappa}=\left[b_{\kappa, 1}, b_{\kappa, 2}, \cdots, b_{\kappa, N}\right]\left[I_{h}\right]=b_{\kappa, 1} i_{h}^{1}+b_{\kappa, 2} i_{h}^{2}+\cdots+b_{\kappa, N} i_{h}^{N}
$$

Na equação, $\left[b_{\kappa, 1}, b_{\kappa, 2}, \cdots, b_{\kappa, N}\right]$ é a linha da matriz $\left[B_{h}\right]_{N \times N}$ associada ao modo crítico (autovetor crítico em $\left[B_{h}\right]$ ), e $j_{h}^{\kappa}$ é o elemento de $\left[J_{h}\right]_{N \times 1}$ acoplado ao modo crítico.

Da equação (50), constata-se que os elementos do autovetor crítico em $\left[B_{h}\right]$ determinam a proporção da contribuição de cada corrente nodal para a corrente modal $j_{h}^{\kappa}$. Se algum dos elementos do autovetor crítico em $\left[B_{h}\right]$ for nulo, por exemplo, $b_{\kappa, 2}=0$, a corrente no nó 2 do sistema $\left(i_{h}^{2}\right)$ não terá alguma contribuição para excitar o modo crítico $\kappa$, mesmo que $i_{h}^{2}$ apresente magnitude significativamente elevada. A excitabilidade de um nó pode ser ainda interpretada como sendo "[...] uma forma de controlabilidade, já que os barramentos 
com a maior excitabilidade são os locais mais eficazes para injetar sinais para cancelar as harmônicas" (XU et al., 2005, p. 1183, tradução nossa) ${ }^{2}$.

Conforme exposto por $\mathrm{Xu}$ et al. (2005), a caracterização da excitabilidade e observabilidade de um mesmo nó simultaneamente, é feita através do índice denominado fator de participação. A equação (51) mostra o cálculo do fator de participação a partir dos elementos dos vetores $\left[A_{h}\right]$ e $\left[B_{h}\right]$.

$$
F P_{n \kappa}=a_{n, \kappa} b_{\kappa, n}
$$

Para o cálculo, $n$ é o índice do nó avaliado e $\kappa$ o modo crítico. Cabe destacar que a avaliação do fator de participação é somente válida para um determinado modo crítico, pois para que a equação (51) seja verdadeira a impedância modal no modo crítico dever ser muito maior do que as demais impedâncias modais (XU et al., 2005).

A avaliação do fator de participação pode ser útil, por exemplo, quando há o interesse em se localizar os nós do sistema nos quais tanto a observabilidade como a excitabilidade são máximas em relação aos demais nós. Estes locais (nós) possuem os maiores valores de fator de participação e são chamados de centro da ressonância (XU et al., 2005).

Além do fator de participação, observabilidade e excitabilidade, $\mathrm{Xu}$ et al. (2005) apresentam também outros índices que integram a teoria de ARHM. Contudo, no âmbito do monitoramento otimizado das condições de ressonância no qual se propõe esta pesquisa, somente a medida de observabilidade será utilizada como parâmetro para o processo de otimização. Isto é, a alocação otimizada dos medidores de QEE será orientada de acordo com a observabilidade de cada nó do sistema, priorizando, portanto, a instalação em nós cuja observabilidade da ressonância é máxima. É importante esclarecer que a solução final do arranjo otimizado também contemplará a observabilidade das VTCDs, conforme detalhadamente já discutido anteriormente no capítulo 3 .

Conforme será detalhado nos itens 4.1 e 4.2 deste capítulo, a partir da Matriz de Cobertura de Ressonância Harmônica (MCRH), o processamento da observabilidade das potenciais condições de ressonância harmônica será incorporado ao processo de otimização. De acordo com o fluxograma geral da metodologia de alocação (Figura 4), apresentado no capítulo 1, a MCRH é parte integrante da "Etapa 1", que será posteriormente concatenada

\footnotetext{
${ }^{2}$ No original: "[...] a form of controllability as buses with highest excitability are the most effective locations to inject signals to cancel harmonics."
} 
com a Matriz de Cobertura das Variações de Tensão (MCVT), cuja obtenção foi explicada no Capítulo 3. Desta concatenação inicia-se a "Etapa 2" (Figura 4), formando-se a Matriz de Cobertura Final (MCF) que será efetivamente utilizada no processo de otimização e obtenção do arranjo otimizado de medidores de QEE. A obtenção da MCF será explicada no capítulo 5.

Vale adiantar que a MCRH, é obtida de maneira que certas condições de operação do sistema elétrico sejam consideradas. Pela obtenção da MCRH como formulada, procura-se retratar situações que são usualmente enfrentadas na operação de um Sistema de Distribuição (SD). A metodologia para obter a MCRH contemplando-se tais condições está descrita no item 4.2 deste capítulo.

Por fim, no item 4.3 do presente capítulo, será apresentado como se deu a obtenção dos autovalores e autovetores críticos da matriz $\left[Y_{h}\right]$. Mais especificamente, no item 4.3.3, apresenta-se uma breve discussão sobre questões técnicas relacionadas ao método numérico utilizado no cálculo dos referidos autovalores e autovetores críticos. Estas questões foram observadas durante o desenvolvimento da pesquisa, e alguns encaminhamentos foram propostos para que futuros aprimoramentos possam ser realizados com base no que se está apresentando.

\subsection{Matriz de cobertura das potenciais condições de ressonância harmônica}

A informação de observabilidade das potenciais condições de ressonância é inicialmente organizada através de uma matriz denominada de Matriz de Observabilidade das Ressonâncias (MOR). Em seguida, a partir da MOR, uma segunda matriz será obtida, sendo esta a própria MCRH, já previamente mencionada.

Para se construir a MOR, a ARHM deve ser executada para todas as frequências harmônicas do intervalo estipulado, permitindo-se assim a identificação dos autovetores críticos (contidos na matriz $\left[A_{h}\right]$ ) que são correspondentes às condições de ressonância (modos críticos).

Para cada configuração específica do SD, espera-se encontrar determinadas frequências harmônicas de ressonância. Em outras palavras, cada configuração do SD implicará em distintas matrizes de admitância $\left[Y_{h}\right]$, levando a diferentes impedâncias modais e, consequentemente, a novos modos críticos. As configurações do SD, consideradas nesta 
pesquisa, estão associadas com o estado de conexão dos bancos de capacitores locais (consumidores), como detalhado mais adiante no item 4.2.

Uma vez que várias frequências harmônicas podem ser determinadas ao se executar a ARHM, como descrito no parágrafo anterior, todas as medidas de observabilidade correspondentes devem ser incorporadas na MOR. Para tanto, as colunas da MOR são construídas com os respectivos autovetores críticos. Esta forma da MOR permite o posterior processamento simultâneo dos graus de observabilidade de cada nó, considerando todas as condições de ressonância harmônica detectadas.

De modo a exemplificar a construção da MOR, considere o exemplo em que $F$ frequências harmônicas de ressonâncias são encontradas no intervalo $\left[h_{\text {mín }}, h_{\text {máx }}\right]$, após a execução completa da ARHM em um SD de $N$ nós. Nesta situação a MOR será composta de $F$ colunas, isto é, $[M O R]_{N \times F}$, sendo cada uma das colunas correspondentes ao $\kappa$-ésimo autovetor crítico $\left[a_{1, \kappa} a_{2, \kappa} \cdots a_{N, \kappa}\right]^{T}$, conforme representado na equação (52).

$$
[M O R]=\left[\begin{array}{cccc}
a_{1, \kappa 1} & a_{1, \kappa 2} & \cdots & a_{1, \kappa F} \\
a_{2, \kappa 1} & a_{2, \kappa 2} & \cdots & a_{2, \kappa F} \\
\vdots & \vdots & \ddots & \vdots \\
a_{N, \kappa 1} & a_{N, \kappa 2} & \cdots & a_{N, \kappa F}
\end{array}\right]
$$

Após a obtenção da MOR, uma regra binária é aplicada sobre os seus elementos, resultando na MCRH. A dimensão da $\mathrm{MCRH}$ é idêntica à da MOR, ou seja, $[M C R H]_{N \times F}$. A equação (53) descreve a atribuição dos valores aos elementos $\bar{a}_{i, j}$ da matriz [MCRH] a partir dos elementos $a_{i, j}$ de $[M O R]$.

$$
\bar{a}_{i, j}=\left\{\begin{array}{lc}
1, & \text { se } a_{i, j} \geq \tau \\
0, & \text { c.c. }
\end{array}\right.
$$

Em (53), $\tau$ é um limiar que determinará o estado de detecção (valor unitário), ou não detecção (valor nulo), pelo medidor de QEE das $F$ frequências harmônicas de ressonância. Isto significa que se as magnitudes dos elementos dos autovetores críticos permanecerem abaixo de $\tau$ e as correspondentes frequências harmônicas de ressonância não serão consideradas no processo de obtenção do arranjo otimizado de monitores. A razão por adotar uma matriz binária é justificada em função da formulação do problema de otimização que será apresentado no capítulo 5 .

Como pode ser inferido, o limiar $\tau$ possui considerável impacto no processo de otimização, isto é, afetará a quantidade mínima necessária de medidores de QEE. Sendo 
assim, uma análise das soluções de alocação determinadas referente a uma faixa de valores atribuídos para $\tau$ é apresentado mais adiante no capítulo 6, para os SDs testes. Cabe adiantar que a escolha do limiar será de responsabilidade do operador, uma vez que o compromisso entre a disponibilidade de recursos financeiros e qualidade desejada para o monitoramento varia para distintos SDs.

\subsection{Metodologia para a obtenção da MCRH}

Os medidores de QEE são alocados considerando-se diversos cenários que são referentes a distintos estados de conexão de bancos de capacitores. Estes bancos são empregados na correção do Fator de Potência (FP) de algumas cargas reativas presentes no SD. A razão pela inclusão destes cenários na obtenção do arranjo otimizado de monitores deve-se ao fato de possíveis variações da demanda reativa das cargas no transcorrer do dia. Isto significa que eventuais variabilidades decorrentes da conexão e/ou desconexões dos bancos de capacitores locais serão contempladas na otimização. As diferentes combinações do estado de conexão destes bancos levam a distintas impedâncias modais, e, consequentemente, a distintas frequências de ressonâncias, que devem ser incluídas no processo de otimização, para que o arranjo final de monitores esteja apto a eventualmente detectá-las.

A Figura 11 traz o fluxograma da metodologia utilizada para a obtenção da MCRH.

É importante relembrar que o fluxograma da Figura 11 detalha somente um dos dois procedimentos que compõem a "Etapa 1" (Figura 4) da metodologia de alocação de monitores, isto é, a obtenção da MCRH. Sendo assim, a etapa de aquisição dos dados do SD, ou seja, dos parâmetros dos cabos e linhas do SD, dos dados das cargas, dos parâmetros dos bancos de capacitores e das informações da topologia do sistema como um todo, não está evidenciada no fluxograma da Figura 11, partindo-se diretamente da obtenção do conjunto $C$.

O conjunto $C=\left\{c_{1}, c_{2}, \cdots, c_{m a ́ x}\right\}$, é dependente das posições dos capacitores sobre o SD em questão, já que conterá os distintos cenários de conexão dos bancos de capacitores. Como pode ser observado no fluxograma da Figura 11, este conjunto é definido antes que a ARHM seja iniciada.

Para $M$ bancos de capacitores, cada um com a possibilidade de assumir dois estados (conectado ou desconectado), tem-se que $C$ possuirá $2^{M}$ elementos, isto é, $c_{\text {máx }}=2^{M}$. Caso o estado de conexão de um ou mais bancos de capacitores presentes no SD sejam considerados fixos, estes bancos não serão incluídos no conjunto $C$, isto é, estarão sempre conectados e não 
influenciarão no número de cenários do conjunto $C$. Uma melhor compreensão acerca da formação do conjunto de cenários se dará mais adiante no capítulo 6 .

Figura 11 - Fluxograma que descreve a metodologia de obtenção da MCRH.

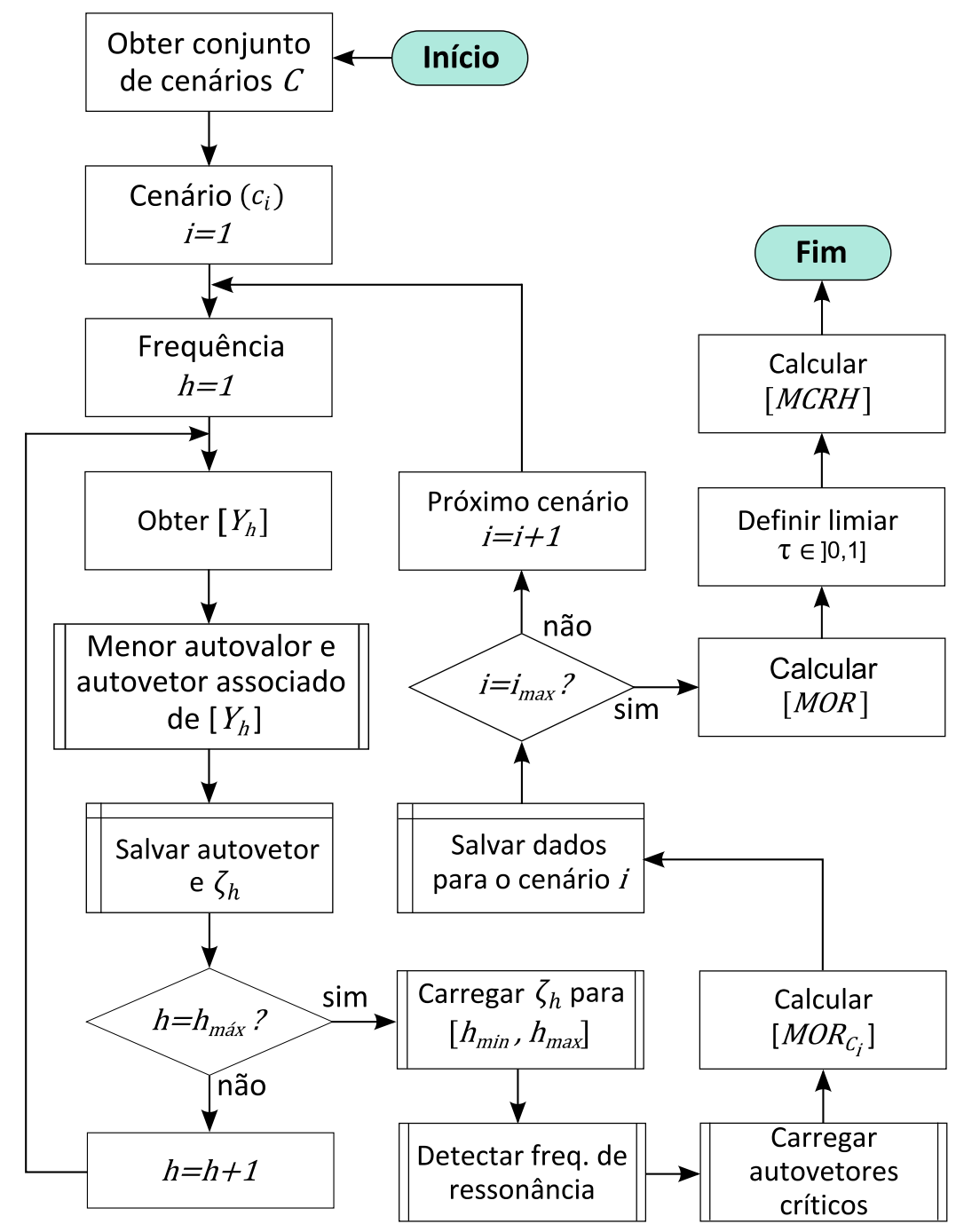

Retomando o fluxograma da Figura 11, após a aquisição de todos os dados referentes ao $\mathrm{SD}$ e construção do conjunto $C$, o primeiro cenário é selecionado $\left(c_{1}\right)$ e a ARHM é executada para o intervalo de frequência $\left[h_{\text {mín }}, h_{\text {máx }}\right]$.

Como ilustrado na Figura 11, para a frequência $h$ (iniciando-se para a frequência fundamental, ou seja, $h=1$ ), o cálculo da matriz de admitância $\left[Y_{h}\right]$ é realizado, seguido da determinação do autovalor de menor magnitude de $\left[Y_{h}\right]$, bem como de seus autovetores associados. O cálculo dos referidos autovalores e autovetores é feito através do Método da Potência Inversa (MPI), que será apresentado e discutido em detalhes no item 4.3. 
Uma vez que o MPI fornece sempre os autovalores de menores magnitudes no intervalo de frequência $\left[h_{\text {mín }}, h_{\text {máx }}\right]$, as respectivas impedâncias modais $\left(\zeta_{h}\right)$, calculadas para este intervalo, estarão sempre referidas àquelas de maior magnitude dentre todos os $N$ modos existentes em $\left[Y_{h}\right]_{N \times N}$. Ou seja, para uma dada frequência $h$, tem-se $\zeta_{h}=m a ́ x\left\{\zeta_{h}^{1}, \zeta_{h}^{2}, \cdots \zeta_{h}^{N}\right\}$, caracterizando assim a envoltória da amplitude máxima das impedâncias modais (dentre todos os $N$ modos) no intervalo $\left[h_{\text {mín }}, h_{\text {máx }}\right]$.

De fato, conforme anteriormente comentado no início deste capítulo, quando verificada uma condição de ressonância, os autovalores de menor magnitude de $\left[Y_{h}\right]$ coincidirão com os modos críticos propriamente ditos. Logo, nesta condição, a respectiva impedância modal obtida pelo MPI será aquela correspondente à do modo crítico $\left(\zeta_{h}=\zeta_{h}^{\kappa}\right)$.

Cabe salientar que para esta metodologia é de interesse a determinação do(s) modo(s) crítico(s), sendo que a determinação dos demais modos não é necessária para o atual estágio de desenvolvimento da pesquisa. Este fato é verdade, pois para o problema de otimização formulado serão utilizados apenas os graus de observabilidade dos nós no(s) modo(s) crítico(s), isto é, os elementos do(s) autovetor(es) crítico(s), já que estes influenciarão diretamente na escolha dos melhores pontos de instalação dos monitores de QEE.

Diante do exposto, e retomando o fluxograma da Figura 11, o menor autovalor (correspondente à impedância modal $\zeta_{h}$ ) e seu autovetor associado são armazenados, sendo ambos calculados para uma dada frequência $h$ e cenário $c_{1}$ do conjunto $C$. Em seguida, ainda para o cenário $c_{1}$, a impedância modal $\zeta_{h}$ e seu respectivo autovetor são calculados para a próxima frequência harmônica $(h=h+1)$ e então finalmente armazenados. Segue-se com o mesmo procedimento até que $h=h_{\text {máx }}$. É importante salientar que a partir de $h=2$, as matrizes $\left[Y_{h}\right]$ são calculadas com base na matriz de impedâncias obtida para a frequencia fundamental, ou seja, os valores dos elementos matriciais para as novas matrizes $\left[Y_{h}\right]$ serão apenas atualizados para a nova frequência $h$, não havendo nenhuma alteração estrutural na matriz como um todo.

Ao término do ciclo de cada cenário do conjunto $C$, finaliza-se o processamento das impedâncias modais de todo o intervalo das frequências harmônicas. Este processamento consiste em examinar a magnitude de $\zeta_{h}$ no intervalo de frequências harmônicas $\left[h_{\text {mín }}, h_{\text {máx }}\right]$, identificando-se os picos de elevadas magnitudes que correspondem às condições de ressonância. As frequências harmônicas em que os picos ocorrem são as 
próprias frequências de ressonância harmônica, sendo estas as frequências que se deseja monitorar através do arranjo de medidores de QEE.

Detectadas as $F$ frequências harmônicas, os autovetores críticos são carregados, e inicia-se a assim a construção da MOR. Cada autovetor crítico associado a uma frequência de ressonância harmônica formará as colunas da MOR. Assim, a MOR para o cenário $c_{1}$, denotada por $\left[M O R_{C_{1}}\right]$, é construída.

Seguindo o fluxograma da Figura 11, o mesmo procedimento descrito para o cenário $c_{1}$ até a obtenção de $\left[M O R_{c_{1}}\right]$ é então executado para todos os cenários do conjunto $C$. Ao término do laço correspondente à ARHM para todos os cenários de $C$, tem-se a construção da MOR final, obtida pela concatenação horizontal (justaposição) das matrizes MOR de cada cenário, como mostrado pela equação (54).

$$
[M O R]=\left[\begin{array}{cccccccccc}
a_{1, \kappa 1}^{c_{1}} & \cdots & a_{1, \kappa F}^{c_{1}} & a_{1, \kappa 1}^{c_{2}} & \cdots & a_{1, \kappa F}^{c_{2}} & \cdots & a_{1, \kappa 1}^{c_{m} x^{\prime}} & \cdots & a_{1, \kappa F}^{c_{\text {máx }}} \\
\vdots & \ddots & \vdots & \vdots & \ddots & \vdots & \cdots & \vdots & \ddots & \vdots \\
a_{N, \kappa 1}^{c_{1}} & \cdots & a_{N, \kappa F}^{c_{1}} & a_{N, \kappa 1}^{c_{2}} & \cdots & a_{N, \kappa F}^{c_{2}} & \cdots & a_{N, \kappa 1}^{c_{m a ́ x}} & \cdots & a_{N, \kappa F}^{c_{m} x}
\end{array}\right]
$$

Em (54), $c_{1}, c_{2}, \cdots, c_{\text {máx }}$ denotam o respectivo cenário do conjunto $C$. Para simplificar, a notação da MOR da equação (52) é preservada, ou seja, a matriz [MOR] na equação (54) ainda permanece uma matriz de dimensão $N \times F$, sendo agora $F$ a representação do número total de frequências harmônicas de ressonância que foram detectadas em todos os cenários do conjunto $C=\left\{c_{1}, c_{2}, \cdots, c_{m a ́ x}\right\}$. Por esta razão, a mesma notação anteriormente utilizada neste capítulo continua a ser utilizada deste ponto em diante.

Seguindo para a parte final do fluxograma, tem-se a atribuição do valor ao limiar $\tau$, o qual determinará a obtenção da MCRH propriamente dita. Os elementos matriciais da MCRH são obtidos aplicando-se a equação (53) sobre a MOR, construída segundo a concatenação descrita na equação (54). $\mathrm{O}$ valor de $\tau$ pode assumir qualquer valor não nulo entre 0 e 1 , isto é, $0<\tau \leq 1$, uma vez que as magnitudes dos elementos dos autovalores críticos são normalizados. Esta normalização ocorre durante a etapa de obtenção dos autovalores dominantes pelo Método das Potências - MP (FRANCO, 2008).

Como mencionado anteriormente, a escolha do valor de $\tau$ será mais bem discutida no capítulo 6 , todavia, cabe adiantar que pela atribuição do valor unitário a $\tau$, a otimização será conduzida a buscar os nós com máxima observabilidade para as frequências harmônicas de 
ressonância. Em contrapartida, ao se atribuir um valor mais distante do unitário, a otimização considerará a busca por nós cujas observabilidades não são máximas, ou até mesmo baixas. Embora o valor de $\tau$ ainda seja assunto para pesquisas futuras, um estudo de uma ampla faixa de valores para este limiar foi realizada no capítulo 6, procurando-se evidenciar a sua influência nas soluções de alocação determinadas.

É importante relembrar que a MCRH será posteriormente concatenada com a MCVT no momento da etapa de otimização. Esta concatenação será explicada mais adiante no capítulo 5 .

\subsection{Cálculo dos autovalores e autovetores críticos da matriz $\left[Y_{h}\right]$}

A determinação dos autovalores e autovetores da inversa da matriz de admitância do sistema elétrico são fundamentais para se aplicar a ARHM. Além disso, como visto em maiores detalhes no item 4.2, a busca pelos autovalores de menor magnitude permite o cálculo da impedância modal $\zeta_{h}$ para o intervalo de frequências harmônicas desejadas. Consequentemente, são determinadas as frequências harmônicas de ressonância e os respectivos graus de observabilidade dos nós do sistema, parâmetros estes que são utilizados na etapa de otimização, dedicada a encontrar o arranjo final de monitores de QEE.

Dentre os métodos numéricos para o cálculo de autovalores, optou-se pela aplicação do MPI à metodologia de alocação otimizada de monitores de QEE. A decisão por utilizar este método deve-se, principalmente, à possibilidade de se obter o menor autovalor em magnitude da matriz $\left[Y_{h}\right]$ e seu respectivo autovetor (graus de observabilidade), sem a necessidade de se obter explicitamente a matriz inversa de $\left[Y_{h}\right]$, como será mais bem exposto no item 4.3.2.

Embora outros métodos possam calcular todos os autovalores de uma matriz de ordem $N$, somente o menor autovalor de $\left[Y_{h}\right]$ é de interesse no atual estágio de desenvolvimento da pesquisa, conforme já discutido anteriormente. Sendo assim, acredita-se que o MPI se apresenta como uma escolha adequada para o cálculo dos autovalores de $\left[Y_{h}\right]$ no intervalo $\left[h_{m i ́ n}, h_{m a ́ x}\right]$.

Com a finalidade de melhor organizar o texto e formar uma base para a compreensão do MPI, será apresentado inicialmente uma breve discussão sobre o MP no item 4.3.1. 


\subsubsection{Método das potências}

O MP tem por objetivo obter o autovalor de maior magnitude, assim como seu respectivo autovetor, de uma matriz $[Q]$, sem a necessidade de se obter o polinômio característico de [Q] (TREFETHEN; III BAU, 1997; FRANCO, 2008). Vale destacar que nesta tese, a exposição do método foi inspirada na demonstração realizada por Franco (2008), na qual se assume o caso de $[Q] \in \mathbb{R}^{N \times N}$ (espaço $N$-dimensonal de variáveis reais) com uma base de autovetores linearmente independentes. Esta consideração também é comumente feita por outros autores, tais como Demmel (1997), Trefethen e III Bau (1997) e Datta (2010). Todavia, como pode ser verificado em Golub e Van Loan (1996) e em Watkins (2010), por exemplo, é possível afirmar que os resultados aqui apresentados, bem como a aplicação do método, valem também para o caso de $[Q] \in \mathbb{C}^{N \times N}$ (espaço $N$-dimensional de variáveis complexas).

É importante ressaltar que para a ARHM o objetivo final é obtenção do autovalor de menor magnitude de $\left[Y_{h}\right] \in \mathbb{C}^{N \times N}$, assim como seu autovetor associado, conforme será adequadamente abordado mais adiante no item 4.3.2. Vale lembrar que $N$, neste caso, será igual ao número de nós elétricos do $\mathrm{SD}$ em estudo.

Diante do exposto, assume-se $[Q] \in \mathbb{C}^{N \times N}$ com uma base de autovetores linearmente independentes. Ademais, assume-se que os $N$ autovalores de $[Q]$ estejam ordenados, de modo que o autovalor a ser encontrado $\left(\lambda_{1}\right)$ possua módulo maior do que os demais autovalores. Sendo assim, $\left|\lambda_{1}\right|>\left|\lambda_{2}\right| \geq \cdots \geq\left|\lambda_{N}\right|$ (GOLUB; VAN LOAN, 1996; WATKINS, 2010).

Desde que $[Q]$ possua uma base linearmente independente de autovetores, um vetor arbitrário $y_{0} \in \mathbb{C}^{N \times 1}$ pode ser descrito conforme a equação (55).

$$
y_{0}=\sum_{j=1}^{N} c_{j} v_{j}
$$

Sendo $v_{j}$ a base de autovetores linearmente independentes da matriz $[Q]$; e $c_{j}$ constantes escalares quaisquer, com $c_{1} \neq 0$. Desse modo, $y_{0}$ será uma combinação linear da base de autovetores formada por $v_{j}$, com ao menos uma componente na direção do autovetor associado a $\lambda_{1}$. 
Partindo-se da sequência $y_{t+1}=[Q] y_{t}$, com $t=0,1,2, \cdots$, é possível escrever $y_{t}$ em termos do vetor arbitrário da equação (55) e das potências da matriz $[Q]$, conforme mostra a equação (56).

$$
\begin{gathered}
y_{1}=[Q] y_{0} \\
y_{2}=[Q] y_{1}=[Q] \cdot[Q] y_{0}=[Q]^{2} y_{0} \\
\vdots \\
y_{t}=[Q] y_{t-1}=[Q]^{t} y_{0}
\end{gathered}
$$

Expandindo-se a forma final da sequência na equação (56), e lembrando que $[Q] v_{j}=\lambda_{j} v_{j}$, reescreve-se a sequência conforme mostrado na equação (57).

$$
\begin{aligned}
y_{t} & =[Q]^{t} y_{0}=[Q]^{t} \sum_{j=1}^{N} c_{j} v_{j}=\sum_{j=1}^{N} c_{j} \lambda_{j} v_{j}= \\
& =\lambda_{1}^{t}\left[c_{1} v_{1}+c_{2}\left(\frac{\lambda_{2}}{\lambda_{1}}\right)^{t} v_{2}+\cdots+c_{N}\left(\frac{\lambda_{N}}{\lambda_{1}}\right)^{t} v_{N}\right]
\end{aligned}
$$

Uma vez que $\left|\lambda_{1}\right|>\left|\lambda_{2}\right| \geq \cdots \geq\left|\lambda_{N}\right|$, conforme assumido, por hipótese, inicialmente, tem-se que $\left|\frac{\lambda_{j}}{\lambda_{1}}\right|<1$ para $j=1,2, \cdots, N$. Sendo assim, quando $t \rightarrow \infty$, os quocientes $\left(\frac{\lambda_{j}}{\lambda_{1}}\right)^{t} \rightarrow 0$. Além disso, como pode ser verificado na equação (55), o vetor entre colchetes que multiplica $\lambda_{1}^{t}$, converge para $c_{1} v_{1}$, que é um múltiplo do autovetor associado a $\lambda_{1}$ (GOLUB; VAN LOAN, 1996; FRANCO, 2008; WATKINS, 2010).

Segundo Franco (2008), o autovalor $\lambda_{1}$ é então obtido do limite mostrado na equação (58).

$$
\lambda_{1}=\lim _{t \rightarrow \infty} \frac{\left(y_{t+1}\right)_{r}}{\left(y_{t}\right)_{r}}=\lim _{t \rightarrow \infty} \frac{\left([Q]^{t+1} y_{0}\right)_{r}}{\left([Q]^{t} y_{0}\right)_{r}}
$$

$\mathrm{Na}$ equação, $r=1,2, \cdots, N$ e indica a $r$-ésima componente de $y$. Além disso, Franco (2008) afirma também que quando $t \rightarrow \infty, y_{t}$ tende ao autovetor associado a $\lambda_{1}$. Este resultado é obtido de maneira semelhante, com variações na apresentação de sua forma final, por Golub e Van Loan (1996) e em Watkins (2010).

Para a obtenção de $\lambda_{1}$ e seu autovetor correspondente, utiliza-se, na prática, um algoritmo iterativo, que é finalizado ao atingir a precisão desejada na estimativa de $\lambda_{1}$ (FRANCO, 2008). 
O algoritmo parte de um vetor arbitrário $y_{i}$ não nulo, obtendo-se em seguida os vetores $y_{i+1}$ e $z_{i+1}$, conforme mostrado na equação (59).

$$
\begin{gathered}
z_{i+1}=[Q] y_{i} \\
y_{i+1}=\frac{1}{\alpha_{i+1}} z_{i+1}
\end{gathered}
$$

Em (59), $\alpha_{i+1}$ é o termo utilizado para normalizar o vetor $z_{i+1}$ a cada iteração. O termo $\alpha_{i+1}$ é calculado conforme a equação (60).

$$
\alpha_{i+1}=\max _{1 \leq r \leq P}\left|\left(z_{i+1}\right)_{r}\right|
$$

De acordo com o exposto por Franco (2008), a estimativa do valor de $\lambda_{1}$ será obtida pelo quociente expresso na equação (61). Além disso, no limite quando $i \rightarrow \infty$, todas as $r$-ésimas componentes do quociente da equação (61) tenderão ao valor de $\lambda_{1}$.

$$
\lambda_{1}^{(i)}=\frac{\left(z_{i+1}\right)_{r}}{\left(y_{i}\right)_{r}}
$$

Contudo, como as velocidades de convergência das $r$ componentes do quociente da equação (61) podem variar, interrompe-se o processo iterativo quando alguma componente atingir a precisão desejada (FRANCO, 2008). Logo, a aproximação final do maior autovalor de [Q] será dada por $\left(\lambda_{1}^{(i)}\right)_{r=r^{*}}$, e seu correspondente autovalor por $\left(y_{i}\right)_{r=r^{*}}$; onde $r^{*}$ é a componente em que se verificou o atendimento ao critério de parada.

O critério de parada é atingido quando o erro relativo $\varepsilon_{r e l}$ entre duas aproximações sucessivas do autovalor $\lambda_{1}$, dado pela equação (62), é menor ou igual ao erro pré-definido $(\varepsilon)$. Cabe salientar que o critério de parada é satisfeito quando ao menos uma das $r$ componentes de $\varepsilon_{r e l}$ é menor ou igual a $\varepsilon$.

$$
\varepsilon_{\text {rel }}=\frac{\left|\lambda_{1}^{(i+1)}-\lambda_{1}^{(i)}\right|_{r}}{\left|\lambda_{1}^{(i)}\right|_{r}}
$$

De fato, como inicialmente comentado, a aplicação direta do MP para a matriz de admitância $\left[Y_{h}\right]$, isto é, fazendo $[Q]=\left[Y_{h}\right]$, não permite o cálculo direto da impedância modal, uma vez que para tanto, deve-se buscar os menores autovalores de $\left[Y_{h}\right]$. Sendo assim, optou-se pelo uso do MPI, como melhor exposto na sequência. 


\subsubsection{Método da potência inversa}

O MPI pode ser interpretado como uma variação do MP, sendo capaz de fornecer o menor autovalor em módulo da matriz $[Q]$, desde que, novamente, esta possua uma base linearmente independente de autovetores. Diferentemente do MP, desta vez assume-se que $\left|\lambda_{1}\right| \geq\left|\lambda_{2}\right| \geq \cdots>\left|\lambda_{P}\right|$; sendo que $\left|\lambda_{P}\right|$ é o autovalor a ser calculado.

Uma vez que $\lambda_{j}$ é autovalor de $[Q]$, então $\lambda_{j}^{-1}$ é autovalor de $[Q]^{-1}$, ademais se $\left|\lambda_{P}\right|$ é o menor autovalor e módulo de $[Q]$, então $\left|\lambda_{P}^{-1}\right|$ é o maior autovalor em módulo de $[Q]$. Logo, o MPI consiste em se calcular o maior autovalor em módulo de $[Q]^{-1}$ através do MP, obtendo-se, portanto, o menor autovalor em módulo de [Q] (FRANCO, 2008).

Analogamente ao realizado para o MP no item 4.3.1, a partir de um vetor arbitrário $y_{i}$ não nulo, calcula-se $z_{i+1}$ e $y_{i+1}$ como mostrado na equação (63).

$$
\begin{aligned}
z_{i+1} & =[Q]^{-1} y_{i} \\
y_{i+1} & =\frac{1}{\alpha_{i+1}} z_{i+1}
\end{aligned}
$$

Sendo $\alpha_{i+1}$ calculado assim como descrito pela equação (60) no MP.

De fato, o cálculo explícito da matriz inversa $[Q]^{-1}$ não é necessário, uma vez que $Z_{i+1}$ pode ser obtido através da solução de um sistema linear, como mostrado na equação (64). O referido sistema linear pode, por exemplo, ser resolvido pela decomposição LU de $[Q]$ (FRANCO, 2008; DATTA, 2010).

$$
[Q] z_{i+1}=y_{i}
$$

A decomposição LU não será discutida neste texto, uma vez que não faz parte do escopo principal da tese. Entretanto, vale ressaltar que esta técnica de fatoração é amplamente difundida e está disponível em todas as referências citadas neste item e no item 4.3.1. Cabe ainda adiantar que para as matrizes $\left[Y_{h}\right]$, relativas aos SDs testes utilizados neste trabalho, utilizou-se o comando $[L, U]=I u(Q)$ do MATLAB $^{\circledR}$ (MATHWORKS, 2018a) para a obtenção das matrizes $[L]$ e $[U]$ da fatoração LU. Posteriormente, dispondo-se das matrizes $[L]$ e $[U]$, prossegue-se com a resolução do sistema linear mencionado.

Levando-se em consideração toda a discussão conduzida no item 4.3.1, tem-se que a aproximação do menor autovalor de $[Q]$, para a $i$-ésima iteração, é dada pela equação (65) (FRANCO, 2008). 


$$
\left.\lambda_{P}^{(i)}\right)^{-1}=\frac{\left(z_{i+1}\right)_{r}}{\left(y_{i}\right)_{r}}
$$

O critério de parada adotado para o MPI é o erro relativo entre duas aproximações sucessivas, assim como descrito pela equação (66).

$$
\varepsilon_{r e l}=\frac{\left|\lambda_{P}^{(i+1)^{-1}}-\lambda_{P}^{(i)^{-1}}\right|_{r}}{\left|\lambda_{P}^{(i)^{-1}}\right|_{r}}
$$

Diante do exposto, é possível fazer $[Q]=\left[Y_{h}\right]$, de maneira que a aproximação final da impedância modal $\left(\zeta_{h}\right)$ seja dada por $\left(\lambda_{P}^{(i)^{-1}}\right)_{r=r^{*}}$, e a do autovetor contendo a observabilidade dos nós por $\left(y_{i}\right)_{r=r^{*}}$, onde $r^{*}$ é a componente em que se verificou o atendimento ao critério de parada.

Em suma, para uma dada frequência $h$, o MPI calcula o menor autovalor em módulo de $\left[Y_{h}\right]$, que corresponde à própria impedância modal. Logo, o método fornecerá o perfil de $\zeta_{h}$, quando este for executado para todo intervalo de frequências $\left[h_{m i ́ n}, h_{m a ́ x}\right]$.

É importante destacar que, em uma condição de ressonância, $\left(y_{i}\right)_{r=r^{*}}$ será a aproximação do autovetor crítico em $\left[A_{h}\right]_{N \times N}$, isto é, conterá os graus de observabilidade de cada nó do sistema para a determinada frequência $h$, como mostra a equação (49).

\subsubsection{Considerações importantes sobre a matriz de admitâncias $\left[Y_{h}\right]$}

Embora o MPI se apresente como uma ferramenta adequada para os propósitos desta pesquisa é importante observar algumas características de $\left[Y_{h}\right]$ que eventualmente podem ser relevantes, apresentando, contudo, algumas dificuldades.

Uma dessas características se refere ao fato de $\left[Y_{h}\right]$ ser possivelmente uma matriz singular, o que inviabiliza a solução do sistema linear necessário para a estimação dos autovalores (WATKINS, 2010). Cabe salientar que na condição de ressonância, a matriz [ $\left.Y_{h}\right]$ se aproxima da singularidade. Ademais, conforme exposto por Xu et al. (2005), analisar o comportamento da $\left[Y_{h}\right]$ nestas condições pode fornecer informações úteis sobre a condição de ressonância verificada. De fato, na teoria da ARHM, a busca pelos autovalores críticos 
determina a busca pelo menor autovalor de $\left[Y_{h}\right]$ que se aproxima de zero. Logo, $\left[Y_{h}\right]$ poderá se aproximar da singularidade, mas se for singular, o MPI falha.

Outra característica de $\left[Y_{h}\right]$ indesejável, é quando esta favorecer a configuração de um sistema linear de equações mal condicionado, o que poderá comprometer a estimação dos autovalores e respectivos autovetores por erros de precisão numérica (TREFETHEN; III BAU, 1997; FRANCO, 2008; DATTA, 2010).

Para SDs radiais de grande porte, a matriz $\left[Y_{h}\right]$ tenderá a se tornar mais esparsa. Neste caso, os nós situados nos ramais que são laterais ao alimentador principal, especialmente aqueles situados ao final do ramal, implicarão em mais elementos nulos na matriz de admitância. Conforme aponta Demmel (1997), em matrizes com tal característica, a aplicação de técnicas para a resolução de sistemas lineares esparsos poderá se tornar mais apropriada, isto é, propiciando a melhoria no desempenho do algoritmo em termos de esforço computacional.

Como uma abordagem alternativa aos problemas supracitados, acredita-se que seria conveniente trabalhar somente com a matriz de impedância do sistema $\left[Z_{h}\right]$, que é a inversa da matriz de admitâncias, isto é, $\left[Y_{h}\right]^{-1}$. Em Stevenson (1986) e em Kempner (2016), por exemplo, demonstra-se que a matriz de impedâncias pode ser obtida diretamente por meio dos parâmetros do sistema elétrico e do seu diagrama unifilar, sem a necessidade da inversão da matriz de admitância $\left[Y_{h}\right]$. Dessa maneira, o MP (item 4.3.1) poderia ser executado fazendose $[Q]=\left[Z_{h}\right]$, obtendo-se assim os maiores autovalores em módulo de $\left[Z_{h}\right]$, que por sua vez serão exatamente os maiores autovalores de $\left[Y_{h}\right]^{-1}$.

Com base na discussão previamente realizada nos itens 4.3.1 e 4.3.2, verifica-se que com esta abordagem alternativa, a impedância modal $\zeta_{h}$ pode ser calculada para o intervalo $\left[h_{\text {mín }}, h_{\text {máx }}\right]$ evitando-se a necessidade do cálculo da inversa da matriz de admitâncias, calculada explicitamente ou por meio da resolução de um sistema linear (como no caso do MPI).

Além disso, a possibilidade do emprego de $\left[Z_{h}\right]$ diretamente ao MP pode ainda contornar os problemas de esparsidade mencionados. Mesmo em uma eventual esparsidade de $\left[Z_{h}\right]$, o uso do MP será adequado, uma vez que este prevê apenas multiplicações entre matriz e vetor. Dessa maneira, as entradas nulas da matriz esparsa não serão preenchidas durante o processo como um todo (DATTA, 2010). De fato, esta característica do MP está em concordância com o destacado por Demmel (1997), pois este afirma que os algoritmos 
especializados no processamento de matrizes esparsas evitam o armazenamento ou a operação em suas entradas nulas.

Tendo em vista as características topológicas dos SDs utilizados para esta pesquisa, optou-se por adotar o MPI. A obtenção da inversa de $\left[Y_{h}\right]$, é realizada por meio da resolução do sistema linear via decomposição LU, como explicado anteriormente no item 4.3.2.

Por fim, salienta-se que o estudo de algoritmos mais estáveis para a determinação dos autovalores de $\left[Y_{h}\right]$, ou ainda que sejam mais adequados para o tratamento de $\left[Y_{h}\right]$, como no caso do sistema de equações lineares associado ser mal condicionado, ou de sua esparsidade, por exemplo, devem ser objeto de estudo para a continuidade desta pesquisa de doutorado. É possível ainda que, na ocasião, decida-se considerar a investigação da viabilidade em determinar todos os autovalores de $\left[Y_{h}\right]$ e sua base de autovetores correspondentes. Com esta investigação seria possível explorar o aprimoramento da metodologia de alocação de medidores com relação à observabilidade das potenciais condições de ressonância harmônica. Embora a afirmação seguinte seja decorrente de uma análise ainda incipiente, acredita-se que um dos possíveis benefícios deste aprimoramento seria a melhor correlação entre a impedância modal (para todos os modos) e a impedância propriamente dita da rede elétrica, que, de fato, possui influência no fenômeno de amplificação da tensão na condição de ressonância. 


\section{Formulação do problema de otimização}

A "Etapa 2" da metodologia de alocação (Figura 4) inicia-se com a obtenção da Matriz de Cobertura Final (MCF), derivada da concatenação da Matriz de Cobertura das Variações de Tensão (MCVT) e da MCRH. Eventualmente, a MCF deverá ainda sofrer um redimensionamento antes do processo de otimização propriamente dito. A obtenção da MCF, bem como seu redimensionamento, estão descritos nos itens 5.1 e 5.1.1.

A “Etapa 2" encerra-se com a execução da otimização e a disponibilização ao usuário do melhor arranjo de monitores de Qualidade da Energia Elétrica (QEE) para o Sistema de Distribuição (SD) em estudo. Dessa forma, os itens 5.2 e 5.3 trazem toda a formulação do problema de otimização inteira concebido, detalhando-se as restrições (item 5.2); a função objetivo e a apresentação da forma geral do problema (item 5.3).

\subsection{Matriz de cobertura final}

Analogamente à concatenação realizada para as matrizes de cobertura (equação 40), bem como para a concatenação das matrizes de observabilidade das ressonâncias (equação 54), a MCF é obtida pela justaposição horizontal da MCVT e a Matriz de Cobertura de Ressonância Harmônica (MCRH).

Uma vez que a MCVT é uma matriz com dimensão $N \times 2 N$ (sendo $N$ o número de nós do $\mathrm{SD}$ ) e que a MCRH (Equação 54) possui dimensão $N \times F$ (sendo $F$ o número de frequências de ressonância harmônicas encontradas no intervalo $\left[h_{\text {mín }}, h_{\text {máx }}\right]$ ), a MCF possuirá dimensão $N \times M$, onde $M=2 N+F$, conforme indica a equação (67). Cabe ainda ressaltar que a MCF é uma matriz binária, já que é derivada de matrizes igualmente binárias.

$$
[M C F]_{N \times M}=\left[\begin{array}{cccccccc}
t_{1,1} & t_{1,2} & \cdots & t_{1,2 N} & w_{1,1} & w_{1,2} & \cdots & w_{1, F} \\
\vdots & \vdots & \vdots & \vdots & \vdots & \vdots & \vdots & \vdots \\
t_{N, 1} & t_{N, 2} & \cdots & t_{N, 2 N} & w_{N, 1} & w_{N, 2} & \cdots & w_{N, F}
\end{array}\right]
$$

Nesta, $t_{i, j}$ denota o elemento matricial de $[M C V T]_{N \times 2 N}$ (Equação 40); e $w_{i, j}$ denota o elemento matricial de $[M C R H]_{N \times F}$ (Equação 54).

Da maneira como a matriz $[M C F]$ é calculada, afirma-se que ela será capaz de reunir as informações de observabilidade tanto para as VTCDs como para as potenciais condições de 
ressonância harmônica. Ou seja, a concatenação de $[M C V T]$ e $[M C R H]$ (Equação 67) implicará em direcionar a solução final a encontrar um arranjo final de medidores de QEE sensíveis às VTCDs, bem como às condições de ressonância. Destaca-se ainda que a solução final da alocação priorizará os nós do SD que possam observar simultaneamente as VTCDs como as condições de ressonância harmônicas.

Cada linha $i$ da $[M C F]$ representará um nó do sistema, e cada coluna $j$ conterá a observabilidade (valor unitário do elemento $(i, j)$ de $[M C F]$ ), ou então, a não observabilidade (valor nulo do elemento $(i, j)$ de $[M C F]$ ) para as VTCDs e frequências de ressonância harmônica. Ou seja, para uma dada linha $i$ da matriz $[M C F]$, as colunas de $j=1,2, \cdots, 2 N$ contêm o status da observabilidade ( 0 ou 1) para os afundamentos e elevações de tensão. Já as colunas de $j=2 N+1,2 N+2, \cdots, 2 N+F$, contêm o status da observabilidade ( 0 ou 1) para as $F$ frequências de ressonância harmônica de todos os cenários do conjunto $C=$ $\left\{c_{1}, c_{2}, \cdots, c_{\text {máx }}\right\}$.

O item 5.2, traz uma explicação mais detalhada sobre como a observabilidade de cada linha da MCF é processada na otimização de maneira a permitir que o arranjo de monitores esteja sensível às VTCDs e às condições de ressonância.

\subsubsection{Redimensionamento da MCF}

O redimensionamento da MCF poderá ocorrer em dois casos: linhas idênticas e colunas nulas. Sendo assim, o resultado do redimensionamento será a redução das linhas e/ ou colunas de $[M C F]$, conforme explicado no que segue.

Ocasionalmente, a MCF pode apresentar linhas idênticas, indicando assim a mesma observabilidade de cada nó correspondente. Cabe relembrar que esta observabilidade é referente às VTCDs e às condições de ressonância, conforme explicado no item 5.1.

Considere, por exemplo, que a primeira, segunda e quarta linhas da matriz $[M C F]$ sejam idênticas, indicando que os nós 1, 2 e 4 de um SD hipotético possuem a mesma observabilidade. Neste caso, um monitor de QEE instalado no nó 1, por exemplo, será capaz de monitorar exatamente as mesmas ocorrências de VTCDs e das potenciais frequências de ressonância harmônica que um monitor instalado no nó 2 ou nó 4 . Sendo assim, é suficiente a inclusão de apenas uma das três linhas repetidas de $[M C F]$ no processo de otimização.

Diante do exposto, o redimensionamento de $[M C F]$ em relação às linhas consiste em eliminar todas as linhas idênticas e conservar apenas uma delas para o processo de 
otimização. Todavia, assim como proposto por Kempner (2006), as posições das linhas eliminadas são armazenadas, permitindo a posterior disponibilização ao usuário dos nós equivalentes de instalação. A existência desses nós equivalentes no arranjo final de medidores de QEE pode oferecer à concessionária flexibilidade para instalar, por exemplo, o medidor em um local (nó) mais acessível e/ ou conveniente, em detrimento de seu equivalente que foi originalmente apresentado na solução final de alocação.

Dessa maneira, após o redimensionamento das linhas, a MCF torna-se uma matriz de dimensão $N^{\prime} \times M, \operatorname{com} N^{\prime}<N$.

O redimensionamento da MCF ainda continua quando nesta são verificadas colunas nulas. Neste caso, estas colunas são eliminadas, já que não fornecem informações relevantes para o processo de otimização. De fato, uma coluna nula da MCF denota a não verificação de quaisquer VTCDs para os casos de curtos-circuitos considerados pelo Método de Posição de Faltas (MPF), indicando que para todas as situações a tensão remanescente permaneceu dentro dos valores nominais.

Afirma-se ainda que a possibilidade de ocorrência de colunas nulas na MCF se dará somente para as colunas de $j=1,2, \cdots, 2 N$; uma vez que tais colunas são provenientes da MCVT. As demais colunas da MCF jamais serão nulas, uma vez que são formadas pelos autovetores direitos normalizados, conforme anteriormente explicado ao longo do item 4.3 do capítulo 4.

Cabe salientar que o armazenamento das posições referentes às colunas nulas eliminadas não é necessário, já que somente as linhas da MCF representam as posições de instalação dos medidores de QEE.

Logo, após a exclusão das colunas nulas, a MCF torna-se, finalmente, uma matriz com dimensão $N^{\prime} \times M^{\prime}$, sendo $M^{\prime}<M=2 N+F$. É importante salientar que se nenhum redimensionamento das linhas for executado, tem-se que $N^{\prime}=N$; e se nenhum redimensionamento das colunas for realizado, tem-se que $M^{\prime}=M$.

\subsection{Restrições do problema de otimização}

Considere o sistema elétrico de distribuição radial da Figura 12, em cujos nós serão instalados um ou mais medidores de QEE com o objetivo de realizar um plano de monitoramento. Salienta-se que este conjunto de monitores será capaz de considerar a observabilidade tanto das VTCDs como das potenciais condições de ressonância harmônica. 
Figura 12 - SD hipotético de 4 nós.

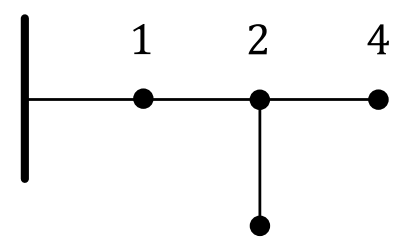

3

Como pode ser constatado, o sistema de distribuição exemplificado possui quatro nós que são potenciais locais de instalação dos monitores de QEE.

A instalação de um medidor de QEE em um determinado nó do SD é representada pelo valor unitário do respectivo elemento em um vetor $[X]_{N^{\prime} \times 1}=\left[x_{1}, x_{2}, \cdots, x_{N^{\prime}}\right]^{T}$. Complementarmente, os valores nulos indicam a ausência de medidor de QEE. Este vetor é chamado de vetor de alocação e contém as variáveis de decisão do problema de otimização linear inteira. É válido relembrar que se não forem encontradas linhas idênticas no processo de redimensionamento da MCF então $N^{\prime}=N$.

$\mathrm{O}$ vetor resultante do produto matricial entre a matriz $[M C F]^{T}$ e o vetor de alocação $[X]$, conforme mostra a equação (68), indicará quantos monitores de QEE serão sensibilizados pelas VTCDs, determinadas pelo MPF, e também pelas potenciais condições de ressonância, calculadas pela Análise de Ressonância Harmônica Modal (ARHM). Este vetor possuirá dimensão $M^{\prime} \times 1$, e será denotado por $[R]=\left[r_{1}, r_{2}, \cdots, r_{M^{\prime}}\right]^{T}$.

$$
[R]=[M C F]^{T}[X]
$$

De maneira a melhor ilustrar a contabilização que o vetor $[R]$ registra, considere uma MCF hipotética $\left([M C F]^{*}\right)$ do SD exemplo da Figura 12, representada na equação (69), e um vetor de alocação $[X]^{*}=[0,0,1,1]^{T}$.

$$
[M C F]^{*}=\left(\begin{array}{cccccccc|cc}
1 & 0 & 0 & 0 & 0 & 0 & 0 & 0 & 0 & 0 \\
1 & 1 & 1 & 0 & 0 & 1 & 0 & 0 & 1 & 0 \\
1 & 1 & 1 & 1 & 1 & 0 & 1 & 1 & 0 & 1 \\
1 & 1 & 0 & 1 & 0 & 0 & 0 & 0 & 0 & 0
\end{array}\right)
$$

Cabe salientar que a barra separadora presente na matriz $[M C F]^{*}$ indica a parcela referente a uma MCVT hipotética (elementos de matriz à esquerda da barra separadora) e a uma MCRH também hipotética (elementos de matriz à direita da barra separadora). Também é importante destacar que devido à formação da MCVT (equação 40) as colunas $j=1,2,3 \mathrm{e}$ 
4 são referentes ao registro dos afundamentos de tensão, e as colunas $j=5,6,7$ e 8 são referentes ao registro das elevações de tensão. Por fim, as duas últimas colunas $j=9$ e 10 registram a observabilidade das condições de ressonância harmônica, sendo que neste caso, $F=2$. Este entendimento é importante para a discussão que segue.

Aplicando-se a equação (68) com $[M C F]_{4 \times 10}^{*}$ e $[X]_{1 \times 4}^{*}$, tem-se que $[R]_{1 \times 10}=$ $[2,2,1,2,1,0,1,1,0,1]^{T}$. Como é possível observar, o elemento $r_{1}=2$ do vetor $[R]$, por exemplo, informa que ambos os monitores de $[X]^{*}$ (instalados nos nós 3 e 4) são sensibilizados. Uma vez que o elemento $r_{1}=2$ é resultante da multiplicação da primeira linha de $[M C F]^{* T}$ com o vetor $[X]^{*}$, verifica-se que os referidos monitores foram sensibilizados pelos afundamentos de tensão causados pelo curto-circuito aplicado ao nó 1 .

Em contrapartida, o elemento $r_{5}=1$ no vetor $[R]$, por exemplo, indica que apenas um dos monitores de $[X]^{*}$ é sensibilizado. Por este resultado, e inspecionando-se a multiplicação da quinta linha da $[M C F]^{* T}$ com o vetor $[X]^{*}$, constata-se que o monitor instalado no nó 3 é sensibilizado por uma condição de elevação de tensão decorrente da aplicação de um curto-circuito no nó 1 . Cabe ressaltar que as colunas 1 e 5 da matriz $[M C F]^{*}$ estão relacionadas, respectivamente, aos afundamentos e elevações de tensão (VTCDs) devido à aplicação de curtos-circuitos no nó 1 do SD hipotético da Figura 12.

Se considerarmos agora o exemplo da aplicação das situações de curtos-circuitos no nó 2 do SD (registros das VTCDs nas colunas 2 e 6 de $[M C F]^{*}$ ), ambos os monitores instalados nos nós 3 e 4 serão sensibilizados pelos afundamentos de tensão (elemento $r_{2}=2$ no vetor $[R])$. Contudo, nenhum dos monitores instalados estará detectando a ocorrência da situação de elevação de tensão (elemento $r_{6}=0$ no vetor $[R]$ ) que é manifestada no nó 2 do SD hipotético da Figura 12. Vale comentar que a coluna 6 de $[M C F]^{*}$ contém o registro da ocorrência da referida elevação de tensão no 2 que não é monitorada.

Referente à observabilidade das frequências de ressonância harmônica, o resultado do vetor $[R]$ revela que o arranjo de monitores, denotados pelo vetor de alocação $[X]^{*}$, estará preparado para monitorar apenas uma das frequências de ressonância harmônica, sendo esta detectada apenas pelo monitor instalado no nó 3 (elemento $r_{9}=1$ no vetor $[R]$ ). De fato, o monitor instalado no nó 4 não estará sensível para a condição de ressonância evidenciada na coluna $j=9$ da matriz $[M C F]^{*}$, assim como confirma o vetor $[R]\left(\right.$ elemento $r_{9}=0$ ).

Considere agora, um novo arranjo de monitores, representado pelo vetor de alocação $[X]^{\dagger}=[0,1,1,0] . \quad \mathrm{O}$ produto matricial de $[M C F]^{* T}$ com $[X]^{\dagger}$ resultará em $[R]=[2,2,2,1,1,1,1,1,1]^{T}$, do qual é possível observar que nenhuma de suas componentes 
é nula, implicando assim na completa observabilidade das situações de VTCDs e potenciais condições de ressonância registradas na matriz $[M C F]^{*}$.

Diante do exposto, constata-se que a condição para se obter a completa observabilidade das VTCDs e das potenciais condições de ressonância, é a de que todos os elementos de $[R]$ devam ser maiores ou iguais a 1, isto é, não podem ser nulos. Esta restrição implica que ao menos um dos monitores do arranjo será sensibilizado para as VTCDs e as potenciais condições de ressonância consideradas.

Sendo assim, as $M^{\prime}$ restrições do problema de otimização podem ser escritas conforme mostra a equação (70). Nesta equação, $[M C F]_{i, j}$ refere-se ao elemento $(i, j)$ de $[M C F]$.

$$
\left\{\begin{array}{cl}
x_{1} \cdot[M C F]_{1,1}+x_{2} \cdot[M C F]_{2,1}+\cdots+x_{N^{\prime}}[M C F]_{N^{\prime}, 1} & \geq 1 \\
x_{1} \cdot[M C F]_{1,2}+x_{2} \cdot[M C F]_{2,2}+\cdots+x_{N^{\prime}}[M C F]_{N^{\prime}, 2} & \geq 1 \\
\vdots & \vdots \\
x_{1} \cdot[M C F]_{1, M^{\prime}}+x_{2} \cdot[M C F]_{2, M^{\prime}}+\cdots+x_{N^{\prime}}[M C F]_{N^{\prime}, M^{\prime}} & \geq 1
\end{array}\right.
$$

\subsection{Função objetivo e forma geral do problema de otimização}

Simultaneamente à condição de completa observabilidade aos distúrbios mencionados, é desejável que o monitoramento seja feito pela menor quantidade possível de monitores de QEE. Ou seja, o processo de otimização deverá minimizar a quantidade de monitores, disponibilizando assim uma solução com a menor quantidade admissível de monitores de QEE que garanta a completa observabilidade das VTCDs e das potenciais condições de ressonância harmônica.

Neste contexto, a função objetivo $f([X])$ do problema de otimização foi formulada como sendo a soma das posições do vetor de alocação binário $[X]_{N^{\prime} \times 1}$, conforme mostra a equação (71).

$$
f([X])=\sum_{i=1}^{N^{\prime}} x_{i}
$$

Finalmente, o problema de otimização linear inteira é apresentado em sua forma geral na equação (72). 


$$
\begin{array}{ll}
\text { Minimize } & f([X])=\sum_{i=1}^{N^{\prime}} x_{i} \\
\text { sujeito a } \begin{cases}x_{1} \cdot[M C F]_{1,1}+x_{2} \cdot[M C F]_{2,1}+\cdots+x_{N^{\prime}}[M C F]_{N^{\prime}, 1} & \geq 1 \\
x_{1} \cdot[M C F]_{1,2}+x_{2} \cdot[M C F]_{2,2}+\cdots+x_{N^{\prime}}[M C F]_{N^{\prime}, 2} & \geq 1 \\
\vdots & \vdots \\
x_{1} \cdot[M C F]_{1, M^{\prime}}+x_{2} \cdot[M C F]_{2, M^{\prime}}+\cdots+x_{N^{\prime}}[M C F]_{N^{\prime}, M^{\prime}} & \geq 1 \\
x_{i} \in \Omega=\{0,1\} & \\
i=1,2, \cdots, N^{\prime}\end{cases}
\end{array}
$$

Sendo $\Omega$ o conjunto de valores binários que determina a restrição de integralidade para as variáveis de decisão $x_{i}$.

Nesta pesquisa, para a resolução do problema de Programação Linear Inteira (PLI) enunciado na equação (72), foi utilizado o toolbox de otimização do MATLAB ${ }^{\circledR}$ (MATHWORKS, 2018b). A partir deste toolbox, utilizou-se a função "intlinprog", que consiste em um algoritmo de PLI baseado no algoritmo B\&B. Vale comentar que a função "intlinprog" foi adequadamente definida para a resolução do PLI caracterizado, uma vez que esta também pode ser utilizada para a resolução de programação linear inteira mista. 


\section{Resultados}

Neste capítulo, serão apresentados os dois sistemas elétricos (itens 6.1 e 6.2) utilizados para a aplicação e teste da metodologia proposta para a alocação de medidores de Qualidade da Energia Elétrica (QEE). Toda a metodologia foi inicialmente desenvolvida a partir do Sistema de Distribuição (SD) do item 6.1 e, posteriormente, aplicada ao SD apresentado no item 6.2, de modo a verificar a aplicabilidade do método em um sistema maior e com características distintas.

Os resultados obtidos para a alocação dos monitores de QEE para ambos os sistemas serão apresentados nos itens 6.1.1 e 6.2.1.

\subsection{Sistema de 15 nós}

O SD de 15 nós é um sistema baseado em uma rede de distribuição de média tensão do CIGRÉ (Conseil International des Grands Réseaux Électriques) (RUDION et al., 2006; CONSEIL INTERNATIONAL DES GRANDS RÉSEAUX ÉLECTRIQUES, 2014) e adaptado do trabalho de Denoel (2016). A configuração original do SD do CIGRÉ foi desenvolvida com o objetivo de permitir que fossem conduzidos estudos sobre o impacto da geração distribuída em redes de média tensão (RUDION et al. 2006).

$\mathrm{O}$ sistema adaptado para esta pesquisa consiste em uma rede de média tensão $20 \mathrm{kV}$ com dois alimentadores principais e 15 nós. A Figura 13 mostra o diagrama unifilar deste SD.

Figura 13 - Sistema de distribuição teste de 15 nós.

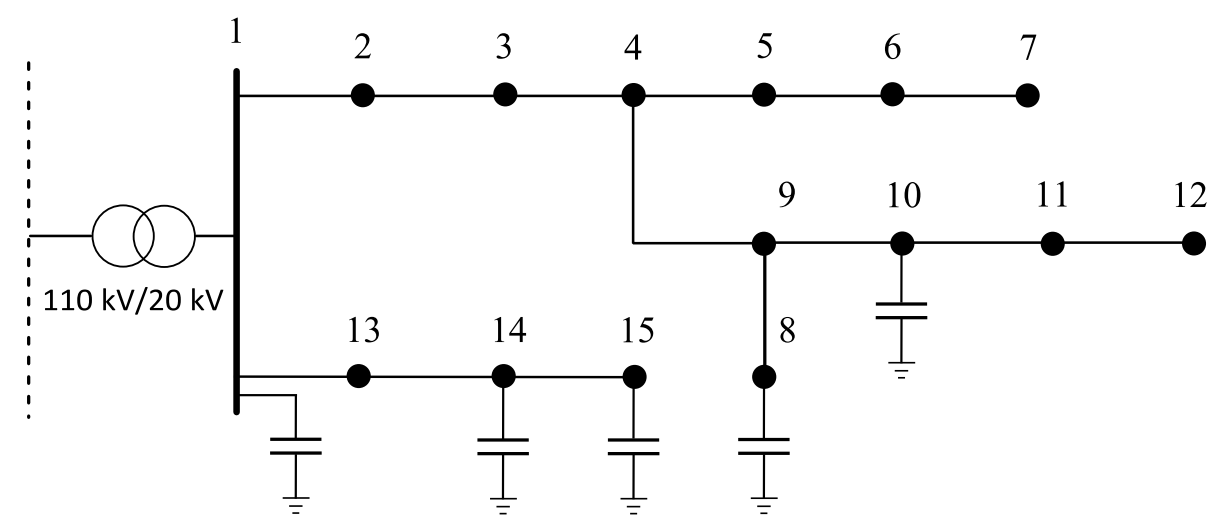

A subestação do SD contém um transformador de potência que o conecta à rede de alta tensão de $110 \mathrm{kV}$ (CONSEIL INTERNATIONAL DES GRANDS RÉSEAUX 
ÉLECTRIQUES, 2014). A potência nominal atribuída ao transformador é de $36 M V A$ e o mesmo possui reatância $X=17 \%$ (DENOEL, 2016), que foi modelada como uma reatância puramente indutiva (referenciada ao lado de baixa). Ademais, considerou-se que a barra de referência do SD é um barramento infinito.

Nesta pesquisa, assume-se que o SD de 15 nós é um sistema trifásico transposto e perfeitamente balanceado, operando com a frequência nominal fundamental de $50 \mathrm{~Hz}$ (frequência fundamental adotada pelo padrão europeu). Os parâmetros das cargas e das linhas estão apresentados nas tabelas do Anexo A deste documento. Cabe salientar que para o Método de Posição de Faltas (MPF) (capítulo 3) serão utilizadas somente as impedâncias de sequência, sendo que as admitâncias shunt não são previstas no modelo. Além disso, para o MPF considerou-se também que a impedância de sequencia positiva é igual à impedância de sequência negativa (KERSTING, 2002).

Por sua vez, a Análise de Ressonância Harmônica Modal (ARHM) (capítulo 4) emprega somente os parâmetros de sequência positiva, já que considera o sistema transposto e balanceado, e não prevê a análise de condições assimétricas, como os curtos-circuitos analisados no MPF. Destaca-se ainda a inclusão da susceptância de sequência positiva (B1) na análise, que é necessária para o adequado cálculo das frequências de ressonância harmônica. Embora a susceptância de sequência zero (B0) também esteja apresentada na tabela dos parâmetros das linhas (Anexo A), afirma-se que ela não é utilizada pela metodologia de alocação, sendo sua apresentação somente para fins de registro e referência futura.

Para a modelagem das cargas utilizou-se o modelo do tipo 2 (carga $R L$ em paralelo) (Burch et al. 2003). Como mencionado por Burch et al. (2003), este modelo de carga, apesar de sua simplicidade, constitui uma boa aproximação para estudos referentes às distorções harmônicas. Além disso, de acordo com Xu (2001), este modelo se apresenta como adequado quando o objetivo do estudo é o de verificar as características da resposta em frequência da impedância equivalente, impedância esta representativa da carga em estudo. Cabe ressaltar ainda que a opção por este modelo também foi motivada pelo fato de que normalmente as concessionárias de energia não possuem informações mais detalhadas sobre as cargas dos clientes, sendo mais comum a disponibilidade no banco de dados dos valores de potência ativa e reativa das cargas. Verifica-se também a aplicação deste modelo de carga em distintos estudos harmônicos recentes, bem como as discussões correlatas sobre possíveis impactos do modelo utilizado nos referidos estudos (BARAKOU et al. 2016; EGGENSCHWILER et al. 2017; VIEIRA et al. 2018; AMINI, JALILIAN, BEHBAHANI, 2019). 
A Figura 14 mostra o modelo de carga do tipo 2. Nesta figura, $R=U_{L L}^{2} / P$ e $X=$ $U_{L L}^{2} / Q$, sendo: $U_{L L}^{2}$ a tensão de linha; $P$ a potência ativa; $Q$ a potência reativa; e $n$ a ordem harmônica.

Figura 14 - Modelo de carga utilizado (modelo tipo 2) com a resistência $\boldsymbol{R}$, reatância capacitiva $\boldsymbol{X}$, e ordem harmônica $\boldsymbol{n}$ evidenciadas.

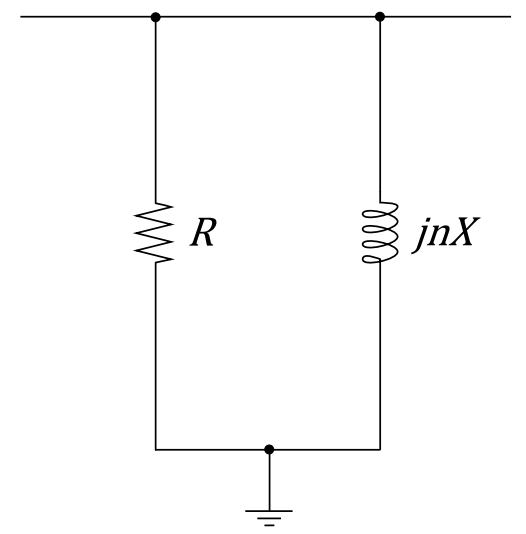

Fonte: Burch et al. (2003).

Salienta-se também que a metodologia proposta, assim como a ARHM, tem como objetivo detectar frequências de ressonância paralela. Sendo assim, quaisquer modificações no modelo de carga, desde que este seja um modelo linear, deve refletir diretamente na admitância em derivação equivalente na matriz de admitâncias $\left[Y_{h}\right]$. Isto é, a admitância em derivação do novo modelo de carga deve ser adicionada ao respectivo elemento matricial, localizado na diagonal da matriz de admitâncias do sistema $\left[Y_{h}\right]$.

As linhas aéreas e cabos subterrâneos foram modelados utilizando-se o modelo $\pi$ equivalente para linhas longas (Figura 15a). Neste modelo, tem-se incorporado o efeito para linhas longas, e seus parâmetros podem ser obtidos dos parâmetros do modelo $\pi$ - nominal (Figura 15b). Esta abordagem é necessária para uma representação mais exata do comportamento das linhas e cabos em altas frequências, já que o intuito desta pesquisa é o de analisar o SD em potenciais condições de ressonância (XU, 2001; ARRILLAGA e WATSON, 2003).

No modelo $\pi$-nominal da Figura $15 \mathrm{~b}, Z=\left(R+j n \omega_{f} L\right) l$ e $Y=\left(j n \omega_{f} C\right) l / 2$; sendo $n$ a ordem harmônica; $\omega_{f}$ a frequência fundamental do sistema; $R, L$ e $C$ a resistência, indutância e capacitância shunt da linha/cabo por unidade de comprimento; e $l$ o comprimento do cabo. Dessa forma, os parâmetros do modelo $\pi$ equivalente, isto é, $Z_{E q}$ e $Y_{E q}$, são obtidos pelas equações (73) e (74). 
Figura 15 - Modelo $\boldsymbol{\pi}$ - nominal (a), e modelo $\boldsymbol{\pi}$ equivalente (b).

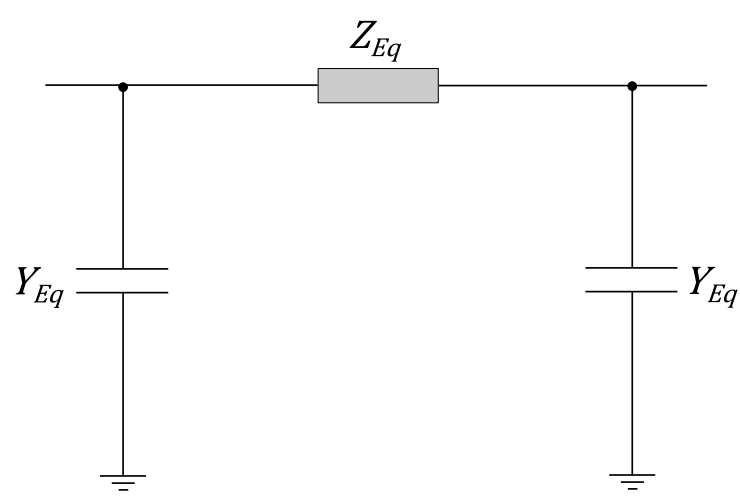

(a)

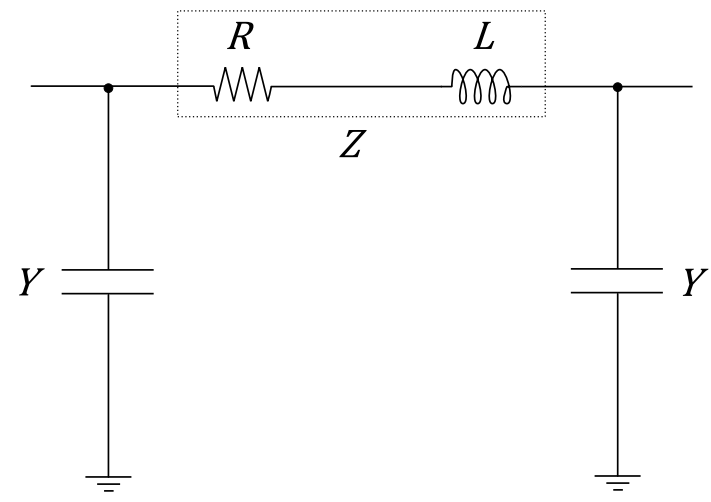

(b)

Fonte: Adaptado de Xu (2001).

$$
\begin{gathered}
Z_{E q}=Z \frac{\operatorname{senh}(\alpha)}{\alpha} \\
Y_{E q}=Y \frac{\tanh (\alpha / 2)}{(\alpha / 2)}
\end{gathered}
$$

Nestas equações, $\alpha=\sqrt{2 Z Y}$. Cabe ainda destacar que em ambos os modelos as respectivas admitâncias shunt por unidade de comprimento das linhas são divididas igualmente em cada um dos ramos laterais, já que se definiu anteriormente $Y=\left(j n \omega_{f} C\right) l / 2$.

Ainda com relação à modelagem do SD, afirma-se que alimentadores adicionais, atendidos pelo mesmo transformador da subestação, foram representados pela carga conectada ao nó 1. Esta simplificação, portanto, não permite a aplicação da ARHM em tais alimentadores. Entretanto, contribui com uma melhor caracterização do carregamento do SD como um todo.

O SD de 15 nós, contém 5 bancos de capacitores locais, responsáveis pelo melhoramento do FP. As posições destes bancos de capacitores encontram-se evidenciadas na Figura 13 e especificadas na Tabela 1, assim como as respectivas potências nominais e valores de capacitância. Os valores de potência e capacitância destes bancos de capacitores foram calculados para se elevar o FP das cargas até 0,92 .

Conforme anteriormente explicado no item 4.2 do Capítulo 4, para a obtenção da Matriz de Cobertura de Ressonância Harmônica (MCRH) são considerados distintos cenários de conexão dos bancos de capacitores na ARHM. Dessa forma, os cinco bancos de capacitores alocados no SD de 15 nós formarão o conjunto $C$ de distintos cenários. Para este 
conjunto será considerada a variação de estado de conexão de apenas quatro $(m=4)$ dos cinco capacitores apresentados, pois o banco de capacitor da subestação permanecerá fixo durante toda a análise. Sendo assim, o conjunto $C$ possuirá $2^{4}=16$ elementos, conforme mostra a Tabela 2.

Tabela 1 - Nós de instalação, capacitância e potência reativa trifásica nominal dos bancos de capacitores.

\begin{tabular}{ccc}
\hline Nós & $\begin{array}{c}\text { Capacitância } \\
(\mu F)\end{array}$ & $\begin{array}{c}\text { Potência } \\
(k V A r)\end{array}$ \\
\hline 1 & 14,04 & $1.764,7$ \\
8 & 0,14 & 17,6 \\
10 & 1,03 & 129,1 \\
14 & 0,06 & 7,4 \\
15 & 0,36 & 44,8 \\
\hline
\end{tabular}

Tabela 2 - Cenários de bancos de capacitores do conjunto $\boldsymbol{C}$ para o sistema de 15 nós.

\begin{tabular}{cc}
\hline $\begin{array}{c}\text { Cenário } \\
\left(c_{i}\right)\end{array}$ & $\begin{array}{c}\text { Bancos conectados } \\
\text { (nós) }\end{array}$ \\
\hline 1 & 1 \\
2 & $1 ; 8$ \\
3 & $1 ; 10$ \\
4 & $1 ; 14$ \\
5 & $1 ; 15$ \\
6 & $1 ; 8 ; 10$ \\
7 & $1 ; 8 ; 14$ \\
8 & $1 ; 8 ; 15$ \\
9 & $1 ; 10 ; 14$ \\
10 & $1 ; 10 ; 15$ \\
11 & $1 ; 14 ; 15$ \\
12 & $1 ; 8 ; 10 ; 14$ \\
13 & $1 ; 8 ; 10 ; 15$ \\
14 & $1 ; 8 ; 14 ; 15$ \\
15 & $1 ; 10 ; 14 ; 15$ \\
16 & $1 ; 8 ; 10 ; 14 ; 15$ \\
\hline
\end{tabular}

\subsubsection{Resultados para o SD de 15 nós}

No item 6.1.1.1 as soluções de alocação final obtida pela aplicação da metodologia proposta são apresentadas e analisadas.

Com o intuito de melhor detalhar a análise das soluções de alocação da metodologia, optou-se por também analisar separadamente a influência das matrizes Matriz de Cobertura das Variações de Tensão (MCVT) e MCRH na alocação final obtida via Matriz de Cobertura 
Final (MCF). Sendo assim, as soluções de alocação obtidas para a cobertura das VTCDs (obtidas via MCVT), e das condições de ressonância (obtidas via MCRH), são apresentadas e analisadas, separadamente, nos item 6.1.1.2 e 6.1.1.3, respectivamente. É importante destacar que esta análise foi possível uma vez que o MPF e a ARHM são executadas de forma independente (Figura 4).

$\mathrm{Na}$ sequência, no item 6.1.1.4, é feita uma breve análise comparativa entre as frequências de ressonância obtidas pela ARMH e pela varredura em frequência (item 1.3) para o cenário 16 do conjunto $C$ quando todos os bancos de capacitores utilizados para corrigir o FP estão conectados (Tabela 2). Este estudo tem como objetivo ilustrar como se validou os valores das frequências determinados pela ARHM. Nesta análise, pretende-se ainda ressaltar as dificuldades em se determinar os graus de observabilidade das condições de ressonância pelo método da varredura em frequência.

Por fim, no item 6.1.1.5, avalia-se a sensibilidade da solução de alocação obtida frente à variabilidade das potências dos bancos de capacitores utilizados para a correção do fator de potência. Esta avaliação foi conduzida somente para as soluções da alocação obtidas do ponto de vista das condições de ressonância harmônica (soluções obtidas via MCRH), já que distintas potências dos referidos bancos de capacitores podem acarretar diferentes condições de ressonância. Todavia, como será melhor exposto ao longo deste item, as conclusões poderão ser estendidas para a solução da alocação final que contempla tanto as VTCDs como as condições de ressonância.

\subsubsection{Análise da solução de alocação final}

A metodologia de alocação dos medidores de QEE foi executada seguindo todo o procedimento descrito nos capítulos anteriores. O MPF foi aplicado seguindo-se as mesmas condições descritas no capítulo 3 para a derivação das expressões das MTDFs.

Com relação à ARHM, todas as 16 combinações dos bancos de capacitores (Tabela 2) foram consideradas, sendo que a análise foi feita de $50 \mathrm{~Hz}\left(h_{\text {mín }}\right)$ até $6,4 \mathrm{kHz}\left(h_{\text {máx }}\right)$. Estas condições de avaliação para a ARHM foram escolhidas de maneira a realizar uma ampla investigação do SD no que se refere às potenciais condições de ressonância que possam ser encontradas.

Cabe salientar que, recentemente, tem-se reportado a preocupação em se estudar uma maior faixa de frequências (supraharmônicos) (BOLLEN et al., 2014; ELPHICK et al. 2017), 
essencialmente em função da crescente introdução de dispositivos que são fontes de distorção harmônica de alta frequência. Desse modo, o limite superior do intervalo de frequências harmônicas $\left(h_{m a ́ x}\right)$ foi definido para $6,4 \mathrm{kHz}$, valor este referente à máxima frequência admissível a ser medida por um medidor de QEE típico com taxa de amostragem de 256 amostras/ciclo.

Conforme já comentado nos capítulos 3 e 4, as soluções de alocação fornecidas pela metodologia são dependentes da definição dos limiares de tensão $\left(\delta_{\text {inf }}\right.$ e $\left.\delta_{\text {sup }}\right)$ e do limiar que define o estado de detecção das frequências de ressonância $(\tau)$. Sendo assim, explorou-se a resposta da metodologia de alocação em função destes três parâmetros, conforme mostram a Tabela 3 e a Tabela 4. Nestas tabelas, para cada valor dos limiares, tem-se a solução de alocação e os respectivos nós equivalentes (discriminados entre chaves).

Tabela 3 - Soluções de alocação e nós equivalentes para $\boldsymbol{\tau}$ variando de 1,0 a 0,$5 ; \boldsymbol{\delta}_{\text {sup }}$ de 1,1 p.u. a 1,2 p.u. e $\boldsymbol{\delta}_{\text {inf }}$ de 0,9 p.u. a 0,5 p.u..

\begin{tabular}{|c|c|c|c|c|c|c|c|c|c|}
\hline$\tau$ & $\begin{array}{l}\delta_{\text {sup }} \\
\text { (p.u.) }\end{array}$ & $\begin{array}{c}\delta_{i n f} \\
\text { (p.u.) }\end{array}$ & $\begin{array}{c}\text { Alocação } \\
\text { (nós) }\end{array}$ & $\begin{array}{c}\text { Nós } \\
\text { equivalentes }\end{array}$ & $\tau$ & $\begin{array}{l}\delta_{\text {sup }} \\
\text { (p.u.) }\end{array}$ & $\begin{array}{c}\delta_{i n f} \\
\text { (p.u.) }\end{array}$ & $\begin{array}{c}\text { Alocação } \\
\text { (nós) }\end{array}$ & $\begin{array}{c}\text { Nós } \\
\text { equivalentes }\end{array}$ \\
\hline \multirow{10}{*}{1,0} & \multirow{5}{*}{1,1} & 0,9 & \multirow{5}{*}{$3 ; 8 ; 12 ; 15$} & \multirow{5}{*}{ - } & \multirow{10}{*}{0,7} & \multirow{5}{*}{1,1} & 0,9 & \multirow{5}{*}{$12 ; 15$} & \multirow{5}{*}{$\begin{array}{c}12\{8,10,11\} \\
15\{14\}\end{array}$} \\
\hline & & 0,8 & & & & & 0,8 & & \\
\hline & & 0,7 & & & & & 0,7 & & \\
\hline & & 0,6 & & & & & 0,6 & & \\
\hline & & 0,5 & & & & & 0,5 & & \\
\hline & \multirow{5}{*}{1,2} & 0,9 & \multirow{5}{*}{$3 ; 8 ; 12 ; 15$} & \multirow{5}{*}{ - } & & \multirow{5}{*}{1,2} & 0,9 & \multirow{5}{*}{$12 ; 15$} & \multirow{5}{*}{$\begin{array}{c}12\{8,10,11\} \\
15\{14\}\end{array}$} \\
\hline & & 0,8 & & & & & 0,8 & & \\
\hline & & 0,7 & & & & & 0,7 & & \\
\hline & & 0,6 & & & & & 0,6 & & \\
\hline & & 0,5 & & & & & 0,5 & & \\
\hline \multirow{10}{*}{0,9} & \multirow{5}{*}{1,1} & 0,9 & \multirow{5}{*}{$8 ; 12 ; 15$} & \multirow{5}{*}{$12\{11\}$} & \multirow{10}{*}{0,6} & \multirow{5}{*}{1,1} & 0,9 & \multirow{5}{*}{$12 ; 15$} & \multirow{5}{*}{$\begin{array}{c}12\{8,9,10,11\} \\
15\{14\}\end{array}$} \\
\hline & & 0,8 & & & & & 0,8 & & \\
\hline & & 0,7 & & & & & 0,7 & & \\
\hline & & 0,6 & & & & & 0,6 & & \\
\hline & & 0,5 & & & & & 0,5 & & \\
\hline & \multirow{5}{*}{1,2} & 0,9 & \multirow{5}{*}{$8 ; 12 ; 15$} & \multirow{5}{*}{$12\{11\}$} & & \multirow{5}{*}{1,2} & 0,9 & \multirow{5}{*}{$12 ; 15$} & \multirow{5}{*}{$\begin{array}{c}12\{8,9,10,11\} \\
15\{14\}\end{array}$} \\
\hline & & 0,8 & & & & & 0,8 & & \\
\hline & & 0,7 & & & & & 0,7 & & \\
\hline & & 0,6 & & & & & 0,6 & & \\
\hline & & 0,5 & & & & & 0,5 & & \\
\hline \multirow{10}{*}{0,8} & & 0,9 & & & & & 0,9 & & \\
\hline & 11 & 0,8 & & & & & 0,8 & & \\
\hline & 1,1 & 0,7 & $12 ; 15$ & $\begin{array}{c}12\{8,11\} \\
15\{14\}\end{array}$ & & 1,1 & 0,7 & $12 ; 15$ & $12\left\{\begin{array}{l}12,9,11,11\} \\
15\{14\}\end{array}\right.$ \\
\hline & & 0,6 & & & & & 0,6 & & \\
\hline & & 0,5 & & & 05 & & 0,5 & & \\
\hline & & 0,9 & & & 0,3 & & 0,9 & & \\
\hline & 12 & 0,8 & & & & 12 & 0,8 & & \\
\hline & 1,2 & 0,7 & $12 ; 15$ & $\begin{array}{c}12\{8,11\} \\
15\{14\}\end{array}$ & & 1,2 & 0,7 & $12 ; 15$ & $12\{0,9,14,11\}$ \\
\hline & & 0,6 & & & & & 0,6 & & \\
\hline & & 0,5 & & & & & 0,5 & & \\
\hline
\end{tabular}


Conforme é possível observar na Tabela 3 e na Tabela 4, para o SD de 15 nós, a variação dos limiares de tensão, tanto superior como o inferior, não exerceram influência na solução de alocação final, já que nenhuma variação entre as soluções foi observada como mostram a quarta e nona coluna das referidas tabelas.

Tabela 4 - Soluções de alocação e nós equivalentes para $\boldsymbol{\tau}$ variando de 0,4 p.u. a 0,1 p.u.; $\boldsymbol{\delta}_{\text {sup }}$ de 1,1 p.u. a 1,2 p.u. e $\boldsymbol{\delta}_{\text {inf }}$ de 0,9 a $0,5$.

\begin{tabular}{|c|c|c|c|c|c|c|c|c|c|}
\hline$\tau$ & $\begin{array}{l}\delta_{\text {sup }} \\
\text { (p.u.) }\end{array}$ & $\begin{array}{l}\delta_{\text {inf }} \\
\text { (p.u.) }\end{array}$ & $\begin{array}{l}\text { Alocação } \\
\text { (nós) }\end{array}$ & $\begin{array}{c}\text { Nós } \\
\text { equivalentes }\end{array}$ & $\tau$ & $\begin{array}{l}\delta_{\text {sup }} \\
\text { (p.u.) }\end{array}$ & $\begin{array}{l}\delta_{\text {inf }} \\
\text { (p.u.) }\end{array}$ & $\begin{array}{l}\text { Alocação } \\
\text { (nós) }\end{array}$ & $\begin{array}{c}\text { Nós } \\
\text { equivalentes }\end{array}$ \\
\hline \multirow{10}{*}{0,4} & \multirow{5}{*}{1,1} & 0,9 & \multirow{5}{*}{$12 ; 15$} & \multirow{5}{*}{$\begin{array}{c}12\{8,9,10,11\} \\
15\{14\}\end{array}$} & \multirow{10}{*}{0,2} & \multirow{5}{*}{1,1} & 0,9 & \multirow{5}{*}{$12 ; 15$} & \multirow{5}{*}{$\begin{array}{c}12\{7,8,9,10,11\} \\
15\{14\}\end{array}$} \\
\hline & & 0,8 & & & & & 0,8 & & \\
\hline & & 0,7 & & & & & 0,7 & & \\
\hline & & 0,6 & & & & & 0,6 & & \\
\hline & & 0,5 & & & & & 0,5 & & \\
\hline & \multirow{5}{*}{1,2} & 0,9 & \multirow{5}{*}{$12 ; 15$} & \multirow{5}{*}{$\begin{array}{c}12\{3,8,9,10,11\} \\
15\{14\}\end{array}$} & & \multirow{5}{*}{1,2} & 0,9 & \multirow{5}{*}{$12 ; 15$} & \multirow{5}{*}{$\begin{array}{c}12\{3,7,8,9,10,11\} \\
15\{14\}\end{array}$} \\
\hline & & 0,8 & & & & & 0,8 & & \\
\hline & & 0,7 & & & & & 0,7 & & \\
\hline & & 0,6 & & & & & 0,6 & & \\
\hline & & 0,5 & & & & & 0,5 & & \\
\hline \multirow{10}{*}{0,3} & & 0,9 & \multirow{5}{*}{$12 ; 15$} & \multirow{5}{*}{$\begin{array}{c}12\{8,9,10,11\} \\
15\{14\}\end{array}$} & \multirow{10}{*}{0,1} & \multirow{5}{*}{1,1} & 0,9 & \multirow{5}{*}{$12 ; 15$} & \multirow{5}{*}{$\begin{array}{c}12\{5,6,7,8,9,10,11\} \\
15\{14\}\end{array}$} \\
\hline & \multirow{4}{*}{1,1} & 0,8 & & & & & 0,8 & & \\
\hline & & 0,7 & & & & & 0,7 & & \\
\hline & & 0,6 & & & & & 0,6 & & \\
\hline & & 0,5 & & & & & 0,5 & & \\
\hline & \multirow{5}{*}{1,2} & 0,9 & \multirow{5}{*}{$12 ; 15$} & \multirow{5}{*}{$\begin{array}{c}12\{3,8,9,10,11\} \\
15\{14\}\end{array}$} & & \multirow{5}{*}{1,2} & 0,9 & \multirow{5}{*}{$12 ; 15$} & \multirow{5}{*}{$\begin{array}{c}12\{3,5,6,7,8,9,10,11\} \\
15\{14\}\end{array}$} \\
\hline & & 0,8 & & & & & 0,8 & & \\
\hline & & 0,7 & & & & & 0,7 & & \\
\hline & & 0,6 & & & & & 0,6 & & \\
\hline & & 0,5 & & & & & 0,5 & & \\
\hline
\end{tabular}

De fato, verifica-se que a variação do valor do limiar $\tau$ foi fator determinante para fornecer soluções de alocação com um número distinto de monitores necessário ao monitoramento. Este comportamento pode ser observado partindo-se do limiar $\tau=1,0$ na Tabela 3 até o limiar $\tau=0,1$ na Tabela 4, em que a quantidade mínima necessária de monitores variou de 4 (monitores alocados nos nós 3, 8, 12 e 15) para 2 (monitores alocados nos nós 12 e 15). Com relação às soluções de alocação para os valores de $\tau$, observa-se ainda certa uniformidade das soluções no que se refere aos locais de instalação dos monitores (nós), sendo que os nós 12 e 15, por exemplo, mantém-se para todos os limiares de tensão analisados $\left(\delta_{\text {inf }}\right.$ e $\left.\delta_{\text {sup }}\right)$. Além disso, ressalta-se que a partir de $\tau=0,8$, todas as soluções de alocação permanecem inalteradas.

Além da citada uniformidade que é observada para as soluções de alocação, nota-se que a quantidade de nós equivalentes é diversificada em função dos limiares $\tau$, porém, apresenta certa uniformidade para a variação de $\delta_{\text {sup }}$ quando o limiar $\tau$ é fixo. Em alguns 
casos, como por exemplo, para $\tau=1,0$ na Tabela 3 , não existem nós equivalentes, sendo que a solução de alocação disponibilizada é única. Em contrapartida, para $\tau=0,9$, por exemplo, alternativamente à solução disponibilizada $(8 ; 12 ; 15)$ tem-se a solução equivalente 8,11 e 15 , na qual o nó 11 pode ser substituto do nó 12 , tanto para $\delta_{\text {sup }}=1,1$ como para $\delta_{\text {sup }}=1,2$. Os nós 11 e 12 são equivalentes por possuírem o mesmo grau de observabilidade em relação aos fenômenos de QEE monitorados, conduzindo a soluções de alocação equivalentes. Cabe destacar que os nós equivalentes são identificados quando o redimensionamento da matriz MCF é realizado (item 5.1.1).

Para prosseguir a análise das soluções de alocação é necessário apresentar neste momento os resultados obtidos da ARHM para o SD de 15 nós. A ARHM resultou em $F=52$, sendo que dessas 52 frequências de ressonância algumas se repetem para mais de um cenário analisado, totalizando apenas 9 frequências de ressonância distintas, conforme mostra a Tabela 5. Ainda nesta tabela, para cada frequência de ressonância harmônica $F_{i}$ encontrada, tem-se apresentada sua respectiva ordem harmônica $h$, bem como seu valor em $\mathrm{Hz}\left(f_{h}\right)$, além da magnitude da impedância modal $\left|\zeta_{h}\right|$ associada à condição de ressonância.

Tabela 5 - Frequências de ressonância harmônicas encontradas pela ARHM e suas respectivas magnitudes de impedância modal.

\begin{tabular}{cccc||cccc}
\hline$F_{i}$ & $h$ & $\begin{array}{c}f_{h} \\
(\mathrm{~Hz})\end{array}$ & $\begin{array}{c}\left|\zeta_{h}\right| \\
\text { (p.u.) }\end{array}$ & $F_{i}$ & $h$ & $\begin{array}{c}f_{h} \\
(\mathrm{~Hz})\end{array}$ & $\begin{array}{c}\left|\zeta_{h}\right| \\
\text { (p.u.) }\end{array}$ \\
\hline 1 & 10 & 500 & 239,9 & 27 & 28 & 1.400 & 396,4 \\
2 & 10 & 500 & 245,4 & 28 & 28 & 1.400 & 351,8 \\
3 & 10 & 500 & 370,9 & 29 & 28 & 1.400 & 355,9 \\
4 & 10 & 500 & 417,2 & 30 & 28 & 1.400 & 388,8 \\
5 & 10 & 500 & 378,8 & 31 & 29 & 1.450 & 368,0 \\
6 & 10 & 500 & 423,7 & 32 & 29 & 1.450 & 365,6 \\
7 & 10 & 500 & 343,6 & 33 & 75 & 3.750 & 881,4 \\
8 & 10 & 500 & 393,2 & 34 & 75 & 3.750 & 884,8 \\
9 & 10 & 500 & 351,6 & 35 & 75 & 3.750 & 880,8 \\
10 & 10 & 500 & 401,2 & 36 & 75 & 3.750 & 884,4 \\
11 & 11 & 550 & 270,3 & 37 & 79 & 3.950 & 1074,9 \\
12 & 11 & 550 & 306,9 & 38 & 79 & 3.950 & 1075,0 \\
13 & 11 & 550 & 254,1 & 39 & 79 & 3.950 & 1074,8 \\
14 & 11 & 550 & 297,2 & 40 & 79 & 3.950 & 1075,0 \\
15 & 11 & 550 & 246,7 & 41 & 106 & 5.300 & 249,9 \\
16 & 11 & 550 & 278,5 & 42 & 106 & 5.300 & 249,4 \\
17 & 25 & 1.250 & 249,8 & 43 & 106 & 5.300 & 250,1 \\
18 & 25 & 1.250 & 268,6 & 44 & 106 & 5.300 & 249,4 \\
19 & 25 & 1.250 & 252,8 & 45 & 108 & 5.400 & 298,4 \\
20 & 25 & 1.250 & 271,5 & 46 & 108 & 5.400 & 298,1 \\
21 & 26 & 1.300 & 287,9 & 47 & 108 & 5.400 & 298,5 \\
22 & 26 & 1.300 & 276,9 & 48 & 108 & 5.400 & 298,1 \\
23 & 26 & 1.300 & 286,4 & 49 & 123 & 6.150 & 466,2 \\
24 & 26 & 1.300 & 274,7 & 50 & 123 & 6.150 & 466,5 \\
25 & 28 & 1.400 & 395,9 & 51 & 123 & 6.150 & 466,2 \\
26 & 28 & 1.400 & 390,3 & 52 & 123 & 6.150 & 466,4 \\
\hline
\end{tabular}


A verificação dos dados da Tabela 3 e da Tabela 4 não permite concluir sobre a influência de cada parâmetro (limiares $\tau, \delta_{\text {inf }}$ e $\delta_{\text {sup }}$ ) na determinação da quantidade de nós equivalentes. Para tanto, é essencial observar o comportamento da MCF para cada uma das variações de limiares mencionados. Dessa forma, é possível isolar a influência da alteração do limiar $\tau$, associado à MCRH, e da influência dos limiares de tensão $\delta_{\text {inf }}$ e $\delta_{\text {sup }}$, associados à MCVT.

Tendo em vista que o estudo do comportamento da MCF para todos os limiares pode ser trabalhoso e pouco eficiente, considerou-se a análise das soluções dos arranjos otimizados para a cobertura das VTCDs, dissociadas da cobertura das potenciais condições de ressonância, e vice-versa, como será apresentado posteriormente nos itens 6.1.1.2 e 6.1.1.3.

Todavia, para ilustrar a forma final da MCF e a cobertura dos fenômenos de QEE considerados nas soluções de alocação, quatro configurações de limiares e as respectivas representações gráficas das MCFs correspondentes são analisadas na sequência. É importante ressaltar que as MCFs possuem dimensão $N \times M$, onde $M=2 N+F$, conforme indica a equação (67). Ademais, para o SD de 15 nós, $N=15$ e, conforme mostrado na Tabela 5, $F=52$. Sendo assim, as referidas MCFs possuem 15 linhas e 82 colunas. Ainda de acordo com a equação (67), os elementos matriciais compreendidos entre as 15 linhas e as 30 primeiras colunas da MCF correspondem exatamente à MCVT, sendo que os elementos matriciais restantes, isto é, compreendidos entre as 15 linhas e colunas de 31 até 82, constituem a própria MCRH.

A primeira MCF analisada, representada na Figura 16, foi obtida para $\tau=1,0$, $\delta_{\text {inf }}=0,5$ p.u. e $\delta_{\text {sup }}=1,1$ p.u.. Já a MCF correspondente à segunda configuração de limiares está representada graficamente na Figura 17 , na qual $\tau=1,0, \delta_{\text {inf }}=0,5$ p.u. e $\delta_{\text {sup }}=1,2$ p.u.

Nestas figuras, os espaços preenchidos com a cor azul escuro representam os valores unitários da MCF, denotando a cobertura do monitoramento, ou a observabilidade ao distúrbio de QEE estudado. No eixo horizontal tem-se a numeração das colunas da MCF, e no eixo vertical a numeração das linhas da MCF, que corresponde aos nós do SD em questão.

Como é possível observar, as duas primeiras configurações da MCF diferem apenas para os elementos presentes nas colunas de 16 a 30, sendo esta parcela de ambas MCFs responsável por introduzir a observabilidade às elevações de tensão (equação 40 e 67). De fato, a diferença entre as duas configurações está na atribuição de valores distintos de $\delta_{\text {sup }}$, 
isto é, o limiar $\delta_{\text {sup }}$ da MCF da Figura 17 é superior em relação ao limiar $\delta_{\text {sup }}$ da MCF da Figura 16.

Figura $16-$ MCF obtida para $\boldsymbol{\tau}=\mathbf{1}, \mathbf{0}, \boldsymbol{\delta}_{\text {inf }}=\mathbf{0 , 5}$ p.u. e $\boldsymbol{\delta}_{\text {sup }}=\mathbf{1}, \mathbf{1}$ p.u..

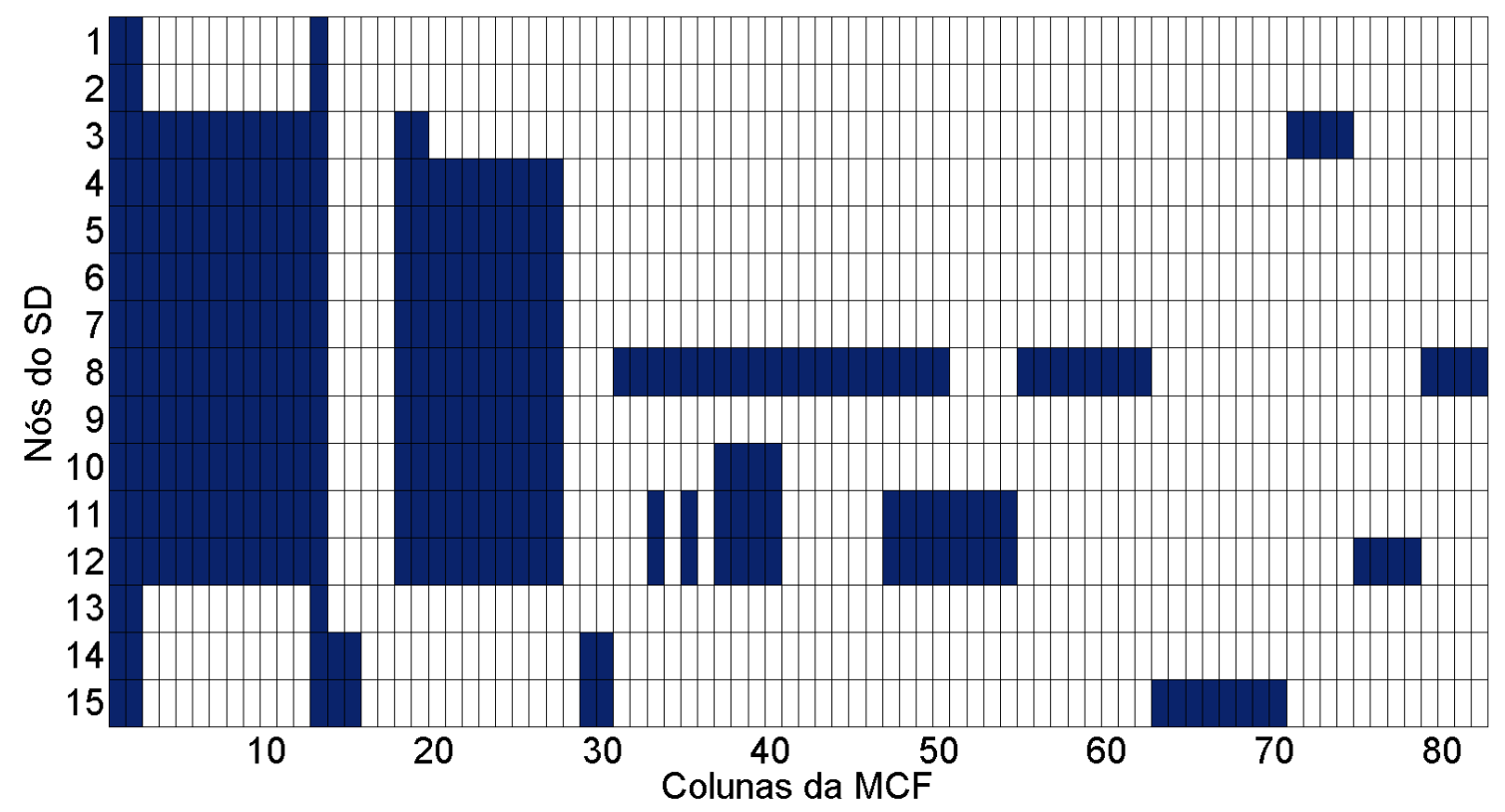

Figura $17-$ MCF obtida para $\boldsymbol{\tau}=\mathbf{1}, \mathbf{0}, \boldsymbol{\delta}_{\text {inf }}=\mathbf{0}, \mathbf{5}$ p.u. e $\boldsymbol{\delta}_{\text {sup }}=\mathbf{1}, 2$ p.u.

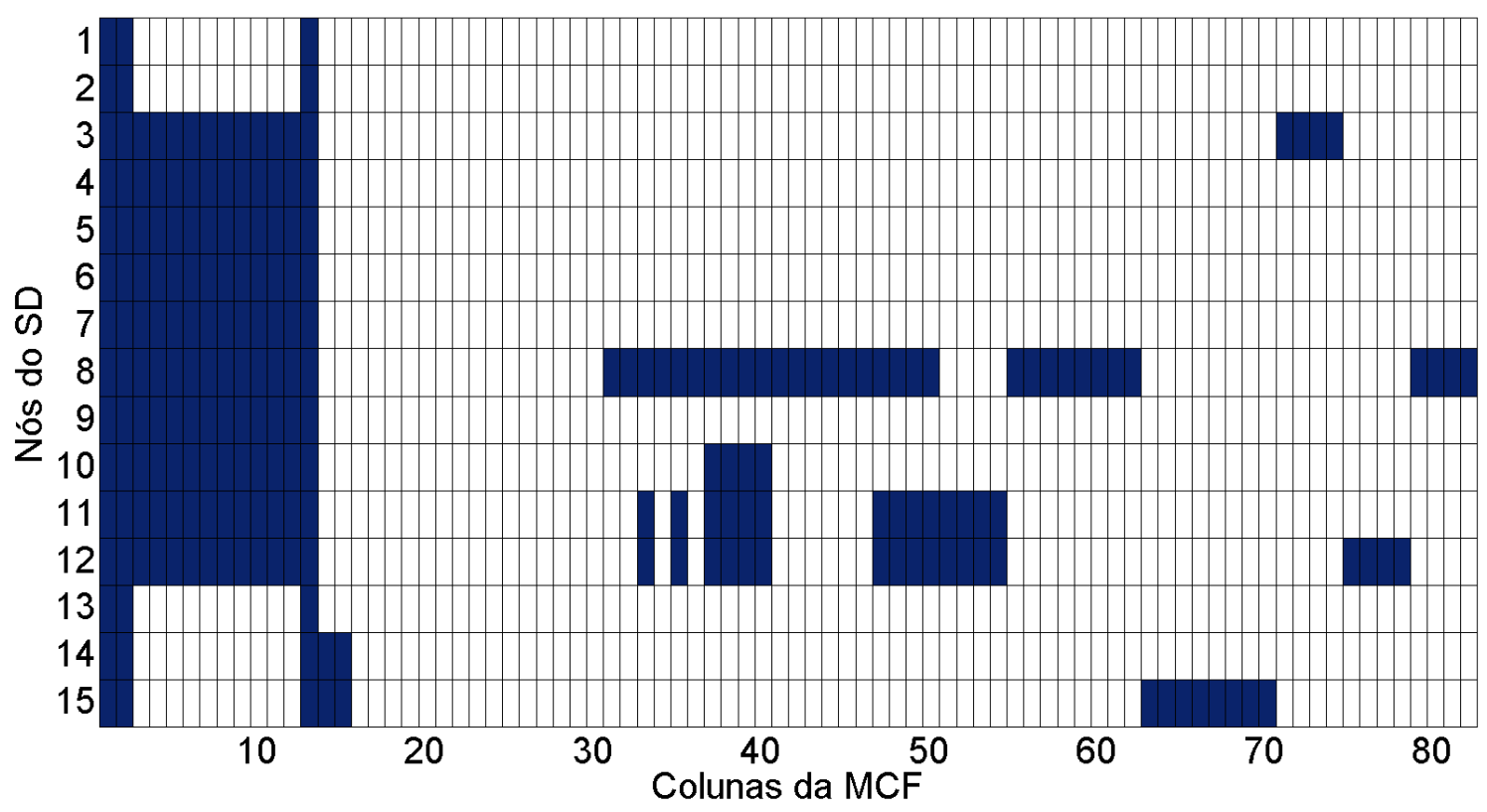

A observação destas duas configurações, como discutido a seguir, ilustra como que a determinação da solução ótima é determinada pelo algoritmo de otimização. Nestas condições, conforme a Tabela 3 , as soluções de alocação fornecidas pela metodologia indicam a necessidade de instalação dos medidores de QEE nos nós 3, 8, 12 e 15, sendo que não existem nós equivalentes disponíveis para formar soluções alternativas. Uma maneira de 
compreender graficamente se o critério de completa observabilidade dos fenômenos de QEE estudados é atendido pela solução de alocação, consiste em observar se a projeção ao longo do eixo horizontal das linhas da MCF associadas à solução de alocação forma uma sequência contínua de valores unitários (espaços preenchidos), desconsiderando-se as colunas nulas. A Figura 18 traz destacado em azul claro as linhas associadas à solução de alocação.

Figura 18 - MCF obtida para $\boldsymbol{\tau}=\mathbf{1}, \mathbf{0}, \boldsymbol{\delta}_{\text {inf }}=\mathbf{0}, \mathbf{5}$ p.u.e $\boldsymbol{\delta}_{\text {sup }}=\mathbf{1}, \mathbf{1}$ p.u. com a solução de alocação destacada.

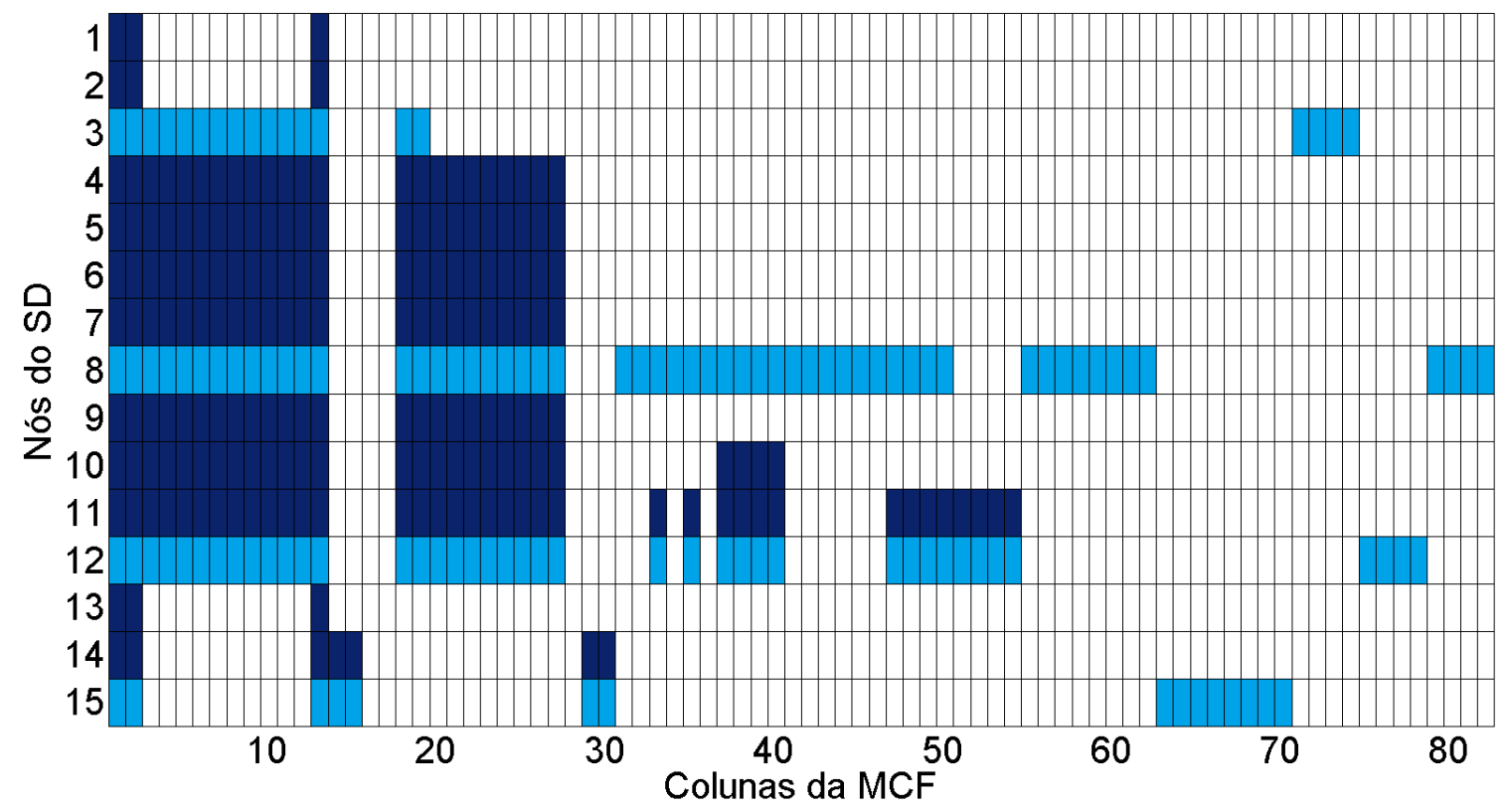

De fato, pela Figura 18, constata-se que a combinação das linhas 3, 8, 12 e 15, quando projetadas ao longo do eixo horizontal formam uma sequência de valores unitários, desconsiderando-se as colunas nulas, denotando assim a completa observabilidade provida pela solução de alocação. É importante relembrar que no processo de redimensionamento da MCF as colunas nulas são eliminadas por estarem associadas às condições de curtos-circuitos que não provocaram afundamentos e/ ou elevações de tensão. Para melhor ilustrar graficamente a solução de alocação destacada na Figura 18, somente as linhas 3, 8, 12 e 15 foram extraídas da MCF já reduzida e mostradas na Figura 19.

Figura $19-$ MCF reduzida a partir da MCF para $\boldsymbol{\tau}=\mathbf{1}, \mathbf{0}, \boldsymbol{\delta}_{\text {inf }}=\mathbf{0}, \mathbf{5}$ p.u. e $\boldsymbol{\delta}_{\text {sup }}=\mathbf{1}, \mathbf{1}$ p.u. , somente com as linhas $3 ; 8 ; 12$ e 15 (solução de alocação).

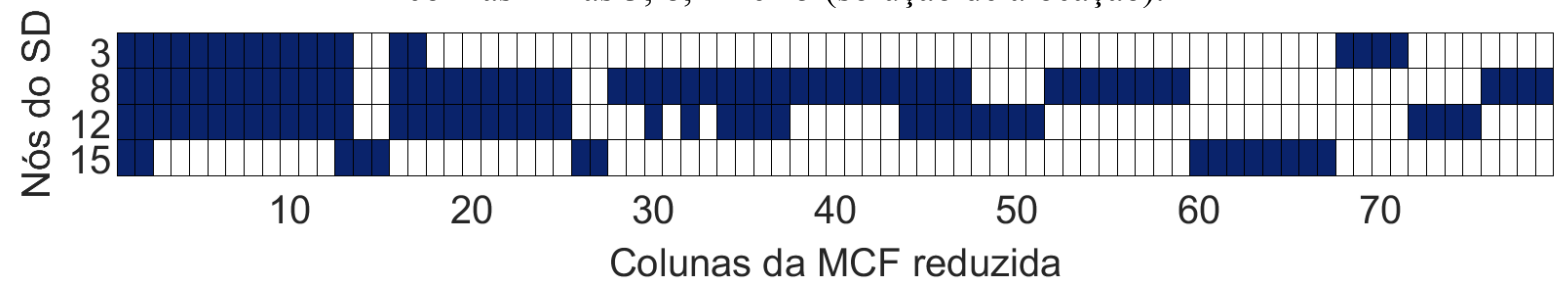


Como pode ser verificado na Figura 19, a MCF reduzida possui 4 colunas a menos do que a MCF da Figura 18, correspondendo exatamente às colunas nulas que devem ser desconsideradas no processo de otimização.

Terminando a análise das duas primeiras configurações, considere agora a MCF representada na Figura 17. Desta, constata-se que os valores das colunas 16 a 30 são nulos, denotando que não foram verificadas elevações de tensão acima de 1,2 p.u. em nenhum dos casos de curtos-circuitos considerados pelo MPF. Logo, para o processo de otimização, estas colunas foram descartadas e a solução de alocação permaneceu inalterada em relação ao limiar de $\delta_{\text {sup }}=1,1$ p.u., isto é, os monitores continuam a serem instalados nos nós 3, 8, 12 e 15. Assim como feito para a MCF da primeira configuração de limiares, a Figura 20 traz destacado em azul claro as linhas correspondentes à alocação na MCF para $\tau=1,0, \delta_{\text {inf }}=$ 0,5 p.u. e $\delta_{\text {sup }}=1,2$ p.u.. Já a Figura 21 mostra as linhas correspondentes à solução de alocação da respectiva MCF reduzida, que agora possui 67 linhas.

De fato, comparando-se a Figura 18 com a Figura 20 verifica-se graficamente que as condições de elevação de tensão não foram determinantes para que o processo de otimização encontrasse a solução de alocação final. Sendo assim, infere-se que foram determinantes para o processo de otimização os elementos matriciais correspondentes às frequências de ressonância harmônica (ultimas 52 colunas das referidas MCFs, isto é, da coluna 31 a 82) e os elementos matriciais referentes aos afundamentos de tensão (primeiras 30 colunas das referidas MCFs).

Figura 20 - MCF obtida para $\boldsymbol{\tau}=\mathbf{1}, \mathbf{0}, \boldsymbol{\delta}_{\text {inf }}=\mathbf{0 , 5}$ p.u. e $\boldsymbol{\delta}_{\text {sup }}=\mathbf{1}, \mathbf{2}$ p.u. com a solução de alocação destacada.

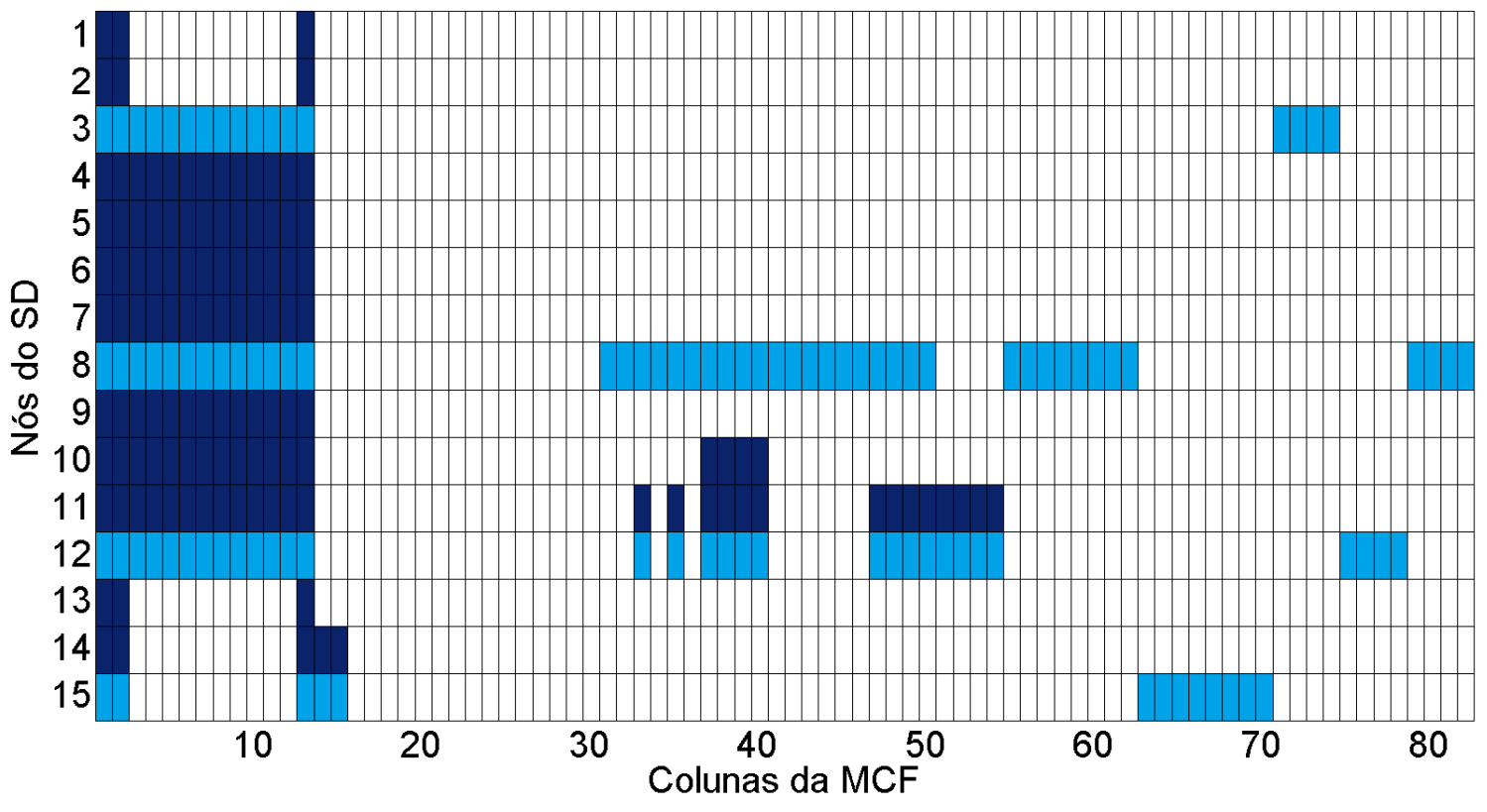


Figura 21 - MCF reduzida a partir da MCF para $\boldsymbol{\tau}=\mathbf{1}, \mathbf{0}, \boldsymbol{\delta}_{\text {inf }}=\mathbf{0}, \mathbf{5}$ p.u. e $\boldsymbol{\delta}_{\text {sup }}=\mathbf{1}, \mathbf{2}$ p.u., somente com as linhas $3,8,12$ e 15 (solução de alocação).

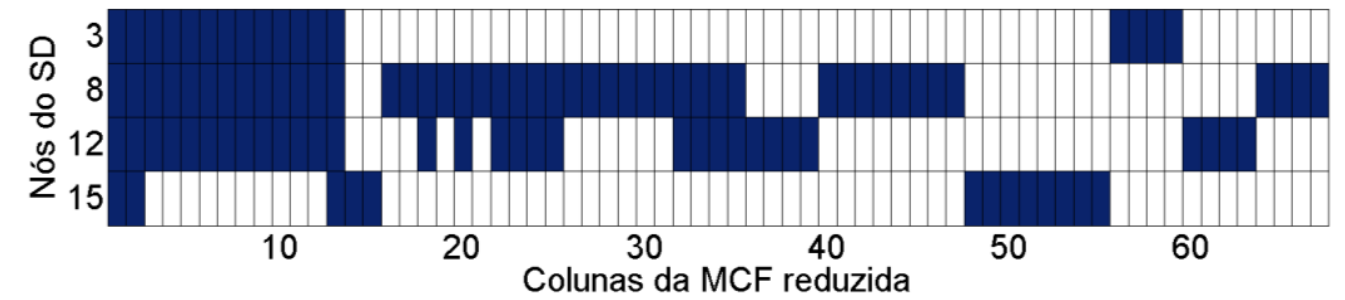

Para as duas outras configurações de limiares das MCFs observa-se comportamento semelhante ao discutido para as duas primeiras configurações. Todavia, pretende-se ilustrar graficamente como se verifica a identificação dos nós equivalentes na solução (linhas repetidas das MCFs), além do comportamento da MCF para um limiar $\tau$ mais baixo.

Neste contexto, a Figura 22 apresenta a MCF obtida para a terceira configuração de limiares, sendo $\tau=0,8, \delta_{\text {inf }}=0,5$ p.u. e $\delta_{\text {sup }}=1,1$ p.u.. Já a MCF obtida da quarta configuração de limiares está mostrada na Figura 23, sendo que $\tau=0,8, \delta_{\text {inf }}=0,5$ p.u. e $\delta_{\text {sup }}=1,2$ p.u..

Ao comparar as MCFs da Figura 22 e da Figura 23, verifica-se que as situações de elevação com tensão remanescente maiores ou iguais a 1,2 p.u. serão desconsideradas no processo de otimização, já que nenhuma condição de curto-circuito pelo MPF resultou em elevações de tensão com tais características (colunas de 16 a 30 nulas para a MCF da Figura 23).

Figura $22-$ MCF obtida para $\tau=\mathbf{0 , 8}, \boldsymbol{\delta}_{\text {inf }}=\mathbf{0}, \mathbf{5}$ p.u. e $\boldsymbol{\delta}_{\text {sup }}=\mathbf{1}, \mathbf{1}$ p.u..

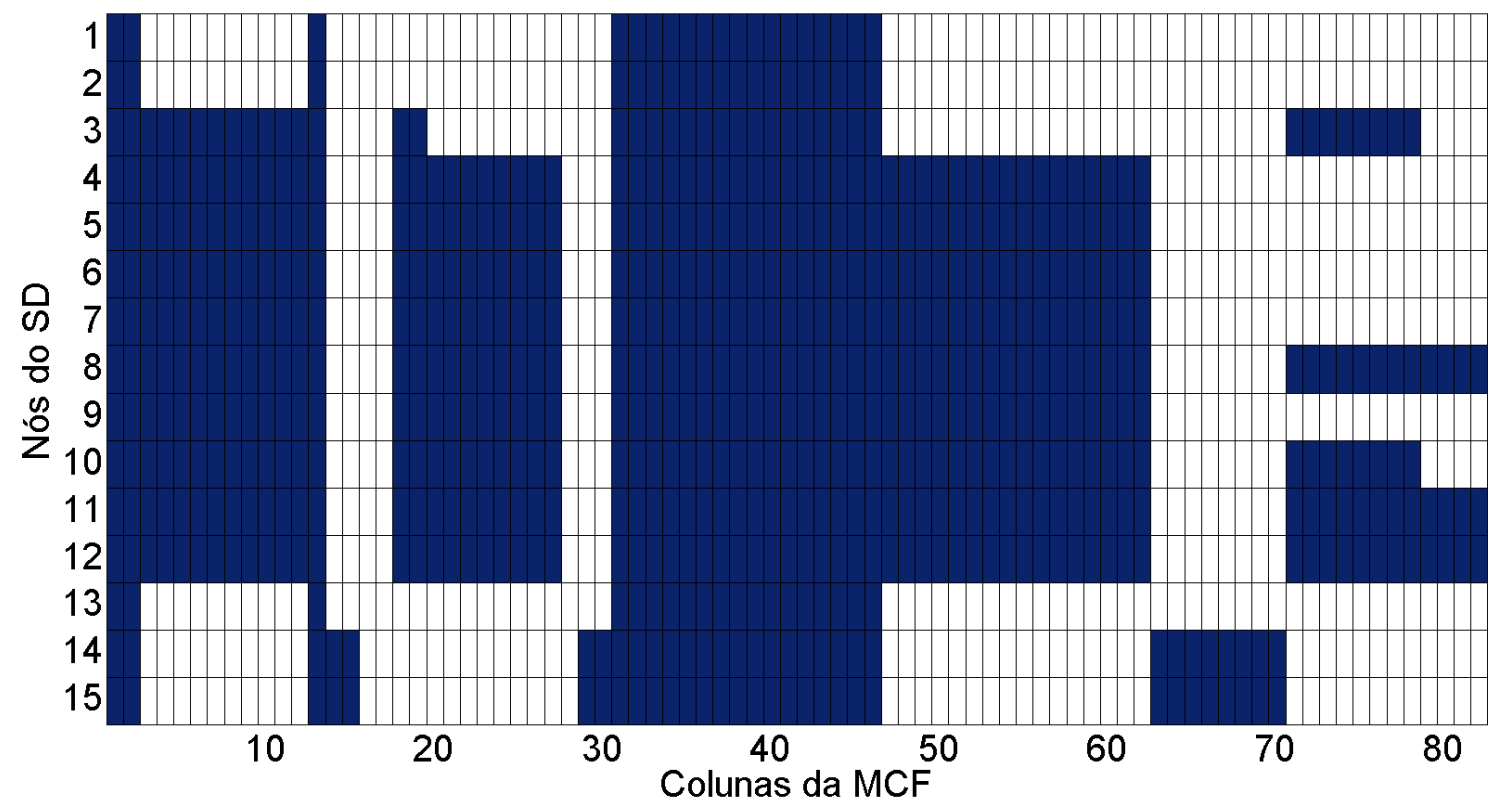


Figura $23-$ MCF obtida para $\boldsymbol{\tau}=\mathbf{0}, \mathbf{8}, \boldsymbol{\delta}_{\text {inf }}=\mathbf{0}, \mathbf{5}$ p.u. e $\boldsymbol{\delta}_{\text {sup }}=\mathbf{1}, \mathbf{2}$ p.u..

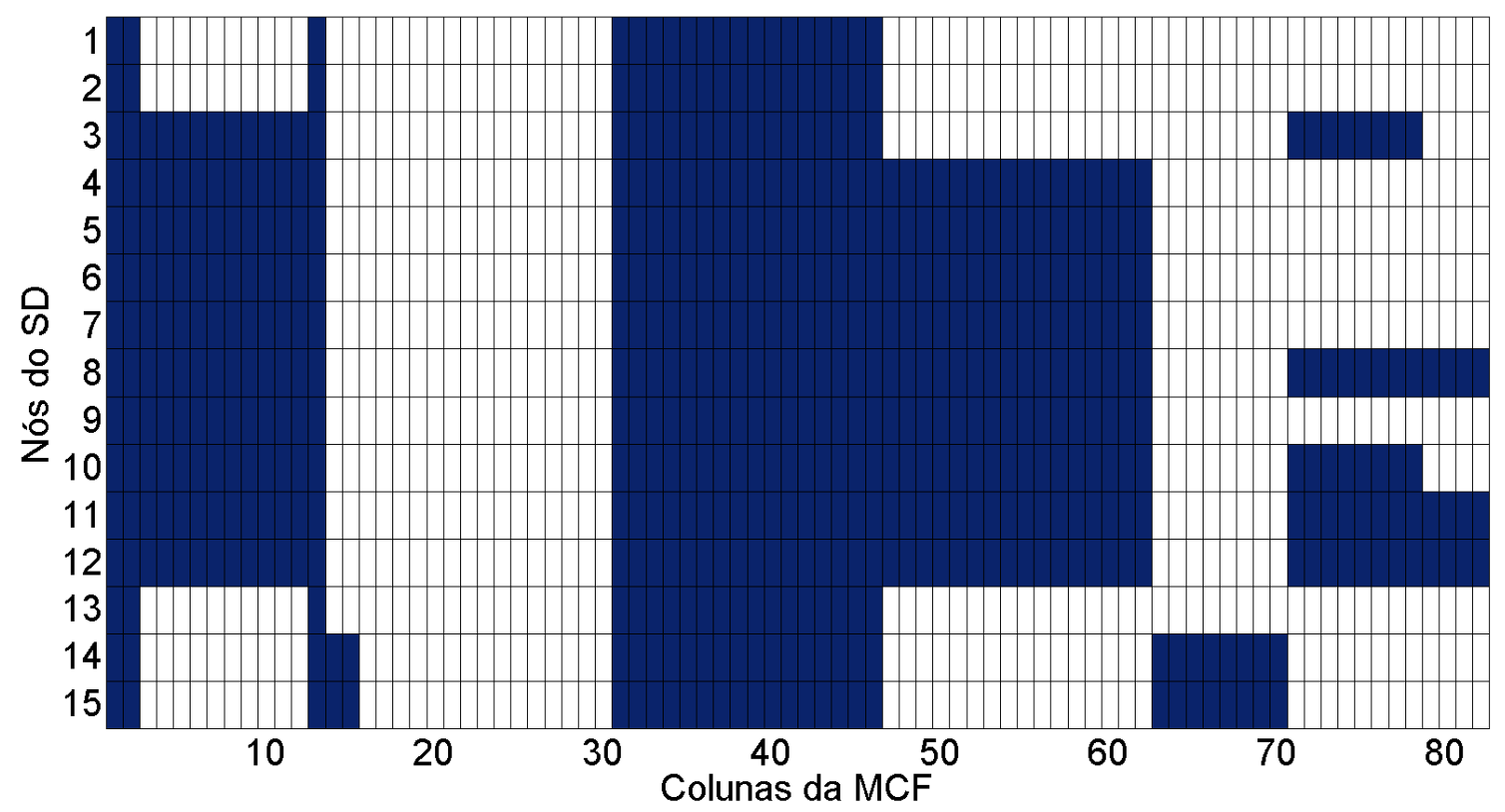

Outra característica bastante evidente (terceira e quarta configurações de limiares das MCFs) é a menor esparsidade observada (menos elementos preenchidos) para os elementos matriciais das ultimas 52 colunas. Conforme anteriormente mencionado, estes elementos correspondem à MCRH e a definição de um menor limiar $\tau$ implica em considerar uma ampliação da observabilidade de certo nó para as condições de ressonância (frequência de ressonância harmônica). Em outras palavras, certo nó será capaz de observar mais frequências de ressonância que estão dispostas nas últimas 52 colunas das MCFs.

Como efeito prático da diminuição do limiar $\tau$, o processo de otimização tenderá a encontrar soluções de alocação com um menor número de monitores. Esta situação pode ser verificada com o resultado da alocação para os limiares definidos (Tabela 3 e Tabela 4). Para ambas MCFs da Figura 22 e Figura 23, a solução de alocação resulta na instalação de dois monitores nos nós 12 e 15 . Na Tabela 3 verifica-se ainda que para estas soluções existem nós equivalentes, sendo que para $\delta_{\text {sup }}=1,1$ p.u., tem-se os nós 8 e 11 equivalentes ao nó 12; assim como o nó 14 equivalente ao nó 15.

A observação das MCFs da Figura 24 e Figura 25 com as linhas correspondentes à solução de alocação destacadas em azul claro auxilia na compreensão da obtenção dos referidos nós equivalentes. 
Figura 24 - MCF obtida para $\boldsymbol{\tau}=\mathbf{0}, \mathbf{8}, \boldsymbol{\delta}_{\text {inf }}=\mathbf{0}, \mathbf{5}$ p.u. e $\boldsymbol{\delta}_{\text {sup }}=\mathbf{1}, \mathbf{1}$ p.u. com a solução de alocação destacada.

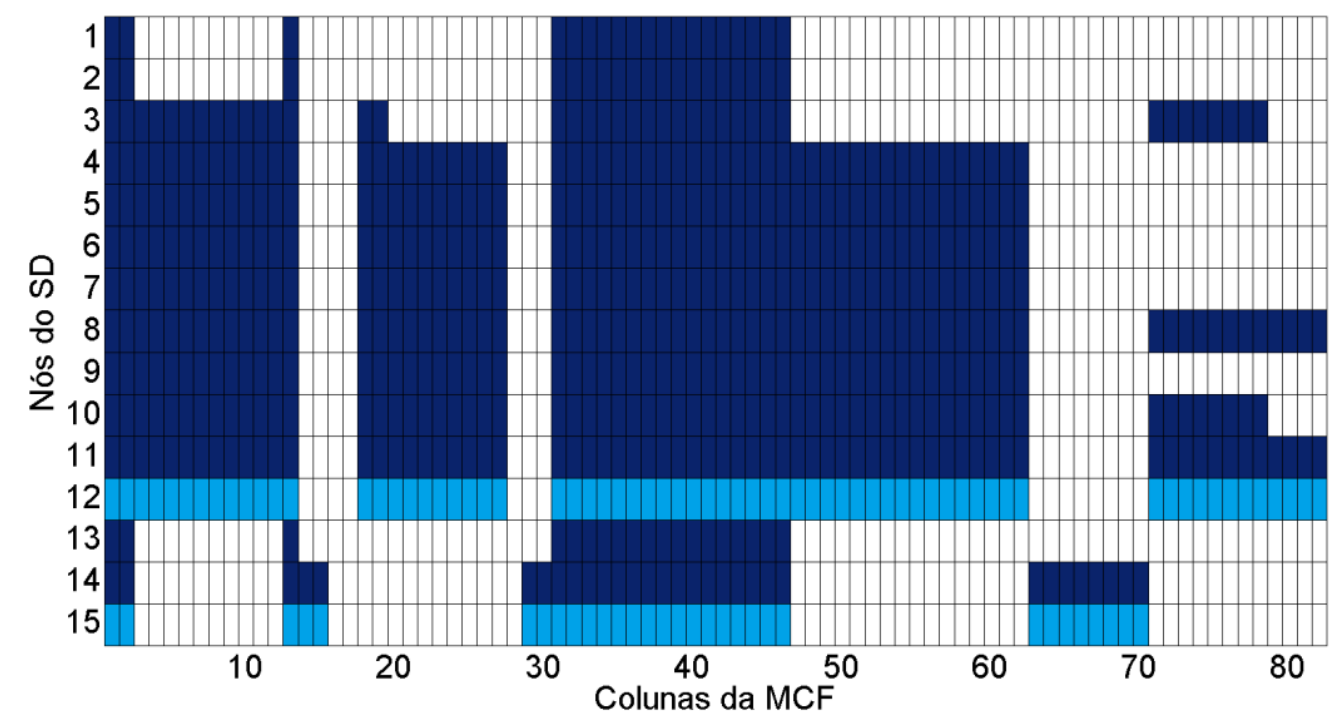

Pela Figura 24, fica evidenciado que as linhas 8 e 11 são idênticas à linha 12, e que a linha 14 é idêntica à linha 15, caracterizando coberturas equivalentes aos distúrbios de QEE considerados na metodologia. Além disso, assim como observado nos casos anteriores, a projeção das linhas correspondentes à solução no eixo horizontal forma uma sequência de valores unitários, denotando assim a completa observabilidade do arranjo de monitores às VTCDs e às condições de ressonância (frequências de ressonância harmônica).

Figura 25 - MCF obtida para $\boldsymbol{\tau}=\mathbf{0}, \mathbf{8}, \boldsymbol{\delta}_{\text {inf }}=\mathbf{0}, \mathbf{5}$ p.u. e $\boldsymbol{\delta}_{\text {sup }}=\mathbf{1}, \mathbf{2}$ p.u. com a solução de alocação destacada.

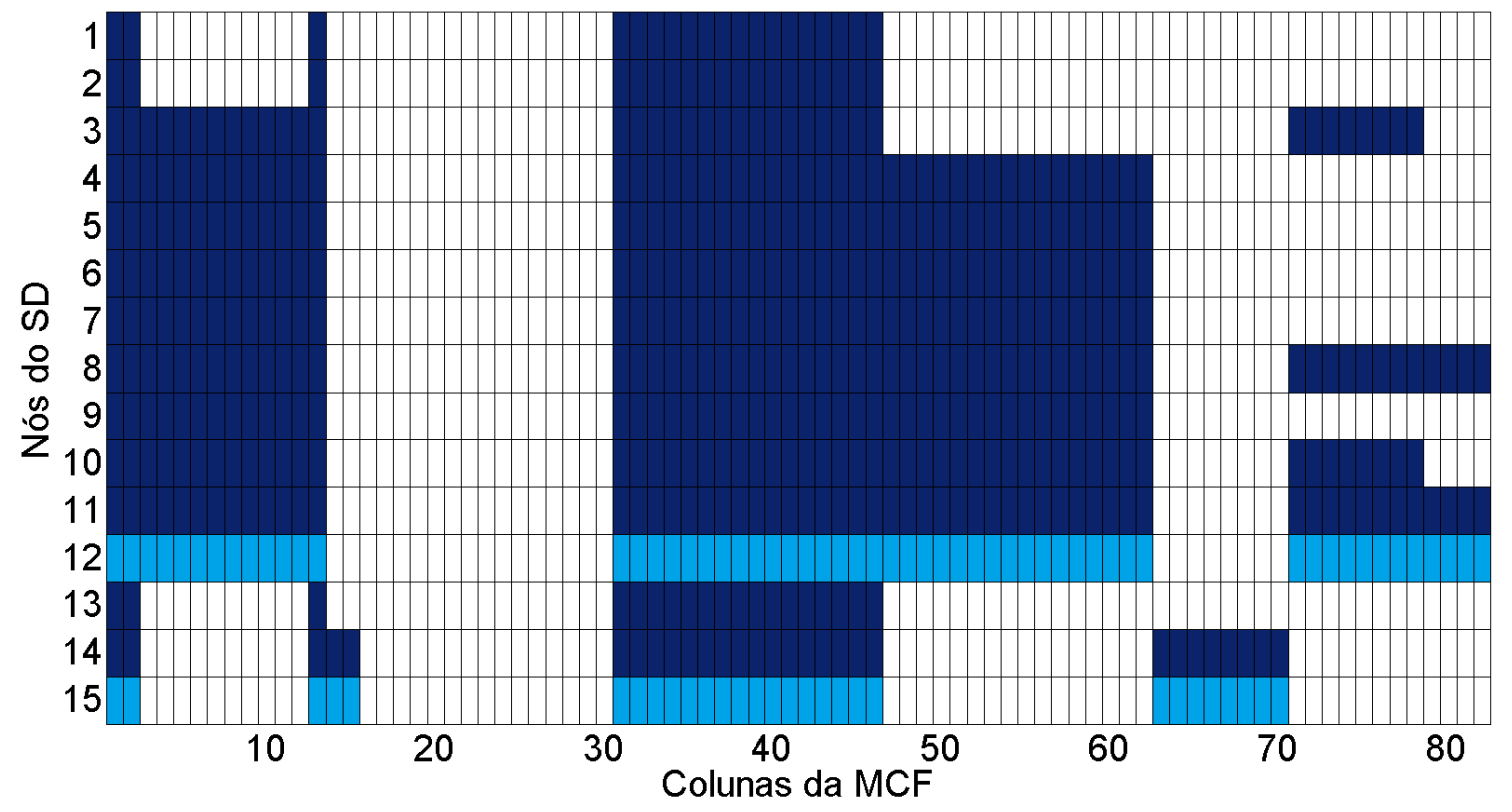

Conforme pode ser verificado na Figura 25, novamente as linhas 8 e 11 são idênticas à linha 12, denotando nós de instalação equivalentes (ou alternativos) ao nó 12. Observa-se 
ainda que a linha 14 (associada ao nó 14 do SD) é idêntica à linha 15 (nó 15 da solução de alocação).

Na Figura 26 e na Figura 27 tem-se a MCF reduzida com as linhas correspondentes à solução de alocação, isto é, linhas 12 e 15, para as MCFs da terceira e quarta configuração de limiares. Como pode ser verificado nestas figuras, confirma-se a completa observabilidade dos distúrbios de QEE considerados, além do descarte das colunas nulas das referidas MCFs.

Figura $26-$ MCF reduzida a partir da MCF para $\boldsymbol{\tau}=\mathbf{0}, \mathbf{8}, \boldsymbol{\delta}_{\text {inf }}=\mathbf{0}, \mathbf{5}$ p.u. e $\boldsymbol{\delta}_{\text {sup }}=\mathbf{1}, \mathbf{1}$ p.u., somente com as linhas 12 e 15 (solução de alocação).

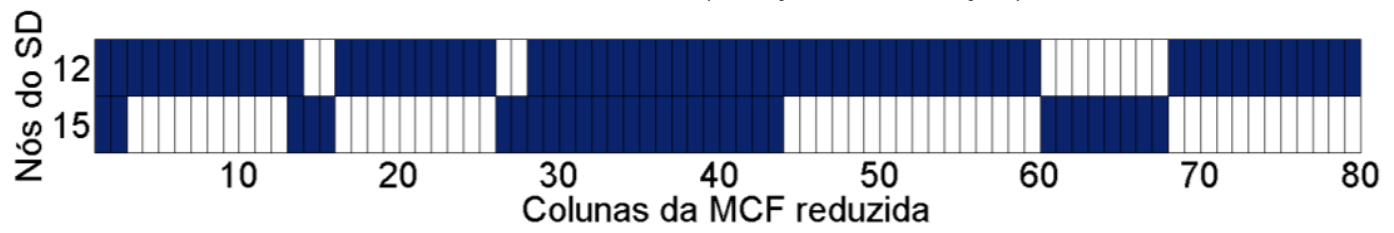

Figura $27-$ MCF reduzida a partir da MCF para $\boldsymbol{\tau}=\mathbf{0}, \mathbf{8}, \boldsymbol{\delta}_{\text {inf }}=\mathbf{0}, \mathbf{5}$ p.u. e $\boldsymbol{\delta}_{\text {sup }}=\mathbf{1}, \mathbf{2}$ p.u., somente com as linhas 12 e 15 (solução de alocação).

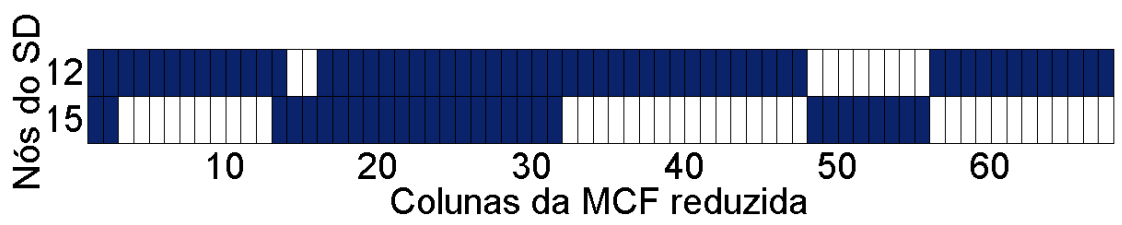

Desta breve análise, conclui-se que a determinação dos limiares será fator decisivo para a solução de alocação. Cabe ainda comentar que como regra geral, a tendência em se obter uma MCF menos esparsa está associada a menores valores de $\tau$ e de $\delta_{\text {sup }}$ e maiores valores de $\delta_{\text {inf }}$, possibilitando assim a determinação de uma menor quantidade necessária de medidores de QEE e mais soluções equivalentes (linhas idênticas da MCF).

Afirma-se ainda que valores menores de $\tau$, conforme já comentado, implicam em aumentar as chances de mais frequências de ressonância ser observadas por um dado nó do SD.

No que se refere aos limiares de tensão, é esperado que mais afundamentos de tensão sejam monitorados pelo mesmo nó quando $\delta_{\text {inf }}$ assume valores maiores (mais próximos de 0,9 p.u.); e que mais elevações de tensão sejam monitoradas quando $\delta_{\text {sup }}$ assume valores menores (mais próximos de 1,1 p.u.).

É importante destacar que não somente os valores dos limiares são determinantes, mas também são determinantes os resultados obtidos do MPF e da ARHM, os quais são inerentes e distintos para diferentes SDs analisados. 
Cabe ainda comentar que os vetores de alocação resultantes das soluções de alocação sempre respeitam o critério de prioridade de instalação imposto nas restrições do problema de otimização, como explicado no item 5.3 do capítulo 5 . Ou seja, estes vetores de alocação contém sempre a mínima quantidade necessária de monitores para a completa observação das VTCDs e potenciais condições de ressonância harmônica, priorizando, quando possível, a instalação dos medidores em nós que observam a maior quantidade de distúrbios (VTCDs e frequências harmônicas de ressonância).

Quanto à disposição física da solução de alocação, é possível verificar que para os distintos limiares definidos, os monitores são instalados preferencialmente ao final dos alimentadores do SD (nós 8, 12 e 15). Somente para as soluções com $\tau=1,0$, o nó 3 , que está localizado mais próximo da subestação, também é determinado como um nó necessário para a instalação de um medidor. Verifica-se ainda que os nós equivalentes tendem a ficar dispostos próximos entre si, como, por exemplo, os nós 8, 9, 10 e 11, equivalentes do nó 12 , e o nó 14 equivalente do nó 15 , quando $\tau=0,6$, e para todas as variações de $\delta_{\text {inf }}$ e $\delta_{\text {sup }}$, como na Tabela 3.

Conforme anteriormente mencionado, nos itens 6.1.1.2 e 6.1.1.3 maiores detalhes sobre as soluções de alocação serão apresentados. Vale ressaltar que o objetivo da análise destes itens é o de investigar a influência de cada parcela da MCF, isto é, a parcela associada à MCVT e a parcela associada à MCRH. Dessa maneira, as análises para as soluções dissociadas complementarão e permitirão melhor concluir sobre o desempenho da metodologia de alocação como um todo, isto é, referente à obtenção do arranjo de monitores que contempla tanto as VTCDs como as potenciais condições de ressonância harmônica. Vale adiantar que a intersecção das soluções dissociadas coincide com a solução final obtida via MCF completa, como será visto.

\subsubsection{Análise da solução de alocação do ponto de vista das VTCDs (MCF igual à MCVT)}

A Tabela 6 mostra as soluções de alocação para o SD de 15 nós do ponto de vista da cobertura das VTCDs, para todas as combinações dos limiares de tensão ( $\delta_{\text {inf }}$ e $\delta_{\text {sup }}$ ). 
Tabela 6 - Soluções de alocação e nós equivalentes para a MCF igual à MCVT variando-se os limiares de tensão $\boldsymbol{\delta}_{\text {inf }}$ e $\boldsymbol{\delta}_{\text {sup }}$.

\begin{tabular}{c|c|c|c}
\hline $\begin{array}{c}\delta_{\text {sup }} \\
\text { (p.u.) }\end{array}$ & $\begin{array}{c}\delta_{\text {inf }} \\
\text { (p.u.) }\end{array}$ & $\begin{array}{c}\text { Alocação } \\
\text { (nós) }\end{array}$ & $\begin{array}{c}\text { Nós } \\
\text { equivalentes }\end{array}$ \\
\hline \multirow{4}{*}{1,1} & 0,9 & & $12\{4 ; 5 ; 6 ; 7 ; 8 ; 9 ; 10 ; 11\}$ \\
& 0,8 & & $15\{14\}$ \\
& 0,7 & \multirow{2}{*}{$12 ; 15$} & $12\{1 ; 2 ; 3 ; 4 ; 5 ; 6 ; 7 ; 8 ; 9 ; 10 ; 11 ; 13 ; 14 ; 15\}$ \\
& 0,6 & & $12\{2 ; 3 ; 4 ; 5 ; 6 ; 7 ; 8 ; 9 ; 10 ; 11\}$ \\
& 0,5 & & $12\{3 ; 4 ; 5 ; 6 ; 7 ; 8 ; 9 ; 10 ; 11\}$ \\
\hline \multirow{5}{*}{1,2} & 0,9 & 12 & $12\{3 ; 4 ; 5 ; 6 ; 7 ; 8 ; 9 ; 10 ; 11\}$ \\
\cline { 2 - 4 } & 0,8 & 12 & $15\{13 ; 14\}$ \\
\cline { 2 - 4 } & 0,7 & 12 & $12\{3 ; 4 ; 5 ; 6 ; 7 ; 8 ; 9 ; 10 ; 11\}$ \\
\cline { 2 - 3 } & 0,6 & $12 ; 15$ & $15\{14\}$ \\
\cline { 2 - 4 } & 0,5 & $12 ; 15$ & \\
\hline
\end{tabular}

As soluções de alocação mostradas na Tabela 6 consideram a execução do processo de otimização fazendo-se a MCF ser igual à MCVT, conforme mostra a equação (75). Portanto, a concatenação da MCVT com a MCRH, como descrita anteriormente pela equação (67) no capítulo 5, é desconsiderada. Consequentemente, somente as VTCDs serão incorporadas ao processo de otimização, sendo que as soluções de alocação disponibilizadas estarão direcionadas para somente para a observação das VTCDs, atendendo assim aos objetivos da análise dissociada de alocação.

$$
[M C F]_{N \times M}=[M C V T]_{N \times 2 N}
$$

Conforme é possível observar na Tabela 6 , para o limiar de tensão fixado $\delta_{\text {sup }}=1,1$ p.u. e para $\delta_{\text {inf }}$ variando de 0,9 p.u. a 0,5 p.u., a solução de alocação fornecida é a mesma, assim como os nós equivalentes encontrados também são os mesmos.

A Figura 28 mostra a representação gráfica da MCF para $\delta_{\text {sup }}=1,1$ p.u. e $\delta_{\text {inf }}=$ 0,5 p.u.. Nesta figura, tem-se ainda evidenciadas as linhas correspondentes à solução de alocação, isto é 12 e 15. Ainda nesta figura, é possível observar as linhas (nós do SD) equivalentes. Ressalta-se ainda que ao confrontar a Figura 28 com a Figura 22, por exemplo, é possível confirmar como a MCF total (considerando-se a concatenação da MCRH com a MCVT, representada graficamente na Figura 22) é composta pela parcela responsável pela cobertura das VTCDs da MCF da Figura 22. 
Figura 28 - MCF obtida para $\boldsymbol{\delta}_{\text {inf }}=\mathbf{0 , 5}$ p.u. e $\boldsymbol{\delta}_{\text {sup }}=\mathbf{1}, \mathbf{1}$ p.u. com a solução de alocação destacada.

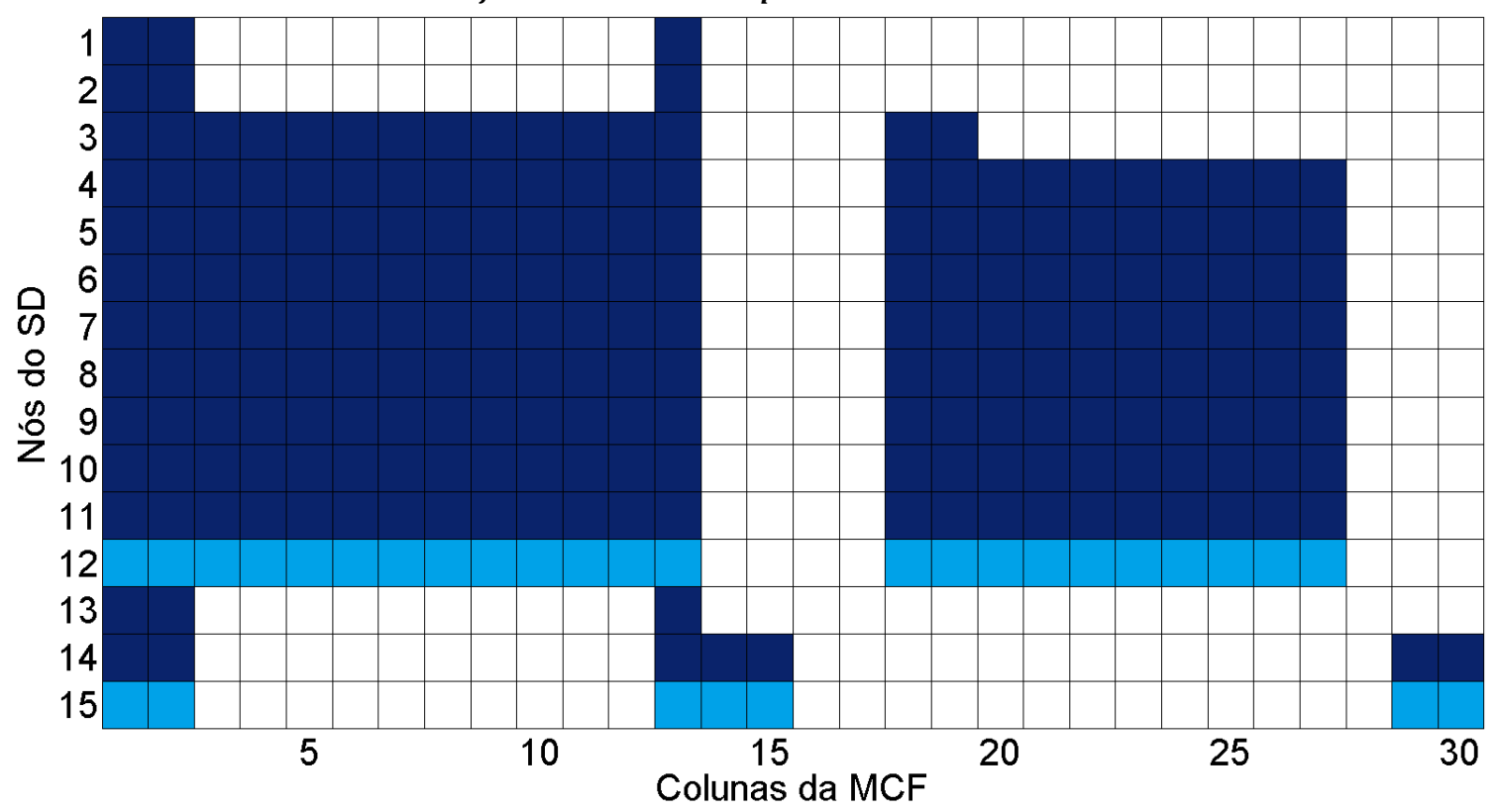

Pela Figura 28, verifica-se ainda que a projeção no eixo horizontal das linhas referentes à alocação forma uma sequência contínua de valores unitários, descontando-se as colunas nulas, denotando a completa observabilidade às VTCDs. Esta situação é mais bem visualizada através da Figura 29, na qual se tem representada as linhas associadas à alocação da MCF reduzida associada à MCF da Figura 28.

Figura 29 - MCF reduzida a partir da MCF para $\boldsymbol{\delta}_{\text {inf }}=\mathbf{0}, \mathbf{5}$ p.u.e $\boldsymbol{\delta}_{\text {sup }}=\mathbf{1}, \mathbf{1}$ p.u., somente com as linhas 12 e 15 (solução de alocação).

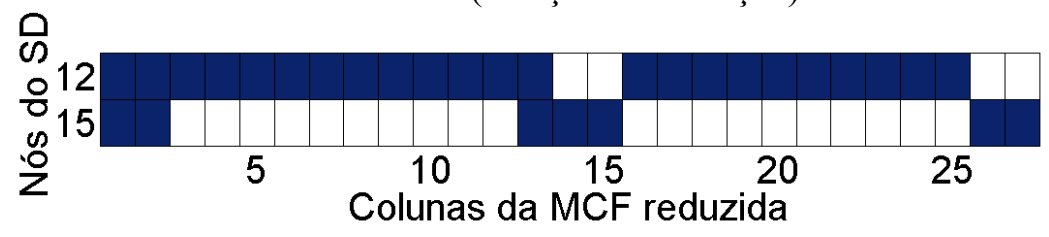

Para o limiar fixo $\delta_{\text {sup }}=1,2$ p.u. e para $\delta_{\text {inf }}$ variando de 0,9 p.u. a 0,7 p.u., apenas um monitor é necessário para o completo monitoramento do SD, sendo que, especificamente para o limiar $\delta_{\text {inf }}=0,9$ p.u., o monitor pode ser instalado em quaisquer nós do SD que este será sempre sensibilizado para as condições de curto-circuito consideradas pelo MPF. No entanto, na medida em que $\delta_{\text {inf }}$ diminui até 0,5 p.u., a quantidade de nós equivalentes também diminui. Este comportamento é esperado em função do aumento da esparsidade da MCF (ou MCVT neste caso), que reduz a possibilidade de encontrar nós equivalentes. Ademais, para os limiares $\delta_{\text {inf }}=0,6$ p.u. e $\delta_{\text {inf }}=0,5$ p.u., observa-se ainda que a solução de 
alocação determina que seja instalado um monitor adicional no nó 15 , sendo seu equivalente o nó 14 , nó este eletricamente mais próximo ao nó 15 .

A Figura 30 mostra a representação gráfica da MCF para $\delta_{\text {sup }}=1,2$ p.u. e $\delta_{\text {inf }}=$ 0,5 p.u. Nesta figura, tem-se novamente evidenciadas as linhas correspondentes à solução de alocação (12 e 15), na qual é possível verificar a razão pelo cálculo dos diversos nós equivalentes ao nó 12 (linhas equivalentes à linha 12).

Figura 30 - MCF obtida para $\boldsymbol{\tau}=\mathbf{1}, \mathbf{0}, \boldsymbol{\delta}_{\text {inf }}=\mathbf{0}, \mathbf{5}$ p.u.e $\boldsymbol{\delta}_{\text {sup }}=\mathbf{1}, \mathbf{2}$ p.u.com a solução de alocação destacada.

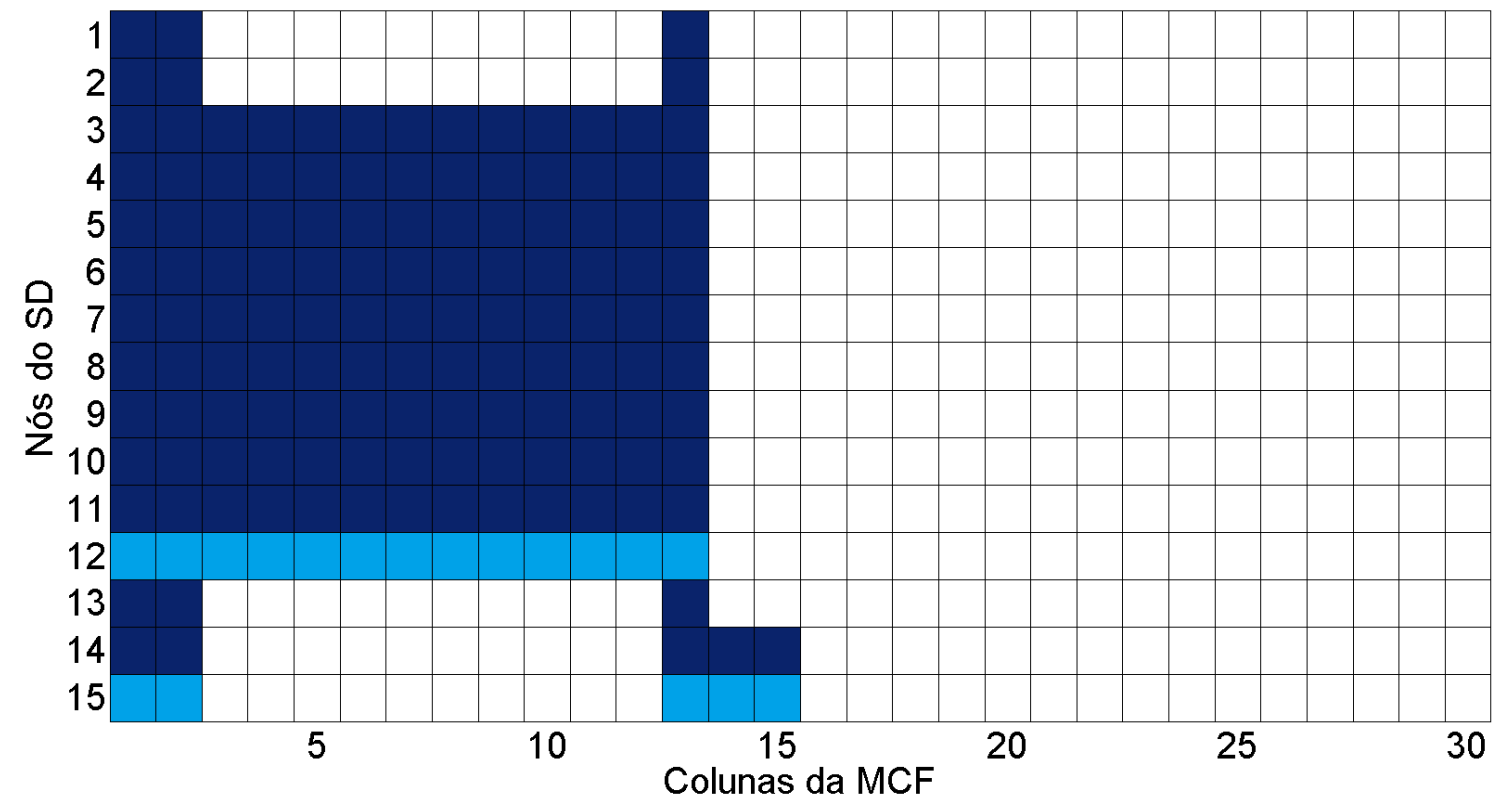

Assim como para a MCF com $\delta_{\text {sup }}=1,2$ p.u., verifica-se que a projeção no eixo horizontal das linhas referentes à alocação, descontando-se as colunas nulas, forma uma sequência contínua de valores unitários, confirmando a total observabilidade às VTCDs. Resultado este confirmado na Figura 31, na qual se tem representada as linhas associadas à alocação da MCF reduzida associada à MCF da Figura 30.

Destaca-se ainda que não foram verificadas elevações de tensão com tensão remanescentes maiores ou iguais a 1,2 p.u., como pode ser confirmado pelos elementos matriciais nulos (não preenchidos) nas colunas de 16 a 30 da MCF da Figura 30. Este fato implica em afirmar que somente os afundamentos de tensão (primeiras 15 linhas da MCF) são determinantes para a solução da alocação dos monitores de QEE. 
Figura $31-\mathrm{MCF}$ reduzida a partir da MCF para $\boldsymbol{\delta}_{\text {inf }}=\mathbf{0}, \mathbf{5}$ p.u. e $\boldsymbol{\delta}_{\text {sup }}=\mathbf{1}, \mathbf{2}$ p.u., somente com as linhas 12 e 15 (solução de alocação).

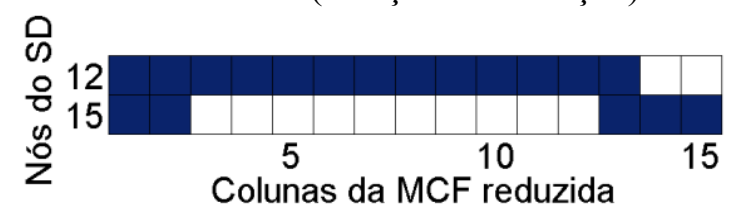

Observando-se os dados de maneira mais abrangente, afirma-se que ao menos um dos monitores tende a ser alocado ao final do alimentador (nó 15) para diversos valores de limiares definidos. O mesmo comportamento foi observado para a alocação final considerando a MCF completa (Tabela 3 ).

Conclui-se também que a menor quantidade de nós equivalentes encontrados para o caso da MCF completa pode ser explicada pelas restrições impostas pela MCRH, que reduz a possibilidade de se encontrar linhas idênticas na MCF.

Assim como anteriormente observado no item 6.1.1.1, os vetores de alocação associados às soluções de alocação respeitam o critério de prioridade de instalação, que neste caso prioriza a instalação dos medidores de QEE em nós capazes de observar a maior quantidade de VTCDs possível.

Por fim, cabe comentar que uma vez projetada e alcançada a alocação dos monitores, com base nos limiares desejados para a construção da MCF, os monitores em campo, na prática, poderão ser ajustados, por exemplo, com $\bar{\delta}_{\text {inf }}=0,9$ p.u. e $\bar{\delta}_{\text {inf }}=1,1$ p.u., e a observabilidade do arranjo projetado continuará sendo válida. Logo, a escolha dos limiares é mais crítica na etapa de projeto e mais flexível quando implementada em campo.

\subsubsection{Análise da solução de alocação do ponto de vista das potenciais condições de ressonância (MCRH)}

Após a execução da ARHM, 52 potenciais frequências harmônicas foram detectadas $(F=52)$ analisando-se a impedância modal do SD no intervalo de 50 a $6,4 \mathrm{kHz}$, sendo algumas repetidas, permitindo totalizar 9 frequências harmônicas distintas. Estes resultados já foram anteriormente apresentados na Tabela 5 do item 6.1.1.1, na qual todas as frequências de ressonância e as respectivas magnitudes das impedâncias modais são apresentadas. Cabe relembrar que para estes SD a frequência fundamental é de $50 \mathrm{~Hz}$.

A obtenção da Tabela 5 anteriormente apresentada, equivale a considerar a execução do processo de otimização fazendo a MCF ser igual à MCRH, conforme mostra a equação 
(76). Portanto, a concatenação da MCVT com a MCRH, como descrita anteriormente pela equação (67) no capítulo 5, é desconsiderada. Logo, somente as potenciais condições de ressonância harmônica serão incorporadas ao processo de otimização, conforme objetivo inicial desta análise de solução dissociada das VTCDs.

$$
[M C F]_{N \times M}=[M C D H]_{N \times F}
$$

A solução de alocação para $\tau=1,0$ determina que 4 monitores são necessários para que todas as 52 frequências de ressonância harmônica sejam observadas, conforme mostrado na Tabela 7. Para esta solução não foram encontrados nós equivalentes que pudessem resultar em soluções de alocação alternativas.

Tabela 7 - Soluções de alocação e nós equivalentes para a MCF igual à MCRH variando-se $\boldsymbol{\tau}$.

\begin{tabular}{|c|c|c|}
\hline$\tau$ & $\begin{array}{l}\text { Alocação } \\
\text { (nós) }\end{array}$ & Nós equivalentes \\
\hline 1,0 & $3 ; 8 ; 12 ; 15$ & - \\
\hline 0,9 & $8 ; 12 ; 15$ & $11\{12\}$ \\
\hline 0,8 & $12 ; 15$ & $\begin{array}{c}12\{8 ; 11\} \\
15\{14\}\end{array}$ \\
\hline 0,7 & $12 ; 15$ & $\begin{array}{c}12\{8 ; 10 ; 11\} \\
15\{14\}\end{array}$ \\
\hline 0,6 & $12 ; 15$ & $\begin{array}{c}12\{8 ; 9 ; 10 ; 11\} \\
15\{14\}\end{array}$ \\
\hline 0,5 & $12 ; 15$ & $\begin{array}{c}12\{8 ; 9 ; 10 ; 11\} \\
15\{14\} \\
\end{array}$ \\
\hline 0,4 & $12 ; 15$ & $\begin{array}{c}12\{3 ; 8 ; 9 ; 10 ; 11\} \\
15\{14\}\end{array}$ \\
\hline 0,3 & $12 ; 15$ & $\begin{array}{c}12\{3 ; 8 ; 9 ; 10 ; 11\} \\
15\{14\}\end{array}$ \\
\hline 0,2 & $12 ; 15$ & $\begin{array}{c}12\{3 ; 7 ; 8 ; 9 ; 10 ; 11\} \\
15\{14\}\end{array}$ \\
\hline 0,1 & $12 ; 15$ & $\begin{array}{c}12\{3 ; 5 ; 6 ; 7 ; 8 ; 9 ; 10 ; 11\} \\
15\{14\}\end{array}$ \\
\hline
\end{tabular}

Além disso, a Tabela 7 mostra as demais soluções de alocação, bem como seus respectivos nós equivalentes, para outros valores do limiar $\tau$. Conforme pode ser constatado, as soluções de alocação associadas a valores mais baixos de $\tau$ requerem uma menor quantidade de monitores de QEE. Este comportamento é esperado, uma vez que se aumentam as chances de mais frequências de ressonância serem observadas por certo nó do SD.

Uma vez que $\tau$ está diretamente relacionado ao grau de observabilidade dos modos críticos (equação 49), a escolha pelo máximo valor de $\tau$ aumentará a possibilidade de encontrar nós que são mais susceptíveis a sofrerem maiores distorções harmônicas na tensão. 
É importante destacar que um estudo mais aprofundado deve ser conduzido para melhor definir o valor de $\tau$ para a obtenção das soluções de alocação. Todavia, é possível afirmar que definir $\tau=1,0$ garantirá a obtenção de uma solução de alocação mais conservadora possível no que diz respeito à maximização da observabilidade das potenciais condições de ressonância harmônica. Neste contexto, uma solução conservadora significa uma solução factível que conduza a uma abordagem mais cautelosa possível que venha a ser considerada para alocação dos medidores de QEE.

Ainda analisando as soluções da Tabela 7, verifica-se a presença dos nós 12 e 15 desde $\tau=0,1$ até a solução mais conservadora. De fato, estes nós também foram indicados como locais de instalação de monitores de QEE quando se considerou a alocação somente do ponto de vista das VTCDs (análise do item 6.1.1.2), ou seja, são nós comuns tanto para a alocação das condições de ressonância como para as VTCDs. Este fato pode ser confirmado observando-se as soluções associadas às configurações de limiares correspondentes que constam na Tabela 3 e na Tabela 4 do item 6.1.1.1. Cabe relembrar que estas soluções apresentadas inicialmente são relativas a MCF que consideram a concatenação da MCVT com a MCRH, conforme propõe a metodologia de alocação.

No que se refere ao atendimento do critério de prioridade de instalação que foi incorporado ao processo de otimização, confirma-se que os vetores de alocação, associados à solução final, priorizam a instalação de medidores em nós capazes de observar a maior quantidade possível de frequências de ressonância harmônica.

Ainda, confrontando-se os resultados das soluções de alocação apresentados no item 6.1.1.1 com aqueles apresentados no item 6.1.1.2 e no presente item, conclui-se que o direcionamento de instalação dos monitores nos nós 3 e 8 , foram exclusivamente determinados pela solução mais conservadora obtida da otimização da MCRH.

De fato, constata-se que o local de instalação dos monitores não coincide necessariamente com os nós onde estão presentes os bancos de capacitores do SD, revelando que tais locais de instalação são dependentes da topologia do sistema, parâmetros e condições de operação considerados.

Como observação geral, nota-se ainda que a instalação dos medidores dá-se preferencialmente nos nós localizados na porção final dos alimentadores, assim como já observado para a alocação do ponto de vista das VTCDs. 


\subsubsection{Análise de varredura em frequência}

Conforme anteriormente comentado, o cenário número 16 do conjunto $C$ (Tabela 2), referente à conexão de todos os bancos de capacitores do SD também foi analisado. Para este cenário, executou-se a varredura em frequência para que fosse possível validar os valores das frequências de ressonância harmônicas encontradas pela ARHM.

Os gráficos apresentados da Figura 32 à Figura 35 mostram, respectivamente, a varredura em frequência das impedâncias da rede de 15 nós para uma injeção de corrente de 1,0 p.u. nos nós $3,8,12$ e 15 para o cenário de número 16 do conjunto $C$. É importante destacar que estes nós correspondem aos nós de instalação de monitores determinados pela solução de alocação mais conservadora, isto é, para $\tau=1,0$ p.u., como registrado na Tabela 7.

Figura 32 - Varredura em frequência para 1,0 p.u. de corrente injetada no nó 3 do SD de 15 nós sob operação nas condições do cenário de número 16.

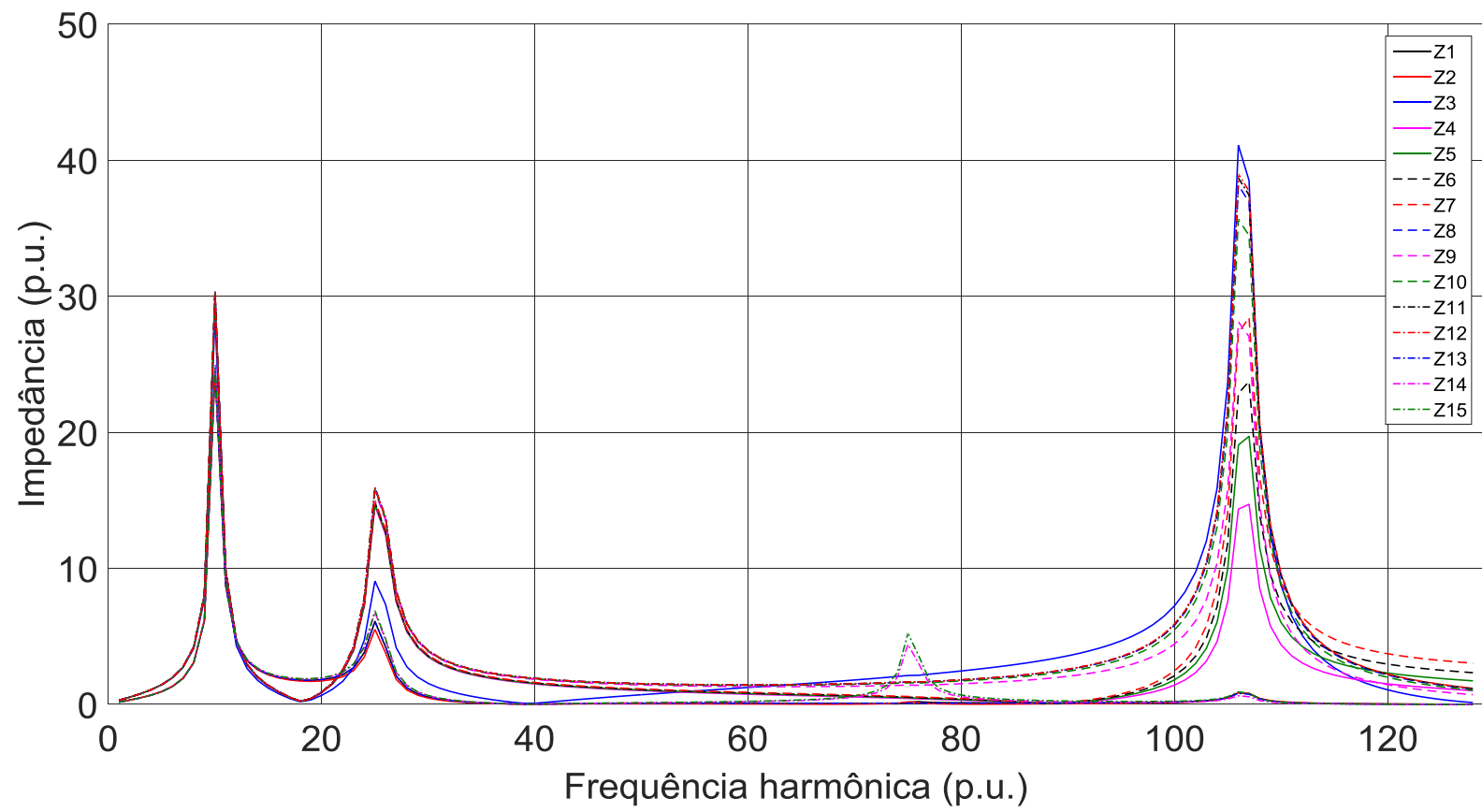

A varredura em frequência foi executada de $50 \mathrm{~Hz}\left(h_{\text {mín }}\right)$ até $6,4 \mathrm{kHz}\left(h_{\text {máx }}\right)$. Ademais, para cada gráfico, os segmentos de linha nomeados de Z1 a Z15 representam a impedância própria e as impedâncias de transferência da rede de 15 nós. No gráfico da Figura 32, por exemplo, o segmento de linha Z3 é a impedância própria, e os demais segmentos de linha são as impedâncias de transferência.

Como é possível observar nos gráficos da Figura 32 à Figura 35, os picos das impedâncias harmônicas são verificados para a $10^{\mathrm{a}}, 25^{\mathrm{a}}, 75^{\mathrm{a}}$ e $106^{\mathrm{a}}$ harmônicas, isto é, 500 
$\mathrm{Hz}, 1.250 \mathrm{~Hz}, 3.750 \mathrm{~Hz}$ e $5.300 \mathrm{~Hz}$, respectivamente. Especificamente para o gráfico da Figura 35, os picos de ressonância harmônica significativos são verificados para a $10^{\mathrm{a}}, 25^{\mathrm{a}} \mathrm{e}$ $75^{\mathrm{a}}$ harmônicas, o que significa que a condição de ressonância para a $106^{\mathrm{a}}$ harmônica não está presente no nó 15 quando uma corrente de 1,0 p.u. é injetada neste nó.

Figura 33 - Varredura em frequência para 1,0 p.u. de corrente injetada no nó 8 do SD de 15 nós sob operação nas condições do cenário de número 16.

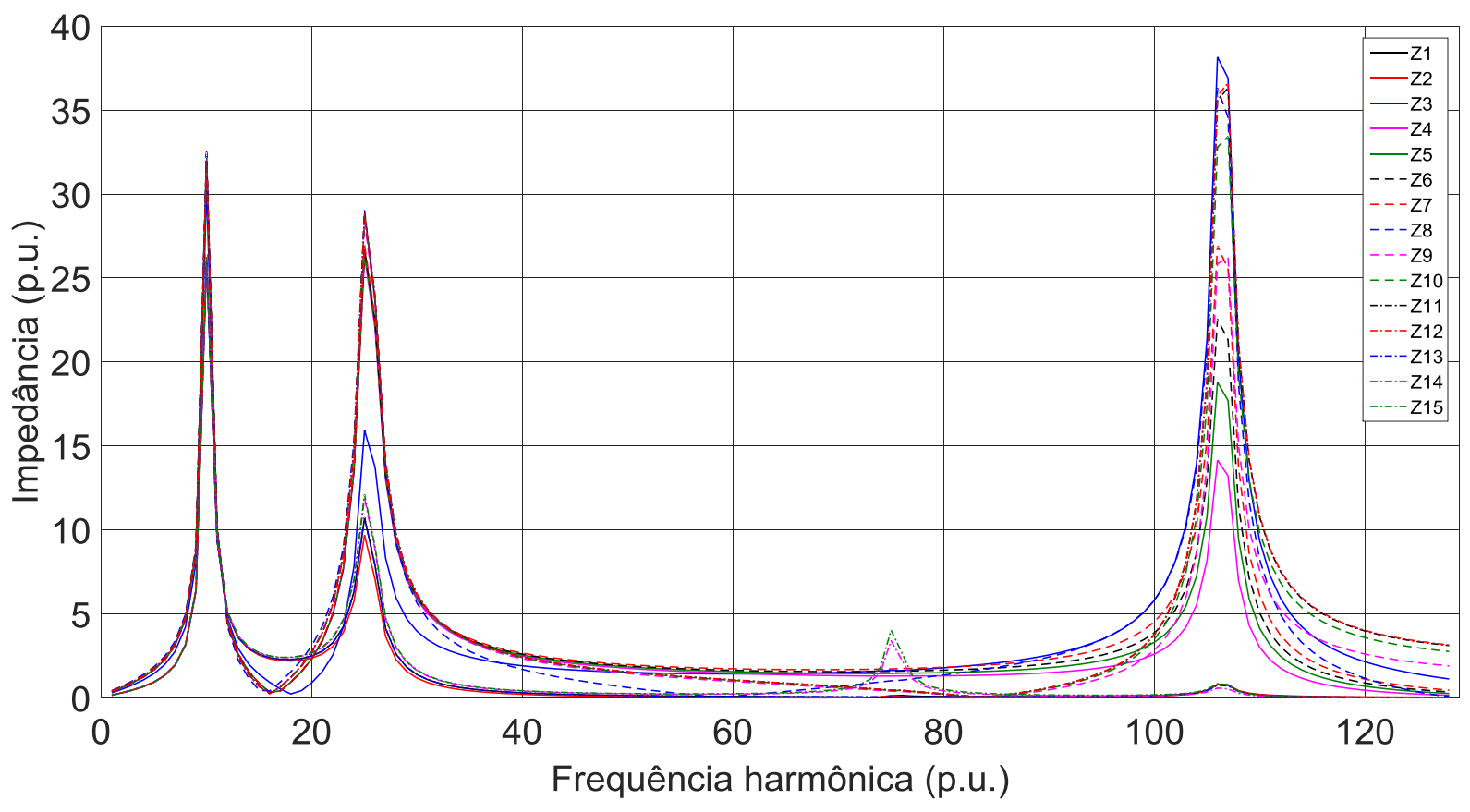

Figura 34 - Varredura em frequência para 1,0 p.u. de corrente injetada no nó 12 do SD de 15 nós sob operação nas condições do cenário de número 16.

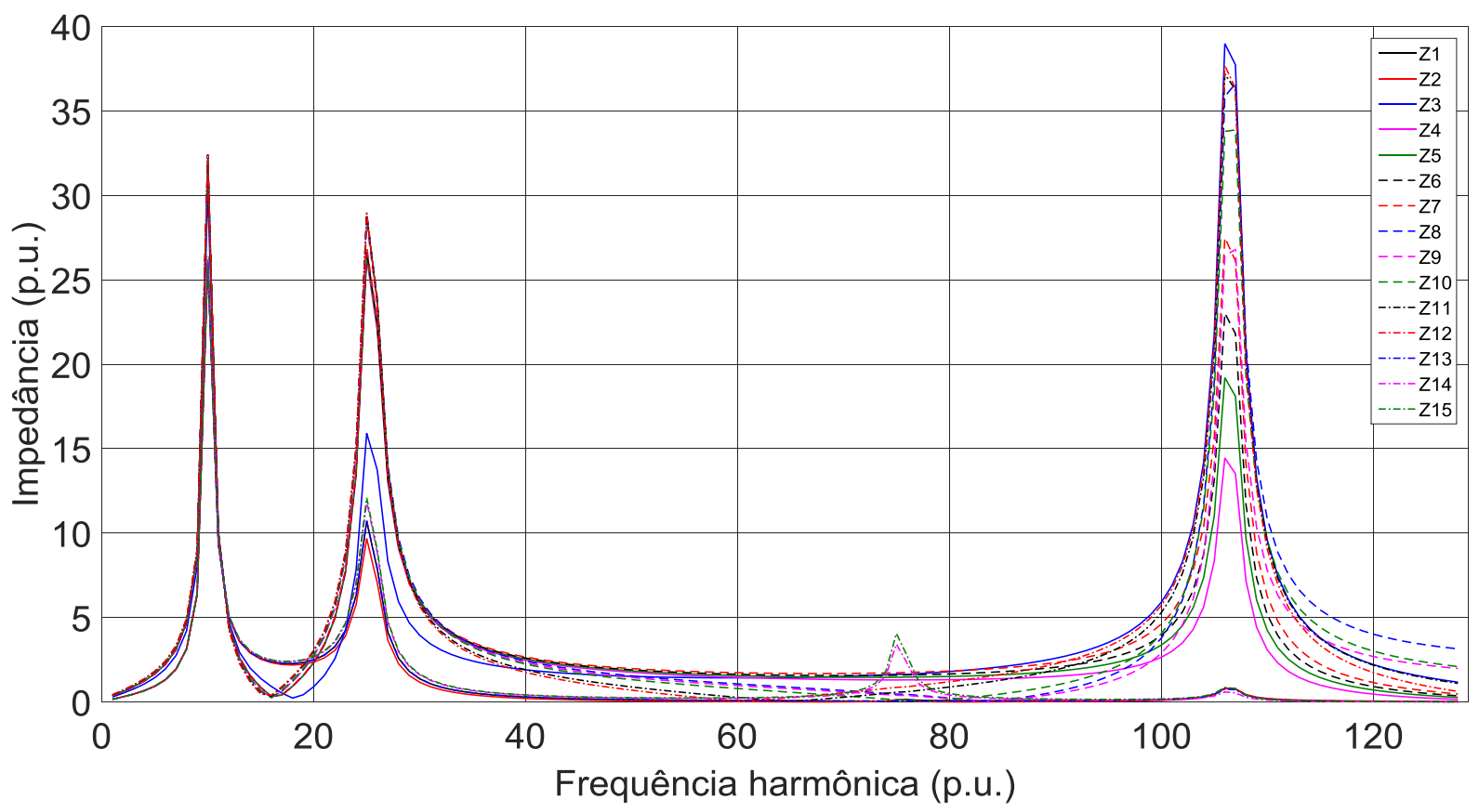


Figura 35 - Varredura em frequência para 1,0 p.u. de corrente injetada no nó 15 do SD de 15 nós sob operação nas condições do cenário de número 16.

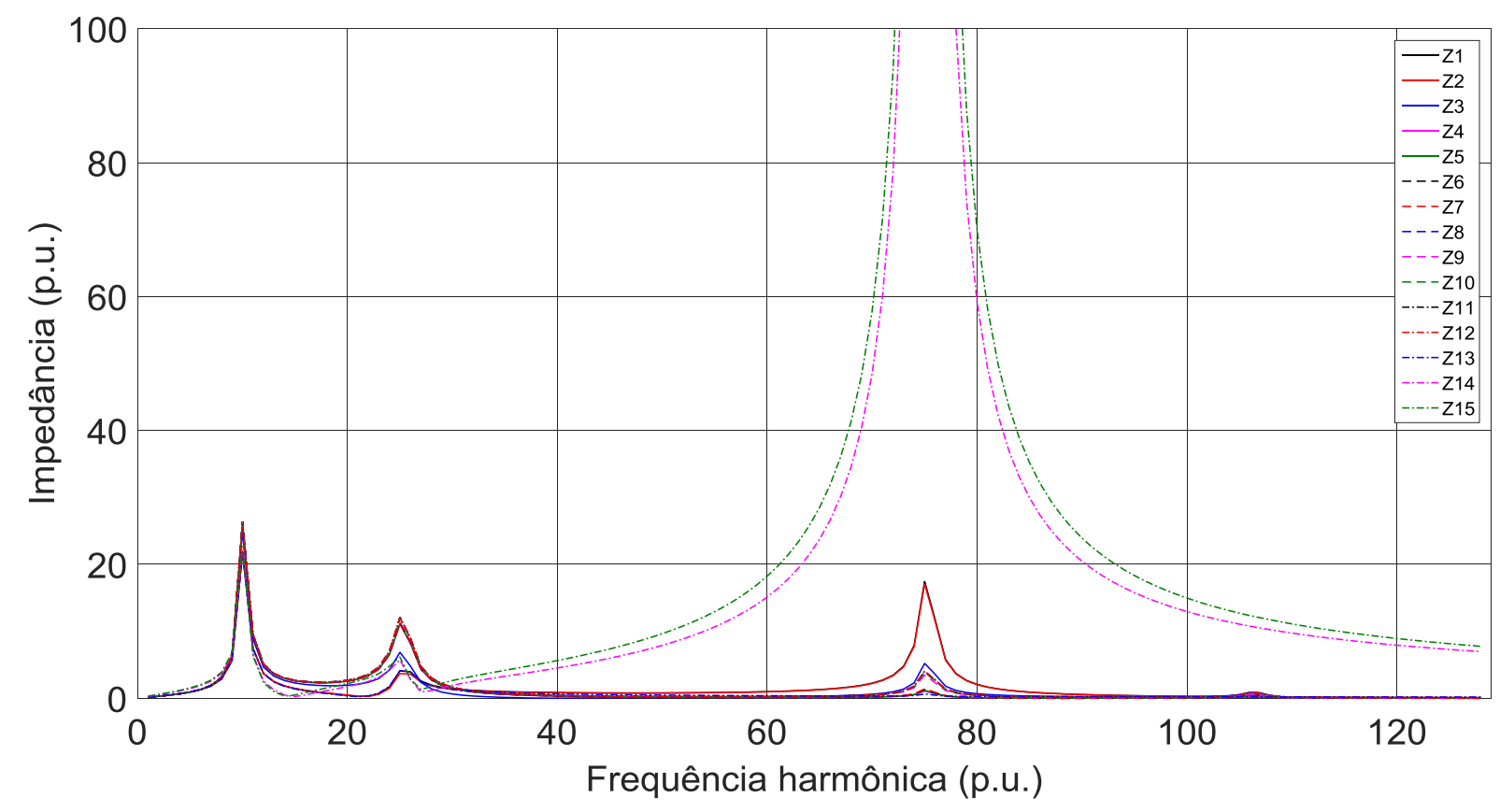

De fato, as quatro frequências harmônicas identificadas pelas varreduras em frequência apresentadas constituem parte das frequências harmônicas calculadas pela ARHM, conforme registrado na Tabela 5. Conforme mostra o gráfico da Figura 36, estas frequências de ressonância harmônica coincidem com os picos da impedância modal igualmente calculada para o intervalo de frequências de $50 \mathrm{~Hz}\left(h_{\text {mín }}\right)$ até $6,4 \mathrm{kHz}\left(h_{\text {máx }}\right)$.

Conforme é possível constatar dos gráficos apresentados, as magnitudes das impedâncias harmônicas, obtidas via varredura em frequência, não são congruentes com os valores das magnitudes da impedância harmônica modal. Entretanto, este comportamento é esperado, uma vez que as referidas impedâncias são obtidas em domínios distintos (XU et al., 2005). Salienta-se que para o atual estágio de desenvolvimento da pesquisa, a magnitude da impedância modal não está sendo considerada. A mesma será incorporada na continuidade da pesquisa com o intuito de aprimoramento do desempenho da metodologia como um todo.

Afirma-se que esta congruência entre as frequências harmônicas de ressonância obtidas pela varredura em frequência e pela ARHM foi verificada para todas as frequências apresentadas na Tabela 5 . 
Figura 36 - Perfil da Impedância modal obtida pela execução da ARHM.

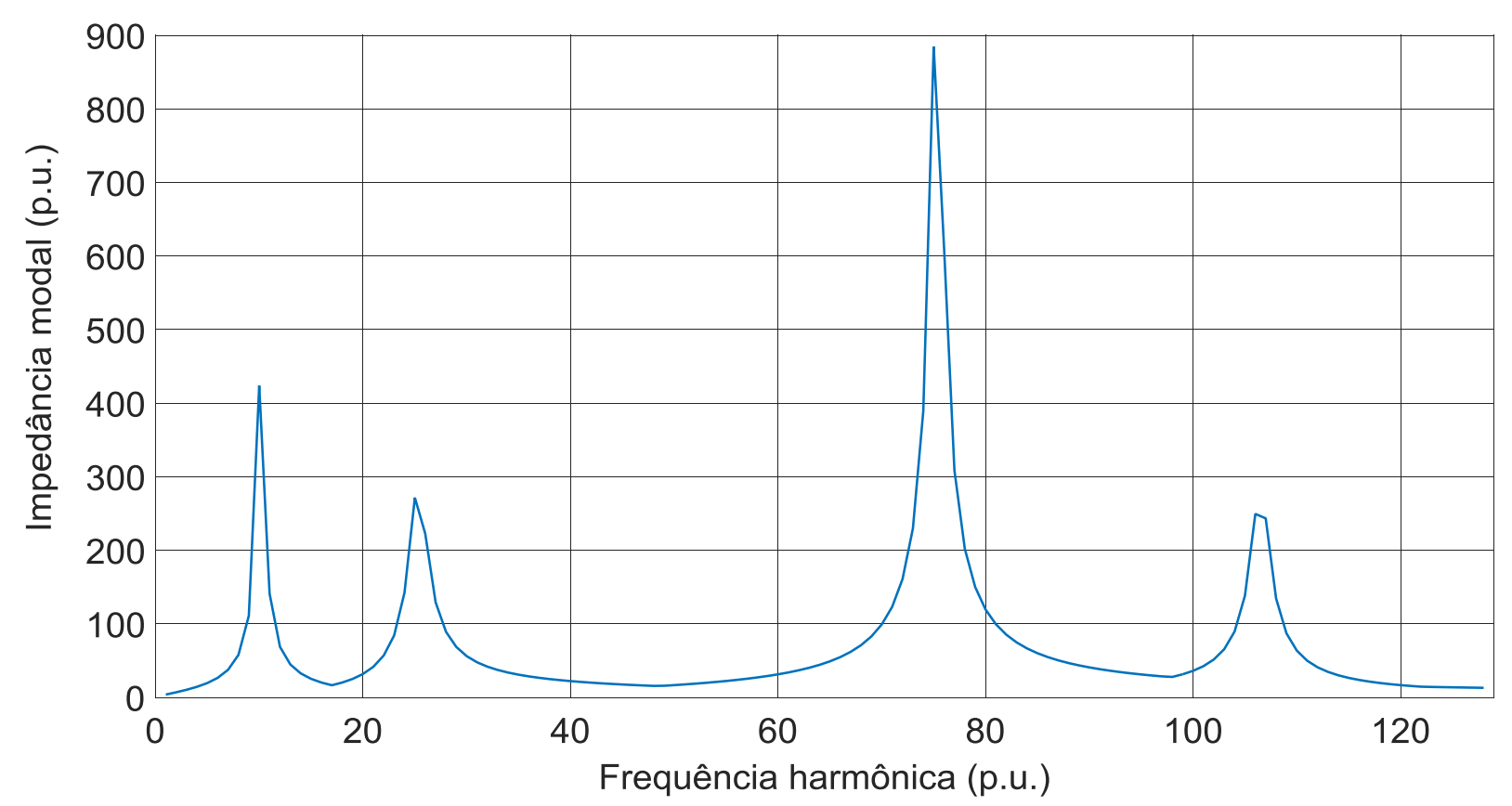

Os resultados decorrentes dos estudos de varredura em frequência encontrados ilustram as dificuldades em se utilizar esta técnica para se determinar os níveis de observabilidade das frequências harmônicas, bem como da importância relativa ou contribuição de cada nó analisado para as condições de ressonância harmônica.

Diante do exposto, afirma-se que a atribuição dos graus de observabilidade para cada nó do SD efetuado através da ARHM é mais conveniente, sendo estes diretamente obtidos pela análise dos autovetores, como anteriormente explicado e discutido no capítulo 4.

\subsubsection{Sensibilidade da solução de alocação conservadora frente às variações de potência reativa dos bancos de capacitores locais}

Com o objetivo de analisar o comportamento da solução de alocação fornecida pela metodologia, distintos valores de potência reativa dos bancos de capacitores, responsáveis pela correção do fator de potência das cargas conectadas aos nós $8,10,14$ e 15, foram analisados.

Esta variação da potência reativa implica em distintos valores de capacitância que podem ser observados, por exemplo, em operações reais de bancos de capacitores automáticos, que compensam a potência reativa que pode variar ao longo do dia de acordo com o perfil de carga do SD. 
Para esta avaliação, quatro distintos casos foram considerados: $(i)$ todos os bancos de capacitores locais com 50\% da potencia reativa nominal; (ii) capacitores conectados aos nós 10 e 15 com 50\% da potência nominal; (iii) capacitores conectados aos nós 8 e 14 com 50\% da potência nominal; e (iv) capacitores conectados aos nós 8, 10, 14 e 15 com 50\%, 25\%, 75\% e $25 \%$ da potência nominal, respectivamente.

Os casos (ii) e (iii) contém modificações nos pares de capacitores com as maiores e menores potências reativas nominais, respectivamente. $\mathrm{O}$ caso (iv) foi escolhido arbitrariamente e que pode representar uma condição de operação dos bancos de capacitores em algum ponto de operação específico do SD.

A Tabela 8 contém as soluções de alocação final, $\operatorname{com} \tau=1,0$, para os quatro casos estudados.

Tabela 8 - Soluções de alocação e nós equivalentes para $\boldsymbol{\tau}=\mathbf{1}, \mathbf{0}$ para os quatro casos estudados e o número de frequências de ressonância harmônicas calculadas pela $\operatorname{ARHM~}(\boldsymbol{F})$.

\begin{tabular}{ccccc}
\hline Caso & $\tau$ & $\begin{array}{c}\text { Alocação } \\
\text { (nós) }\end{array}$ & $\begin{array}{c}\text { Nós } \\
\text { equivalentes }\end{array}$ & $F$ \\
\hline$i$ & 1,0 & $8 ; 12 ; 15$ & - & 52 \\
$i i$ & 1,0 & $8 ; 12 ; 15$ & - & 52 \\
$i i i$ & 1,0 & $8 ; 12 ; 15$ & - & 52 \\
$i v$ & 1,0 & $8 ; 12 ; 15$ & - & 45 \\
\hline
\end{tabular}

Como pode observado, as soluções de alocação são estáveis para variações consideráveis das capacitâncias associadas aos bancos de capacitores. Com relação à solução de alocação conservadora $(\tau=1,0)$, apresentada anteriormente na Tabela 7 do no item 6.1.1.3, nota-se que o nó 3 não é mais indicado como um local de instalação de um monitor de QEE, entretanto, os demais nós permanecem os mesmos. De acordo com esses resultados, é possível verificar que a variabilidade da capacitância associada aos bancos de capacitores não demandará a instalação de medidores em novos locais do SD. Isto significa que a solução de alocação conservadora $(\tau=1,0)$ apresentada na Tabela 7 é adequada para uma significativa variabilidade da capacitância dos referidos bancos.

Uma das razões para que o nó 3 não apareça nas soluções dos casos de $(i)$ a (iv) pode ser atribuída ao deslocamento para valores mais elevados das novas frequências harmônicas calculadas, isto é, valores que recaem além dos valores máximos admitidos na análise (de 50 $\mathrm{Hz}$ até $6,4 \mathrm{kHz}$ ). Esta variação foi causada com a diminuição da potência reativa dos bancos de capacitores. Os novos valores de frequências de ressonância harmônica acabam por atribuir novos valores para os graus de observabilidade dos nós do SD, levando o processo de 
otimização a excluir o nó 3 das soluções finais de alocação. Como, consequência, menos monitores de QEE são requeridos para o completo monitoramento para as condições de ressonância calculadas.

Embora uma quantidade $F$ de frequências de ressonância calculadas para o caso (iv) tenha variado, como mostra a Tabela 7 , a solução de alocação continua a mesma em relação aos demais casos estudados.

Para maiores detalhes e verificação das conclusões apresentadas neste item, as tabelas apresentadas no Apêndice A deste documento podem ser consultadas. Nestas tabelas, estão registradas as novas frequências de ressonância harmônicas calculadas, bem como os respectivos valores das magnitudes das impedâncias modais associadas, para os quatro casos estudados.

De fato, as conclusões deste estudo podem ser estendidas para a solução de alocação em que se considera também a observabilidade das VTCDs. Esta afirmação é plausível, uma vez que os resultados das soluções dissociadas (itens 6.1.1.2 e 6.1.1.3) mostram que as soluções obtidas via otimização a partir da MCRH são preponderantes na determinação dos nós finais de instalação dos monitores de QEE. Ademais, como pelo MPF assume-se a tensão de pré-falta como sendo igual a $1,0 \angle 0^{\circ}$ p.u., a variabilidade dos bancos de capacitores não precisa ser levada em conta quando do cálculo da MCVT.

Também é importante mencionar que a completa desconexão dos bancos de capacitores já é levada em consideração no processo de alocação, já que esta situação também é contemplada no conjunto $C$ de cenários analisados.

\subsection{Sistema de 24 nós}

Este SD é baseado no SD de 34 nós do IEEE (KERSTING, 2001; INSTITUTE OF ELECTRICAL AND ELECTRONIC ENGINEERS, 2010), do qual apenas os segmentos trifásicos foram considerados, resultando assim em um SD teste de 24 nós (Figura 37). Na Figura 37, os nós foram nomeados da mesma maneira que o sistema de 34 nós original do IEEE. Além disso, o SD de 24 nós é considerado transposto e perfeitamente balanceado, uma vez que se pressupõe o balanceamento das cargas dispostas no alimentador em média tensão. Além disso, este sistema opera com a frequência nominal fundamental de $60 \mathrm{~Hz}$. 
Assim como o SD de 15 nós, o transformador da subestação foi modelado como uma reatância puramente indutiva (referenciada ao lado de baixa), sendo a barra de referência do sistema considerada como um barramento infinito.

As cargas distribuídas do SD original de 34 nós foram concentradas no segundo nó que define o segmento ao qual a carga distribuída estava originalmente designada. Por exemplo, a carga distribuída presente no trecho entre os nós 802 a 806, foi concentrada no nó 806.

Figura 37 - Sistema de distribuição de 24 nós.

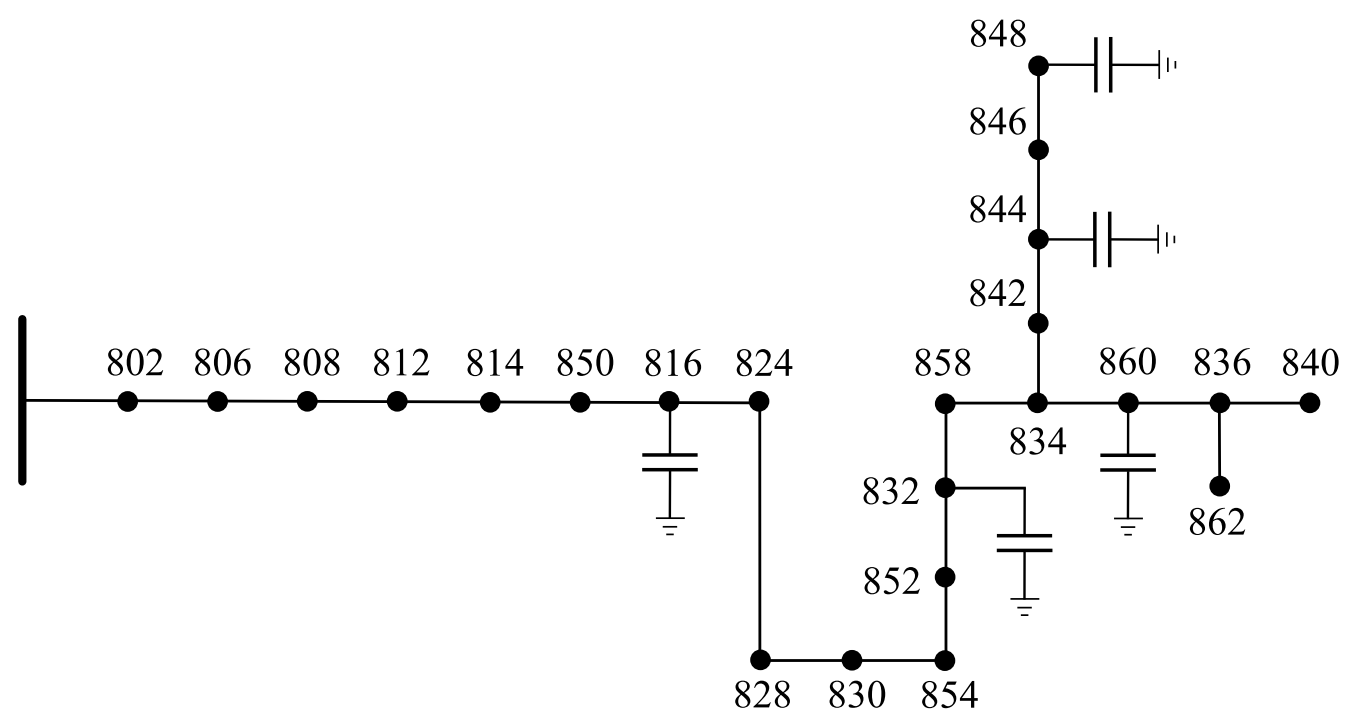

Fonte: Adaptado de INSTITUTE OF ELECTRICAL AND ELECTRONICS ENGINEERS (2010).

Uma vez que o SD teste de 24 nós contém somente trechos trifásicos, as cargas presentes nos ramos monofásicos do sistema original de 34 nós foram redefinidas de forma concentrada para os respectivos nós trifásicos que deram origem aos referidos ramais monofásicos.

Todas as cargas desbalanceadas do SD original foram recalculadas de maneira a se obter cargas totalmente balanceadas. Sendo assim, para uma carga desbalanceada (incluindose o caso de uma carga monofásica), calculou-se a média aritmética das potências alocadas em cada fase. Esta potência média foi então distribuída igualmente entre as três fases do SD, tornando a carga balanceada.

No Anexo B estão apresentadas as cargas do SD de 24 nós após todas as referidas considerações. Destaca-se ainda que tais cargas foram modeladas segundo o modelo do tipo 2 (BURCH et al., 2003), segundo as mesmas justificativas apresentadas para o SD de 15 nós.

Os parâmetros das linhas utilizados para a construção do SD de 24 nós foram derivados do SD original do IEEE. No SD original, existem cinco configurações que se 
distinguem pelo tipo de cabo/linha utilizados, espaçamento entre os condutores e número de fases (KERSTING, 2001). Como somente trechos trifásicos foram considerados para a construção do SD de 24, apenas duas destas cinco configurações (configuração 300 e 301), referentes a linhas aéreas, estão presentes no novo sistema construído. No Anexo B também estão apresentos os parâmetros de linha de sequências positiva e zero para as duas configurações empregadas no sistema teste de 24 nós.

Para o cálculo das impedâncias de sequência, considerou-se a transposição das linhas do SD. Embora na prática esta situação é raramente verificada, como é o caso do SD de 34 nós original, esta é uma consideração que pode ser assumida para se calcular as impedâncias de sequência a partir das matrizes de impedância de fase do sistema não transposto (KERSTING, 2002).

De acordo com Kersting (2002), as matrizes de impedância de fase $\left[Z_{a b c}\right]$ dos sistemas não transpostos podem ser modificadas, assumindo a forma da equação (77). Esta modificação consiste em fazer com que os elementos da diagonal principal da matriz modificada $\left[Z_{a b c}^{\prime}\right]$ sejam iguais à média aritmética dos elementos da diagonal da matriz $\left[Z_{a b c}\right]$; e que os elementos fora da diagonal de $\left[Z_{a b c}^{\prime}\right]$ sejam iguais à média aritmética dos elementos fora da diagonal da matriz $\left[Z_{a b c}\right]$, conforme mostram as equações (78) e (79) (KERSTING, 2002).

$$
\begin{aligned}
& {\left[Z_{a b c}^{\prime}\right]=\left[\begin{array}{ccc}
z_{p} & z_{m} & z_{m} \\
z_{m} & z_{p} & z_{m} \\
z_{m} & z_{m} & z_{p}
\end{array}\right]} \\
& z_{p}=\frac{1}{3}\left(z_{a a}+z_{b b}+z_{c c}\right) \\
& z_{m}=\frac{1}{3}\left(z_{a b}+z_{b c}+z_{c a}\right)
\end{aligned}
$$

Com a matriz $\left[Z_{a b c}^{\prime}\right]$, a matriz de impedância de sequência $\left[Z_{012}\right]$, que é derivada de $\left[Z_{a b c}^{\prime}\right]$, será uma matriz diagonal, como mostra a equação (77). Nesta equação, $z_{00}, z_{11}$ e $z_{22}$ são as impedâncias de sequência zero, positiva e negativa, respectivamente, calculadas conforme as equações (81) e (82) (KERSTING, 2002).

$$
\left[Z_{012}\right]=\left[\begin{array}{ccc}
Z_{00} & 0 & 0 \\
0 & Z_{11} & 0 \\
0 & 0 & Z_{22}
\end{array}\right]
$$




$$
\begin{gathered}
z_{00}=z_{p}+2 z_{m} \\
z_{11}=z_{22}=z_{p}-z_{m}
\end{gathered}
$$

Para o cálculo da susceptância em derivação shunt de sequência positiva $\left(B_{1}\right)$ optouse por efetuar procedimento análogo ao descrito para as impedâncias de sequência. Contudo, desta vez, partiu-se das matrizes de susceptância de fase do SD original de 34 nós.

Vale comentar que, de acordo com Kersting e Phillips (1995), considerar o acoplamento entre as sequências (elementos fora da diagonal não nulos) não é vantajoso para a análise utilizando componentes simétricos, sendo que "é apenas quando os termos fora da diagonal são zero que as redes de sequência tornam-se desacopladas e a aplicação das componentes simétricas é garantida" (KERSTING e PHILLIPS, 1995), p. 716, tradução nossa). ${ }^{3}$

Conforme mencionado anteriormente no item 6.1 , o parâmetro $B_{1}$ só será aplicável à ARHM (capítulo 4), já que nas equações das MTDFs (capítulo 3), não se considera a admitância shunt no modelo, sendo necessárias apenas as impedâncias de sequência. Da mesma maneira que para o sistema do item 6.1 , o parâmetro $B 0$ consta na tabela do Anexo $\mathrm{B}$ somente para fins de registro e referência futura, já que este parâmetro não é utilizado na metodologia de alocação de medidores de QEE proposta.

$\mathrm{Na}$ Tabela 9, estão especificadas as informações dos trechos do SD de 24 nós, isto é, nó de origem e destino (primeira e segunda colunas da tabela), comprimento da linha e tipo de configuração.

Similarmente ao SD do item 6.1.1, bancos de capacitores locais (consumidores) estão presentes com o propósito de corrigir o FP local para 0,92. Uma vez que o SD de 24 nós é um sistema fracamente carregado, ou seja, sua carga total é relativamente pequena, apenas cargas com potência aparente acima de $100 \mathrm{kVA}$ foram selecionadas para terem o FP corrigido. As respectivas capacitâncias e potências nominais destes bancos de capacitores são apresentadas na Tabela 10, e as posições destes podem ser visualizadas na Figura 37 do sistema.

\footnotetext{
${ }^{3}$ No original: "It is only when the off-diagonal terms are zero that the sequence networks become uncoupled and the application of symmetrical components is warranted."
} 
Tabela 9 - Trechos de linhas (nós de origem e nós de destino), comprimento e configuração do trecho.

\begin{tabular}{lcccc}
\hline \multicolumn{2}{c}{ Linhas } & $\begin{array}{c}\text { Comprimento } \\
(\text { milhas })\end{array}$ & $\begin{array}{c}\text { Comprimento } \\
(\mathrm{km})\end{array}$ & Configuração \\
\hline 800 & 802 & 0,4886 & 0,7863 & 300 \\
802 & 806 & 0,3277 & 0,5274 & 300 \\
806 & 808 & 6,1042 & 9,8237 & 300 \\
808 & 812 & 7,1023 & 11,4300 & 300 \\
812 & 814 & 5,6307 & 9,0617 & 300 \\
814 & 850 & 0,0019 & 0,0031 & 301 \\
816 & 824 & 1,9337 & 3,1120 & 301 \\
824 & 828 & 0,1591 & 0,2560 & 301 \\
828 & 830 & 3,8712 & 6,2301 & 301 \\
830 & 854 & 0,0985 & 0,1585 & 301 \\
832 & 858 & 0,9280 & 1,4935 & 301 \\
834 & 860 & 0,3826 & 0,6157 & 301 \\
834 & 842 & 0,0530 & 0,0853 & 301 \\
836 & 840 & 0,1629 & 0,2622 & 301 \\
836 & 862 & 0,0530 & 0,0853 & 301 \\
842 & 844 & 0,2557 & 0,4115 & 301 \\
844 & 846 & 0,6894 & 1,1095 & 301 \\
846 & 848 & 0,1004 & 0,1616 & 301 \\
850 & 816 & 0,0587 & 0,0945 & 301 \\
852 & 832 & 0,0019 & 0,0031 & 301 \\
854 & 852 & 6,9754 & 11,2258 & 301 \\
858 & 834 & 1,1042 & 1,7770 & 301 \\
860 & 836 & 0,5076 & 0,8169 & 301 \\
\hline
\end{tabular}

Tabela 10 - Nós de instalação, capacitância e potência reativa trifásica nominal dos bancos de capacitores.

\begin{tabular}{ccc}
\hline Nós & $\begin{array}{c}\text { Capacitância } \\
(\mu F)\end{array}$ & $\begin{array}{c}\text { Potência } \\
(k V A r)\end{array}$ \\
\hline 816 & 0,064 & 15,01 \\
832 & 0,142 & 33,3 \\
844 & 0,614 & 143,64 \\
848 & 0,101 & 23,64 \\
860 & 0,142 & 33,24 \\
\hline
\end{tabular}

Além dos capacitores dos consumidores, é importante mencionar que o sistema de 34 nós original já possui dois capacitores shunt. Para esta pesquisa, estes dois bancos de capacitores foram considerados permanentemente conectados ao sistema durante a realização de todas as análises, com o propósito de regularem a tensão nos respectivos pontos de conexão. Este dois capacitores são originalmente instalados nos nós 844 e 848 do SD de 34 nós, e suas posições permanecem inalteradas no novo sistema. Por simplicidade, estes capacitores não estão representados na Figura 37. Na Tabela 11 são apresentados os valores da potência reativa trifásica nominal para este par de bancos de capacitores e respectiva capacitância. 
Tabela 11 - Capacitância e potência reativa trifásica nominal para os bancos de capacitores fixos.

\begin{tabular}{ccc}
\hline Nós & $\begin{array}{c}\text { Capacitância } \\
(\mu F)\end{array}$ & $\begin{array}{c}\text { Potência } \\
(k V A r)\end{array}$ \\
\hline 844 & 1,283 & 300 \\
848 & 1,925 & 450 \\
\hline
\end{tabular}

De acordo com o procedimento descrito no item 4.2 do Capítulo 4, para os cinco capacitores instalados $(m=5)$, o conjunto $C$ possuirá $2^{5}=32$ cenários distintos de operação, isto é, cenários distintos com relação ao estado de conexão dos bancos, que serão incluídos na ARHM e, posteriormente, considerados no processo de alocação dos medidores de QEE.

Uma vez que o estado de conexão dos capacitores do nó 844 e 848 , isto é, dos capacitores já conectados no SD original, permanece inalterado, estes não influenciarão na quantidade de cenários do conjunto $C$, ou seja, são considerados capacitores fixos na etapa de execução da ARHM. Os 32 cenários estão listados na Tabela 12. Nesta tabela, as nomenclaturas $844^{*}$ e $848^{*}$ denotam os nós em que os dois capacitores fixos estão conectados, respectivamente.

Tabela 12 - Cenários de bancos de capacitores do conjunto $\boldsymbol{C}$ para o sistema de 24 nós.

\begin{tabular}{cc|cc}
\hline $\begin{array}{c}\text { Cenário } \\
\left(c_{i}\right)\end{array}$ & $\begin{array}{c}\text { Bancos conectados } \\
\text { (nós) }\end{array}$ & $\begin{array}{c}\text { Cenário } \\
\left(c_{i}\right)\end{array}$ & $\begin{array}{c}\text { Bancos conectados } \\
(\text { nós })\end{array}$ \\
\hline 1 & $844^{*} ; 848^{*}$ & 17 & $844^{*} ; 848^{*} ; 816$ \\
2 & $844^{*} ; 848^{*} ; 860$ & 18 & $844^{*} ; 848^{*} ; 816 ; 860$ \\
3 & $844^{*} ; 848^{*} ; 848$ & 19 & $844^{*} ; 848^{*} ; 816 ; 848$ \\
4 & $844^{*} ; 848^{*} ; 848 ; 860$ & 20 & $844^{*} ; 848^{*} ; 816 ; 848 ; 860$ \\
5 & $844^{*} ; 848^{*} ; 844$ & 21 & $844^{*} ; 848^{*} ; 816 ; 844$ \\
6 & $844^{*} ; 848^{*} ; 844 ; 860$ & 22 & $844^{*} ; 848^{*} ; 816 ; 844 ; 860$ \\
7 & $844^{*} ; 848^{*} ; 844 ; 848$ & 23 & $844^{*} ; 848^{*} ; 816 ; 844 ; 848$ \\
8 & $844^{*} ; 848^{*} ; 844 ; 848 ; 860$ & 24 & $844^{*} ; 848^{*} ; 816 ; 844 ; 848 ; 860$ \\
9 & $844^{*} ; 848^{*} ; 832$ & 25 & $844^{*} ; 848^{*} ; 816 ; 832$ \\
10 & $844^{*} ; 848^{*} ; 832 ; 860$ & 26 & $844^{*} ; 848^{*} ; 816 ; 832 ; 860$ \\
11 & $844^{*} ; 848^{*} ; 832 ; 848$ & 27 & $844^{*} ; 848^{*} ; 816 ; 832 ; 848$ \\
12 & $844^{*} ; 848^{*} ; 832 ; 848 ; 860$ & 28 & $844^{*} ; 848^{*} ; 816 ; 832 ; 848 ; 860$ \\
13 & $844^{*} ; 848^{*} ; 832 ; 844 ;$ & 29 & $844^{*} ; 848^{*} ; 816 ; 832 ; 844$ \\
14 & $844^{*} ; 848^{*} ; 832 ; 844 ; 860$ & 30 & $844^{*} ; 848^{*} ; 816 ; 832 ; 844 ; 860$ \\
15 & $844^{*} ; 848^{*} ; 832 ; 844 ; 848$ & 31 & $844^{*} ; 848^{*} ; 816 ; 832 ; 844 ; 848$ \\
16 & $844^{*} ; 848^{*} ; 832 ; 844 ; 848 ; 860$ & 32 & $844^{*} ; 848^{*} ; 816 ; 832 ; 844 ; 848 ; 860$ \\
\hline
\end{tabular}

É possível notar que os capacitores com estado de conexão fixo estão sempre conectados em todos os cenários $(844 * ; 848 *)$. Verifica-se também que nos mesmos nós 844 e 848 existem capacitores eventualmente conectados simultaneamente. Todavia, é importante salientar que cada um dos cenários do conjunto $C$ representam valores de capacitância distintos, impactando em diferentes e potenciais frequências de ressonância harmônica. Os 
cenários 1 e 7 da Tabela 12, por exemplo, resultarão em distintas potenciais condições de ressonância harmônica a serem consideradas no processo de alocação.

Por fim, afirma-se que os demais parâmetros do SD teste de 24 nós são definidos de acordo com o SD original de 34 nós do IEEE, com exceção dos reguladores de tensão que não são considerados para o sistema simplificado.

\subsubsection{Resultados da alocação para o SD de 24 nós}

Neste item estão apresentados os resultados para o sistema de 24 nós derivado do sistema de 34 nós do IEEE.

A organização da apresentação dos resultados segue praticamente a mesma ordem da apresentação feita para o SD de 15 nós no item 6.1.1, com exceção da análise de varredura em frequência e do estudo da variabilidade das potências nominais dos bancos de capacitores. Vale adiantar que a apresentação do SD de 15 nós possui um maior detalhamento, já que este foi considerado o SD base para o desenvolvimento e teste da metodologia. Em contrapartida, o estudo do sistema de 24 nós tem como principal objetivo verificar a aplicabilidade do método em um sistema com características distintas. Sendo assim, optou-se pela apresentação mais direta dos resultados obtidos. Todavia, cabe salientar que tanto a varredura em frequência como o estudo de variabilidade das potências nominais dos bancos de capacitores poderiam ser executados de maneira a verificar os pontos comentados para o SD de 15 nós.

Diante do exposto, no item 6.2.1.1 tem-se a análise das soluções de alocação que contempla tanto as VTCDs como as potencias condições de ressonância harmônica, assim como originalmente proposto pela metodologia de alocação. Em seguida, nos itens 6.2.1.2 e 6.2.1.3, são apresentadas as soluções de apresentação dissociadas, isto é, soluções obtidas via otimização da MCVT e MCRH separadamente.

\subsubsection{Análise da solução de alocação final}

As soluções de alocação em função dos limiares $\tau, \delta_{i n f}$ e $\delta_{\text {sup }}$, estão apresentadas na Tabela 13 e na Tabela 14. Nestas tabelas, para cada valor dos limiares, tem-se a solução de alocação e os respectivos nós equivalentes (discriminados entre chaves). 
Tabela 13 - Soluções de alocação e nós equivalentes para $\tau$ variando de 1,0 a 0,$5 ; \boldsymbol{\delta}_{\text {sup }}$ de 1,1 a 1,2 p.u. e $\boldsymbol{\delta}_{\text {inf }}$ de 0,9 a 0,5 p.u..

\begin{tabular}{|c|c|c|c|c|c|c|c|c|c|}
\hline$\tau$ & $\begin{array}{l}\delta_{\text {sup }} \\
\text { (p.u.) }\end{array}$ & $\begin{array}{l}\delta_{\text {inf }} \\
\text { (p.u.) }\end{array}$ & $\begin{array}{l}\text { Alocação } \\
\text { (nós) }\end{array}$ & $\begin{array}{c}\text { Nós } \\
\text { equivalentes }\end{array}$ & $\tau$ & $\begin{array}{l}\delta_{\text {sup }} \\
\text { (p.u.) }\end{array}$ & $\begin{array}{l}\delta_{\text {inf }} \\
\text { (p.u.) }\end{array}$ & $\begin{array}{l}\text { Alocação } \\
\text { (nós) }\end{array}$ & $\begin{array}{c}\text { Nós } \\
\text { equivalentes }\end{array}$ \\
\hline \multirow{10}{*}{1,0} & \multirow{5}{*}{1,1} & 0,9 & \multirow{4}{*}{$802 ; 806 ; 812 ; 814 ; 832 ; 836 ; 848 ; 858$} & \multirow{4}{*}{$\begin{array}{c}814\{850\} \\
832\{852\} \\
836\{840 ; 862\}\end{array}$} & \multirow{10}{*}{0,7} & \multirow{5}{*}{1,1} & 0,9 & \multirow{2}{*}{$806 ; 812 ; 832$} & \multirow{2}{*}{$832\{852 ; 858\}$} \\
\hline & & 0,8 & & & & & 0,8 & & \\
\hline & & 0,7 & & & & & 0,7 & $806 ; 814 ; 832$ & $814\{816 ; 828 ; 850\} ; 832\{852 ; 858\}$ \\
\hline & & 0,6 & & & & & 0,6 & $806 ; 812 ; 832$ & $832\{852 ; 858\}$ \\
\hline & & 0,5 & $800 ; 802 ; 806 ; 812 ; 814 ; 832 ; 836 ; 848 ; 858$ & $814\{850\} ; 832\{852\} ; 836\{840 ; 862\}$ & & & 0,5 & $800 ; 806 ; 812 ; 858$ & - \\
\hline & \multirow{5}{*}{1,2} & 0,9 & \multirow{4}{*}{$802 ; 806 ; 812 ; 814 ; 832 ; 836 ; 848 ; 858$} & \multirow{4}{*}{$\begin{array}{c}814\{850\} \\
832\{852\} \\
836\{840 ; 862\}\end{array}$} & & \multirow{5}{*}{1,2} & 0,9 & \multirow{4}{*}{$806 ; 812 ; 832$} & \multirow{4}{*}{$\begin{array}{c}806\{802\} ; \\
832\{852 ; 858\}\end{array}$} \\
\hline & & 0,8 & & & & & 0,8 & & \\
\hline & & 0,7 & & & & & 0,7 & & \\
\hline & & 0,6 & & & & & 0,6 & & \\
\hline & & 0,5 & $800 ; 802 ; 806 ; 812 ; 814 ; 832 ; 836 ; 848 ; 858$ & $814\{850\} ; 832\{852\} ; 836\{840 ; 862\}$ & & & 0,5 & $800 ; 812 ; 832$ & $832\{852\}$ \\
\hline \multirow{10}{*}{0,9} & \multirow{5}{*}{1,1} & 0,9 & \multirow{3}{*}{$806 ; 812 ; 814 ; 832 ; 848 ; 858$} & \multirow{3}{*}{$\begin{array}{c}814\{816 ; 824 ; 828 ; 850\} \\
832\{852\}\end{array}$} & \multirow{10}{*}{0,6} & \multirow{5}{*}{1,1} & 0,9 & \multirow{4}{*}{$806 ; 836 ; 854$} & \multirow{4}{*}{$\begin{array}{c}806\{802\} ; \\
836\{840 ; 860 ; 862\}\end{array}$} \\
\hline & & 0,8 & & & & & 0,8 & & \\
\hline & & 0,7 & & & & & 0,7 & & \\
\hline & & 0,6 & $806 ; 812 ; 828 ; 832 ; 848 ; 858$ & $828\{824\} ; 832\{852\}$ & & & 0,6 & & \\
\hline & & 0,5 & $800 ; 806 ; 812 ; 814 ; 832 ; 848 ; 858$ & $814\{816 ; 824 ; 828 ; 850\} ; 832\{852\}$ & & & 0,5 & $\begin{array}{l}800 ; 806 ; 854 ; \\
858\end{array}$ & - \\
\hline & \multirow{5}{*}{1,2} & 0,9 & \multirow{3}{*}{$806 ; 812 ; 814 ; 832 ; 848 ; 858$} & \multirow{3}{*}{$\begin{array}{c}814\{816 ; 824 ; 828 ; 850\} \\
832\{852\}\end{array}$} & & \multirow{5}{*}{1,2} & 0,9 & \multirow{4}{*}{$806 ; 836 ; 854$} & \multirow{4}{*}{$\begin{array}{c}806\{802\} ; \\
836\{840 ; 860 ; 862\}\end{array}$} \\
\hline & & 0,8 & & & & & 0,8 & & \\
\hline & & 0,7 & & & & & 0,7 & & \\
\hline & & 0,6 & $806 ; 812 ; 828 ; 832 ; 848 ; 858$ & $828\{824\} ; 832\{852\}$ & & & 0,6 & & \\
\hline & & 0,5 & $800 ; 812 ; 814 ; 832 ; 848 ; 858$ & $814\{816 ; 824 ; 828 ; 850\} ; 832\{852\}$ & & & 0,5 & $800 ; 854 ; 858$ & - \\
\hline \multirow{10}{*}{0,8} & & 0,9 & & & & & 0,9 & & \\
\hline & & 0,8 & & & & & 0,8 & & \\
\hline & 1,1 & 0,7 & $806 ; 814 ; 848 ; 852$ & $814\{816 ; 828 ; 850\}$ & & 1,1 & 0,7 & $806 ; 854$ & - \\
\hline & & 0,6 & & & & & 0,6 & & \\
\hline & & 0,5 & $800 ; 806 ; 814 ; 848 ; 858$ & $814\{816 ; 850\}$ & 0,5 & & 0,5 & $\begin{array}{l}800 ; 806 ; 834 \\
854\end{array}$ & $834\{836 ; 840 ; 842 ; 858 ; 860 ; 862\}$ \\
\hline & & 0,9 & & & & & 0,9 & & \\
\hline & & 0,8 & $806 ; 812 ; 848 ; 852$ & $806\{802\}$ & & & 0,8 & & \\
\hline & 1,2 & 0,7 & $806 ; 814 ; 848 ; 852$ & $806\{802 ; 802\} ; 814\{816 ; 828 ; 850\} ;$ & & 1,2 & 0,7 & $806 ; 832 ; 854$ & $832\{852\}$ \\
\hline & & 0,6 & $806 ; 812 ; 848 ; 852$ & $806\{802\}$ & & & 0,6 & & \\
\hline & & 0,5 & $800 ; 812 ; 848 ; 858$ & - & & & 0,5 & $800 ; 834 ; 854$ & $834\{836 ; 840 ; 842 ; 858 ; 860 ; 862\}$ \\
\hline
\end{tabular}


Tabela 14 - Soluções de alocação e nós equivalentes para $\tau$ variando de 0,4 a 0,$1 ; \boldsymbol{\delta}_{\text {sup }}$ de 1,1 a 1,2 p.u. e $\boldsymbol{\delta}_{\text {inf }}$ de 0,9 a 0,5 p.u..

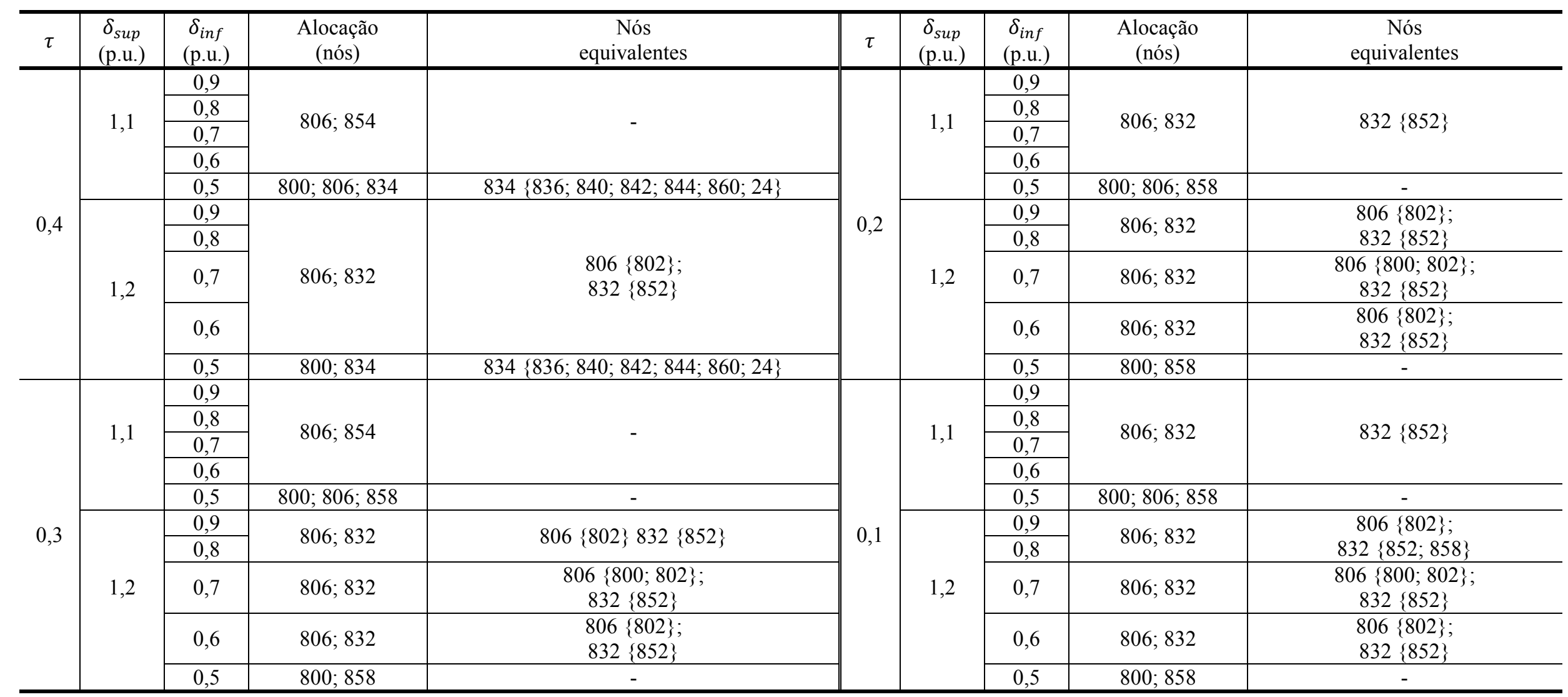


Conforme é possível observar, a variação dos limiares de tensão, tanto superior como o inferior, quando comparado ao SD de 15 nós, exerceram maior influência na solução de alocação final para um mesmo limiar $\tau$. Cabe recordar que para o SD de 15 nós nenhuma variação foi detectada. Além disso, para o SD de 24 nós, também foi observada certa regularidade com relação aos nós equivalentes obtidos quando $\delta_{\text {sup }}$ foi variado e $\tau$ mantido fixo, sendo este comportamento também observado para o SD de 15 nós.

Verifica-se que a quantidade mínima de monitores para o completo monitoramento do SD de 24 nós é em geral superior à quantidade mínima necessária para o SD de 15 nós, comportamento este que é observado mesmo para valores mais baixos de $\tau$. Todavia, conforme $\tau$ diminui, a quantidade mínima de monitores tende a diminuir, partindo de 9 monitores para 2 monitores. Esta redução na quantidade de monitores é esperada, pois a esparsidade da MCF tende a diminuir.

Para a maioria das soluções de alocação apresentadas, a disposição física dos monitores é relativamente bem distribuída ao longo do SD de 24 nós, concentrando-se, principalmente, em três principais regiões. A primeira região compreende os nós 800,802 , $806,808,812,814,816,824,828$ e 850 . Já a segunda região os nós 832,851 e 858 . E por último, a terceira região que se refere ao nó 848. Na Figura 38, as três regiões estão evidenciadas sobre o diagrama do SD.

Figura 38 -Diagrama unifilar do SD de 24 nós com as três principais regiões referentes aos nós de instalação dos medidores de QEE, segundo a maioria das soluções de alocação

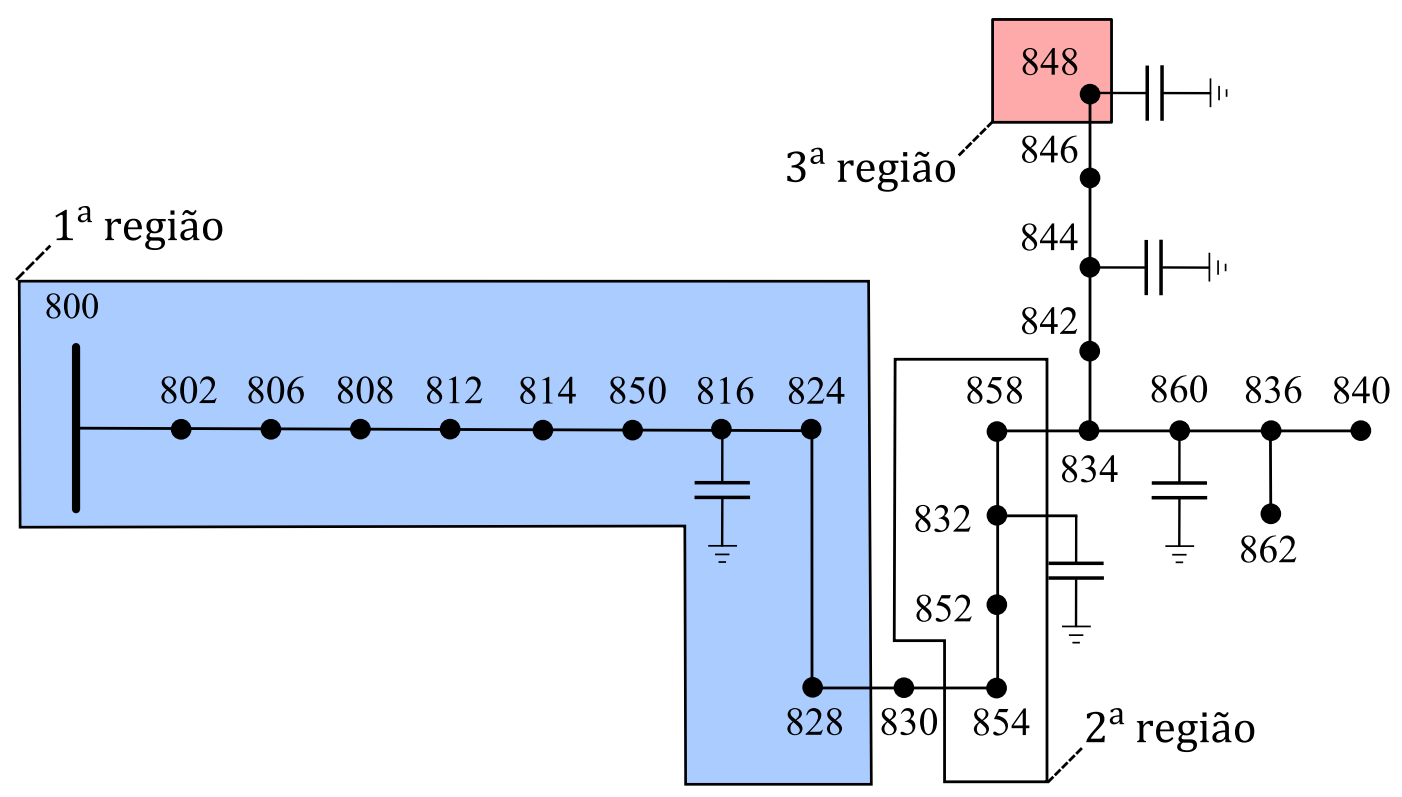


Também é possível observar que os nós equivalentes tendem a estarem dispostos próximos uns dos outros, como é o caso, por exemplo, dos nós equivalentes ao nó 814 , que recaem na primeira região (nós $816,824,828,850$ ).

Outro nó equivalente bastante recorrente é o nó 852, equivalente ao nó 832, situado na segunda região. Originalmente, no sistema de 34 nós do IEEE, entre estes nós, existia um regulador de tensão, o qual foi desconsiderado no SD simplificado de 24 nós. Entretanto, o trecho existente entre estes nós foi mantido no sistema simplificado e representa uma distância de 10 pés (aproximadamente 3 metros). Esta mesma situação ocorre entre os nós 814 e 850 (primeira região), onde no SD original também existia conectado um regulador de tensão e que foi desconsiderado na simplificação. Especificamente nestes casos, afirma-se que a significativa proximidade física destes nós os tornam eletricamente idênticos (832 e 852; e 814 e 850), resultando assim na mesma observabilidade para as VTCDs e para as condições de ressonância, consequentemente, resultando em linhas idênticas na MCF.

Em contrapartida, para o nó 848 não foi encontrado nenhum nó equivalente, mesmo este nó constando em todas as soluções de $\tau=1,0$ até $\tau=0,8$, como pode ser visto na Tabela 13.

Os resultados apresentados até o momento dão indícios de que a alocação dos medidores não é uma tarefa simples e que realmente depende da topologia, parâmetros e condições de operação do sistema, bem como da definição dos limiares. Conclusão similar foi esboçada para o SD de 15 nós. Porém, para o SD de 24 nós, esta característica demonstrou-se mais evidente.

Antes de prosseguir com a presente análise, é conveniente apresentar os resultados obtidos para a ARHM aplicada ao SD de 24 nós. A ARHM foi realizada para todas as 32 combinações dos bancos de capacitores (Tabela 12), sendo que a análise foi feita de $60 \mathrm{~Hz}$ $\left(h_{\text {mín }}\right)$ até 7,68 $\mathrm{kHz}\left(h_{\text {máx }}\right)$. Cabe comentar que a frequência fundamental deste sistema é distinta do SD de 15 nós e que a frequência harmônica máxima admissível para a ARHM foi calculada com base em um medidor de QEE típico com taxa de amostragem de 256 amostras/ciclo.

Foram encontradas $F=150$ frequências harmônicas de ressonância, sendo que algumas destas frequências são repetidas. No total, 32 frequências distintas foram encontradas. Estes dados encontram-se mais convenientemente apresentados na tabela do Apêndice B. Nesta tabela podem ser consultadas as frequências de ressonância harmônica $F_{i}$ encontradas, as respectivas ordens harmônicas $h$, bem como os valores em $\mathrm{Hz}\left(f_{h}\right)$. Ainda 
nesta tabela, têm-se as magnitudes das impedâncias modais $\left|\zeta_{h}\right|$ associadas às condições de ressonância.

Retomando a análise das soluções de alocação, e de maneira a ilustrar a forma das MCFs obtidas para o SD de 24 nós, duas MCFs serão apresentadas graficamente na sequência. Para cada uma das MCFs também estão representadas graficamente as linhas correspondentes às soluções de alocação das respectivas MCFs reduzidas, assim como feito anteriormente para o SD de 15 nós.

Ressalta-se que as MCFs calculadas para o SD de 24 nós possuem 24 linhas (referentes aos 24 nós do sistema elétrico) e 198 colunas, sendo as 48 primeiras colunas relacionadas à MCVT e as colunas de 49 a 198 relativas à MCRH.

Como as soluções de alocação não diferem muito em relação à variação dos limiares de tensão, escolheu-se variar somente o valor de $\tau$. Dessa maneira, na Figura 39 e na Figura 40 estão respectivamente apresentadas a representação gráfica da MCF para $\tau=1,0, \delta_{\text {sup }}=$ 1,1 p.u. e $\delta_{\text {inf }}=0,5$ p.u. e a representação gráfica das linhas da MCF reduzida que são correspondentes à solução de alocação para os referidos limiares. Analogamente na Figura 41 tem-se a representação para a MCF para $\tau=1,0, \delta_{\text {sup }}=1,1$ p.u. e $\delta_{\text {inf }}=0,5$ p.u., e na Figura 42 a representação das linhas da MCF reduzida que são correspondentes à solução de alocação para os referidos limiares.

Para a MCF da Figura 39, é possível verificar que as primeiras 48 colunas, referentes à MCVT, configuram a porção menos esparsa da matriz MCF como um todo. As colunas de 25 a 48, associadas às elevações de tensão, tendem a possuir menor importância na determinação da solução de alocação em comparação aos afundamentos de tensão. Esta afirmação é possível devido à presença de mais elementos matriciais unitários (espaços preenchidos) para a região das elevações e de menos elementos matriciais nulos (espaços em branco) para a região relacionada aos afundamentos de tensão.

As demais colunas da MCF, correspondentes à cobertura das frequências de ressonância calculadas, configuram a região mais esparsa de toda a $\mathrm{MCF}$, sendo, portanto, a parcela desta matriz que preponderantemente influenciará na determinação das soluções de alocação.

$\mathrm{Na}$ MCF reduzida da Figura 40, associada à MCF da Figura 41, verifica-se que a projeção no eixo horizontal constitui uma sequência de valores unitários, garantindo a completa observabilidade das VTCDs, bem como das frequências de ressonância harmônica. 
Figura $39-$ MCF obtida para $\boldsymbol{\tau}=\mathbf{1}, \mathbf{0}, \boldsymbol{\delta}_{\text {inf }}=\mathbf{0}, \mathbf{5}$ p.u. e $\boldsymbol{\delta}_{\text {sup }}=\mathbf{1}, \mathbf{1}$ p.u.

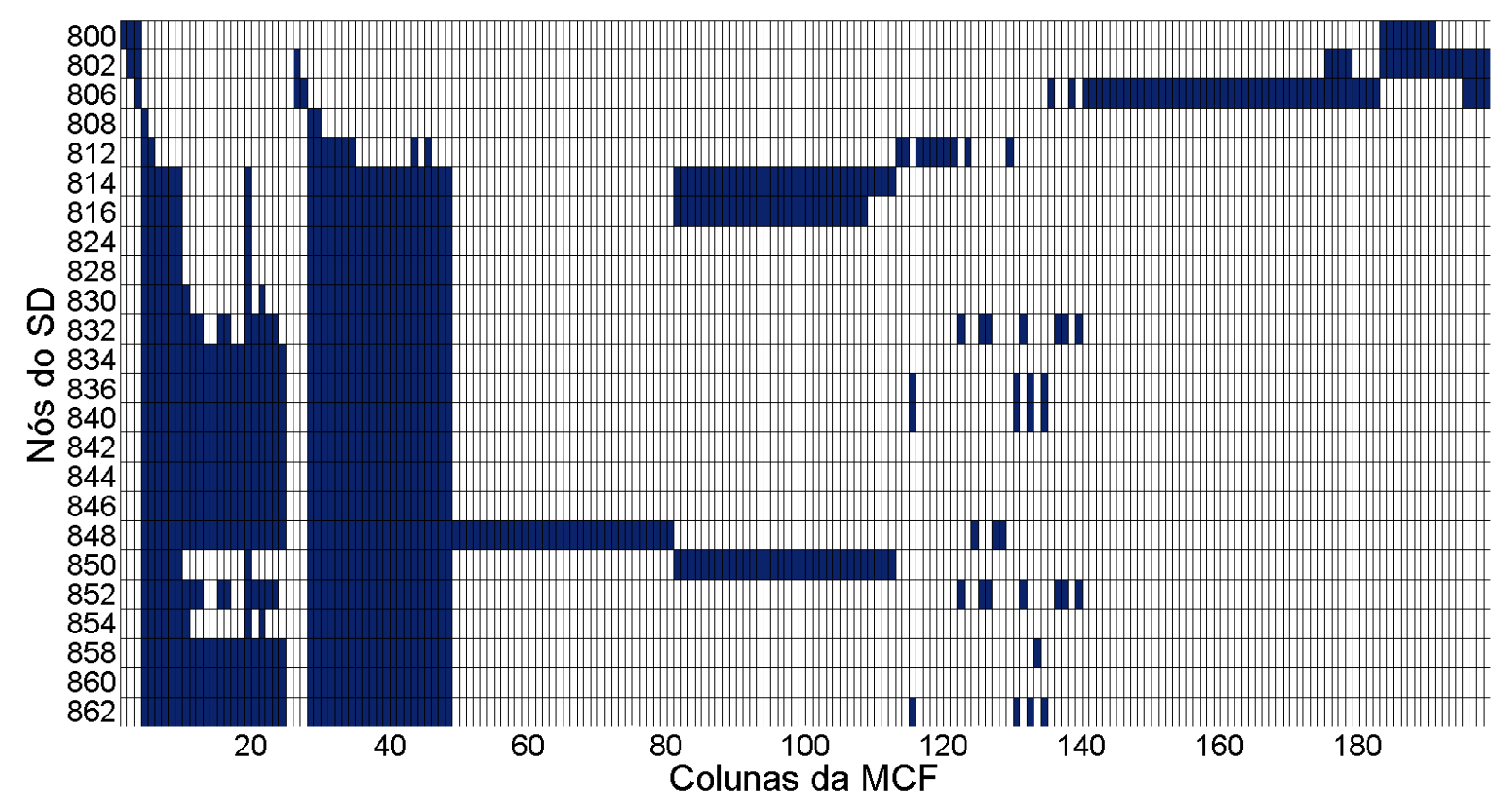

Figura 40 - MCF reduzida a partir da MCF para $\boldsymbol{\tau}=\mathbf{1}, \mathbf{0} ; \boldsymbol{\delta}_{\text {inf }}=\mathbf{0}, \mathbf{5}$ p.u. e $\boldsymbol{\delta}_{\text {sup }}=\mathbf{1}, \mathbf{1}$ p.u., somente com linhas relativas às solução de alocação.

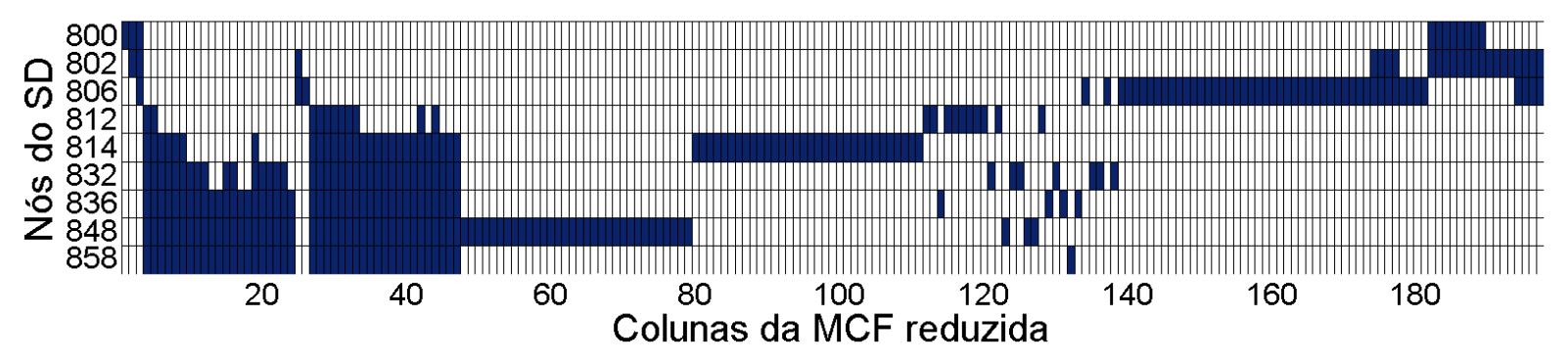

Em oposição à MCF da Figura 39, a MCF da Figura 41 mostra-se menos esparsa, e, por esta razão, a solução de alocação associada a esta matriz contém cinco monitores de QEE a menos do que a MCF anteriormente apresentada (Figura 39).

Uma vez que os limiares de tensão superior e inferior foram mantidos, conclui-se que a diminuição do limiar $\tau$ foi fator fundamental para a mínima quantidade de monitores necessária para o completo monitoramento. Vale salientar que diminuir o valor de $\tau$, significa considerar que certo nó do sistema observa mais frequências em relação a um valor de $\tau$ maior. O mesmo comportamento pode ser observado para as VTCDs, como será mais bem apresentado no item 6.2.1.2.

Novamente, para a MCF reduzida mostrada na Figura 42, obtida a partir da MCF da Figura 41, verifica-se a completa observabilidade dos fenômenos de QEE monitorados. 
A complementação dos comentários sobre o as soluções de alocação apresentadas neste item está registrada nos itens 6.2.1.2 e 6.2.1.3, nos quais as soluções dissociadas serão estudadas.

Figura $41-$ MCF obtida para $\boldsymbol{\tau}=\mathbf{0}, \mathbf{7}, \boldsymbol{\delta}_{\text {inf }}=\mathbf{0}, \mathbf{5}$ p.u.e $\boldsymbol{\delta}_{\text {sup }}=\mathbf{1}, \mathbf{1}$ p.u..

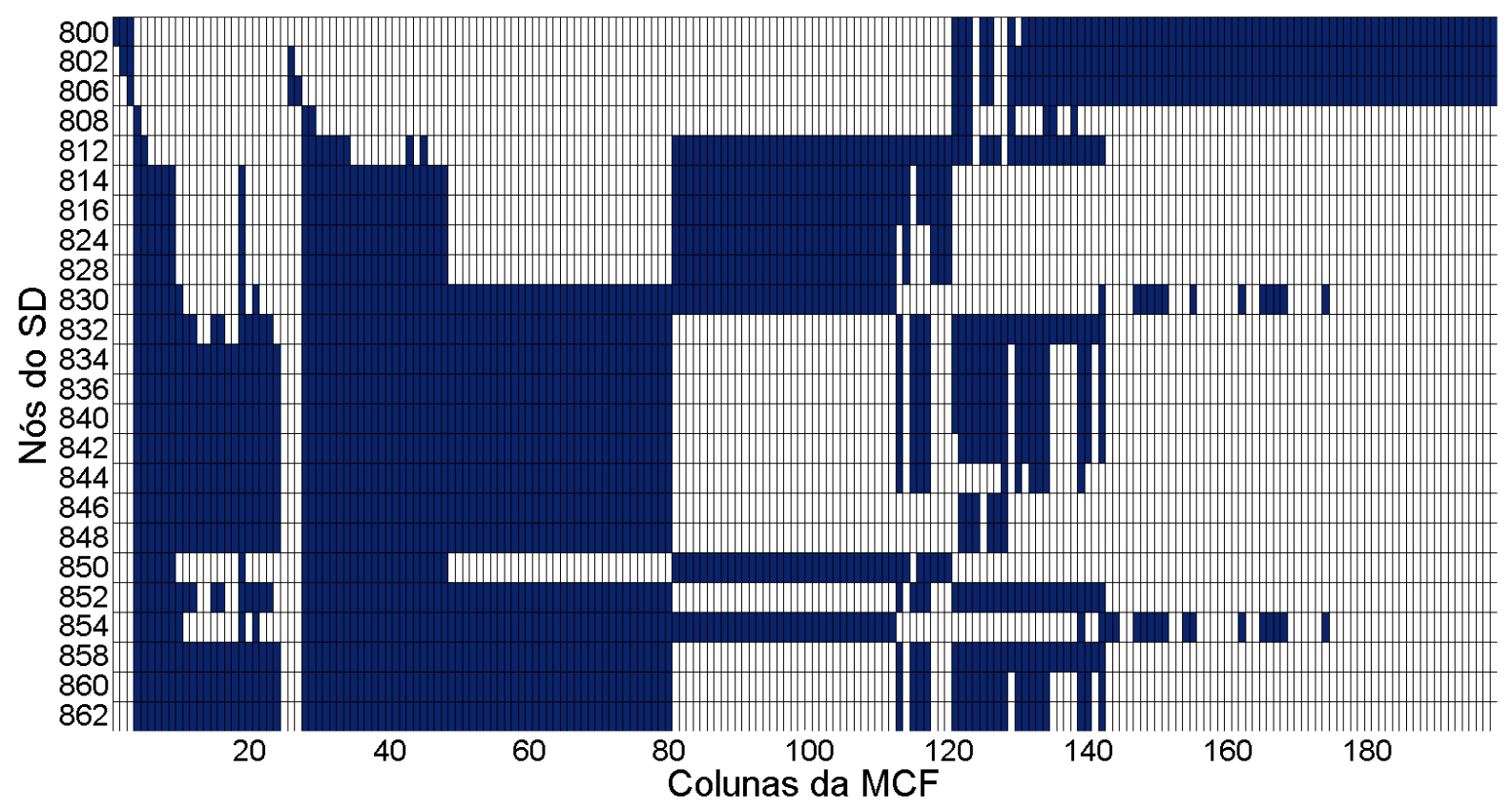

Figura 42 - MCF reduzida a partir da MCF para $\boldsymbol{\tau}=\mathbf{0}, \mathbf{7} ; \boldsymbol{\delta}_{\text {inf }}=\mathbf{0}, \mathbf{5}$ e $\boldsymbol{\delta}_{\text {sup }}=\mathbf{1}, \mathbf{1}$, somente com linhas relativas às solução de alocação.

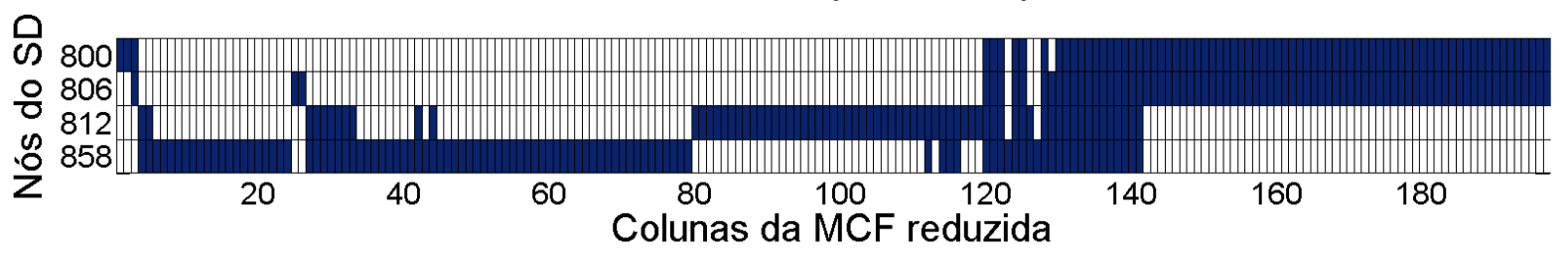

\subsubsection{Análise da solução de alocação do ponto de vista das VTCDs (MCF igual à MCVT)}

A Tabela 15 mostra as soluções de alocação pra o SD de 24 nós do ponto de vista da cobertura das VTCDs, para todas as combinações dos limiares de tensão $\left(\delta_{\text {inf }}\right.$ e $\left.\delta_{\text {sup }}\right)$.

É importante ressaltar que as soluções de alocação mostradas na Tabela 15 consideram a execução do processo de otimização fazendo-se a MCF ser igual à MCVT, conforme mostrado na equação (75) do item 6.1.1.2. 
Tabela 15 - Soluções de alocação e nós equivalentes para MCF igual à MCVT variando-se os limiares de tensão $\boldsymbol{\delta}_{\text {inf }}$ e $\boldsymbol{\delta}_{\text {sup }}$ para o SD de 24 nós.

\begin{tabular}{|c|c|c|c|}
\hline $\begin{array}{l}\delta_{\text {sup }} \\
\text { (p.u.) }\end{array}$ & $\begin{array}{l}\delta_{\text {inf }} \\
\text { (p.u.) }\end{array}$ & $\begin{array}{l}\text { Alocação } \\
\text { (nós) }\end{array}$ & Nós equivalentes \\
\hline \multirow{5}{*}{1,1} & 0,9 & $806 ; 834$ & $\begin{array}{l}834\{814 ; 816 ; 824 ; 828 ; 830 ; 832 ; 836 ; 840 ; 842 ; 844 ; 846 ; 848 ; 850852 ; 854 ; \\
\quad 858 ; 860 ; 862\}\end{array}$ \\
\hline & 0,8 & $806 ; 834$ & $\begin{array}{c}834\{814 ; 816 ; 824 ; 828 ; 830 ; 832 ; 836 ; 840 ; 842 ; 844 ; 846 ; 848 ; 850852 ; 854 ; \\
858 ; 860 ; 862\}\end{array}$ \\
\hline & 0,7 & $806 ; 834$ & $\begin{array}{c}834\{814 ; 816 ; 824 ; 828 ; 830 ; 832 ; 836 ; 840 ; 842 ; 844 ; 846 ; 848 ; 850 \text { 852; 854; } \\
858 ; 860 ; 862\}\end{array}$ \\
\hline & 0,6 & $806 ; 834$ & $834\{830 ; 832 ; 836 ; 840 ; 842 ; 844 ; 846 ; 848 ; 852 ; 854 ; 858 ; 860 ; 862\}$ \\
\hline & 0,5 & $800 ; 806 ; 834$ & $834\{836 ; 840 ; 842 ; 844 ; 846 ; 848 ; 858 ; 860 ; 862\}$ \\
\hline \multirow{5}{*}{1,2} & 0,9 & $806 ; 834$ & $806\{802\}$ \\
\hline & 0,8 & $806 ; 834$ & $834\{832 ; 836 ; 840 ; 842 ; 844 ; 846 ; 848 ; 852 ; 858 ; 860 ; 862\}$ \\
\hline & 0,7 & $806 ; 834$ & $\begin{array}{c}806\{800 ; 802\} \\
834\{832 ; 836 ; 840 ; 842 ; 844 ; 846 ; 848 ; 852 ; 858 ; 860 ; 862\}\end{array}$ \\
\hline & 0,6 & $806 ; 834$ & $\begin{array}{c}806\{802\} \\
834\{832 ; 836 ; 840 ; 842 ; 844 ; 846 ; 848 ; 852 ; 858 ; 860 ; 862\}\end{array}$ \\
\hline & 0,5 & $800 ; 834$ & $834\{836 ; 840 ; 842 ; 844 ; 846 ; 848 ; 858 ; 860 ; 862\}$ \\
\hline
\end{tabular}

Conforme esperado, ao se diminuir o $\operatorname{limiar} \delta_{\text {inf }}$ e se aumentar o limiar $\delta_{\text {sup }}$, menor será a quantidade de nós equivalente disponíveis. Isto ocorre em função da diminuição das linhas repetidas da $\mathrm{MCF}$, já que esta tenderá a se tornar mais esparsa.

A considerável quantidade de nós equivalentes encontrados para os diversos limiares indica que as VTCDs, causadas pelas condições de curto-circuito, se propagam com facilidade por uma considerável porção do SD. Logo, uma menor quantidade de monitores é necessária para se monitorar completamente o sistema do ponto de vista das VTCDs.

Para ilustrar a situação acima descrita, considere a representação gráfica de duas configurações de limiares de tensão. A primeira configuração determina que $\delta_{\text {sup }}=1,1$ p.u. e $\delta_{\text {inf }}=0,5$ p.u., e a MCF correspondente está representada na Figura 43. Já na Figura 45 temse a representação da MCF associada a $\delta_{\text {sup }}=1,2$ p.u. e $\delta_{i n f}=0,5$ p.u. As linhas das respectivas MCFs reduzidas, relativas às soluções de alocação correspondentes, mostradas na Tabela 15, estão representadas graficamente na Figura 44 e na Figura 46.

A observação da Figura 43 confirma a considerável quantidade de linhas idênticas, implicando em uma significativa quantidade de nós equivalentes para a solução de alocação. Embora a parcela relativa às elevações de tensões (coluna 25 até a coluna 48) possua baixa esparsidade e relativize sua importância na determinação dos nós de alocação, nota-se, por exemplo, que a linha associada ao nó 806 é determinante para que todas as elevações de tensão sejam observadas. Este fato pode ser verificado de maneira mais clara na Figura 44 da MCF reduzida, que denota a total observabilidade das VTCDs através da continuidade de 
valores unitários (espaços preenchidos) obtida da projeção das linhas relativas à solução de alocação sobre o eixo horizontal.

Figura $43-$ MCF obtida para $\boldsymbol{\delta}_{\text {inf }}=\mathbf{0 , 5}$ p.u. e $\boldsymbol{\delta}_{\text {sup }}=\mathbf{1}, \mathbf{1}$ p.u.

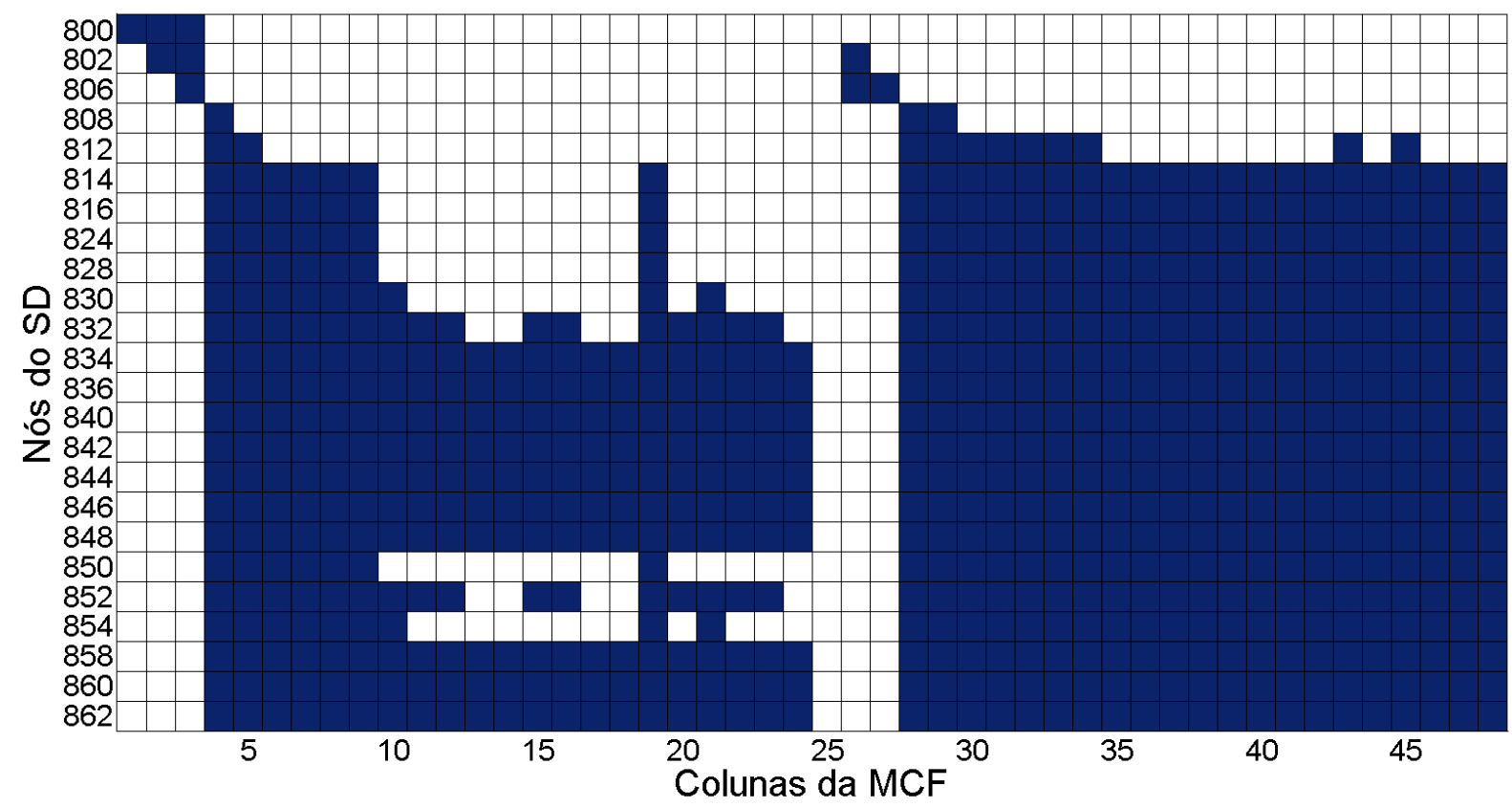

Figura $44-$ MCF reduzida a partir da MCF para $\boldsymbol{\delta}_{\text {inf }}=\mathbf{0}, \mathbf{5}$ p.u. e $\boldsymbol{\delta}_{\text {sup }}=\mathbf{1}, \mathbf{1}$ p.u., somente com as linhas referentes à solução de alocação.

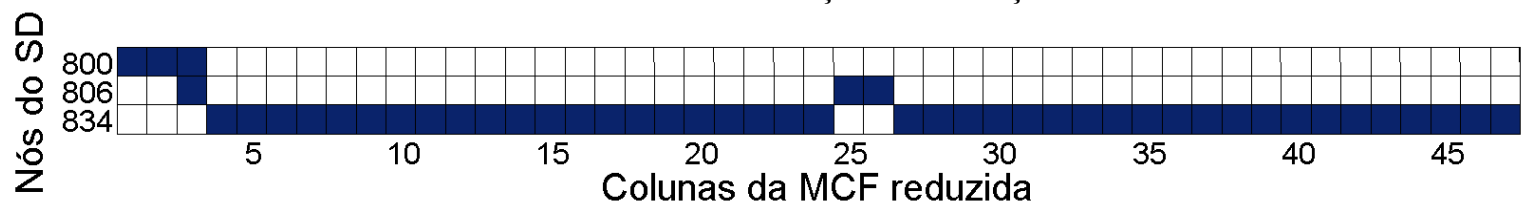

Na Figura 45, nota-se que, em relação ao SD de 15 nós, foram observadas maiores quantidade de elevações de tensão (espaços preenchidos entre a coluna 25 até a coluna 48). De fato, devido a maior esparsidade da MCF em questão, uma menor quantidade de nós equivalentes foi encontrada para a solução de alocação quando $\delta_{\text {sup }}=1,2$ p.u., como mostrado na Tabela 15.

Assim como nos casos anteriormente analisados, na representação gráfica da MCF reduzida, obtida a partir da MCF que está representada na Figura 46, também se verifica a completa observabilidade às VTCDs.

De maneira geral, nota-se da Tabela 16 que as soluções de alocação tendem a sempre favorecer um monitor mais próximo à subestação, isto é, do nó 800 , e um segundo que pode ser posicionado próximo ou dentro das 3 regiões delimitadas inicialmente no item 6.2.2.1 (Figura 38) Especificamente para o caso em que $\delta_{\text {sup }}=1,2$ p.u., o segundo monitor tende a 
ser instalado preferencialmente próximo a segunda e terceira regiões em detrimento da primeira região. Ademais, exclusivamente para o caso em que $\delta_{\text {sup }}=1,1$ p.u. e $\delta_{\text {inf }}=0,5$ p.u. um monitor adicional é alocado na subestação do sistema.

Figura 45 - MCF obtida para $\boldsymbol{\delta}_{\text {inf }}=\mathbf{0}, \mathbf{5}$ p.u. e $\boldsymbol{\delta}_{\text {sup }}=\mathbf{1}, \mathbf{2}$ p.u..

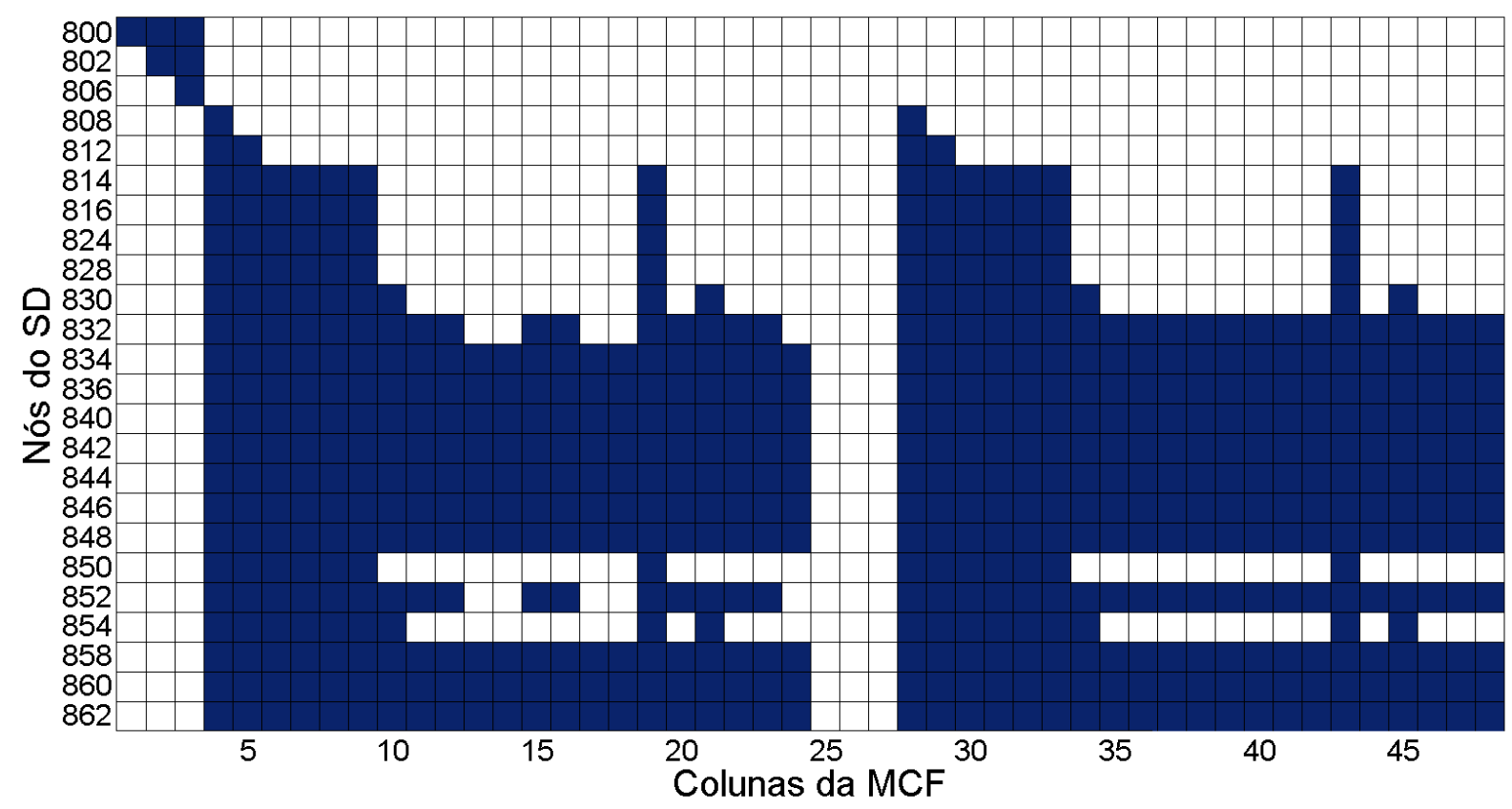

Figura 46 - MCF reduzida a partir da MCF para $\boldsymbol{\delta}_{\text {inf }}=\mathbf{0}, \mathbf{5}$ p.u. e $\boldsymbol{\delta}_{\text {sup }}=\mathbf{1}, 2$ p.u., somente com as linhas referentes à solução de alocação.

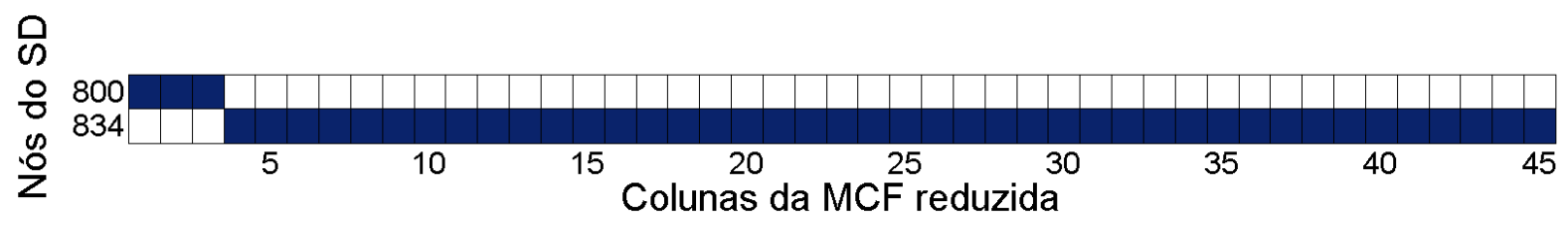

Novamente, assim como observado a partir das análises do SD de 15 nós, afirma-se que a parcela da MCF referente à MCRH, no caso de considerar a MCF completa (item 6.2.1.1), exerceu maior influência na determinação da solução de alocação. Este fato será mais bem explorado no item 6.2.1.3.

\subsubsection{Análise da solução de alocação do ponto de vista das potenciais condições de ressonância (MCRH)}

Após a execução da ARHM, 150 potenciais frequências harmônicas foram detectadas $(F=150)$ analisando-se a impedância modal do SD no intervalo de $60 \mathrm{~Hz}$ a 7,68 $k H z$, sendo que destas 150 frequências algumas são repetidas, totalizando 32 frequências 
harmônicas distintas. Estes resultados estão apresentados na tabela do Apêndice B deste documento, na qual todas as frequências de ressonância e as respectivas magnitudes das impedâncias modais são apresentadas. Cabe relembrar que para este SD a frequência fundamental é de $60 \mathrm{~Hz}$.

A obtenção da tabela do Apêndice B equivale a considerar a execução do processo de otimização fazendo-se a MCF ser igual à MCRH, conforme mostra a equação (76) do item 6.1.1.3.

$\mathrm{Na}$ Tabela 16 estão registradas as soluções de alocação para distintos valores de $\tau$. Conforme pode ser observado, a solução mais conservadora, isto é, para $\tau=1,0$ determina que 8 monitores são necessários para que todas as 52 frequências de ressonância harmônica sejam observadas. Para esta solução o nó 852 é equivalente ao nó 832, sendo assim possível optar-se por uma solução alternativa. Assim como comentado no item 6.2.1.2, entre estes nós equivalentes (852 e 832) tem-se um trecho de linha com distância significativamente curta (10 pés $\cong 3,05 \mathrm{~m}$ ), o que acaba por conferir graus de observabilidade iguais para ambos os referidos nós.

Assim como para o caso do SD de 15 nós, verifica-se que na medida em que o limiar $\tau$ tem seu valor diminuído, uma menor quantidade de monitores é requerida, passando de 8 medidores quando $\tau=1,0$ para 1 monitor quando $\tau=0,1$. Este efeito é esperado já que a esparsidade da MCF (neste caso equivalente à MCRH) diminui. Todavia, diferentemente ao observado para o SD de 15 nós a quantidade de nós equivalentes não aumenta de maneira substancial quando $\tau$ diminui, revelando indícios de que a depender das características de cada SD estudado estas soluções equivalentes podem ter comportamento bastante diversificado.

Tabela 16 - Soluções de alocação e nós equivalentes para a MCF igual à MCRH variando-se $\boldsymbol{\tau}$.

\begin{tabular}{c|c|c}
\hline$\tau$ & $\begin{array}{c}\text { Alocação } \\
\text { (nós) }\end{array}$ & Nós equivalentes \\
\hline 1,0 & $802 ; 806 ; 8126 ; 832 ; 836 ; 848 ; 858$ & $832\{852\}$ \\
\hline 0,9 & $806 ; 812 ; 832 ; 848 ; 858$ & $814\{816 ; 824 ; 828 ; 850\}$ \\
\hline 0,8 & $806 ; 812848 ; 852$ & $806\{800 ; 802\}$ \\
\hline 0,7 & $806 ; 812 ; 832$ & $806\{800 ; 802\}$ \\
\hline 0,6 & $806 ; 832 ; 854$ & $832\{852 ; 858\}$ \\
\hline 0,5 & $806 ; 854$ & $806\{800 ; 802\}$ \\
\hline 0,4 & $806 ; 854$ & $832\{852 ; 858\}$ \\
\hline 0,3 & $806 ; 812$ & $806\{800 ; 802\}$ \\
\hline 0,2 & $806 ; 812$ & $806\{800 ; 802\}$ \\
\hline 0,1 & 800 & $806\{800 ; 802\}$ \\
\hline
\end{tabular}


Nota-se ainda que, em geral, os monitores tendem a serem instalados de acordo com as três regiões delimitadas na Figura 38 do item 6.4.1, quando a MCF é composta tanto da MCVT como da MCRH. Este fato elucida que a MCRH é preponderantemente determinante dos locais de instalação dos medidores de QEE. Verifica-se ainda que para $\tau$ variando de 1,0 a 0,8, os monitores são preferencialmente distribuídos nas três regiões da Figura 38 .

Já para $\tau$ variando de 0,7 a 0,4 , os monitores situam-se na primeira e segunda região. Contudo, a partir de $\tau=0,3$ até 0,1 , os medidores estão alocados preferencialmente na primeira região. Vale ainda ressaltar que os nós equivalentes situam-se proximamente entre si, e internamente e/ ou proximamente das regiões onde estão seus respectivos nós definidos na solução de alocação. 


\section{Conclusões}

A metodologia de alocação otimizada de monitores de QEE foi aplicada para dois sistemas testes, determinando assim os melhores locais de instalação para a cobertura das situações de VTCDs e potenciais condições de ressonância harmônica.

Para alcançar o arranjo final de monitores, utilizou-se de uma matriz binária de cobertura. Esta matriz foi composta por outras duas submatrizes: a MCVT e a MCRH, sendo a primeira responsável pela cobertura das VTCDs, obtidas via o MPF, e a segunda responsável pela cobertura das frequências de ressonância calculadas pela ARHM. A concatenação por justaposição de ambas as matrizes, originando assim a MCF, permitiu ao processo de otimização disponibilizar soluções de alocação que contemplassem simultaneamente a cobertura das VTCDs e das condições de ressonância.

No MPF, foram analisadas e processadas as tensões durante a falta a partir das MTDFs de todas as fases dos SDs teste. Os curtos-circuitos considerados forneceram uma representação diversificada do comportamento das VTCDs (afundamentos e/ ou elevações de tensão) nos SDs em análise. Por uma estratégia de combinação das diversas MTDFs obtidas, relativas a todas as fases do SD e aos quatro tipos de curtos-circuitos considerados, conferiuse a uma única matriz (MCVT), todas as características das situações de afundamentos e elevações de tensão consideradas para a alocação otimizada dos monitores de QEE.

Para a ARHM, uma ampla faixa de frequências foi analisada, variando da frequência fundamental até a $128^{\mathrm{a}}$ harmônica, isto é, de $50 \mathrm{~Hz}\left(h_{\text {mín }}\right)$ até $6,4 \mathrm{kHz}\left(h_{\text {máx }}\right)$ para o SD de 15 nós, e de $60 \mathrm{~Hz}\left(h_{\text {mín }}\right)$ até 7,68 $\mathrm{kHz}\left(h_{\text {máx }}\right)$ para o SD de 24 nós (originado do sistema do IEEE de 34 nós). Estas faixas de frequência foram escolhidas de maneira a realizar uma ampla investigação do SD no que se refere às potenciais condições de ressonância que possam ser encontradas. É importante destacar que o estudo feito para frequências mais elevadas também teve motivação em função da crescente introdução de dispositivos que são fontes de distorção harmônica de alta frequência. Determinou-se o limite superior dos intervalos de frequência como sendo a máxima frequência admissível a ser medida por um medidor de QEE típico com taxa de amostragem de 256 amostras/ciclo.

Pela metodologia de alocação proposta, a MCRH foi construída de modo a registrar os graus de observação às frequências de ressonância calculadas para diversos cenários. Estes cenários compreenderam distintos estados de conexão de bancos de capacitores, utilizados 
para a correção do FP de certas cargas dos SDs estudados. O estudo dos diferentes cenários de operação dos bancos de capacitores teve como objetivo incluir o efeito de possíveis variações da demanda reativa das cargas, já que isto pode conduzir a distintas frequências de ressonância harmônica.

A alocação otimizada dos monitores de QEE foi formulada como um problema de PLI, no qual o vetor solução (vetor de alocação) indica a quantidade mínima necessária, além das posições de instalação dos monitores, para a completa observação das situações de VTCDs e das potenciais condições de ressonância harmônica. Além das constantes de integralidade das variáveis, a MCF e a condição de ao menos um monitor do arranjo ser sensibilizado para os distúrbios de QEE estudados, configuram as condições de restrição impostas pelo problema. Além disso, a inclusão do critério de prioridade de instalação priorizou a instalação dos monitores de QEE em nós cuja observabilidade aos distúrbios de QEE era maior em detrimento dos demais. O problema de otimização descrito foi solucionado utilizando-se um algoritmo de PLI baseado no algoritmo B\&B do toolbox de otimização do Matlab $^{\circledR}$.

As soluções de alocação foram investigadas para diversos valores dos limiares de tensão $\left(\delta_{\text {inf }}\right.$ e $\left.\delta_{\text {sup }}\right)$ e do limiar $\tau$ que determina a sensibilização do medidor de QEE para a condição de ressonância harmônica. Com base nas referências utilizadas, $\delta_{\text {inf }}$ foi analisado entre 0,5 p.u. a 0,9 p.u e $\delta_{\text {sup }}$ de 1,1 p.u. a 1,2 p.u. O limiar $\tau$, por sua vez, foi analisado de 0,1 a 1,0, já que está associado aos valores normalizados dos autovalores críticos.

Para o SD de 15 nós, verificou-se que a variação dos limiares de tensão, tanto superior $\left(\delta_{\text {sup }}\right)$ como o inferior $\left(\delta_{\text {inf }}\right)$, não exerceram influência na variabilidade da solução de alocação final. No entanto, o limiar $\tau$ foi fator determinante para fornecer soluções de alocação com um número distinto de monitores necessários ao monitoramento, sendo que a quantidade mínima necessária variou de 4 (monitores alocados nos nós 3, 8, 12 e 15) para 2 (monitores alocados nos nós 12 e 15). Observou-se ainda certa uniformidade das soluções no que se refere aos locais de instalação dos monitores (nós) em função da variação dos limiares, sendo que os nós 12 e 15, por exemplo, são apontados em todos os casos.

Ainda com relação às soluções de alocação para o SD de 15 nós, nota-se que a quantidade de nós equivalentes é diversificada em função dos limiares $\tau$, porém, apresenta certa uniformidade ou ainda estabilidade para a variação dos limiares de tensão quando um $\operatorname{limiar} \tau$ é fixado. 
No que se refere ao SD de 24 nós, a variação dos limiares de tensão, tanto superior como o inferior, exerceram maior influência na solução de alocação final para um mesmo limiar $\tau$. A quantidade mínima de monitores para o completo monitoramento do SD de 24 nós é em geral superior à quantidade mínima necessária para o SD de 15 nós. Todavia, conforme $\tau$ diminui, a quantidade mínima de monitores tende a diminuir, partindo de 9 monitores e chegando a apenas 2 monitores. Ademais, para o SD de 24 nós, foi constatada certa regularidade com relação aos nós equivalentes obtidos quando $\delta_{\text {sup }}$ foi variado e $\tau$ mantido fixo, sendo que para o limiar $\delta_{\text {inf }}$ uma maior variabilidade de nós equivalente foi verificada.

A observação da disposição dos nós indicados nas soluções de alocação indicou comportamentos específicos em ambos os SDs analisados. No SD de 15 nós, para os distintos limiares definidos, os monitores são instalados preferencialmente ao final dos alimentadores do $\mathrm{SD}$ (nós 8, 12 e 15). Somente para as soluções com $\tau=1,0$, o nó 3 , que está localizado mais próximo da subestação, também é determinado como um nó necessário para a instalação de um medidor. Também é possível verificar que os nós equivalentes tendem a ficarem dispostos próximos entre si. Em contrapartida, para o SD de 24, a disposição física dos monitores é relativamente bem distribuída ao longo do alimentador, concentrando-se, principalmente, em três principais regiões. A primeira região compreende os nós de 800,802 , $806,808,812,814,850,816,824$ e 828 . Já a segunda região os nós 832,851 e 858 ; e a terceira região o nó 848. Observou-se ainda que a disposição dos nós equivalentes tende a ser próxima uns dos outros, assim como observado para o SD de 15 nós.

Pelo estudo das soluções de alocação obtido pela adoção da MCF parcial para os dois SDs, isto é, obtendo-se a alocação somente para as VTCDs (MCF igual à MCVT) e, posteriormente, somente para as condições de ressonância (MCF igual à MCRH), foi possível concluir que a MCRH, em geral, é preponderante para a determinação dos nós de alocação dos medidores de QEE. Este comportamento é uma consequência da maior esparsidade presente nas MCRHs para uma ampla faixa de limiares $\tau$. Contudo, em alguns casos, concluiu-se que a MCVT foi determinante para a definição dos nós de alocação em detrimento da MCRH. Destaca-se ainda que a esparsidade das MCFs (quer seja em sua forma completa ou parcial) é fator significativo para a determinação da quantidade mínima de monitores necessários ao monitoramento. Também é significativa para a determinação da quantidade de soluções equivalentes, já que estas advêm da possibilidade de se encontrar linhas idênticas nas referidas MCFs. 
Para o SD de 15 nós, no momento do estudo da análise da alocação do ponto de vista das potenciais condições de ressonância harmônica, isto é, fazendo-se MCF igual a MCRH, executou-se a varredura em frequência a partir dos nós determinados na solução de alocação para $\tau=1,0$. Pelos resultados, verificou-se que as frequências de ressonância determinadas pela análise de varredura em frequência são condizentes com as frequências de ressonância encontradas pela ARHM. Confrontando-se a varredura em frequência com a ARHM, também foi possível ilustrar como a ARHM pode ser mais prática na determinação dos melhores locais de observação das condições de ressonância. Ademais, conforme mostrado, a ARHM foi aplicada para SDs de média tensão, sendo que originalmente esta técnica foi aplicada para sistemas de transmissão.

Ainda para o SD de 15 nós, durante o estudo de solução parcial, fazendo-se a MCF igual à MCRH, demonstrou-se a estabilidade da solução de alocação para $\tau=1,0$ em função da variabilidade da potência reativa dos bancos de capacitores dos consumidores. Visto que esta variabilidade pode ser determinada por bancos automáticos, por exemplo, de maneira a atender ao perfil de carga do SD no transcorrer do dia.

Pelos resultados obtidos das diversas análises realizadas para as soluções de alocação de ambos os SDs, afirma-se que a alocação dos medidores não é uma tarefa simples, sendo esta dependente da topologia, parâmetros e condições de operação de cada SD. Salienta-se também que nem sempre o melhor local de instalação se verifica proximamente da subestação ou dos bancos de capacitores dos consumidores locais.

O ajuste dos limiares de tensão $\delta_{\text {inf }}$ e $\delta_{\text {sup }}$, e do limiar $\tau$, são importantes para a determinação da quantidade de monitores. De acordo com a disponibilidade de recursos ou necessidades da concessionária de energia estes valores poderão ser ajustados de forma que seja mais conveniente.

Ressalta-se que é recomendado considerar o estudo para $\delta_{\text {inf }}$ entre 0,5 p.u. e 0,9 p.u., e para $\delta_{\text {inf }}$ entre 1,1 p.u. e 1,2 p.u., já que as referências técnicas apontam que a grande maioria das VTCDs possuem magnitudes das tensões remanescentes nestas faixas. Todavia, cabe comentar que uma vez escolhendo-se os limiares desejados para a construção da MCF, os monitores em campo poderão ser ajustados com $\bar{\delta}_{\text {inf }}=0,9$ p.u. e $\bar{\delta}_{\text {inf }}=1,1$ p.u., e que, mesmo assim, será garantida a validade do arranjo projetado para a detecção das VTCDs. Logo, definindo-se o arranjo de monitores para limiares específicos, o ajuste dos monitores em campo é mais simples e flexível. 
Por fim, a metodologia de alocação otimizada de monitores de QEE apresenta-se como uma promissora ferramenta de apoio a ser utilizada pelas concessionárias de energia, ou para estudos no âmbito acadêmico, auxiliando no monitoramento e detecção de indesejáveis VTCDs e condições de ressonância harmônica, provendo assim meios para a melhoria dos índices de QEE.

Além disso, uma vez que os monitores de QEE são instalados em nós estratégicos do $\mathrm{SD}$, ou seja, em nós com a maior observabilidade às VTCDs e potenciais condições de ressonância, os custos capital e operacional associados ao plano de monitoramento tendem a ser minimizados.

\subsection{Propostas de continuidade da pesquisa}

Para o atual estágio de desenvolvimento da metodologia, afirma-se que as soluções de alocação associadas ao limiar $\tau=1,0$ sejam as mais conservadoras, já que $\tau$ está diretamente relacionado ao grau de observabilidade dos modos críticos, isto é, a escolha pelo máximo valor de $\tau$ aumentará a possibilidade de encontrar nós que são mais susceptíveis a sofrerem maiores distorções harmônicas na tensão. Contudo, afirma-se que estudos mais aprofundados devem ser realizados para uma melhor definição da faixa de valores de análise das soluções de alocação, já que na prática esta detecção deverá ser feita através do monitoramento dos níveis de tensão harmônica no nó no qual se tem instalado o monitor de QEE

Embora o MPI tenha se apresentado como um método adequado para o cálculo da impedância modal crítica e dos autovetores críticos, foi observado que a matriz $\left[Y_{h}\right]$ pode eventualmente apresentar características que representem entraves para o uso do MPI. Tais entraves podem ser evidenciados nos casos em que: $(i)\left[Y_{h}\right]$ seja singular para a frequência de ressonância, o que inviabiliza a solução do sistema linear necessário para a estimação dos autovalores; (ii) $\left[Y_{h}\right]$ conduza a um sistema linear de equações mal condicionado, comprometendo assim a estimação dos autovalores e respectivos autovetores por erros de precisão numérica; (iii) observe-se a tendência de $\left[Y_{h}\right]$ se tornar muito esparsa, como, por exemplo, em sistemas radiais de grande porte, sendo eventualmente mais apropriada a aplicação de técnicas para a resolução de sistemas lineares esparsos, propiciando assim a melhoria no desempenho do algoritmo em termos de esforço computacional. 
Como alternativa às dificuldades mencionadas, acredita-se que para a continuidade desta pesquisa de doutorado possa ser conveniente trabalhar somente com a matriz de impedância do sistema $\left[Z_{h}\right]$, obtendo-a diretamente por meio dos parâmetros do sistema elétrico e do seu diagrama unifilar, sem a necessidade da inversão da matriz de admitância $\left[Y_{h}\right]$.

Ainda com relação ao aprimoramento da metodologia desenvolvida, pode-se na continuidade da pesquisa, averiguar o emprego de algoritmos mais estáveis para a determinação dos autovalores de $\left[Y_{h}\right]$, ou ainda que sejam mais adequados para o tratamento de $\left[Y_{h}\right]$, como no caso do mau condicionamento de sistemas de equações, ou esparsidade, por exemplo. Destaca-se também que é possível considerar a investigação da viabilidade em determinar todos os autovalores de $\left[Y_{h}\right]$ e sua base de autovetores correspondentes, explorando-se assim o aprimoramento da metodologia de alocação de medidores com relação à observabilidade das potenciais condições de ressonância harmônica. Deste estudo, acreditase que um dos possíveis benefícios seja a melhor correlação entre a impedância modal (para todos os modos) e a impedância propriamente dita da rede elétrica, que, de fato, possui influência no fenômeno de amplificação da tensão na condição de ressonância.

Também como continuidade desta pesquisa de doutorado, considera-se importante incorporar à metodologia o caso de SDs desequilibrados, situação esta mais comumente observada na prática. Além disso, é relevante ainda se considerar o deslocamento de fase de componentes do SD, como transformadores, por exemplo, já que este fator poderá melhorar a exatidão do cálculo das frequências de ressonância harmônicas no que diz respeito a uma situação de operação do SD mais próxima da real.

Outra possibilidade de aprimoramento da metodologia de alocação é a inclusão de distintas topologias de operação do SD monitorado, isto é, conferir robustez para a solução de alocação no que se refere às mudanças topológicas decorrentes de manobras da concessionária de energia.

Certos aspectos da metodologia poderão ainda ser revistos caso SDs de maior porte sejam considerados. Dos pontos que merecem maior atenção cita-se, por exemplo, a utilização de um algoritmo de otimização mais adequado para o problema de maior porte mencionado, especialmente devido à característica de complexidade de ordem exponencial do problema de otimização formulado para esta pesquisa. A abordagem como proposta atualmente poderá apresentar entraves se além do maior tamanho do SD, mais cenários de operação forem considerados, como, por exemplo, as mudanças topológicas mencionadas. 
Como continuidade da pesquisa também cabe mencionar uma possível abordagem multiobjetivo quando uma relação de custo-benefício seja necessária, como, por exemplo, entre a quantidade do número de monitores disponíveis e a qualidade do monitoramento. Dentre os múltiplos objetivos que podem ser estudados cita-se a maximização da observabilidade às VTCDs, a maximização das potenciais condições de ressonância harmônica e a minimização da quantidade de monitores. Pode ser incluído ainda, como objetivo, a maximização da cobertura de distintas topologias de operação do SD. Deste problema multiobjetivo, a concessionária de energia poderá escolher ou priorizar quais objetivos serão mais importantes dentro do plano de monitoramento desejado.

Finalmente, considera-se igualmente pertinente a inclusão na metodologia da distorção harmônica decorrente da operação normal do SD. Conforme determinado pela norma Std. IEEE 519-1992 (INSTITUTE OF ELECTRICAL AND ELECTRONICS ENGINEERS, 1993), a distorção harmônica de fundo, assim como a sua variação temporal (diária, mensal ou sazonal), devem ser medidas e/ou estimadas em estudos harmônicos. Vale comentar que a referida norma foi recentemente atualizada (INSTITUTE OF ELECTRICAL AND ELECTRONICS ENGINEERS, 2014).

Embora este tipo de distorção de fundo não tenha sido considerada na metodologia proposta, uma vez determinado o padrão das variações das tensões harmônicas devido à operação normal do SD, é possível isolar e identificar as amplificações de tensão causadas pelas condições de ressonância. Além disso, quando da ocasião da implementação desta nova abordagem para a metodologia, sugere-se que os limiares utilizados para a distinção entre a distorção harmônica de fundo e a amplificação harmônica da tensão devido à ressonância devam estar coerentes com os níveis de DHT admissíveis no SD monitorado. 


\section{Referências Bibliográficas}

AGÊNCIA NACIONAL DE ENERGIA ELÉTRICA. Procedimentos de Distribuição de Energia Elétrica no Sistema Elétrico Nacional - PRODIST/ Módulo 8. Revisão 10. [s.1.]: [s.n.], 2018. Disponivel em: <http://www.aneel.gov.br/modulo-8>. Acesso em: 01 fev. 2019.

AMINI, M.; JALILIAN, A.; BEHBAHANI, M. R. P. Fast network reconfiguration in harmonic polluted distribution network based on developed backward/forward sweep harmonic load flow. Electric Power Systems Research, v. 168, p. 295-304, mar., 2019.

AMORNVIPAS, C.; HOFMANN, L. Resonance analyses in transmission systems: Experience in Germany. In: IEEE PES General Meeting, 2010, Providence. Proceedings... Providence: [s.n.], 2010. p. 1-8.

ARRILlaGA, J.; WATSON, N. R. Power System Harmonics. 2nd. ed. [S.1.]: John Wiley \& Sons Ltd., 2003.

ARRUDA, E. F.; KAGAN, N.; RIBEIRO, P. F. Harmonic Distortion State Estimation Using an Evolutionary Strategy. IEEE Transactions on Power Delivery, v. 25, p. 831-842, 2010.

BARAKOU, F. et al. Impact of load modeling on the harmonic impedance seen from the transmission network. In: $17^{\text {th }}$ Conference on Harmonics and Power Quality (ICHQP), Belo Horizonte, 2016. Proceedings... Belo Horizonte: [s.n.], 2016. p. 283-288.

BELLMAN, R. Introduction to Matrix Analysis. 2nd. ed. New York: Mc-Graw-Hill, 1970.

BOLLEN, M. et al. Standards for supraharmonics. IEEE Electromagnetic Compatibility Magazine, v. 3, n. 1, p. 114-119, 2014.

BOLLEN, M. et al. Power quality concerns in implementing smart distribution-grid applications. IEEE Transactions on Smart Grid, v. 8, n. 1, p. 391-399, jan., 2017.

BOllen, M. H. J.; GU, I. Y.-H. Signal Processing of Power Quality Disturbances. Piscataway, NJ: IEEE Press, 2006.

BONNER, A. et al. Modeling and simulation of the propagation of harmonics in electric power networks. I. Concepts, models, and simulation techniques. IEEE Transactions on Power Delivery, v. 11, n. 1, p. 452-465, janeiro 1996. ISSN 0885-8977. 
BRADT, M. et al. Harmonics and resonance issues in wind power plants. In: IEEE Power and Energy Society General Meeting, 2011, Detroit. Proceedings... Detroit: [s.n.], 2011. p. 1-8.

BRANCO, H. M. G. C. et al. Optimized allocation of power quality monitors in transmisssion systems: a multiobjective approach. International Journal of Electrical Power \& Energy Systems, v. 64, p. 156-166, 2015.

BRANCO, H. M. G. C. et al. Multiobjective optimization for power quality monitoring allocation considering voltage sags in distribution systems. International Journal of Electrical Power and Energy Systems, v. 97, p. 1-10, April 2018.

BURCH, R. et al. Impact of aggregate linear load modeling on harmonic analysis: a comparison of common practice and analytical models. IEEE Transactions on Power Delivery, v. 18, n. 2, p. 625-630, 2003.

CARPINELLI, G. et al. Complete matrix formulation of fault-position method for voltage-dip characterisation. IET Generation, Transmission \& Distribution, v. 1, n. 1, p. 56-64, Janeiro 2007.

CARPINELLI, G. et al. Methods for Assessing the Robustness of Electrical Power Systems Against Voltage Dips. IEEE Transactions on Power Delivery, v. 24, p. 43-51, janeiro 2009. ISSN 0885-8977.

CEBRIAN, J. C.; ALMEIDA, C. F. M.; KAGAN, N. Genetic algorithms applied for the optimal allocation of power quality monitors in distribution networks. In: 14th International Conference on Harmonics and Quality of Power (ICHQP), 2010, Bergamo. Proceedings... Bergamo: [s.n.], 2010. p. 1-10.

CONRAD, L.; LITTLE, K.; GRIGG, C. Predicting and preventing problems associated with remote fault-clearing voltage dips. IEEE Transactions on Industry Appliations, v. 27, n. 1, p. 167-172, fevereiro 1991. ISSN 0093-9994.

CONSEIL INTERNATIONAL DES GRANDS RÉSEAUX ÉLECTRIQUES. Task Force C6.04.02: Benchmark systems for network integration of renewable and distributed energy resources. CIGRÉ. [S.1.]. 2014. (978-285-873-270-8). 
COUNCIL OF EUROPEAN ENERGY REGULATORS / ENERGY COMMUNITY REGULATORY BOARD. Guidelines of good practice on the implementation and use of voltage quality monitoring systems for regulatory purposes Ref: C12-EQS-51-03. Council of European Energy Regulators/ Energy Community Regulatory Board. [S.1.]. 2012.

CUI, Y.; WANG, X. Modal Frequency Sensitivity for Power System Harmonic Resonance Analysis. IEEE Transactions on Power Delivery, v. 27, n. 2, p. 1010-1017, Abril 2012.

CUI, Y.; XU, W. Assessment of Potential Harmonic Problems for Systems with Distributed or Random Harmonic Sources. In: IEEE Power Engineering Society General Meeting, 2007, Tampa. Proceedings... Tampa: [s.n.], 2007. p. 1-6.

DANG, M. N. D. et al. Wind farm integration in a harmonic environment. In: IEEE Electrical Power and Energy Conference (EPEC), 2015, Londres. Proceedings ... Londres: [s.n.], 2015. p. 1-7.

DATTA, B. N. Numerical Linear Algebra and Applications. 2nd. ed. Philadelphia: Society for Industrial and Applied Mathematics, 2010.

DEMMEL, J. W. Applied Numerical Linear Algebra. Philadelphia: Society for Industrial and Applied Mathematics, 1997.

DENOEL, J. Détermination du niveau d'émission harmonique d'une installation raccordée au réseau de distribution, 2016. Tese (Doutorado) - CentraleSupélec, Université Paris-Saclay, Gif-sur-Yvette, 2016.

DUGAN, R. C. et al. Electrical Power Systems Quality. 3rd. ed. [S.1.]: McGraw-Hill, 2012.

EGGENSCHWILER, O. et al. Frequency scans and resonance mode analysis for resonance problems identification in power networks in presence of harmonic pollution. CIRED - Open Access Proceedings Journal, v. 2017, n.1, p. 650-654, 10, 2017.

ELDERY, M. A. et al. A novel power quality monitoring allocation algorithm. IEEE Transactions on Power Delivery, v. 21, p. 768 - 777, abril 2006. ISSN 0885-8977.

ELECTRIC POWER RESEARCH INSTITUTE. Distribution system power quality assessment: phase II. Voltage sag and interruption analysis. A. Sundaram. Palo Alto: EPRI. 2003. 
ELPHICK, S. et al. Large scale proactive power-quality monitoring: an example from australia. IEEE Transactions on Power Delivery, v. 32, n. 2, p. 881-889, April 2017.

ESPINOSA-JUARÉZ, E.; HERNANDÉZ, A.; OLGUIN, G. An Approach Based on Analytical Expressions for Optimal Location of Voltage Sags Monitors. IEEE Transactions on Power Delivery, v. 24, p. 2034 - 2042, outubro 2009. ISSN 0885-8977.

FARZANEHRAFAT, A.; WATSON, N. R. Power quality state estimation for smart distribution grids. IEEE Transactions on Power Systems, v. 28, p. 2183-2191, agosto 2013.

FORTES, R. R. A. et al. Harmonic resonance in electrical grids with photovoltaic distributed generation. In: 17th International Conference on Harmonics and Quality of Power (ICHQP), 2016, Belo Horizonte. Proceedings... Belo Horizonte: [s.n.], 2016. p. 214-219.

FRANCO, N. B. Cálculo Numérico. São Paulo: Pearson, 2008.

GOLUB, G. H.; VAN LOAN, C. F. Matrix Computations. 3rd. ed. Baltimore: The Johns Hopkins University Press, 1996.

HASAN, K. N. M. et al. Grid harmonic detection and system resonances indentification in wave power plant applications. In: ECON 2013 - 39th Annual Conference of the IEEE Industrial Electronics Society, 2013, Vienna Proceedings... Vienna: [s.n.], 2013. p. 16441649.

HERNANDÉZ, A. et al. SVD Applied to Voltage Sag State Estimation. IEEE Transactions on Power Delivery, v. 28, p. 866 - 874, abril 2013. ISSN 0885-8977.

HOSEINZADEH, B. et al. RTDS Demonstration of Harmonic Amplification in Under Sea/Ground Cables of Offshore Wind Farms. In: IEEE International Conference on Environment and Electrical Engineering and 2018 IEEE Industrial and Commercial Power Systems Europe (EEEIC / I\&CPS Europe), 2018, Palermo. Proceedings... Palermo: [s.n.], 2018. p. $1-5$.

HUAN , C. X.; TAYJASANANT, T. Modeling wind power plants in harmonic resonance study - A case study in Thailand. In: 2013 International Conference on Information Technology and Electrical Engineering (ICITEE), 2013, Yogyakarta. Proceedings... Yogyakarta: [s.n.], 2013. p. 385-390. 
INSTITUTE OF ELECTRICAL AND ELECTRONIC ENGINEERS. IEEE PES Distribution Systems Analysis Subcommittee / IEEE 34 Node Test Feeder, [s.1.]: [s.n.], 2010. Disponivel em: <http://sites.ieee.org/pes-testfeeders/resources/>. Acesso em: 01 de nov. 2018.

INSTITUTE OF ELECTRICAL AND ELECTRONICS ENGINEERS. IEEE Std 493-2007 (Revision of IEEE Std 493-1997) IEEE Recommended Practice for the Design of Reliable Industrial and Commercial Power Systems. [S.1.]: [s.n.], 2007. 1-383 p.

INSTITUTE OF ELECTRICAL AND ELECTRONICS ENGINEERS. IEEE Std 519-1992 (Revision of Std 519-1992) Recommended Practice and Requirements for Harmonic Control In Electric Power Systems. New York: IEEE, 1992.

INSTITUTE OF ELECTRICAL AND ELECTRONICS ENGINEERS. IEEE Std 519-2014 (Revision of Std 519-1992) Recommended Practice and Requirements for Harmonic Control In Electric Power Systems. New York: IEEE, 2014.

INTERNATIONAL ELECTROTECHNICAL COMISSION. IEC $\mathbf{6 1 0 0 0 - 4 - 3 0}$ Electromagnetic Compability (EMC) - Part 4-30: Testing and Measurement. [S.1.]: [s.n.], 2003.

JOHNSON, D. E.; HILBURN, J. L.; JOHNSON, J. R. Fundamentos de análise de circuitos elétricos. Rio de Janeiro: LTC, 2000.

KEMPNER, T. R. Análise da Robustez e da Sensibilidade de Sistemas de Distribuição para a Alocação Otimizada de Medidores frente às Variações de Tensão de Curta Duração, 2016. 217f. Tese (Doutorado em Engenharia Elétrica) - Escola de Engenharia de São Carlos, Universidade de São Paulo, São Carlos, 2016.

KEMPNER, T. R. et al. Optimal Voltage Sags Monitoring Considering Different Loading Profiles in Distribution Systems. Renewable Energies and Power Quality Journal, n. 14, p. 306-311, Maio 2016. ISSN 2172-038X.

KEMPNER, T. R.; OLESKOVICZ, M.; GOMES, D. P. S. Optimal monitoring of voltage sags through simultaneous analysis of short-circuits in distribution systems. IET Generation, Transmission \& Distribution, January 2017. 1801-1808. 
KERSTING, W. H. Radial Distribution Test Feeders. In: IEEE Power Engineering Society Winter Meeting, 2001, Columbus. Proceedings... Columbus: IEEE. 2001, p. 908 - 912 vol 2.

KERSTING, W. H. Distribution System Modeling and Analysis. [S.1.]: CRC Press, 2002.

KERSTING, W. H.; PHILLIPS, W. H. Distribution feeder line models. IEEE Transactions on Industry Applications, n. 4, p. 715-720, Julho/Agosto 1995.

KETABI, A.; SHEIBANI, M. R.; NOSRATABADI, S. M. Power quality meters placement using seeker optimization algorithm. International Journal of Electrical Power \& Energy Systems, v. 43, p. 141-149, 2012.

KINDERMANN, G. Curto-circuito. 2a . ed. Porto Alegre: Sagra Luzzatto, 1997.

LAND, A. H.; DOIG, A. G. An automatic method of solving discrete programming problems. Econometrica, v. 28, n. 3, p. 497-520, 1960.

LUCIO, J.; ESPINOSA-JUARÉZ, E.; HERNANDÉZ, A. Voltage sag state estimation in power systems by applying genetic-algorithms. IET, Generation, Transmission \& Distribution, v. 5, p. 223 - 230, fevereiro 2011. ISSN 1751-8687.

MATHWORKS. Symbolic Math Toolbox (TM) User's guide R2018b. The MathWorks Inc., [s.1.]: [s.n.], 2018a. Disponivel em: https://www.mathworks.com/help/pdf_doc/symbolic/ symbolic_tb.pdf $>$. Acesso em: $26 \mathrm{dez} .2018$.

MATHWORKS. Optimization Toolbox (TM) User's guide R2018b. The MathWorks Inc., [s.1.]: [s.n.], 2018b. Disponivel em: <https://www.mathworks.com/help/pdf_doc/optim/ optim_tb.pdf $>$. Acesso em: 26 dez. 2018.

OLGUIN, G. Voltage dip (sag) estimation in power systems based on stochastic assessment an optimal monitoring, 2005. Ph.D. Dissertation (Electrical Engineering) Department of Energy and Enviroment, Division of Electric Power Engineering, Chalmers University of Technology, Göteborg, 2005.

OLGUIN, G.; BOLLEN, H. H. J. Optimal dips monitoring program for characterization of transmission system. In: Power Engineering Society General Meeting, 2003, Toronto. Proceedings... Toronto: [s.n]. 2003. 
RAD, M. S.; MOKHTARI, H.; KARIMI, H. An optimal measurement placement method for power system harmonic state estimation. In: International Conference and Exposition on Electrical and Power Engineering (EPE), 2012, Iasi. Proceedings... Iasi: [s.n], 2012. p. 271 275 .

RAO, S. S. Engineering optimization: theory and practice. 4th. ed. Hoboken: John Wiley \& Sons, 2009.

REGULA, M. et al. Software for power quality monitoring in model smart grid with using LabView. In: 11th International Conference ELEKTRO, 2016, Strbské Pleso. Proceedings... Strbské Pleso: [s.n.], 2016. p. 355-358.

RUDION, K. et al. Design of benchmark of medium voltage distribution network for investigation of DG integration. In: IEEE Power Engineering Society General Meeting, 2006, Montreal. Proceedings... Montreal: [s.n.], 2006.

SAKSVIK, O. HVDC technology and smart grid. In: 9th IET International Conference on Advances in Power System Control, Operation and Management (APSCOM 2012), 2012, Hong Kong. Proceedings... Hong Kong : IET, 2012, p. 18-21.

SALIM, F.; NOR, K. M. Voltage sags observation through optimal monitor locations. In: 14th International Conference on Harmonics and Quality of Power (ICHQP), 2010, Bergamo. Proceedings... Bergamo: IEEE, 2010,. p. 1-6.

SANKARAN, C. Power Quality. [S.1.]: CRC Press, 2002.

Stevenson, D. Elementos de Análise de Sistemas de Potência. 2a. ed. São Paulo: McGraw-Hill, Ltda, 1986.

TREFETHEN, L. N.; III BAU, D. Numerical Linear Algebra. Philadelphia: Society for Industrial and Applied Mathematics, 1997.

VIEIRA, F. L. et al. Harmonic studies in OpenDSS considering renewable DG aggregate linear load models. In: $13^{\text {th }}$ IEEE International Conference on Industry Applications (INDUSCON), São Paulo, 2018. Proceedings... São Paulo: [s.n.]. 2018.

WATKINS, D. S. Fundamentals of Matrix Computations. 3rd. ed. Hoboken: John Wiley \& Sons Inc., 2010. 
WILKINSON, J. H. The algebraic eigenvalue problem. [S.1.]: Clarendon Press, 1965.

WOLSEY, L. A. Integer Programming. [S.1.]: John Wiley \& Sons, 1998.

XU, W. Component modeling issues for power quality assessment. IEEE Power Engineering Review, v. 21, n. 11, p. 12-17, November 2001.

XU, W. et al. Harmonic resonance mode analysis. IEEE Transactions on Power Delivery, v. 20, n. 2, April 2005. 1182-1190.

ZHENG, R.; BOLLEN, M. H. J.; ZHONG, J. Harmonic resonances due to a grid-connected wind farm. In: Proceedings of 14th International Conference on Harmonics and Quality of Power - ICHQP, 2010, Bergamo. Proceedings... Bergamo: [s.n.], 2010. p. 1-7. 


\section{Anexo A}

A Tabela 17 e a Tabela 18 mostram os parâmetros das cargas e das linhas para o SD de 15 nós apresentado no item 6.1.

Tabela 17 - Nós de instalação, potência ativa trifásica $(\boldsymbol{P})$, potência reativa trifásica $(\boldsymbol{Q})$; e FP das cargas presentes no SD de 15 nós.

\begin{tabular}{cccc}
\hline Nó & $\mathrm{P}(k W)$ & $\mathrm{Q}(\mathrm{kVAr})$ & $\mathrm{FP}$ \\
\hline 1 & $13.088,0$ & $7.329,0$ & 0,87 \\
2 & 500 & 208 & 0,92 \\
3 & 500 & 208 & 0,92 \\
4 & 500 & 208 & 0,92 \\
5 & 432 & 108 & 0,97 \\
6 & 725 & 182 & 0,97 \\
7 & 550 & 138 & 0,97 \\
8 & 77 & 48 & 0,85 \\
9 & 588 & 147 & 0,97 \\
10 & 574 & 356 & 0,85 \\
11 & 545 & 162 & 0,96 \\
12 & 331 & 83 & 0,97 \\
13 & 500 & 208 & 0,92 \\
14 & 32 & 20 & 0,85 \\
15 & 537 & 257 & 0,90 \\
\hline
\end{tabular}

Fonte: Adaptado de Denoel (2016).

Tabela 18 - Segmentos de linhas, parâmetros de sequência $(\boldsymbol{R 0}, \boldsymbol{R 1}, \boldsymbol{X 0}, \boldsymbol{X 1}, \boldsymbol{B 0}, \boldsymbol{B 1})$, comprimento e tipo de linhas do SD de 15 nós.

\begin{tabular}{|c|c|c|c|c|c|c|c|c|}
\hline \multicolumn{2}{|c|}{ Linhas } & $\begin{array}{c}R 0 \\
(\Omega / k m)\end{array}$ & $\begin{array}{c}R 1 \\
(\Omega / k m)\end{array}$ & $\begin{array}{c}X 0 \\
(\Omega / \mathrm{km})\end{array}$ & $\begin{array}{c}X 1 \\
(\Omega / k m)\end{array}$ & $\begin{array}{c}B 0 \text { e } B 1 \\
(\mu S / k m)\end{array}$ & $\begin{array}{c}\text { Comprimento } \\
(\mathrm{km})\end{array}$ & Tipo \\
\hline 1 & 2 & 1,02 & 0,34 & 0,52 & 0,13 & 100 & 0,32 & Cabo subterrâneo \\
\hline 2 & 3 & 0,77 & 0,58 & 1,10 & 0,37 & 5 & 2,82 & Linha aérea \\
\hline 3 & 4 & 0,49 & 0,16 & 0,45 & 0,11 & 100 & 4,42 & Cabo subterrâneo \\
\hline 4 & 5 & 0,79 & 0,26 & 0,48 & 0,12 & 100 & 0,61 & Cabo subterrâneo \\
\hline 5 & 6 & 1,06 & 0,35 & 0,52 & 0,13 & 100 & 0,56 & Cabo subterrâneo \\
\hline 6 & 7 & 1,01 & 0,34 & 0,50 & 0,13 & 100 & 1,54 & Cabo subterrâneo \\
\hline 4 & 9 & 0,52 & 0,17 & 0,46 & 0,12 & 100 & 1,30 & Cabo subterrâneo \\
\hline 9 & 8 & 0,88 & 0,29 & 0,49 & 0,12 & 100 & 1,67 & Cabo subterrâneo \\
\hline 9 & 10 & 1,02 & 0,34 & 0,52 & 0,13 & 100 & 0,32 & Cabo subterrâneo \\
\hline 10 & 11 & 1,20 & 0,40 & 0,53 & 0,13 & 100 & 0,77 & Cabo subterrâneo \\
\hline 11 & 12 & 1,10 & 0,37 & 0,53 & 0,13 & 100 & 0,33 & Cabo subterrâneo \\
\hline 1 & 13 & 1,02 & 0,34 & 0,52 & 0,13 & 100 & 0,32 & Cabo subterrâneo \\
\hline 13 & 14 & 0,45 & 0,34 & 1,07 & 0,36 & 5 & 2,99 & Linha aérea \\
\hline 14 & 15 & 0,27 & 0,20 & 0,37 & 0,12 & 5 & 2,00 & Linha aérea \\
\hline
\end{tabular}

Fonte: Adaptado de Denoel (2016). 


\section{Anexo B}

A Tabela 19 e a Tabela 20 mostram os parâmetros das cargas e das linhas para o SD de 24 nós apresentado no item 6.2.

Tabela 19 - Nós de instalação, potência ativa $(\boldsymbol{P})$ e reativa $(\boldsymbol{Q})$ trifásica nominal; e FP das cargas presentes no SD de 15 nós.

\begin{tabular}{cccc}
\hline Nó & $\mathrm{P}(k W)$ & $\mathrm{Q}(k V A r)$ & $\mathrm{PF}$ \\
\hline 806 & 55 & 29 & 0,88 \\
808 & 16 & 8 & 0,89 \\
816 & 169 & 87 & 0,89 \\
824 & 45 & 22 & 0,90 \\
828 & 4 & 2 & 0,89 \\
830 & 52 & 23 & 0,91 \\
832 & 450 & 225 & 0,89 \\
834 & 32 & 17 & 0,88 \\
836 & 82 & 43 & 0,89 \\
840 & 67 & 41 & 0,85 \\
844 & 414 & 320 & 0,79 \\
846 & 45 & 23 & 0,89 \\
848 & 83 & 59 & 0,82 \\
854 & 4 & 2 & 0,89 \\
858 & 17 & 8 & 0,90 \\
860 & 206 & 121 & 0,86 \\
862 & 28 & 14 & 0,89 \\
\hline
\end{tabular}

Tabela 20 - Parâmetros de sequência dos tipos de linhas presentes no SD de 24 nós, calculados a partir das matrizes de impedância e susceptância de fase do SD de 34 nós original.

\begin{tabular}{ccccccc}
\hline Configuração & $\begin{array}{c}R 0 \\
(\Omega / \text { milha })\end{array}$ & $\begin{array}{c}X 0 \\
(\Omega / \text { milha })\end{array}$ & $\begin{array}{c}R 1 \\
(\Omega / \text { milha })\end{array}$ & $\begin{array}{c}X 1 \\
(\Omega / \text { milha })\end{array}$ & $\begin{array}{c}B 0 \\
(\mu \mathrm{S} / \text { milha })\end{array}$ & $\begin{array}{c}B 1 \\
(\mu \mathrm{S} / \text { milha })\end{array}$ \\
\hline 300 & 1,7498 & 2,3718 & 1,1201 & 0,8333 & 3,0091 & 6,1559 \\
301 & 2,3875 & 2,5782 & 1,6901 & 0,8411 & 2,9327 & 5,9044 \\
\hline
\end{tabular}




\section{Apêndice A}

As Tabelas de 21 a 24 apresentam os dados resultantes dos casos de (i) a (iv) do item 6.1.1.5 do capítulo 6 .

Nestas tabelas estão registrados os valores para cada frequência de ressonância harmônica $F_{i}$ encontrada, bem como sua respectiva ordem harmônica $h$ e seu valor em $\mathrm{Hz}$ $\left(f_{h}\right)$. Constam ainda nestas tabelas as magnitudes da impedância modal $\left|\zeta_{h}\right|$ associada a cada uma das condições de ressonância harmônica.

Tabela 21 - Frequências de ressonância harmônicas encontradas pela ARHM e suas respectivas magnitudes de impedância modal - caso $(i)$.

\begin{tabular}{cccc||cccc}
\hline$F_{i}$ & $h$ & $\begin{array}{c}f_{h} \\
(\mathrm{~Hz})\end{array}$ & $\begin{array}{c}\left|\zeta_{h}\right| \\
(\mathrm{p} . \mathrm{u} .)\end{array}$ & $F_{i}$ & $h$ & $\begin{array}{c}f_{h} \\
(\mathrm{~Hz})\end{array}$ & $\begin{array}{c}\left|\zeta_{h}\right| \\
(\mathrm{p} . \mathrm{u} .)\end{array}$ \\
\hline 1 & 10 & 500 & 266,3 & 27 & 28 & 1.400 & 378,4 \\
2 & 10 & 500 & 285,7 & 28 & 28 & 1.400 & 367,2 \\
3 & 10 & 500 & 269,3 & 29 & 29 & 1.450 & 368,0 \\
4 & 10 & 500 & 289,1 & 30 & 29 & 1.450 & 360,4 \\
5 & 10 & 500 & 256,1 & 31 & 29 & 1.450 & 366,8 \\
6 & 10 & 500 & 274,5 & 32 & 29 & 1.450 & 359,1 \\
7 & 10 & 500 & 259,0 & 33 & 102 & 5.100 & 1709,2 \\
8 & 10 & 500 & 277,8 & 34 & 102 & 5.100 & 1704,7 \\
9 & 11 & 550 & 266,3 & 35 & 102 & 5.100 & 1709,7 \\
10 & 11 & 550 & 287,7 & 36 & 102 & 5.100 & 1705,8 \\
11 & 11 & 550 & 262,3 & 37 & 107 & 5.350 & 1554,9 \\
12 & 11 & 550 & 306,9 & 38 & 107 & 5350 & 1547,0 \\
13 & 11 & 550 & 278,8 & 39 & 107 & 5.350 & 1555,5 \\
14 & 11 & 550 & 302,0 & 40 & 107 & 5.350 & 1549,2 \\
15 & 11 & 550 & 274,5 & 41 & 115 & 5.750 & 362,9 \\
16 & 11 & 550 & 292,2 & 42 & 115 & 5.750 & 364,1 \\
17 & 27 & 1.350 & 335,2 & 43 & 115 & 5.750 & 362,9 \\
18 & 27 & 1.350 & 331,5 & 44 & 115 & 5.750 & 363,5 \\
19 & 27 & 1.350 & 334,7 & 45 & 116 & 5.800 & 364,6 \\
20 & 27 & 1.350 & 330,7 & 46 & 116 & 5.800 & 364,0 \\
21 & 27 & 1.350 & 350,3 & 47 & 116 & 5.800 & 364,7 \\
22 & 27 & 1.350 & 351,4 & 48 & 116 & 5.800 & 364,1 \\
23 & 27 & 1.350 & 350,5 & 49 & 127 & 6.350 & 457,1 \\
24 & 27 & 1.350 & 351,5 & 50 & 127 & 6.350 & 456,7 \\
25 & 28 & 1.400 & 376,9 & 51 & 127 & 6.350 & 457,0 \\
26 & 28 & 1.400 & 368,7 & 52 & 127 & 6.350 & 456,8 \\
\hline & & & & & & &
\end{tabular}


Tabela 22 - Frequências de ressonância harmônicas encontradas pela ARHM e suas respectivas magnitudes de impedância modal - caso (ii).

\begin{tabular}{cccc||cccc}
\hline$F_{i}$ & $h$ & $\begin{array}{c}f_{h} \\
(\mathrm{~Hz})\end{array}$ & $\begin{array}{c}\left|\zeta_{h}\right| \\
(\mathrm{p} . \mathrm{u} .)\end{array}$ & $F_{i}$ & $h$ & $\begin{array}{c}f_{h} \\
(\mathrm{~Hz})\end{array}$ & $\begin{array}{c}\left|\zeta_{h}\right| \\
(\mathrm{p} . \mathrm{u} .)\end{array}$ \\
\hline 1 & 10 & 500 & 277,1 & 27 & 28 & 1.400 & 394,1 \\
2 & 10 & 500 & 297,5 & 28 & 28 & 1.400 & 388,8 \\
3 & 10 & 500 & 283,5 & 29 & 29 & 1.450 & 368,0 \\
4 & 10 & 500 & 304,7 & 30 & 29 & 1.450 & 360,4 \\
5 & 10 & 500 & 256,1 & 31 & 29 & 1.450 & 365,6 \\
6 & 10 & 500 & 274,5 & 32 & 29 & 1.450 & 357,7 \\
7 & 10 & 500 & 261,9 & 33 & 97 & 4.850 & $1.355,3$ \\
8 & 10 & 500 & 281,1 & 34 & 97 & 4.850 & $1.359,0$ \\
9 & 11 & 550 & 254,6 & 35 & 97 & 4.850 & $1.354,3$ \\
10 & 11 & 550 & 270,3 & 36 & 97 & 4.850 & $1.357,6$ \\
11 & 11 & 550 & 247,4 & 37 & 107 & 5.350 & $1.554,0$ \\
12 & 11 & 550 & 306,9 & 38 & 107 & 5.350 & $1.543,6$ \\
13 & 11 & 550 & 278,8 & 39 & 107 & 5.350 & $1.555,5$ \\
14 & 11 & 550 & 297,2 & 40 & 107 & 5.350 & $1.549,2$ \\
15 & 11 & 550 & 270,3 & 41 & 113 & 5.650 & 348,3 \\
16 & 11 & 550 & 278,5 & 42 & 113 & 5.650 & 348,3 \\
17 & 27 & 1.350 & 306,3 & 43 & 113 & 5.650 & 348,4 \\
18 & 27 & 1.350 & 299,8 & 44 & 113 & 5.650 & 348,0 \\
19 & 27 & 1.350 & 304,3 & 45 & 116 & 5.800 & 364,6 \\
20 & 27 & 1.350 & 297,5 & 46 & 116 & 5.800 & 364,0 \\
21 & 27 & 1.350 & 350,3 & 47 & 116 & 5.800 & 364,8 \\
22 & 27 & 1.350 & 351,4 & 48 & 116 & 5.800 & 364,1 \\
23 & 27 & 1.350 & 350,8 & 49 & 123 & 6.150 & 466,1 \\
24 & 27 & 1.350 & 351,5 & 50 & 123 & 6.150 & 466,5 \\
25 & 28 & 1.400 & 393,0 & 51 & 123 & 6.150 & 466,2 \\
26 & 28 & 1.400 & 390,3 & 52 & 123 & 6.150 & 466,4 \\
\hline
\end{tabular}

Tabela 23 - Frequências de ressonância harmônicas encontradas pela ARHM e suas respectivas magnitudes de impedância modal - caso (iii).

\begin{tabular}{cccc||cccc}
\hline$F_{i}$ & $h$ & $\begin{array}{c}f_{h} \\
(\mathrm{~Hz})\end{array}$ & $\begin{array}{c}\left|\zeta_{h}\right| \\
(\text { p.u. })\end{array}$ & $F_{i}$ & $h$ & $\begin{array}{c}f_{h} \\
(\mathrm{~Hz})\end{array}$ & $\begin{array}{c}\left|\zeta_{h}\right| \\
(\text { p.u. })\end{array}$ \\
\hline 1 & 10 & 500 & 357,3 & 27 & 28 & 1.400 & 388,0 \\
2 & 10 & 500 & 405,8 & 28 & 28 & 1.400 & 351,8 \\
3 & 10 & 500 & 361,3 & 29 & 28 & 1.400 & 353,8 \\
4 & 10 & 500 & 409,5 & 30 & 28 & 1.400 & 367,2 \\
5 & 10 & 500 & 343,6 & 31 & 29 & 1.450 & 368,0 \\
6 & 10 & 500 & 393,2 & 32 & 29 & 1.450 & 366,8 \\
7 & 10 & 500 & 347,6 & 33 & 77 & 3.850 & $1.021,4$ \\
8 & 10 & 500 & 397,2 & 34 & 77 & 3.850 & $1.023,0$ \\
9 & 11 & 550 & 243,5 & 35 & 77 & 3.850 & $1.021,3$ \\
10 & 11 & 550 & 287,7 & 36 & 77 & 3.850 & $1.022,9$ \\
11 & 11 & 550 & 240,0 & 37 & 79 & 3.950 & $1.074,8$ \\
12 & 11 & 550 & 306,9 & 38 & 79 & 3.950 & $1.075,0$ \\
\hline
\end{tabular}


Continuação da Tabela 23

\begin{tabular}{cccc||cccc}
\hline$F_{i}$ & $h$ & $\begin{array}{c}f_{h} \\
(H z)\end{array}$ & $\begin{array}{c}\left|\zeta_{h}\right| \\
\text { (p.u.) }\end{array}$ & $F_{i}$ & $h$ & $\begin{array}{c}f_{h} \\
(H z)\end{array}$ & $\begin{array}{c}\left|\zeta_{h}\right| \\
\text { (p.u. })\end{array}$ \\
\hline 13 & 11 & 550 & 254,1 & 39 & 79 & 3.950 & $1.074,8$ \\
14 & 11 & 550 & 302,0 & 40 & 79 & 3.950 & $1.075,0$ \\
15 & 11 & 550 & 250,4 & 41 & 107 & 5.350 & 275,3 \\
16 & 11 & 550 & 292,2 & 42 & 107 & 5.350 & 274,8 \\
17 & 25 & 1.250 & 251,8 & 43 & 107 & 5.350 & 275,3 \\
18 & 25 & 1.250 & 253,5 & 44 & 107 & 5.350 & 274,8 \\
19 & 26 & 1.300 & 263,9 & 45 & 108 & 5.400 & 298,4 \\
20 & 26 & 1.300 & 262,9 & 46 & 108 & 5.400 & 298,1 \\
21 & 26 & 1.300 & 287,9 & 47 & 108 & 5.400 & 298,4 \\
22 & 26 & 1.300 & 276,9 & 48 & 108 & 5.400 & 298,1 \\
23 & 26 & 1.300 & 287,2 & 49 & 127 & 6.350 & 456,9 \\
24 & 26 & 1.300 & 275,8 & 50 & 127 & 6.350 & 456,7 \\
25 & 28 & 1.400 & 386,5 & 51 & 127 & 6.350 & 456,9 \\
26 & 28 & 1.400 & 368,7 & 52 & 127 & 6.350 & 456,8 \\
\hline
\end{tabular}

Tabela 24 - Frequências de ressonância harmônicas encontradas pela ARHM e suas respectivas magnitudes de impedância modal - caso (iv).

\begin{tabular}{cccc|cccc}
\hline$F_{i}$ & $h$ & $\begin{array}{c}f_{h} \\
(\mathrm{~Hz})\end{array}$ & $\begin{array}{c}\left|\zeta_{h}\right| \\
(\mathrm{p} . \mathrm{u} .)\end{array}$ & $F_{i}$ & $h$ & $\begin{array}{c}f_{h} \\
(\mathrm{~Hz})\end{array}$ & $\begin{array}{c}\left|\zeta_{h}\right| \\
\text { (p.u.) }\end{array}$ \\
\hline 1 & 10 & 500 & 239,4 & 24 & 28 & 1.400 & 363,5 \\
2 & 10 & 500 & 243,3 & 25 & 28 & 1.400 & 361,0 \\
3 & 11 & 550 & 278,8 & 26 & 28 & 1.400 & 362,3 \\
4 & 11 & 550 & 285,5 & 27 & 28 & 1.400 & 359,7 \\
5 & 11 & 550 & 272,5 & 28 & 28 & 1.400 & 367,2 \\
6 & 11 & 550 & 247,0 & 29 & 29 & 1.450 & 368,0 \\
7 & 11 & 550 & 242,0 & 30 & 29 & 1.450 & 364,3 \\
8 & 11 & 550 & 306,9 & 31 & 29 & 1.450 & 366,2 \\
9 & 11 & 550 & 292,4 & 32 & 29 & 1.450 & 362,5 \\
10 & 11 & 550 & 299,6 & 33 & 120 & 6.000 & 442,3 \\
11 & 11 & 550 & 285,6 & 34 & 120 & 6.000 & 442,5 \\
12 & 11 & 550 & 258,1 & 35 & 120 & 6.000 & 442,4 \\
13 & 11 & 550 & 247,3 & 36 & 122 & 6.100 & 462,1 \\
14 & 11 & 550 & 252,7 & 37 & 122 & 6.100 & 462,6 \\
15 & 11 & 550 & 242,2 & 38 & 122 & 6.100 & 462,2 \\
16 & 11 & 550 & 292,2 & 39 & 124 & 6.200 & 2858,0 \\
17 & 28 & 1.400 & 372,0 & 40 & 124 & 6.200 & 2838,9 \\
18 & 28 & 1.400 & 369,5 & 41 & 124 & 6.200 & 2860,8 \\
19 & 28 & 1.400 & 374,3 & 42 & 124 & 6.200 & 2806,6 \\
20 & 28 & 1.400 & 323,2 & 43 & 127 & 6.350 & 456,6 \\
21 & 28 & 1.400 & 319,6 & 44 & 127 & 6.350 & 456,7 \\
22 & 28 & 1.400 & 321,5 & 45 & 127 & 6.350 & 456,8 \\
23 & 28 & 1.400 & 317,8 & - & - & - & - \\
\hline
\end{tabular}




\section{Apêndice B}

A Tabela 25 apresenta os dados resultantes da análise realizada no item 6.2.1.1 e 6.2.1.3 do capítulo 6.

Tabela 25 - Frequências de ressonância harmônicas encontradas pela ARHM e suas respectivas magnitudes de impedância modal - SD de 24 nós.

\begin{tabular}{|c|c|c|c|c|c|c|c|}
\hline$F_{i}$ & $h$ & $\begin{array}{c}f_{h} \\
(\mathrm{~Hz})\end{array}$ & $\begin{array}{c}\left|\zeta_{h}\right| \\
\text { (p.u.) }\end{array}$ & $F_{i}$ & $h$ & $\begin{array}{c}f_{h} \\
(\mathrm{~Hz})\end{array}$ & $\begin{array}{l}\left|\zeta_{h}\right| \\
\text { (p.u.) }\end{array}$ \\
\hline 1 & 4 & 240 & 16,2 & 76 & 59 & 3.540 & 12,1 \\
\hline 2 & 4 & 240 & 16,2 & 77 & 59 & 3.540 & 35,9 \\
\hline 3 & 4 & 240 & 14,6 & 78 & 59 & 3.540 & 15,1 \\
\hline 4 & 4 & 240 & 14,2 & 79 & 59 & 3.540 & 14,8 \\
\hline 5 & 4 & 240 & 16,1 & 80 & 60 & 3.600 & 12,4 \\
\hline 6 & 4 & 240 & 16,2 & 81 & 61 & 3.660 & 40,3 \\
\hline 7 & 4 & 240 & 14,8 & 82 & 61 & 3.660 & 32,2 \\
\hline 8 & 4 & 240 & 14,5 & 83 & 61 & 3.660 & 36,3 \\
\hline 9 & 4 & 240 & 16,2 & 84 & 61 & 3.660 & 31,0 \\
\hline 10 & 4 & 240 & 16,2 & 85 & 64 & 3.840 & 31,3 \\
\hline 11 & 4 & 240 & 16,1 & 86 & 64 & 3.840 & 33,7 \\
\hline 12 & 4 & 240 & 14,6 & 87 & 65 & 3.900 & 36,0 \\
\hline 13 & 4 & 240 & 14,2 & 88 & 65 & 3.900 & 36,0 \\
\hline 14 & 4 & 240 & 16,1 & 89 & 66 & 3.960 & 35,0 \\
\hline 15 & 4 & 240 & 14,8 & 90 & 67 & 4.020 & 37,6 \\
\hline 16 & 4 & 240 & 14,5 & 91 & 68 & 4.080 & 30,9 \\
\hline 17 & 5 & 300 & 24,1 & 92 & 68 & 4.080 & 30,7 \\
\hline 18 & 5 & 300 & 18,9 & 93 & 70 & 4.200 & 31,7 \\
\hline 19 & 5 & 300 & 17,9 & 94 & 70 & 4.200 & 32,0 \\
\hline 20 & 5 & 300 & 23,8 & 95 & 77 & 4.620 & 56,6 \\
\hline 21 & 5 & 300 & 23,7 & 96 & 77 & 4.620 & 56,6 \\
\hline 22 & 5 & 300 & 19,7 & 97 & 77 & 4.620 & 57,4 \\
\hline 23 & 5 & 300 & 18,7 & 98 & 77 & 4.620 & 57,4 \\
\hline 24 & 5 & 300 & 23,8 & 99 & 78 & 4.680 & 58,0 \\
\hline 25 & 5 & 300 & 24,2 & 100 & 78 & 4.680 & 58,0 \\
\hline 26 & 5 & 300 & 18,8 & 101 & 78 & 4.680 & 57,2 \\
\hline 27 & 5 & 300 & 17,8 & 102 & 78 & 4.680 & 57,2 \\
\hline 28 & 5 & 300 & 19,8 & 103 & 81 & 4.860 & 59,8 \\
\hline 29 & 5 & 300 & 18,8 & 104 & 81 & 4.860 & 56,0 \\
\hline 30 & 5 & 300 & 23,7 & 105 & 81 & 4.860 & 59,0 \\
\hline 31 & 6 & 360 & 24,8 & 106 & 82 & 4.920 & 53,6 \\
\hline 32 & 6 & 360 & 24,6 & 107 & 82 & 4.920 & 50,4 \\
\hline 33 & 36 & 2.160 & 108,1 & 108 & 82 & 4.920 & 56,0 \\
\hline 34 & 37 & 2.220 & 132,7 & 109 & 83 & 4.980 & 91,2 \\
\hline 35 & 37 & 2.220 & 132,0 & 110 & 83 & 4.980 & 91,0 \\
\hline
\end{tabular}


Continuação da Tabela 25.

\begin{tabular}{|c|c|c|c|c|c|c|c|}
\hline$F_{i}$ & $h$ & $\begin{array}{c}f_{h} \\
(\mathrm{~Hz})\end{array}$ & $\begin{array}{c}\left|\zeta_{h}\right| \\
\text { (p.u.) }\end{array}$ & $F_{i}$ & $h$ & $\begin{array}{c}f_{h} \\
(\mathrm{~Hz})\end{array}$ & $\begin{array}{c}\left|\zeta_{h}\right| \\
\text { (p.u.) }\end{array}$ \\
\hline 36 & 37 & 2.220 & 115,1 & 111 & 83 & 4.980 & 91,4 \\
\hline 37 & 37 & 2.220 & 115,1 & 112 & 83 & 4.980 & 91,1 \\
\hline 38 & 37 & 2.220 & 130,5 & 113 & 83 & 4.980 & 48,8 \\
\hline 39 & 37 & 2.220 & 129,6 & 114 & 83 & 4.980 & 51,1 \\
\hline 40 & 37 & 2.220 & 122,3 & 115 & 84 & 5.040 & 78,3 \\
\hline 41 & 37 & 2.220 & 122,3 & 116 & 84 & 5.040 & 85,1 \\
\hline 42 & 37 & 2.220 & 111,9 & 117 & 84 & 5.040 & 88,7 \\
\hline 43 & 37 & 2.220 & 110,2 & 118 & 84 & 5.040 & 88,4 \\
\hline 44 & 37 & 2.220 & 126,2 & 119 & 84 & 5.040 & 86,9 \\
\hline 45 & 37 & 2.220 & 126,2 & 120 & 84 & 5.040 & 86,4 \\
\hline 46 & 37 & 2.220 & 108,4 & 121 & 85 & 5.100 & 82,0 \\
\hline 47 & 38 & 2.280 & 115,1 & 122 & 85 & 5.100 & 79,4 \\
\hline 48 & 38 & 2.280 & 115,1 & 123 & 85 & 5.100 & 81,8 \\
\hline 49 & 40 & 2.400 & 141,6 & 124 & 85 & 5.100 & 88,7 \\
\hline 50 & 40 & 2.400 & 142,1 & 125 & 86 & 5.160 & 84,1 \\
\hline 51 & 40 & 2.400 & 137,7 & 126 & 86 & 5.160 & 82,0 \\
\hline 52 & 40 & 2.400 & 135,6 & 127 & 108 & 6.480 & 119,1 \\
\hline 53 & 41 & 2.460 & 147,6 & 128 & 108 & 6.480 & 119,1 \\
\hline 54 & 41 & 2.460 & 150,0 & 129 & 108 & 6.480 & 124,0 \\
\hline 55 & 41 & 2.460 & 149,8 & 130 & 108 & 6.480 & 124,0 \\
\hline 56 & 41 & 2.460 & 156,8 & 131 & 108 & 6.480 & 141,4 \\
\hline 57 & 41 & 2.460 & 154,9 & 132 & 108 & 6.480 & 135,1 \\
\hline 58 & 41 & 2.460 & 145,5 & 133 & 108 & 6.480 & 141,1 \\
\hline 59 & 41 & 2.460 & 140,8 & 134 & 108 & 6.480 & 134,5 \\
\hline 60 & 41 & 2.460 & 147,8 & 135 & 112 & 6.720 & 13,9 \\
\hline 61 & 42 & 2.520 & 142,5 & 136 & 112 & 6.720 & 13,9 \\
\hline 62 & 42 & 2.520 & 142,1 & 137 & 112 & 6.720 & 13,9 \\
\hline 63 & 42 & 2.520 & 142,7 & 138 & 112 & 6.720 & 13,9 \\
\hline 64 & 42 & 2.520 & 142,2 & 139 & 112 & 6.720 & 13,9 \\
\hline 65 & 50 & 3.000 & 19,2 & 140 & 112 & 6.720 & 13,9 \\
\hline 66 & 51 & 3.060 & 28,5 & 141 & 112 & 6.720 & 13,9 \\
\hline 67 & 51 & 3.060 & 14,3 & 142 & 112 & 6.720 & 13,9 \\
\hline 68 & 51 & 3.060 & 15,2 & 143 & 116 & 6.960 & 95,8 \\
\hline 69 & 51 & 3.060 & 18,5 & 144 & 116 & 6.960 & 96,0 \\
\hline 70 & 51 & 3.060 & 22,4 & 145 & 116 & 6.960 & 96,8 \\
\hline 71 & 52 & 3.120 & 24,6 & 146 & 116 & 6.960 & 97,0 \\
\hline 72 & 52 & 3.120 & 20,8 & 147 & 116 & 6.960 & 105,5 \\
\hline 73 & 59 & 3.540 & 38,1 & 148 & 116 & 6.960 & 104,3 \\
\hline 74 & 59 & 3.540 & 14,9 & 149 & 116 & 6.960 & 105,6 \\
\hline 75 & 59 & 3.540 & 16,7 & 150 & 116 & 6.960 & 104,2 \\
\hline
\end{tabular}

